UNIVERSIDADE DE BRASÍLIA

INSTITUTO DE GEOCIÊNCIAS

\title{
O RIFTE ARAÍ: NOVAS PERSPECTIVAS COM BASE EM DADOS GRAVIMÉTRICOS, MAGNÉTICOS E GEOLÓGICOS
}

\author{
POLYANNA DE SOUSA MORO \\ DISSERTAÇÃO DE MESTRADO No 115
}

PROGRAMA DE PÓS GRADUAÇÃO EM GEOCIÊNCIAS APLICADAS

Brasília - DF 


\title{
O RIFTE ARAÍ: NOVAS PERSPECTIVAS COM BASE EM DADOS GRAVIMÉTRICOS, MAGNÉTICOS E GEOLÓGICOS
}

\author{
POLYANNA DE SOUSA MORO
}

Dissertação apresentada à Universidade de Brasília, como parte das exigências do Programa de Pós-Graduação em Geociências Aplicadas, área de concentração em Geofísica Aplicada, para a obtenção do título de Mestre.

Orientadora: Profa. Dra ${ }^{a}$ Roberta Mary Vidotti 


\title{
O RIFTE ARAÍ: NOVAS PERSPECTIVAS COM BASE EM DADOS GRAVIMÉTRICOS, MAGNÉTICOS E GEOLÓGICOS
}

\author{
POLYANNA DE SOUSA MORO
}

Orientadora: Profa. Dra ${ }^{\mathrm{a}}$. Roberta Mary Vidotti

Comissão Examinadora:

Prof. Dr. Carlos José Souza de Alvarenga (IG-UnB)

Prof. Dr. Fabrício de Andrade Caxito (UFMG) 
Ficha catalográfica elaborada automaticamente, com os dados fornecidos pelo(a) autor(a)

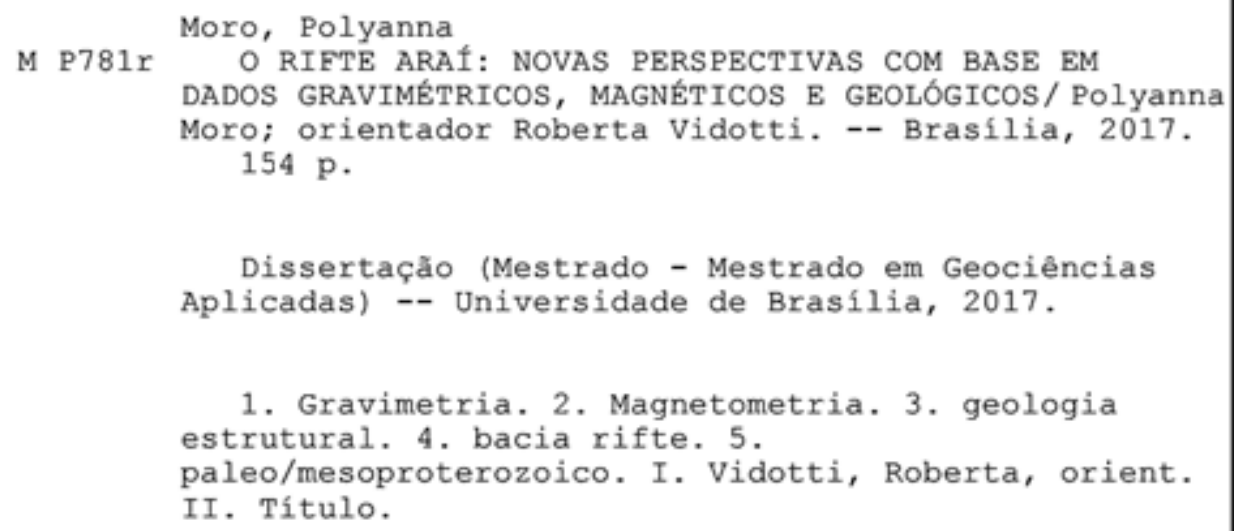


"Eu já ultrapassei a barreira do som, fiz o que pude às vezes fora do tom, mas a semente que eu ajudei a plantar já nasceu." 


\section{Agradecimentos}

Agradeço primeiramente a Deus por permitir chegar onde cheguei e traçar os caminhos que percorri. Tudo acontece por um motivo e Ele sabe porque me colocou exatamente onde estou.

À minha orientadora Roberta Mary Vidotti, pela sua orientação apontando sempre os melhores caminhos e dando estímulos para o desenvolvimento deste trabalho. Ao professor Elton Luiz Dantas por todas as discussões e sugestões ao longo desta dissertação.

À CAPES pela bolsa de estudos e ao Programa de Pós-Graduação em Geociências Aplicadas (PPGA) do Instituto de Geociências - IG/UnB pela oportunidade de realização desta pesquisa.

Aos meus familiares e amigos do coração, por sempre me apoiarem e acreditarem em mim e por me arrancarem sorrisos e bons momentos.

A todos que, embora não citados nominalmente, contribuíram direta e indiretamente para a execução deste trabalho. 


\section{Resumo}

A bacia-rifte Araí, localizada na porção setentrional da Faixa Brasília, é uma entidade tectônica paleo/mesoproterozoica ainda pouco conhecida. Possui história evolutiva complexa, com inversão do rifte em meio a uma tectônica thick-skinned no Brasiliano. Alguns autores mencionam estruturas profundas desconhecidas tanto em termos de profundidade quanto em sua geometria. A utilização de dados geofísicos aplicados a essa problemática forneceram indicadores regionais essenciais ao entendimento das estruturas do rifte, permitindo uma melhor compreensão de seu arcabouço estrutural evolutivo. Nesse contexto, a bacia foi investigada com relação à sua resposta magnética e gravimétrica integrada a dados geológicos estruturais. A fim de esclarecer sua compartimentação tectônica, sistemas de falhas principais e profundidade do embasamento foi realizada análise geofísica por meio da Deconvolução de Euler e espectro radial de potência. Foram aplicados ainda os filtros Derivada Vertical, Derivada Tilt, Ângulo Tilt Horizontal e Derivada Tilt do Gradiente Horizontal Total sobre malhas individualizadas pelo Matched Filter. A partir destas, foram traçados os lineamentos magnéticos da região. $\mathrm{O}$ arcabouço tectônico interpretado apresentou direção preferencial N40E, compreendendo principalmente feições relacionadas ao Brasiliano. O Grupo Araí apresentou assinatura magnética preferencial em N50-80E composta por dois grupos de estruturas: aquelas relacionadas a reativações de falhas extensionais do rifte e estruturas associadas (pertencentes aos sistemas São Jorge-Alto Paraíso-Cormari, Cavalcante-Teresina e Teresina-Nova Roma) e as geradas essencialmente no Brasiliano. A integração de todos os resultados obtidos resultou num modelo conceitual 2D da bacia, com assinaturas geofísicas importantes em $37 \mathrm{~km} ; 22,6 \mathrm{~km} ; 15,6 \mathrm{~km} ; 9,7 \mathrm{~km} ; 8-2,3 \mathrm{~km}$ e 0,54 km; interpretadas, respectivamente, como a Descontinuidade de Mohorovicic, Superfície Curie, Descontinuidade de Conrad, intrusões graníticas pontuais, profundidades do embasamento e falhas superficiais. Os sistemas descritos evidenciam as principais falhas relacionadas ao rifte, convergindo para uma falha principal detectada até $22,6 \mathrm{~km}$. As falhas diretamente relacionadas ao estágio rifte foram demarcadas pela Deconvolução de Euler e confirmadas pela presença de conglomerados de leques aluviais ao longo das mesmas. A compartimentação atual da bacia-rifte remonta ao Brasiliano, limitando blocos crustais com características distintas que condicionaram a atual geometria da bacia. Observando os resultados geofísicos, é válida a sugestão de que o Rifte Araí estaria associado a um processo extensional incompleto, não desenvolvendo margem passiva, mas compreendendo um rifte intracontinental isolado similar ao Midcontinent Rift.

Palavras-chave: Rifte Araí, Magnetometria, Gravimetria, Modelagem Direta, Paleo/mesoproterozoico. 


\section{Abstract}

Located in the northern part of the Brasília Belt, the Araí Rift comprises a paleomesoproterozoic sedimentary basin which has been poorly studied. It has a complex evolutionary history, with inversion of the rift in a thick-skinned tectonic corresponding to Brasiliano Orogeny. Some authors mention deep structures that are unknown in terms of both depth and geometry. The use of geophysical data applied to such problem provided regional indexes that were essential to a better understanding of the rift structures and its evolutionary structural framework. In this context, the basin was investigated with respect to its magnetic and gravity responses integrated to structural geological data. A geophysical analysis was performed through the Euler Deconvolution and radial power spectra, to clarify the evolutionary scenario in which the basin is involved, its main fault systems, and depth of the basement. The Vertical Derivative, Tilt Derivative, Horizontal Tilt Angle, and Tilt Angle of the Total Horizontal Gradient filters were also applied to the grids individualized by the Matched Filtering. The magnetic structures of the region were delineated from these responses. The interpreted tectonic framework showed main direction in N40E, which mainly comprises features related to Brasiliano Orogeny. The Araí Group presented a magnetic signature in the direction N50-80E, composed of two main groups of structures: those related to reactivation of extension rift faults and associated structures (belonging to the São Jorge-Alto Paraíso-Cormari, Cavalcante-Teresina, and Teresina-Nova Roma systems) and the structures essentially formed in the Brasiliano. The integration of results obtained in this work resulted in a $2 \mathrm{D}$ conceptual model of the basin with important geophysical signatures in $37 \mathrm{~km}, 22.6 \mathrm{~km}, 15.6 \mathrm{~km}, 9.7 \mathrm{~km}$, $8-2.3 \mathrm{~km}$ and $0.54 \mathrm{~km}$, respectively interpreted as Mohorovicic Discontinuity, Curie Surface, Conrad Discontinuity, granitic intrusions, basement depths, and superficial faults. The fault systems previously mentioned describe the main faults related to the rift, converging to a main fault detected up to the depth of $22.6 \mathrm{~km}$. The faults directly related to the rift stage were delineated by the Euler Deconvolution and confirmed by the presence of conglomerates of alluvial fans along these faults. The current geometry of the rift basin goes back to the Brasiliano, where the rift arms limited crustal blocks with distinct characteristics. From the observation of the geophysical results, it is suggested that the Araí Rift would be associated with an incomplete extensional process, comprising an isolated intracontinental rift similar to the Midcontinent Rift.

Keywords: Araí Rift, Magnetometric Method, Gravity Method, Forward Modelling, paleomesoproterozoic. 


\section{Sumário}

\section{CAPÍtULO 1}

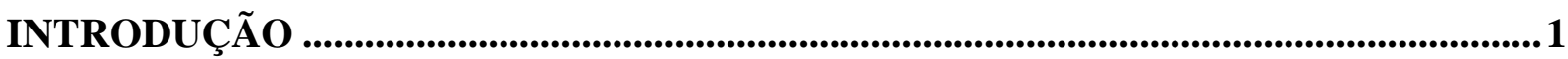

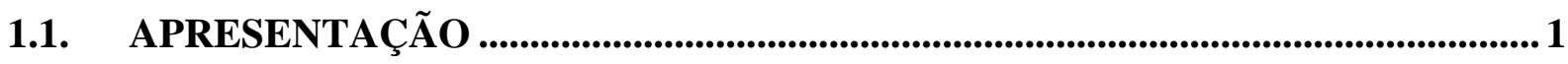

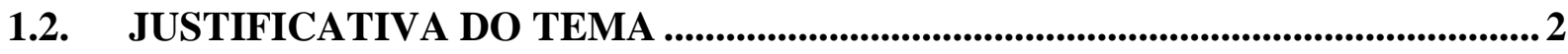

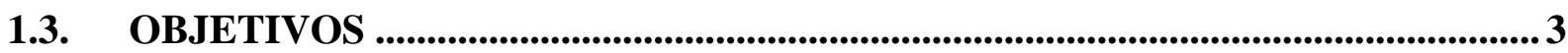

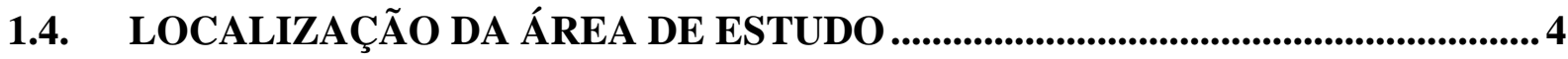

1.5. MÉTODOS E BASE DE DADOS .......................................................................4

CAPÍTULO 2

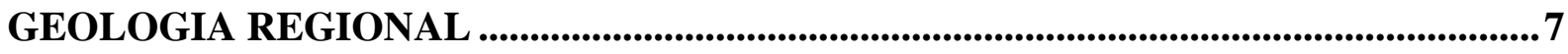

2.1. Província Tocantins ............................................................................................................. 7

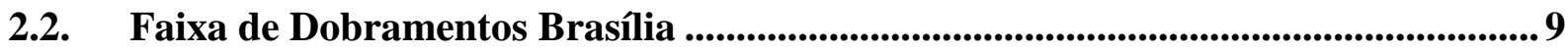

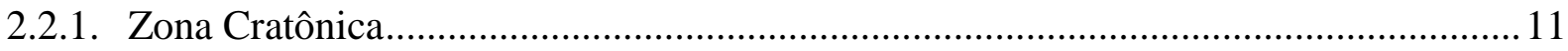

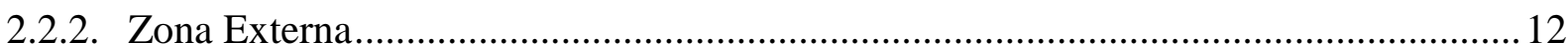

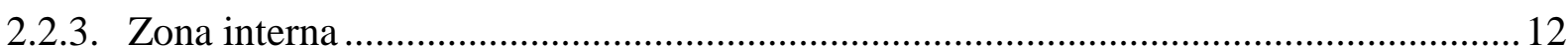

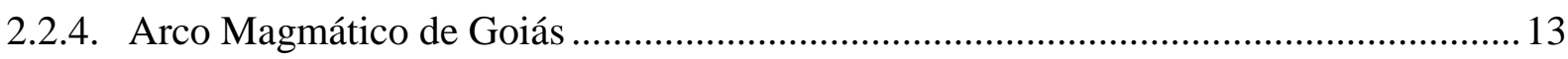

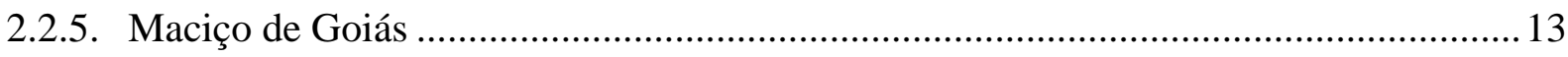

2.3. O embasamento e as coberturas metassedimentares ........................................... 13

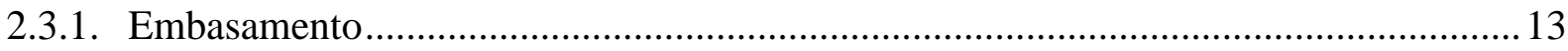

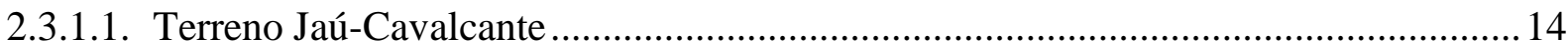

2.3.1.1.1. Formação Ticunzal................................................................................................. 14

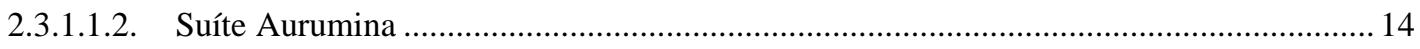

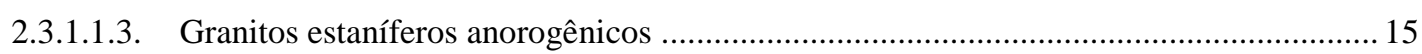

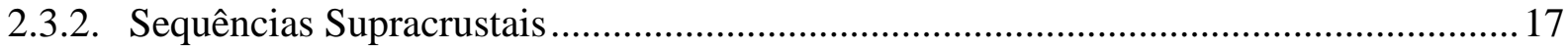

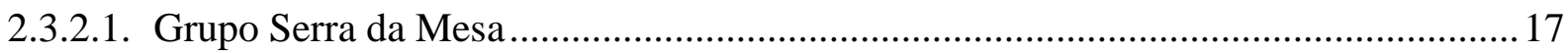

2.3.2.2. Complexos Máfico-Ultramáficos (Barro Alto, Cana Brava e Niquelândia) .............. 17

2.3.2.3. Sucessões vulcanossedimentares (Palmeirópolis, Indaianópolis e Juscelândia)......... 18

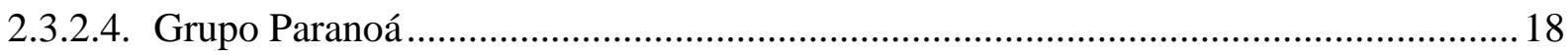

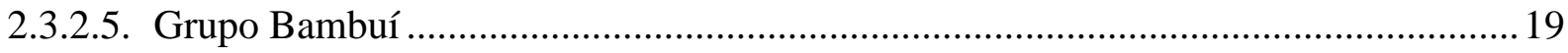

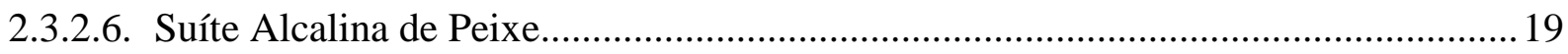

2.4. Grupo Araí

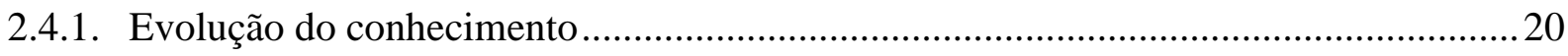

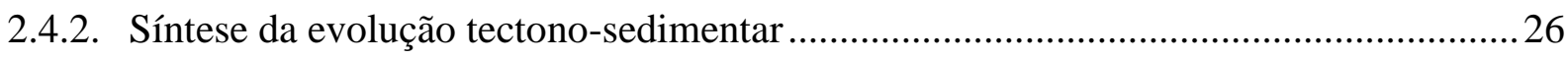




\section{CAPÍTULO 3}

TEORIA GRAVIMÉTRICA E MAGNÉTICA..............................................................31

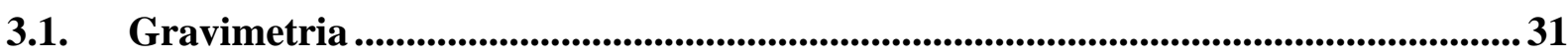

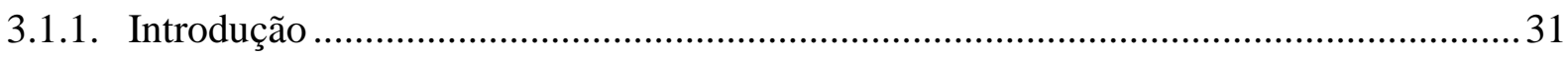

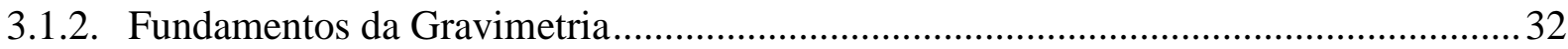

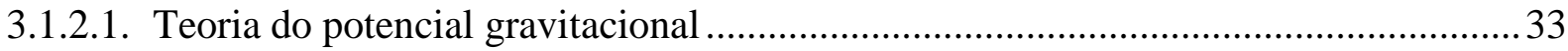

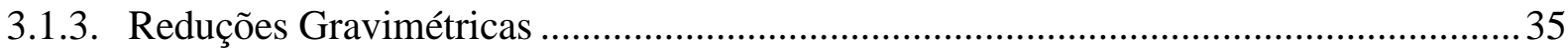

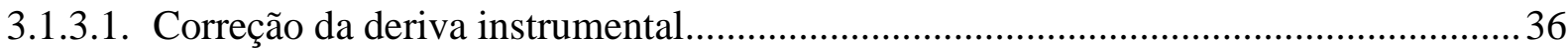

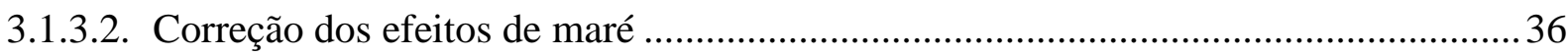

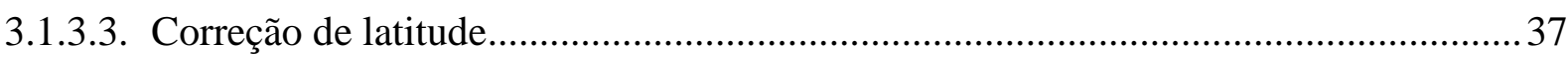

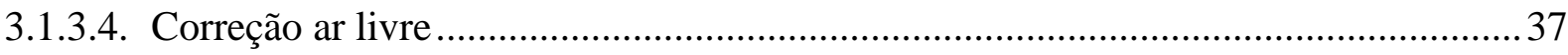

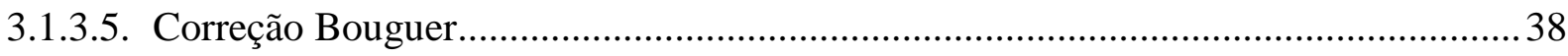

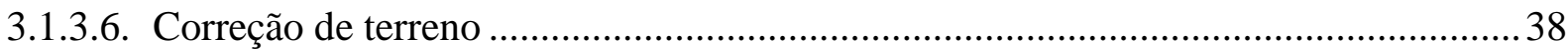

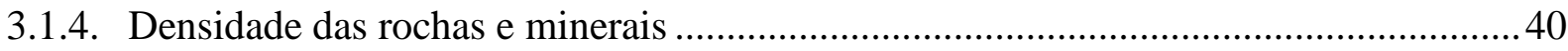

3.2. Magnetometria ....................................................................................................................... 41

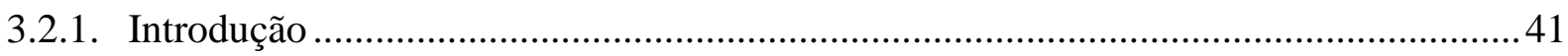

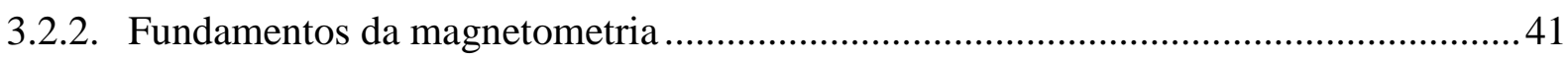

3.2.2.1. Teoria do potencial magnético de um dipolo pontual ................................................4

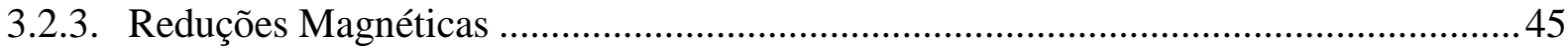

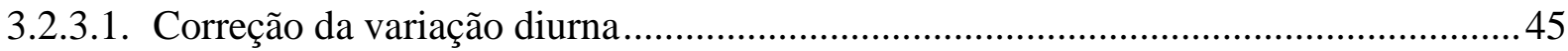

3.2.3.2. Remoção do campo geomagnético de referência (IGRF) ........................................... 46

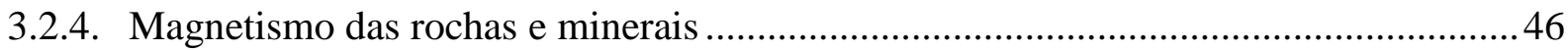

3.2.4.1. Susceptibilidade magnética de rochas e minerais ........................................................4 48

\section{CAPÍTULO 4}

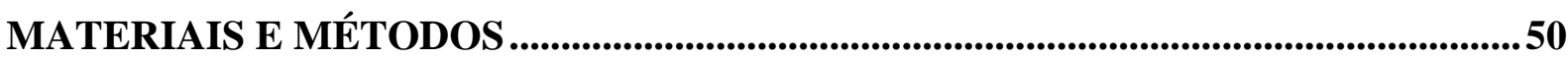

4.1. Reconhecimento geológico de campo ..........................................................................50

4.2. Aquisição de dados gravimétricos ...............................................................................53

4.3. Pré-Processamento dos dados..............................................................................55

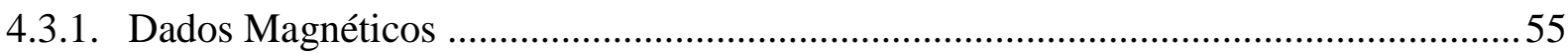

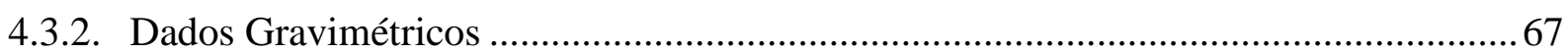

4.4. Processamento e técnicas de realce ......................................................................68

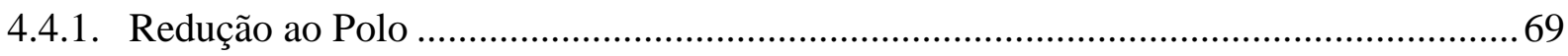

4.4.2. Derivadas direcionais....................................................................................... 72 


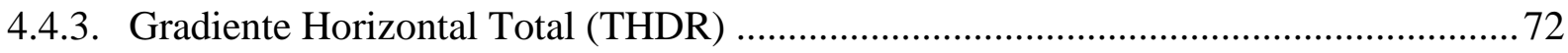

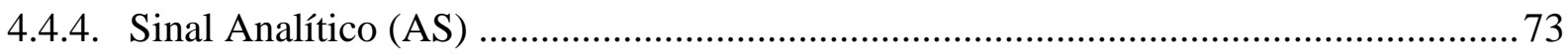

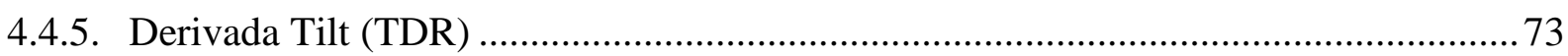

4.4.6. Ângulo Tilt Horizontal (Horizontal Tilt Angle - TDX).............................................. 74

4.4.7. Ângulo Tilt do Gradiente Horizontal Total (TAHG) ................................................ 74

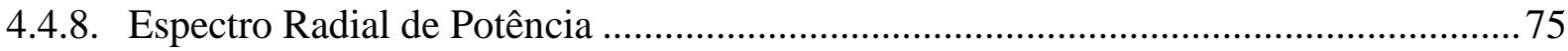

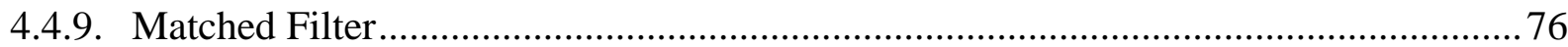

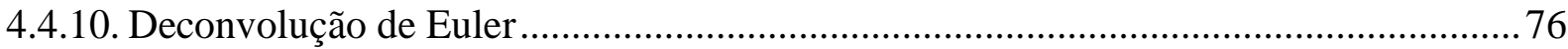

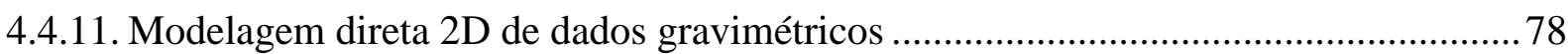

CAPÍTULO 5

RESULTADOS E INTERPRETAÇÕES GEOFÍSICAS......................................................79

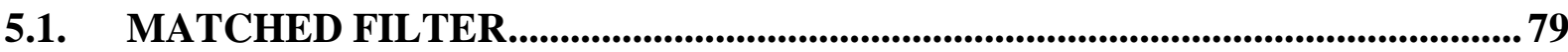

5.1.1. Espectro radial de potência dos dados magnéticos e gravimétricos ........................... 79

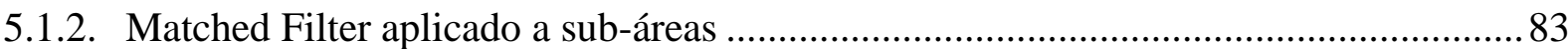

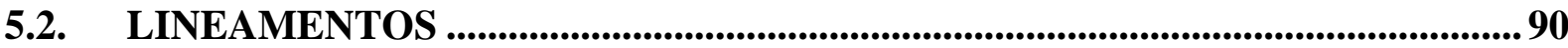

5.3. Deconvolução de euler ............................................................................... 101

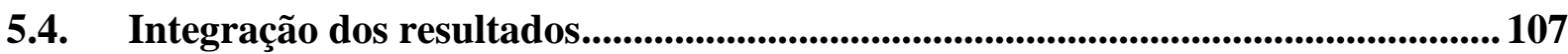

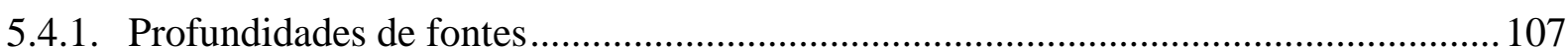

5.4.2. Sistema de lineamentos na região do rifte Araí .......................................................... 109

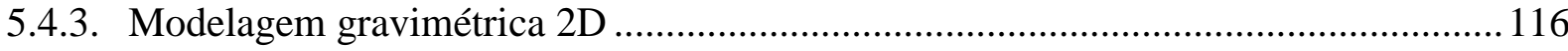

\section{CAPÍTULO 6}

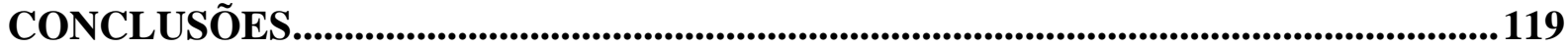

REFERÊNCIAS BIBLIOGRÁFICAS .....................................................................................122

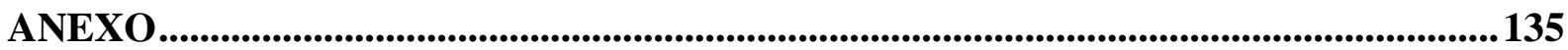




\section{Lista de Figuras}

Figura 1.1 Mapa de localização da área de estudo e vias de acesso.

Figura 2.1. Elementos tectônicos da América do Sul e da parte oeste da África que participaram da aglutinação do Gondwana Ocidental e da formação da Província Tocantins. Na parte superior, em vermelho, a Província Tocantins em sua configuração atual. Modificado de Klein \& Moura (2008)

Figura 2.2. Unidades tectônicas da Faixa Brasília. O polígono em preto indica a região de estudo deste trabalho. Modificado de Pimentel et al. (2004b).

Figura 2.3. Mapa geológico simplificado envolvendo as unidades litoestratigráficas da área de estudo, com base nos mapas na escala 1:1.000.000 por Lacerda Filho et al. (2004) e Souza et al. (2004)

Figura 2.4. Correlação estratigráfica das propostas de Dyer (1970), Marini et al. (1976), Araújo \& Alves (1979), Braun (1980), Dardenne et al. (1999), Martins (1999), Marques (2010) e Tanizaki (2013). Modificado de Tanizaki (2013). 22

Figura 2.5. Mapa simplificado evidenciando os sistemas de falhas na região de estudo segundo Fonseca (1996). SRM - Sistema Rio Maranhão, SACB - Sistema Arraias-Campos Belos, STNR - Sistema Teresina de Goiás-Nova Roma-Monte Alegre-Campos Belos, SSAC - São Jorge-Alto Paraíso-Cormari e SCT - Sistema Cavalcante-Teresina.

Figura 2.6. (a) Mapa magnético integrado neste trabalho, onde o polígono preto representa a localização de (b) Análise da Amplitude do Sinal Analítico de Almeida (2009) com as subdivisões dos grandes domínios magnéticos (A, B, C e D) e dos maciços graníticos da Suíte Pedra Branca.

Figura 2.7. Rifteamentos do Paleo e Mesoproterozoico em parte do Brasil. Fonte: Delgado et al. (2003).

Figura 2.8. Evolução do rifte Araí e deposição dos sedimentos dos grupos Araí e Serra da Mesa. Figura adaptada segundo modelo teórico de Marques (2010). 29

Figura 3.1. Ilustração de dois corpos atraídos um em direção ao outro com uma força gravitacional $\mathrm{F}_{\mathrm{g}}$ proporcional ao produto das suas massas $\mathrm{m}_{1}$ e $\mathrm{m}_{2}$ e inversamente proporcional ao quadrado da distância $r$ entre os centros das massas (modificado de Hinze et al., 2013). .. 32 Figura 3.2. Gráfico ilustrando os efeitos de maré e deriva instrumental na aceleração da gravidade (retirado de Reynolds, 1997). 37 
Figura 3.3. (a) Correção ar livre para uma altura $h$ acima do datum utilizado, (b) Correção Bouguer, considerando uma placa infinita de espessura $h$ e (c) Correção de Terreno, considerando a falta ou excesso de massa entre o ponto medido e suas adjacências (fonte: Kearey et al., 2009).

Figura 3.4. Arranjo espacial norte $(\mathrm{N})$ ou positivo $(+\mathrm{p})$ e sul $(\mathrm{S})$ ou negativo $(-\mathrm{p})$ apontando polos magnéticos separados pela distância 1 infinitesimal, definindo um dipolo magnético pontual. O dipolo está localizado em (x', y', z') com distância r ao ponto de observação (x, y, $\mathrm{z}$ ) de tal modo que $\mathrm{R}=\mathrm{R}$ - R' no sistema de coordenadas cartesiano centrado na Terra. Fonte: Hinze et al. (2013).

Figura 3.5. Magnetização (seta branca à direita dos quadrados) que uma substância adquire na presença e ausência de um campo magnético aplicado (seta preta). Modificado de Tarling \& Hrouda (1993).

Figura 4.1. (a) Vista panorâmica do contato entre embasamento regional arrasado e Grupo Araí (chapadão e serras de composição quartzítica). Fotografia retirada em frente ao ponto A9 (Tabela 4.1). (b) Quartzito fraturado da Formação Arraiais correspondente ao ponto A9 (Tabela 4.1). Afloramento nas proximidades da cidade de Cavalcante (GO). (c) Dobras com plano axial de direção EW em xistos grafitosos observadas na região de contato entre os grupos Serra da Mesa e Araí, correspondentes ao ponto A11 (Tabela 4.1). 52

Figura 4.2. Roseta com as direção coletadas em juntas e falhas durante o reconhecimento de campo. As direções preferenciais são N10E , N20-40E e N70W. Secundariamente, as direções N10-60E e N20-50W. 52

Figura 4.3. Locais contendo as bases gravimétricas utilizadas nesse estudo: (a) Escola Municipal Maria Auxiliadora - Colinas do Sul/GO e (b) Paróquia Nossa Senhora das Graças Alto Paraíso/GO. Em (c), exemplo de estação de aquisição simultânea de dados gravimétricos e geodésicos utilizando o gravímetro Scintrex CG5 e receptor GNSS/RTK Trimble R4. (d) Base gravimétrica situada na Escola Municipal Maria Auxiliadora, utilizada na aquisição dos dados terrestres na região de Colinas do Sul. .54

Figura 4.4. Localização do perfil gravimétrico utilizado na modelagem $2 \mathrm{D}$ apresentada na Figura 5.23 e estruturas mapeadas com base no mapa na escala 1:1.000.000 000 de Lacerda Filho et al. (2004) e Souza et al. (2004).

Figura 4.5. Mapa da localização dos projetos aerogeofisicos utilizados em relação à presente área de estudo. .56 
Figura 4.6. (a) Linhas de voo de uma porção do levantamento PGBC, que possui espaçamento de $2 \mathrm{~km}$. É possível visualizar desvios mensuráveis no trajeto da aeronave. (b) Exemplo dos perfis empilhados do campo magnético anômalo de parte do levantamento para a verificação de valores espúrios, picos anômalos não associados diretamente ao sinal do campo magnético.

Figura 4.7. Exemplos de dados espúrios ressaltados com a técnica da análise da quarta diferença do campo magnético anômalo em: (a) Projeto Serra da Mesa (1014) e (b) PGBC (1020).

Figura 4.8. Mapas do campo magnético total (CMT) dos levantamentos (a) Serra da Mesa e (b) PGBC e mapas do campo magnético anômalo (CMA) após a remoção do IGRF, respectivamente, em (c) e (d).

Figura 4.9. Mapas do campo magnético anômalo dos levantamentos (a) Serra da Mesa (1014) e (b) PGBC (1020) e mapas do campo magnético anômalo micronivelado, respectivamente, em (c) e (d).

Figura 4.10. Esquema simplificado da definição do método de Sutura (com base em Johnson et al., 1999).

Figura 4.11. a) Mapa do campo magnético anômalo de maior resolução (célula unitária de $125 \mathrm{~m}$ ) e b) Mapa do campo magnético anômalo de menor resolução (célula unitária de 500m). A linha preta indica os limites do mapa recobertos apenas pelo projeto 1020 (PGBC) e a linha cinza indica os limites recobertos apenas pelo projeto 1014 (Serra da Mesa). Devido a ausência de aerolevantamentos recobrindo a parte sul da área estudada, não foi possível a interpolação de dados magnéticos nessa porção.

Figura 4.12. Mapa de Anomalia Bouguer de dados terrestres e localização das estações utilizadas neste estudo. 68

Figura 4.13. Fluxograma exemplificado evidenciando a sequência de processamento dos dados magnéticos e gravimétricos.

Figura 4.14. (a) Modelo de estudo mostrando o impacto da inclinação igual a $15^{\circ}$ no hemisfério sul no reconhecimento da geometria de fontes causadoras no campo magnético anômalo (adaptado de Isles \& Rankin, 2013) e (b) Anomalia dipolar invertida na área de estudo em relação a um comportamento esperado para uma anomalia puramente induzida, representando a possível presença de remanência na região.

Figura 5.1. Espectro radial de potência obtido a partir do mapa do campo magnético anômalo, onde cada segmento assinalado com cor diferente representa uma profundidade de topo de 
fontes distinta. A equação de cada reta ajustada é amostrada, onde $\mathrm{R}^{2}$ indica o melhor ajuste para cada reta.

Figura 5.2. Espectro radial de potência obtido a partir do mapa do campo magnético anômalo, onde cada segmento assinalado com cor diferente representa uma profundidade de topo de fontes distinta. A equação de cada reta ajustada é amostrada, onde $\mathrm{R}^{2}$ indica o melhor ajuste para cada reta.

Figura 5.3. (a) Ajuste das retas ao espectro de potência pelo Matched Filter, onde a linha mais suave representa o sinal ajustado à linha menos suave, que corresponde ao logaritmo da energia pela frequência espacial. (b) Filtros utilizados para a separação das bandas relacionadas às diferentes profundidades encontradas no espectro.

Figura 5.4. Resultados do Matched Filter aplicado ao mapa do campo magnético anômalo, onde os mapas com diferentes bandas de frequência retomam a profundidade de fontes com topo em (a) 21,8 km; (b) 6,6 km; (c) 1,6 km e (d) 0,5 km 83

Figura 5.5. Localização das sub áreas analisadas com a técnica do Matched Filter, sobrepostas ao mapa do campo magnético anômalo. As sub-áreas representam um total de 13 e foram numeradas aleatoriamente de acordo com o recorte do grid e ajuste aos limites do Grupo Araí a fim de obter um recobrimento total do mesmo

Figura 5.6. (a) Histograma de densidades em que os retângulos vermelhos indicam as populações principais. As linhas pontilhadas indicam os limites dos intervalos de dados de cada profundidade respectiva aos gráficos de (b) a (d), correspondentes à média ponderada de cada população. Os retângulos apontam patamares na distribuição dos dados, indicando maior importância para esses intervalos de valores.

Figura 5.7. Níveis de profundidade detectados utilizando o Matched Filter. Note que o nível mais profundo possui valores bastante dispersos variando entre $4200 \mathrm{~m}$ e $10300 \mathrm{~m}$.

Figura 5.8. Profundidades médias associadas aos níveis mais profundos para cada sub-área.

Figura 5.9. Mapas utilizados para o traçado dos lineamentos da área de estudo: (a) Derivada Vertical, (b) Derivada Tilt e (c) Ângulo Tilt Horizontal. 92

Figura 5.10. Estruturas magnéticas interpretadas a partir do mapa da Primeira Derivada Vertical (DZ) do campo magnético anômalo e diagrama de rosetas correspondente a: (a) lineamentos totais extraídos da área de estudo e (b) lineamentos extraídos da parte da Zona Externa da Faixa Brasília que abrange a presente área. Os lineamentos em cinza são aqueles que se localizam fora da ZE e sua direção preferencial se encontra somada aos lineamentos da 
ZE na roseta indicada em (a), que representa os lineamentos totais. Os lineamentos assinalados em (1) a (5) encontram-se comentados no texto subsequente. ZI: Zona Interna; ZE: Zona Externa; CSF: Cráton São Francisco.

Figura 5.11. Estruturas magnéticas interpretadas a partir do mapa da Derivada Tilt (TDR) do campo magnético anômalo e diagrama de rosetas correspondente a: (a) lineamentos totais extraídos da área de estudo e (b) lineamentos extraídos da parte da Zona Externa da Faixa Brasília que abrange a presente área. Os lineamentos em cinza são aqueles que se localizam fora da ZE e sua direção preferencial se encontra somada aos lineamentos da ZE na roseta indicada em (a), que representa os lineamentos totais. Os lineamentos assinalados em (1) a (5) encontram-se comentados no texto subsequente. ZI: Zona Interna; ZE: Zona Externa; CSF: Cráton São Francisco.

Figura 5.12. Estruturas magnéticas interpretadas a partir do mapa do Ângulo Tilt Horizontal (TDX) do campo magnético anômalo e diagrama de rosetas correspondente a: (a) lineamentos totais extraídos da área de estudo e (b) lineamentos extraídos da parte da Zona Externa da Faixa Brasília que abrange a presente área. Os lineamentos em cinza são aqueles que se localizam fora da ZE e sua direção preferencial se encontra somada aos lineamentos da ZE na roseta indicada em (a), que representa os lineamentos totais. Os lineamentos assinalados em (1) a (5) encontram-se comentados no texto subsequente. ZI: Zona Interna; ZE: Zona Externa; CSF: Cráton São Francisco. 95

Figura 5.13. Principais estruturas magnéticas interpretadas a partir dos mapas (a) da Derivada Vertical (DZ) e (b) Derivada Tilt do Gradiente Horizontal Total (TAHG) do campo magnético anômalo, ambos correspondentes a profundidade de $21,8 \mathrm{~km}$, e diagrama de rosetas correspondente a: (c) e (e) lineamentos totais extraídos da área de estudo; (d) e (f) lineamentos extraídos da parte da Zona Externa da Faixa Brasília que abrange a presente área. Os lineamentos em cinza são aqueles que se localizam fora da ZE e sua direção preferencial se encontra somada aos lineamentos da ZE na roseta indicada em (c) e (e), que representam os lineamentos totais. Os lineamentos assinalados em (1) a (5) encontram-se comentados no texto subsequente. ZI: Zona Interna; ZE: Zona Externa; CSF: Cráton São Francisco 96

Figura 5.14. Estruturas magnéticas interpretadas a partir dos mapas (a) da Derivada Vertical (DZ) e (b) Derivada Tilt do Gradiente Horizontal Total (TAHG) do campo magnético anômalo, ambos correspondentes a profundidade de $6,6 \mathrm{~km}$, e diagrama de rosetas correspondente a: (c) e (e) lineamentos totais extraídos da área de estudo; (d) e (f) lineamentos extraídos da parte da Zona Externa da Faixa Brasília que abrange a presente área. Os lineamentos em cinza são 
aqueles que se localizam fora da ZE e sua direção preferencial se encontra somada aos lineamentos da ZE na roseta indicada em (c) e (e), que representam os lineamentos totais. Os lineamentos assinalados em (1) a (5) encontram-se comentados no texto subsequente. ZI: Zona Interna; ZE: Zona Externa; CSF: Cráton São Francisco.

Figura 5.15. Estruturas magnéticas interpretadas a partir dos mapas (a) e (b) da Derivada Vertical (DZ) do campo magnético anômalo, correspondentes às profundidades de 1,6 km e 0,5 $\mathrm{km}$ respectivamente, e diagrama de rosetas correspondente a: (c) e (e) lineamentos totais extraídos da área de estudo; (d) e (f) lineamentos extraídos da parte da Zona Externa da Faixa Brasília que abrange a presente área. Os lineamentos em cinza são aqueles que se localizam fora da ZE e sua direção preferencial se encontra somada aos lineamentos da ZE na roseta indicada em (c) e (e), que representam os lineamentos totais. Os lineamentos assinalados em (1) a (5) encontram-se comentados no texto subsequente. ZI: Zona Interna; ZE: Zona Externa; CSF: Cráton São Francisco. .98

Figura 5.16. Soluções de Euler utilizando o método Padrão para o mapa da Anomalia Bouguer com remoção de tendência regional de ordem 2 (ao fundo), sobrepondo o respectivo sinal. FRM: Falha Rio Maranhão; CSF: Cráton São Francisco. 102

Figura 5.17. Soluções de Euler individualizadas em intervalos de profundidades utilizando o método da Deconvolução Padrão com índice estrutural 2 e janela 10x10 km para o mapa do campo magnético anômalo e histograma de densidades das soluções. 103

Figura 5.18. Integração das soluções de Euler para os dados magnéticos e gravimétricos com janela quadrada fixa de 10x10 km utilizando diferentes índices estruturais na região do Grupo Araí. 106

Figura 5.19. Síntese dos principais resultados de profundidades obtidas destacando as metodologias utilizadas. 108

Figura 5.20. Arranjo estrutural interpretado, com as regiões de influência dos Sistemas: (a) Teresina-Nova Roma, (b) Cavalcante-Teresina e (c) Arraias-Campos Belos. Os indicadores cinemáticos foram alocados apenas na Zona Externa da FDB, nos limites mais importantes relacionados ao Araí, de acordo com a geologia conhecida. Cidades: 1 - Arraias, 2 - Campos Belos, 3 - Monte Alegre, 4 - Nova Roma, 5 - Teresina, 6 - Cavalcante, 7 - Alto Paraíso, 8 Colinas do Sul, 9 - Niquelândia, 10 - Minaçu.

Figura 5.21. Interpretação gravimétrica e magnética na região do Grupo Araí segundo Haralyi \& Hasui $(1982,1985)$. 
Figura 5.22. (a) Mapa geológico a partir da integração das cartas SC.23, SD.22, SD.23, SC.22Z-D, SD.22-X-D, SD.23-V-A, SC.23-Y-C, SD.23-V-C-III, SD.23-V-C-V e SD.23-V-C-VII (adaptado de Cuadros \& Botelho, 2015), o qual é possível identificar as unidades do embasamento e semelhanças à (b) interpretação dos blocos crustais na região do Grupo Araí com base no traçado dos lineamentos magnéticos e na proposta de Haralyi \& Hasui (1985). A descontinuidade do Paranã ajustada aos lineamentos deste trabalho é representada no mapa pela linha tracejada. Os lineamentos magnéticos correspondem aos traçados do TDX (Figura 5.12).

Figura 5.23. Resultado da modelagem direta $2 \mathrm{D}$ de dados gravimétricos: (a) Curva da anomalia Bouguer, (b) Modelo gravimétrico proposto, (c) Mapa da localização das estações gravimétricas e (d) Pseudo 3D acompanhando a linha de aquisição dos dados. 118 


\section{Lista de Tabelas}

Tabela 4.1. Valores de densidade relativa de amostras coletadas em trabalho de campo (Os pontos visitados se encontram no Anexo 1). 51

Tabela 4.2. Especificações técnicas dos aerolevantamentos geofísicos utilizados. 56

Tabela 4.3. Etapas de pré-processamento nos dados aeromagnéticos dos diferentes levantamentos (enumeração está de acordo com o texto subsequente). .57

Tabela 4.4. Índices estruturais como sugeridos por Reid et al. (2014) 77

Tabela 5.1. Características da resposta do espectro radial de potência aplicado aos dados magnéticos para cada profundidade associada.

Tabela 5.2. Características da resposta do espectro radial de potência aplicado aos dados gravimétricos para cada profundidade associada. 81

Tabela 5.3. Resultados das profundidades observadas para cada sub-área. 86

Tabela 5.4. Associação entre as profundidades de cada bloco, em cada tentativa, e suas médias. 


\section{Capítulo 1}

INTRODUÇÃO

\subsection{APRESENTAÇÃO}

Esta dissertação de mestrado apresenta os resultados da análise geofísica na região do Grupo Araí, com ênfase no arranjo estrutural da bacia e profundidades de fontes relacionadas a esta, obtendo como resultado um modelo geológico-estrutural do Grupo Araí a partir de levantantamento gravimétrico e integração de dados geofísicos. Foram empregados dados geológicos regionais objetivando ampliar o conhecimento acerca do arcabouço tectônico e estrutural em ampla extensão territorial e de profundidade, colaborando na obtenção de informações que servirão na integração de todas as informações referentes à área estudada, incluindo grandes domínios crustais, embasamento e cobertura sedimentar.

O texto é composto por seis capítulos. O presente capítulo apresenta uma breve introdução ao tema da dissertação e justifica seu propósito, além de apresentar os objetivos deste estudo, a metodologia empregada e o conjunto de dados utilizados.

O Capítulo 2 contextualiza os aspectos geológicos principais da bacia-rifte Araí (da cobertura sedimentar e de seu embasamento): a evolução dos conhecimentos acerca do Grupo Araí e a evolução tectono-sedimentar da bacia. A contextualização geológica da área de estudo envolve também as unidades adjacentes no contexto da Província Tocantins e da Faixa Brasília, sendo descritos aspectos importantes da geologia destas entidades tectônicas que compõem o arcabouço tectônico regional.

O Capítulo 3 apresenta a contextualização teórica dos métodos geofísicos empregados, envolvendo os principais conceitos físicos referentes a estes métodos.

O Capítulo 4 apresenta os materiais e métodos utilizados neste estudo incluindo os detalhes da campanha de campo que envolveu a aquisição de dados gravimétricos e geológicos estruturais. Também apresenta detalhes do processamento e correções dos dados e as principais técnicas de análise utilizadas nesse trabalho.

O Capítulo 5 apresenta as interpretações geofísicas obtidas em cada metodologia empregada e os resultados encontrados com base na integração de todos os produtos. As conclusões finais do trabalho se encontram detalhadas no Capítulo 6. 


\subsection{JUSTIFICATIVA DO TEMA}

A bacia-rifte Araí é uma entidade tectônica ainda pouco estudada, com uma história complexa composta por um sistema de falhas que envolvem tanto suas unidades sedimentares quanto o embasamento. O Grupo Araí, unidade supracrustal dessa bacia, foi estudado por diversos autores (e.g Barbosa et al., 1969; Dyer, 1970; Araújo \& Alves, 1979; Marini et al. 1976; Martins, 1999; Almeida, 2009; Marques, 2010; Tanizaki, 2013), produzindo um volume de dados geológicos que contribuíram, sobretudo, para a compreensão da configuração litológica e estratigráfica das unidades da região. Porém os avanços no entendimento de sua história tectônica em relação à configuração do arcabouço estrutural/geofísico, sistemas de falhas e estruturas profundas ainda carecem de dados que incorporem a geologia de subsuperfície ao mapeamento geológico. Apesar de estudos já realizados a respeito do Grupo Araí, com enfoque em dados geológicos, são informações pouco correlacionadas entre si e a abordagem de algumas questões relativas à bacia ainda permanecem pouco exploradas. Os estudos geológicos possuem caráter essencialmente sedimentológico/estratigráfico e alguns poucos dados de geocronologia, geoquímica e geologia estrutural independentes entre si. Há poucos registros de pesquisas na região da bacia que caracterizem de forma bem definida sua origem e evolução. A interação entre a crosta subjacente, heterogênea e intensamente deformada no pré-cambriano e os sedimentos depositados em regime extensional permanecem pouco claros devido à complexidade tectônica da região, de forma que o resgate do préBrasiliano é certamente problemático.

Investigar tais problemas perante uma área de tectônica complexa, com vários estágios de evolução superimpostos pode ser bastante complicado e nem sempre as ferramentas geológicas se mostram competentes para decifrar todos os impasses impostos. Diante o exposto, algumas questões ainda permanecem em aberto sobre esta bacia:

(i) qual sua profundidade;

(ii) quais os sistemas de falhas principais;

(iii) como se deu o retrabalhamento tectônico das suas unidades durante a Orogenia Brasiliana.

(iv) qual sua compartimentação tectônica após os grandes eventos que tiveram influência na região central do Brasil.

A região de estudo da presente dissertação encontra-se localizada a leste do Cráton Amazônico e do Maciço de Goiás e a oeste do Cráton São Francisco. Suas unidades encontramse deformadas e falhadas, há exposição do embasamento em algumas áreas e, em outras, o mesmo encontra-se sobreposto a uma espessa cobertura sedimentar. A aplicação de métodos 
potenciais a esta região é hábil a fornecer importantes contribuições na interpretação de zonas de falhas/fraturas, além de técnicas capazes de aferir a profundidade de fontes com diferentes assinaturas magnéticas, seja o embasamento, intrusões ou outros tipos de estruturas que configurem o arcabouço da bacia, com base na elaboração de modelos geológicos/geofísicos qualitativos e quantitativos. Os métodos magnéticos e gravimétricos possuem a grande vantagem de possuírem amplo recobrimento espacial no caso de dados aéreos, baixos custos comparados a outros métodos e sua aplicação de forma integrada é capaz de fornecer soluções para os mais diversos problemas tectônicos.

\subsection{OBJETIVOS}

Com o objetivo de contribuir à evolução do conhecimento desta bacia e auxiliar nas respostas às questões em aberto, este estudo propõe a caracterização e compreensão das estruturas na região da bacia-rifte Araí a partir da análise conjunta de dados geofísicos gravimétricos e magnéticos e de dados geológicos. A fim de cumprir os objetivos primordiais deste estudo, coloca-se em destaque os seguintes objetivos específicos:

(i) Aquisição de dados gravimétricos e compilação e processamento de dados magnéticos e gravimétricos com a aplicação de técnicas específicas para estimar profundidades das fontes, em particular a profundidade do pacote sedimentar e do embasamento em áreas não expostas e fontes magnéticas associadas a estruturas tectônicas;

(ii) Identificação de lineamentos magneto-estruturais e seus domínios a partir de dados aeromagnéticos;

(iii) Interpretação tectônica e estrutural dos lineamentos a partir da integração de dados aeromagnéticos e dados geológicos estruturais;

(iv) Caracterização do arcabouço estrutural geofísico do Grupo Araí e suas adjacências indicando as principais falhas, fraturas e zonas de cisalhamento envolvidas no cenário da bacia e a importância destas no contexto da evolução tectono-sedimentar da região de estudo.

(v) Modelagem gravimétrica direta 2D a partir de seção definida estrategicamente na área de estudo envolvendo o embasamento e unidades sedimentares, utilizando como suporte para sua elaboração dados geológicos e estruturais.

Proposta do modelo geológico-estrutural da região da bacia e sua evolução tectônica a partir da integração dos dados. 


\subsection{LOCALIZAÇÃO DA ÁREA DE ESTUDO}

A região escolhida para este trabalho localiza-se na porção nordeste do Estado de Goiás e extremo sul do Estado de Tocantins e abrange o Grupo Araí em toda sua extensão, compreendendo a região dos municípios Arraias, Paranã, São Salvador do Tocantins e Peixe no Estado do Tocantins e Nova Roma, Teresina de Goiás, Cavalcante, Monte Alegre, Colinas do Sul, Alto Paraíso de Goiás e Niquelândia no Estado de Goiás (Figura 1.1). Limita-se pelos paralelos $12^{\circ} 0^{\prime} \mathrm{S}$ e $14^{\circ} 42^{\prime}$ e meridianos $49^{\circ} 12^{\prime} \mathrm{W}$ e 46 $30^{\prime} \mathrm{W}$. Os principais acessos à região, partindo de Brasília, se dão pela rodovia federal BR-010, rumo à GO-118, que dá acesso aos municípios de Alto Paraíso de Goiás, Teresina de Goiás, Monte Alegre e Campos Belos, no estado do Goiás.

A partir desta, seguindo a norte pela TO-296 tem-se acesso aos municípios Paranã, Arraias e São Salvador do Tocantins, já no estado do Tocantins. Também pela GO-118 tem-se acesso a Colinas do Sul e Minaçu, no acesso à GO-239, conectada a esta rodovia em Alto Paraíso de Goiás. Pela GO-241 tem-se acesso ao município de Cavalcante, à mesma altura da cidade de Teresina de Goiás.

\subsection{MÉTODOS E BASE DE DADOS}

No presente estudo foi realizada a análise conjunta de dados aeromagnéticos, de gravimetria terrestre e dados geológicos estruturais integrados em ambiente SIG (Sistema de Informações Geográficas) após seu processamento e aplicação de técnicas de realce. A metodologia empregada neste trabalho seguiu as seguintes etapas:

(i) Pesquisa bibliográfica e integração das bibliografias disponíveis referentes à região de influência do Rifte Araí, bem como a contextualização da evolução tectono-sedimentar e revisão de estudos anteriores;

(ii) Processamento de dados aeromagnéticos e gravimétricos terrestres cedidos;

(iii) Campanha de campo envolvendo aquisição gravimétrica terrestre e reconhecimento geológico estrutural de feições na mesma região de aquisição dos perfis gravimétricos para o desenvolvimento do modelo geofísico/geológico.

(iv) Integração dos métodos, geração de produtos, interpretação e modelagem direta 2D a partir da integração dos dados;

(v) Descrição do arcabouço tectônico estrutural na região da bacia e proposição de seu modelo geofísico/geológico estrutural. 
Foram utilizados dados geofísicos provenientes de seis levantamentos aéreos com diferentes datas de aquisição. São eles: Projeto Serra da Mesa (1973), Projeto Geofísico BrasilCanadá (1975), Projeto Arco Magmático de Mara Rosa (2004), Projeto Paleo-Neoproterozoico do Nordeste de Goiás (2006), Projeto Tocantins e Projeto Complemento do Tocantins (20052007). Todos os levantamentos incluíram campanha magnética e gamaespectrométrica. No entanto, para cumprir com os objetivos deste estudo foram utilizados apenas os dados magnéticos. O banco de dados gravimétricos compreende uma compilação realizada por Vidotti et al. (1998), com dados provenientes de diversas instituições tais como Instituto Brasileiro de Geografia e Estatística (IBGE), Instituto de Astronomia, Geofísica e Ciências Atmosféricas da Universidade de São Paulo (IAG/USP) e Instituto de Geociências da Universidade de Brasília (IG/UnB). As etapas de processamento e análise dos dados foram realizadas na plataforma Oasis Montaj v8.5. O Capítulo 4 descreve de forma detalhada o processamento e as técnicas utilizadas.

O banco de dados geológicos utilizado neste estudo compreende: (1) mapas geológicos na escala 1:1.000.000, gerados a partir da base de dados SIG (Lacerda Filho et al., 2004 e Souza et al., 2004) disponibilizada pela CPRM (cartas SD22 e SD23); (2) mapas geológicos na escala 1:100:000 das Folhas Cavalcante (SD.23-V-C-V), Monte Alegre de Goiás (SD.23-V-C-III) e Nova Roma (SD.23-V-C-VI) do Programa Geologia do Brasil (PGB/LGB), com coordenação de Botelho et al. (2007), Dardenne et al. (2007) e Alvarenga et al. (2007a); (3) banco de dados geológicos em ambiente SIG, por Almeida (2009), contendo compilações dos trabalhos finais de graduação (IG-UnB/TF) na escala 1:25.000, realizados pelos alunos de graduação do curso de geologia do Instituto de Geociências (IG) da Universidade de Brasília (UnB) nos anos de 1995, 1998, 1999 e 2005; os trabalhos de mapeamento regional desenvolvidos nos projetos Brasília (Barbosa et al., 1969) e Cana Brava - Porto Real (Araújo \& Alves, 1979) e os trabalhos de Botelho (1992), Dardenne et al. (1998) e Massucato (2003); e (4) dados estruturais coletados em campanha de campo realizada durante o desenvolvimento desta dissertação. 


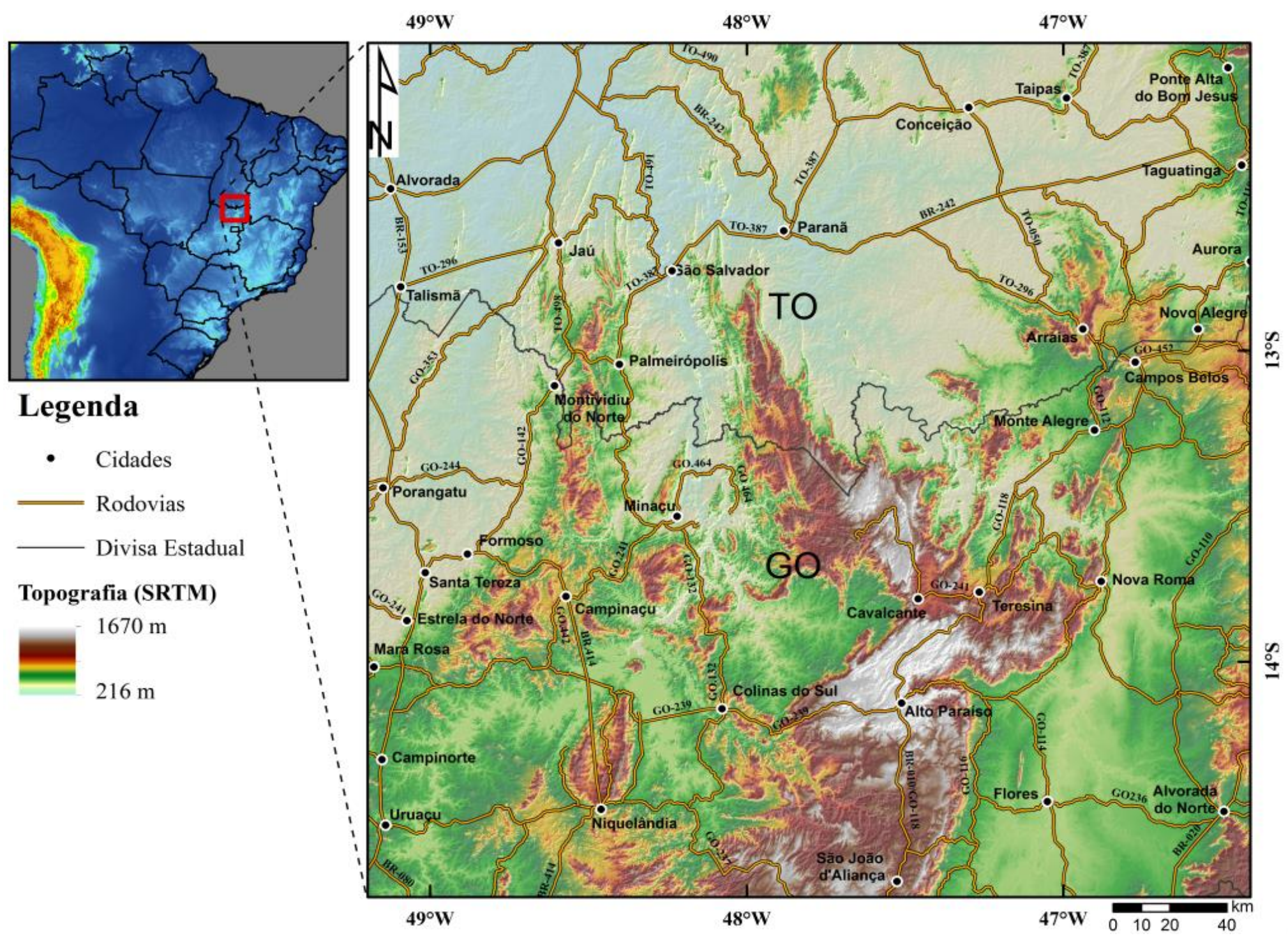

Figura 1.1 Mapa de localização da área de estudo e vias de acesso. 


\section{Capítulo 2}

\section{GEOLOGIA REGIONAL}

Apresenta-se nesse capítulo uma síntese sobre o contexto geológico da área de estudo, compilado de publicações anteriores. A finalidade é expor um resumo das principais características geológicas e geotectônicas relevantes para a investigação geofísica do Grupo Araí e áreas de influência da bacia-rifte Araí. Este capítulo inclui o contexto geotectônico no qual está inserido o Grupo Araí, a evolução tectono-sedimentar da bacia, além de uma compilação dos estudos que colaboraram para a evolução dos conhecimentos relacionados ao Grupo Araí.

\subsection{PROVÍNCIA TOCANTINS}

A Província Tocantins é uma entidade tectônica localizada na porção central da Plataforma Sul Americana, formada durante o ciclo neoproterozoico Brasiliano/Pan-Africano na colisão entre os crátons Amazônico, São Francisco/Congo e Bloco Paranapanema, este último completamente recoberto pelas rochas sedimentares da Bacia do Paraná e inferido a partir de dados geofísicos (Dardenne, 2000; Mantovani \& Brito Neves, 2005) - Figura 2.1. O final do ciclo orogenético que culminou na formação da província é caracterizado, em escala continental, pela aglutinação do supercontinente Gondwana (Almeida, 1968, 1977; Almeida et al., 1981). No Paleozoico-Mesozoico este supercontinente viria a se fragmentar novamente, ocasionando a abertura dos oceanos Índico e Atlântico, a individualização da América do Sul, África e Antártida, a formação do subcontinente da Austrália e formação do bloco continental da Índia (Unrug, 1997).

A orogenia do Brasiliano/Pan-Africano, no contexto da Província Tocantins, incorpora a evolução dos cinturões orogenéticos, compreendendo sua história sin- e pré-orogênese, onde estão presentes eventos de sedimentação, com deposição de sequências terrígenas e carbonáticas em ambientes plataformais, formação de terrenos do tipo arco de ilha, com magmatismo pré, sin- e pós colisional associados (e.g Pimentel et al., 1999; Marini et al., 
1981; Fuck, 1994; Dardenne, 2000), metamorfismo e deformação e a amalgamação de diferentes terrenos às margens continentais, culminando com a colisão de blocos continentais (Brito Neves et al., 2014; Pimentel et al., 2011; Pimentel, 2016).

Três cinturões de dobramento neoproterozoicos são identificados como os principais constituintes da Província Tocantins: (i) a Faixa Brasília, a leste, bordejando o Cráton São Francisco, (ii) a Faixa Araguaia, a noroeste, limitada pelo Cráton Amazônico e (iii) a Faixa Paraguai, a sudoeste, que também possui seus limites junto ao Cráton Amazônico.

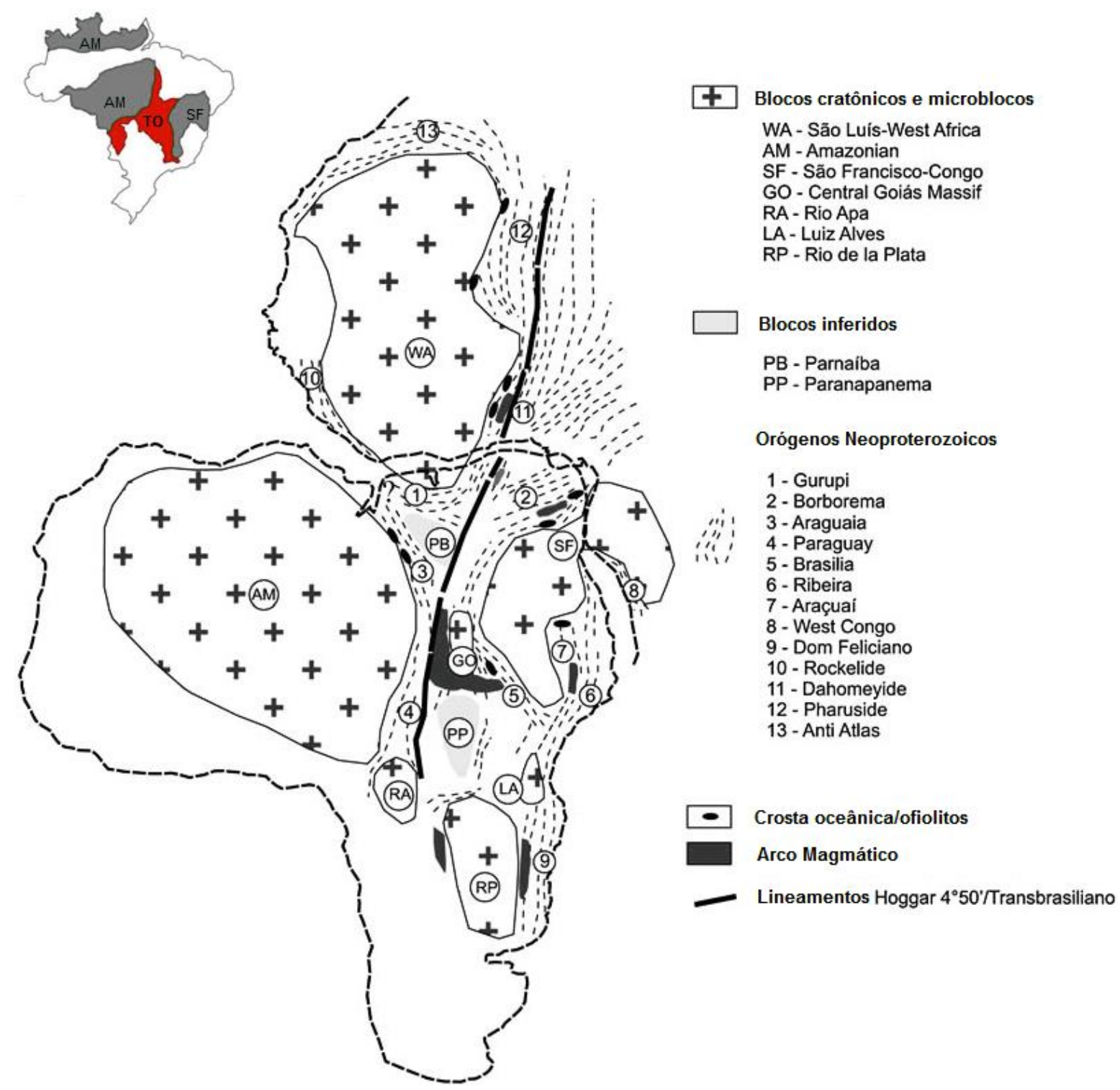

Figura 2.1. Elementos tectônicos da América do Sul e da parte oeste da África que participaram da aglutinação do Gondwana Ocidental e da formação da Província Tocantins. Na parte superior, em vermelho, a Província Tocantins em sua configuração atual. Modificado de Klein \& Moura (2008). 
A compartimentação geotectônica da Província Tocantins sofreu diversas propostas de síntese regional, entre elas as apresentadas por Almeida (1968), Danni \& Fuck (1981), Danni et al. (1982), Marini et al. (1978a, 1984a, 1984b), Almeida \& Hasui (1984), Hasui et al. (1984) e Schobbenhaus et al. (1975). Estes autores sugerem divisão em três unidades: i) Maciço de Goiás, representando um alto do embasamento arqueano; ii) Faixa de Dobramentos Uruaçu, de idade mesoproterozoica; e iii) faixas Brasília e Paraguai-Araguaia de idade neoproterozoica, nos limites entre os crátons Amazônico e São Francisco.

Fuck et al. (1993) e Fuck (1994) propuseram a distribuição de suas unidades tectônicas apresentando uma estruturação essencialmente neoproterozoica (a Faixa Uruaçu estaria incluída no contexto da Faixa Brasília), caracterizada pela seguinte compartimentação, de leste para oeste: i) Zona Cratônica; ii) Faixa Brasília; iii) Maciço de Goiás; iv) Arco Magmático do Oeste de Goiás e v) Faixas Paraguai e Araguaia. Essa subdivisão incorpora a porção com envolvimento cratônico, os cinturões de dobramentos, um microcontinente envolvido na colisão Brasiliana, que foi definido como o Maciço de Goiás e também uma faixa de acresção crustal neoproterozoica, denominada de Arco Magmático de Goiás (Pimentel, 1991; Pimentel \& Fuck, 1992). Os cinturões de dobramentos compõem-se, em grande parte, de rochas supracrustais e intrusões graníticas espalhadas pontualmente. A parte maciça é composta substancialmente por embasamento granito-ortognaissico, greenstone belts, granulitos, complexos máficos-ultramáficos e sequências vulcanossedimentares.

Da mesma forma, Lacerda Filho et al. (1999) e Delgado et al. (2003), com base em dados geológicos, geocronológicos e geofísicos, propõem subdivisão da Província Tocantins com base em idades, significado e ambiência tectônica distintos, sendo segmentada em: i) Terrenos de significado tectônico duvidoso; ii) Terrenos granito-greenstone arqueanos e remanescentes do embasamento arqueano-paleoproterozoico; iii) Faixa móvel paleoproterozoica; iv) Complexos máfico-ultramáficos acamadados; v) Bacia-rifte intracontinental paleoproterozoica; vi) Remanescentes de crosta oceânica; vii) Orógenos Brasilianos - faixas Brasília, Araguaia e Paraguai e Arco magmático de Goiás; Bacias de antepaís meso a neoproterozoicas e viii) Intracratônicas neoproterozoicas.

\subsection{FAIXA DE DOBRAMENTOS BRASÍLIA}

A Faixa de Dobramentos Brasília (FDB), cinturão orogenético que bordeja o Cráton São Francisco (Figura 2.2), estende-se por mais de $1100 \mathrm{~km}$ na direção NS, cobrindo parte dos Estados do Goiás e Tocantins, o Distrito Federal e a parte ocidental do Estado de Minas Gerais. 
Compreende um conjunto de terrenos, fragmentos crustais e rochas metassedimentares cavalgando em direção à parte oeste do cráton (Dardenne, 2000).

Foi primeiramente definida por Almeida (1968) como Geossinclíneo Brasília. Almeida et al. (1976) e Almeida (1977) propuseram o modelo de duas faixas de dobramentos (Uruaçu e Brasília) relacionadas a dois ciclos tectônicos independentes. Sua nomenclatura recente foi adotada a partir dos trabalhos de Dardenne (1978a), Strieder (1990), Fuck (1990), Brod et al. (1991), Pimentel et al. (1992) Araújo Filho (1992) e Fuck et al. (1993), autores estes que propõem um único ciclo tectônico (Brasiliano) e uma única faixa de dobramentos.

Quanto às taxas de deformação e metamorfismo, este cinturão orogenético pôde ser dividido em duas zonas distintas: Zona Externa e Zona Interna, limitadas a leste por uma Zona Cratônica pertencente ao Cráton São Francisco. As unidades sedimentares da FDB apresentam deformação tectônica mais intensa em direção a oeste, com consequente aumento em seu grau de metamorfismo (Dardenne, 2000). A evolução da deformação, associada ao metamorfismo, reflete a clara vergência da FDB em relação ao Cráton São Francisco. Essa compartimentação tectônica foi inicialmente proposta por Costa \& Angeiras (1971), descrita por Dardenne (1978a) e reformulada por Fuck et al. (1994).

A Megainflexão dos Pirineus, ou Sintaxe dos Pirineus, composta pelos lineamentos de direção WNW-SSE mais marcantes no estado de Goiás (Costa et al., 1970; Marini et al., 1981, 1984a; Araújo Filho, 1980), divide a FDB e seu embasamento em duas porções, setentrional e meridional, abrangendo características em comum seja quanto à tectônica, estratigrafia, ao magmatismo ou à metalogênese (Fuck \& Marini, 1979). 


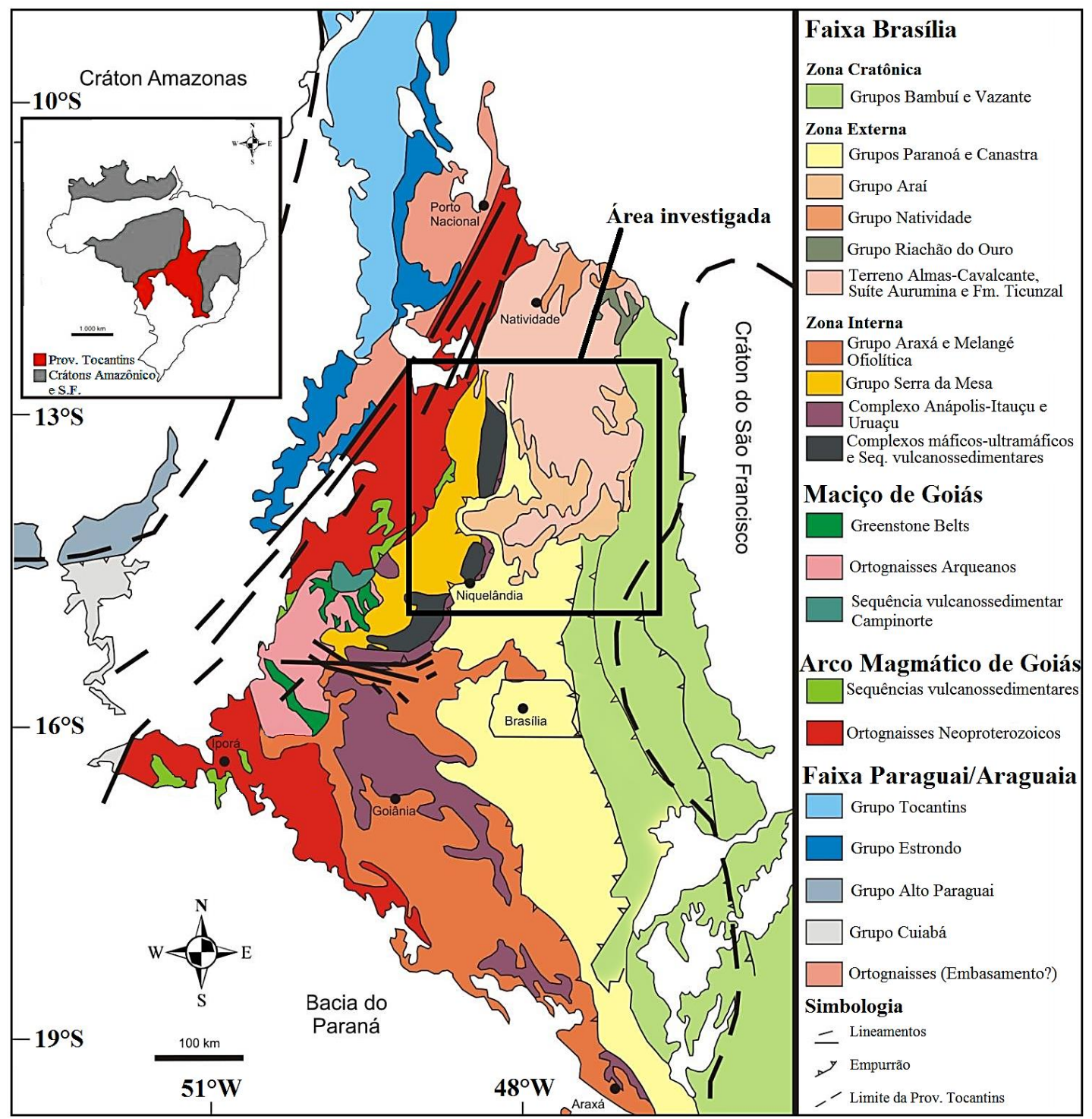

Figura 2.2. Unidades tectônicas da Faixa Brasília. O polígono em preto indica a região de estudo deste trabalho. Modificado de Pimentel et al. (2004b).

\subsubsection{Zona Cratônica}

A Zona Cratônica é constituída pelos grupos Bambuí e Vazante (Dardenne, 1981, 2000), composta por sedimentos argilocarbonáticos dobrados a sub-horizontais e extensas coberturas fanerozoicas. O embasamento desta porção não foi envolvido na deformação e o limite entre o Cráton São Francisco e a Faixa Brasília ocorre por falhas de empurrão de baixo a médio ângulo que expõem o Grupo Paranoá ou o Grupo Canastra, unidades mesoproterozoicas (Uhlein et al., 2012). Este falhamento de empurrão é ocasionalmente trucando por sistemas transcorrentes, sobrepondo as unidades da Zona Externa e o embasamento às coberturas cratônicas (Fuck, 1994). 


\subsubsection{Zona Externa}

A Zona Externa é constituída de unidades metassedimentares de idade mesoproterozoica (Dardenne, 1981, 2000; Faria, 1995; Guimarães, 1997), bem como porções do embasamento arqueano-paleoproterozoico que mostram retrabalhamento devido à tectônica brasiliana (Uhlein et al., 2012). Estas unidades metassedimentares estão estruturadas em um cinturão de dobras e empurrões de antepaís (Fuck et al., 1993; Fuck, 1994).

A cobertura metassedimentar na porção norte da Zona Externa (a qual está inserida a área de estudo da presente dissertação) é caracterizada pelos Grupos Araí/Natividade, Paranoá e Formação Ticunzal, com representantes típicos envolvendo a sedimentação pré, sin- e pós rifte do Grupo Araí, uma estreita faixa de unidades psamo-pelíticas e carbonáticas mais superiores do Grupo Paranoá (Marini et al., 1981) e o restante do setor caracterizado pela ocorrência de rochas vulcanossedimentares, granitos estaníferos e embasamento rochoso, sendo sobrepostos por falhas inversas ao Grupo Bambuí (Fuck et al., 1993; Fuck, 1994).

Esta mesma porção foi subdividida em três setores de acordo com Fonseca \& Dardenne (1994), observando o estilo estrutural apresentado e a natureza de suas unidades: (i) setor norte, que engloba rochas do embasamento cristalino e do Grupo Araí, apresentando tectônica do tipo thick-skinned, onde o embasamento foi envolvido na deformação das rochas da cobertura, tanto em sistemas transcorrentes quanto compressivos frontais; (ii) setor sul, com rochas do Grupo Paranoá, não apresentando uniformidade no estilo estrutural e magnitude de deformação e (iii) setor leste (abrangendo parte da Zona Cratônica), incluindo as unidades neoproterozoicas do Grupo Bambuí, onde parece haver somente deformação induzida.

\subsubsection{Zona interna}

A Zona Interna compreende unidades alóctones dos grupos Araxá e Serra da Mesa e também parte do embasamento fortemente envolvido na Orogenia Brasiliana (Maciço de Goiás, com remanescentes de greenstone belts) (Pimentel et al., 2000). O grupo Araxá apresenta sedimentação turbidítica associada a sedimentos químicos e de origem vulcânica. Localmente ocorrem complexos máfico-ultramáficos granulitizados (Ferreira Filho et al., 1992) e sequências vulcanossedimentares proterozoicas (Pimentel et al., 2000). 


\subsubsection{Arco Magmático de Goiás}

O Arco Magmático de Goiás se localiza na transição entre o Maciço de Goiás e a Zona Interna da FDB e é composto por terrenos ortognáissicos derivados de rochas plutônicas (alcalinas, tonalíticas) e sequências vulcanossedimentares neoproterozoicas. Compreende o Arco Magmático Arenópolis a sul e o Arco Magmático de Mara Rosa a norte.

Esta unidade tectônica é considerada um orógeno acrescionário que foi formado em cerca de 900 Ma, em um sistema de arcos de ilhas intraoceânicos (Pimentel \& Fuck, 1992) com último evento magmático com ocorrência em cerca de 630-600 Ma, durante o fechamento do oceano Goiás-Pharusiano (Cordani et al., 2003)

O Arco Magmático Arenópolis é composto de unidades supracrustais e ortognaisses cálcio-alcalinos, afetados por metamorfismo na fácies anfibolito (Pimentel et al., 1996, 2004b). O Arco Magmático de Mara Rosa é representado por sequências supracrustais, ortognaisses e corpos intrusivos tardios a pós-orogênicos (Pimentel et al., 2000).

\subsubsection{Maciço de Goiás}

O Maciço de Goiás é um fragmento continental alóctone originado a partir de rochas do Arqueano e Paleoproterozoico (Valeriano et al., 2004; Jost et al., 2013). Seus terrenos arqueanos abrangem as faixas de greenstones de Crixás, Guarinos, Pilar de Goiás, Faina e Serra de Santa Rita bem como os complexos gnáissicos associados. A parte paleoproterozoica é caracterizada por um embasamento ortognaissico coberto por unidades metassedimentares altamente metamorfisadas do Grupo Serra da Mesa. Para leste encontram-se complexos máficoultramáficos e sequências vulcanossedimentares associadas (Pimentel et al., 2000).

\subsection{O EMBASAMENTO E AS COBERTURAS METASSEDIMENTARES}

\subsubsection{Embasamento}

O embasamento da área de estudo é representado por rochas granito-gnaissicas, predominantemente constituídas por ortognaisses de composição tonalítica a granodiorítica, pelas rochas metassedimentares e paragnaisses da Formação Ticunzal e por expressiva granitogênese peraluminosa da Suíte Aurumina. Possui distribuição desde o norte de Colinas do Sul, passando por Cavalcante a nordeste, e se estendendo para norte, ocorrendo também de 
forma descontínua nas adjacências do complexo Niquelândia e em uma estreita faixa que se prolonga desde a barra do Paranã até Minaçu (Figura 2.3).

Delgado et al. (2003) atribui o nome de terreno Almas-Cavalcante ao embasamento siálico, subdividindo em Terreno Almas-Dianópolis, mais a norte - complexos granitognáissicos (com características químicas de granitoides de arco magmático) classificados como suítes TTG de natureza calcialcalina (Cruz \& Kuyumjian, 1996; 1998) - e Terreno JaúCavalcante, na região do Grupo Araí - correspondente aos metassedimentos da Formação Ticunzal e granitogênese da Suíte Aurumina. As idades obtidas para as rochas do embasamento variam entre 3067 e 450 Ma (Hasui \& Almeida 1970, Cordani \& Hasui, 1975; Tassinari et al., 1981). Pimentel et al. (1991) posicionaram o complexo de rochas granitoides no ArqueanoPaleoproterozoico. As idades mais jovens estão relacionadas a rejuvenescimentos em ciclos orogenéticos posteriores.

\subsubsection{Terreno Jaú-Cavalcante}

\subsection{Formação Ticunzal}

A Formação Ticunzal ocorre na região das serras do Ticunzal e Tombador, no município de Cavalcante (Marini et al., 1978b; Pimentel et al., 2004b; Fernandes et al., 1982). Situa-se entre o embasamento rochoso e as rochas do grupo Araí, sendo sobreposta ao embasamento por contato erosivo. É formada essencialmente por xistos e paragnaisses frequentemente grafitosos, além de quartzitos micáceos em menores proporções, e raras ocorrências de conglomerados, constituídos por uma paragênese retrometamórfica, onde ocorrem, em concentrações variáveis: quartzo, clorita, epidoto, carbonato e muscovita fina (Alvarenga et al., 2007b). Não possui idade bem definida, podendo ser mais velha que 2,15 Ga, já que apresenta intrusões graníticas da Suíte Aurumina. As idades modelo Sm-Nd mostram $\mathrm{T}_{\mathrm{DM}}$ entre 2,6 e 2,8 Ga, indicando que a fonte dos sedimentos é predominantemente arqueana (Fuck et al., 2002). Os metassedimentos da formação apresentam características politectônicas e polimetamórficas, e sua paragênese mineral atual pertence a fácies xisto-verde alto, caracterizada pela associação biotita-granadamuscovita (Marini et al., 1978b).

\subsection{Suíte Aurumina}

A Suíte Aurumina, anteriormente englobada ao Complexo granito-gnaissico, apresenta um conjunto de intrusões sin-, tardi- e pós-tectônicas, intrusivas nos xistos grafitosos da Formação Ticunzal. Possui composição variando de monzogranito a tonalito, caracterizada principalmente por biotita e muscovita magmáticas, de caráter peraluminoso, responsável pela 
geração de importantes depósitos minerais (Au, EGP, Sn, Ta e U). Esta suíte representa a granitogênese mais antiga relacionada ao rifte Araí, apresentando granitos com idade entre 2.12 e $2.17 \mathrm{Ga}$, datadas pelo método U-Pb (Botelho et al., 2006a).

\subsection{Granitos estaníferos anorogênicos}

Os granitos tipo-A do nordeste do Goiás formam dois grupos de rochas, com idades meso e neoproterozoicas e características químicas e geocronológicas distintas: os granitos das suítes Serra da Mesa e Pedra Branca pertencendo, respectivamente, às subprovíncias Rio Tocantins a oeste, e Rio Paranã a leste (Schobbenhaus, 1993; Marini \& Botelho, 1986). Nestas subprovíncias os granitos foram subdivididas em G1 e G2. O grupo G1 é caracterizado por rochas mais antigas, com idade $\mathrm{U}-\mathrm{Pb}$ em zircões de 1,77 Ga (Pimentel et al., 1991), enquanto no grupo G2 são colocadas as rochas mais jovens, com datação U-Pb em zircões em torno 1,61,5 Ga, apresentando caráter metaluminoso a peraluminoso, frequentemente associadas a depósitos de estanho e índio (Pimentel et al., 1999). A granitogênese anorogênica é comprovada pelas características geoquímicas assim como o ambiente tectônico, que demonstram contemporaneidade ao vulcanismo do Grupo Araí, com colocação e resfriamento em ambiente extensional intracontinental, tomando parte na extensão crustal responsável pela geração do rifte.

Na Subprovíncia Rio Paranã (ou granitos da Suíte Pedra Branca) estão presentes os granitos Serra da Pedra Branca, Mocambo, Mangabeira, Mendes, Sucuri, Soledade, Teresinha e São Domingos, em contato tectônico com os metassedimentos do Grupo Araí e intrusivos em rochas da Suíte Aurumina e Formação Ticunzal. Ocorrem tanto os granitos G1, quanto G2 (denominados de granitos pb1 e pb2 por Alvarenga et al., 2007b). Os granitos G1 apresentam idade de $1.767 \pm 10 \mathrm{Ma}$ a partir de datação U-Pb em zircões obtidos nos granitos Sucuri e Soledade (Pimentel et al., 1991) e os granitos G2 apresentam idade variável entre $1.405 \pm 21$ Ma e $1.781 \pm 197$ Ma a partir de isócronas Rb-Sr (Botelho \& Pimentel, 1993).

A Subprovíncia Rio Tocantins (ou granitos da Suíte Serra da Mesa) é representada pelos granitos Serra Dourada, Serra do Encosto e Serra da Mesa, que afloram a oeste do Rio Tocantins. São granitos mais jovens, com idade $\mathrm{Pb}-\mathrm{Pb}$ de $1,56 \mathrm{Ga}$, relacionados à reativação do rifte e incluídos na classificação de granitos G2 (Dardenne et al., 2003; Rossi et al., 1992). Estes granitos aparentemente foram intrudidos no Grupo Serra da Mesa, apesar de haver controvérsias (Marini et al., 1984a; Macambira \& Villas 1984; Dardenne et al., 2003; Rocha, 2003). 


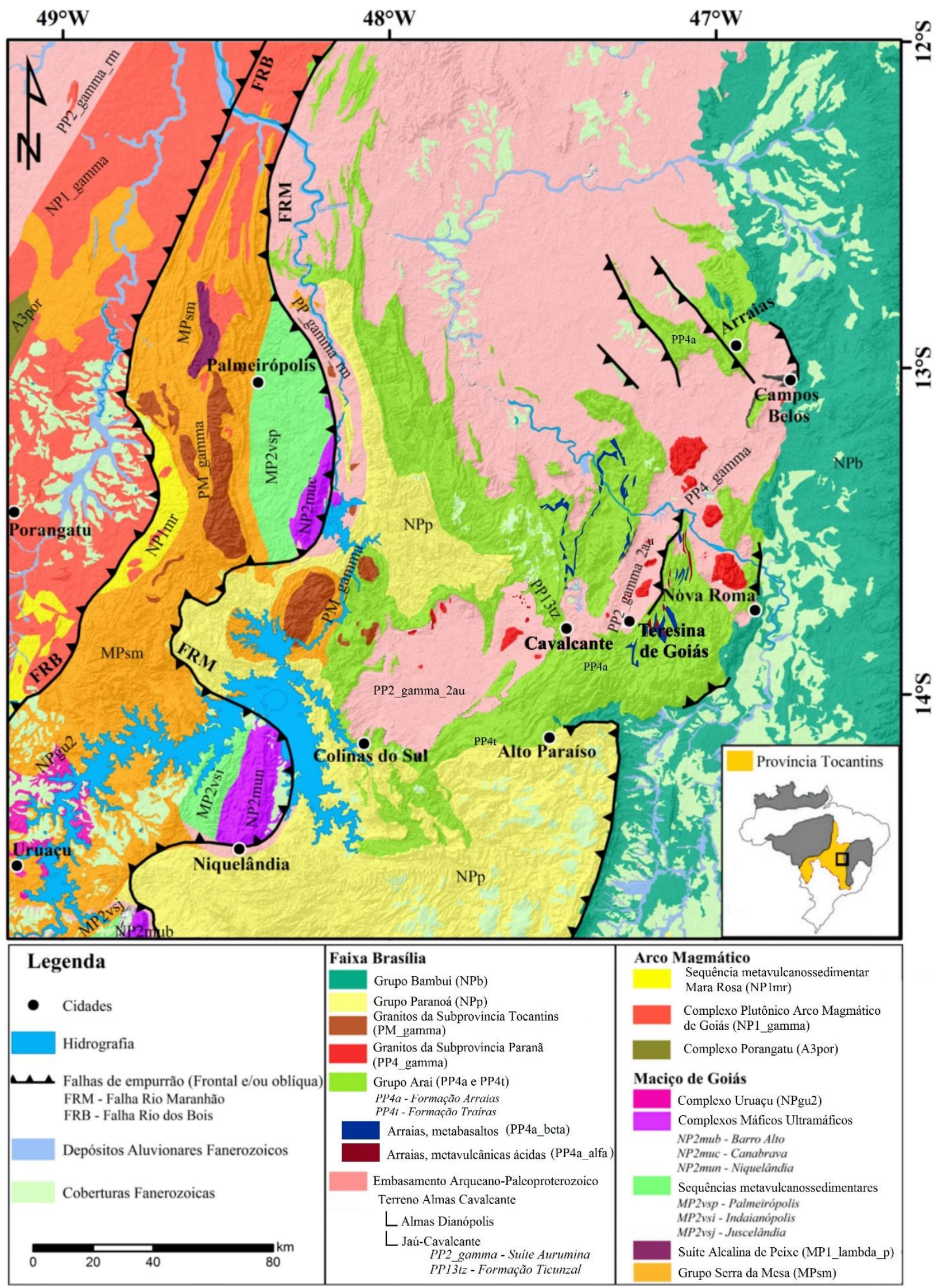

Figura 2.3. Mapa geológico simplificado envolvendo as unidades litoestratigráficas da área de estudo, com base nos mapas na escala 1:1.000.000 por Lacerda Filho et al. (2004) e Souza et al. (2004). 


\subsubsection{Sequências Supracrustais}

\subsubsection{Grupo Serra da Mesa}

O Grupo Serra da Mesa, com ocorrência a oeste do Grupo Araí e dos complexos máficoultramáficos de Cana Brava, Niquelândia e Barro Alto (Fuck \& Marini, 1979, 1981; Schobbenhaus, 1993), se estende desde a porção norte da Faixa Brasília até a Megainflexão dos Pirineus. É representado por um espesso pacote de quartzitos e micaxistos com espessura média de 1850 m e foi correlacionado ao Grupo Araxá (Barbosa et al., 1969, Fuck \& Marini 1981) e, posteriormente, ao Grupo Araí (Marini et al., 1984a e Dardenne, 2000). Este grupo se sobrepõe ao embasamento granito-gnaissico e está em contato com o Grupo Araí por falhas de empurrão (Botelho et al., 1995).

Sua estratigrafia é representada por uma sequência psamo-pelito-carbonatada composta por silimanita xistos, muscovita xistos, lentes de rochas calcissilicáticas e mármores puros na base, quartzito sacaroidal recristalizado e espessas lamelas de muscovita subordinadas na porção intermediária e muscovita-biotita xistos, com lentes decamétricas de rocha calcissilicática, de mármores impuros e de quartzito no topo (Araújo Filho et al., 2007).

\subsubsection{Complexos Máfico-Ultramáficos (Barro Alto, Cana Brava e Niquelândia)}

Os complexos máficos-ultramáficos de Barro Alto, Cana Brava e Niquelândia se localizam na porção centro-norte de Goiás e se inserem no contexto dos terrenos de alto grau da Província Tocantins (Girardi et al., 1978; Correia et al., 1997; Correia \& Girardi, 1998; Moreira et al., 2008). Os três complexos podem representar duas fases ígneas cronológicas e petrologicamente distintas (Pimentel et al., 2005). Datações U-Pb SHRIMP em zircões das séries inferiores indicaram idades de cristalização em torno de 770-760 Ma, pertencentes a abertura de rifte continental. As séries superiores podem ter pertencido à evolução de uma bacia oceânica, em 1,25 Ga, representada pelas sequências vulcanossedimentares Palmeirópolis, Indaianópolis e Juscelândia, cujos basaltos são interpretados como protólitos tholeíticos do tipo MORB (Moraes, 1997; Araújo \& Nilson, 1987; Danni \& Kuyumjian, 1984). Esses sistemas foram justapostos no Brasiliano e seu soerguimento pode ter ocorrido em cerca de $650 \mathrm{Ma}$ (Feininger et al., 1991; Marangoni et al., 1995; Moraes, 1997), quando rochas das sequências vulcanossedimentares Palmeirópolis, Indaianópolis e Juscelândia cavalgaram sobre as rochas dos complexos máfico-ultramáficos acamadados e estes sobre rochas granito-gnáissicas do embasamento, à leste. 


\subsubsection{Sucessões vulcanossedimentares (Palmeirópolis, Indaianópolis e Juscelândia)}

As sequências metavulcanossedimentares que compreendem a região de estudo formam um cinturão descontínuo de direção NE com cerca de $300 \mathrm{~km}$ de comprimento e ocorrem a oeste dos complexos máficos-ultramáficos de Cana Brava, Niquelândia e Barro Alto (Ferreira Filho et al., 1999). São compostas principalmente por remanescentes de crosta oceânica de idade mesoproterozoica (1,3 Ga - Pimentel et al., 2004a), estabilizados após a Orogenia Brasiliana. Segundo Fuck et al. (1981), Danni \& Leonardos (1980) e Ribeiro Filho \& Teixeira (1981) essas sucessões vulcanossedimentares compreendem entidades independentes, sob a denominação de Juscelândia, Indaianópolis e Palmeirópolis. Dados isotópicos $\mathrm{Pb}-\mathrm{Pb}$ e U-Pb indicam idade de 1,25 Ga para a Sequência Palmeirópolis e 1,29 Ga para Indaianópolis (Pimentel et al., 2000). A sequência vulcanossedimentar de Juscelândia não apresenta expressão significativa na presente área de estudo, assim como o complexo de Barro Alto.

A Sequência vulcanossedimentar de Palmeirópolis é representada pelas rochas a oeste de Canabrava (Leão Neto \& Olivatti, 1983; Araújo, 1986; Araújo \& Nilson, 1987; Valente, 1992). É composta por duas unidades, inferior e superior, contendo em sua parte inferior anfibolitos finos a grossos com intercalações de gnaisses e quartzitos e também diques máficos e ultramáficos e corpos graníticos intrusivos e, em sua parte superior, metapelitos com intercalações de quartzitos e raros níveis de anfibolito fino (Ribeiro Filho \& Teixeira, 1981).

A Sequência vulcanossedimentar de Indaianópolis ocorre na borda oeste do Maciço de Niquelândia e é formada, na base, por anfibolitos finos com intercalações de biotita-xistos, biotitagnaisses, metacherts e formações ferríferas bandadas e no topo é composta por riolitos e tufos riolíticos, xistos, quartzitos, anfibolitos finos e metacherts (Souza \& Leão Neto, 1998). As paragêneses minerais desta sequência indicam condições de metamorfismo da fácies xisto verde atingindo, no máximo, a zona da biotita (Brod, 1988).

\subsubsection{Grupo Paranoá}

O Grupo Paranoá é composto por uma sequência sedimentar com presença de rochas psamo-pelíticas e, em menor quantidade, carbonáticas (Dardenne, 1974). Este grupo se sobrepõe discordantemente ao Grupo Araí por contato erosivo, marcado por um metaconglomerado basal matriz-suportado denominado conglomerado São Miguel (Faria, 1995; Fonseca, 1996). Sua coluna estratigráfica se caracteriza, da base para o topo, por: i) Quartzito basal fino de cor cinza pouco silicificado; ii) metassiltitos cinzas em sua porção 
intermediária; iii) ocorrência de camadas finas de diamictitos com clastos de siltitos, quartzitos e clastos de mármore arrendondados e achatados com matriz fílitica/carbonática; conglomerados/brechas intraformacionais em associação com os diamictitos; iv) intercalação de quartzitos finos e brancos, metagrauvacas e metassiltitos no topo (Marques, 2010). Em sua porção superior ocorrem estromatólitos colunares que indicam deposição no Mesoproterozoico entre 1,35-0,95 Ga (Dardenne et al., 1973). Pimentel et al. (2001) realizaram datações Sm-Nd, que indicaram idade $\mathrm{T}_{\mathrm{DM}}$ paleoproterozoica entre 2,3-1,9 Ga, com proveniência exclusivamente continental.

\subsubsection{Grupo Bambuí}

O Grupo Bambuí é composto por uma associação de litofácies pelito-siliciclásticas e carbonáticas de extenso mar epicontinental neoproterozoico e encontra-se sotoposto por falha de empurrão ao Grupo Paranoá (Fonseca, 1996). Sua deposição ocorreu a partir de megaciclos transgressivos-regressivos de plataforma rasa, sendo iniciada por sedimentação glaciogênica, seguida por sucessivas regressões, separadas por períodos de subsidência e aumento da lâmina de água, com consequente deposição de sedimentos argilosos (Santos et al., 2000). Sua estratigrafia é composta, da base para o topo pelas formações Jequitaí, Sete Lagoas, Serra de Santa Helena, Lagoa do Jacaré e Serra da Saudade, reunidas no Subgrupo Paraopeba, e a Formação Três Marias, localizada no topo (Dardenne, 1978b). O limite entre o Bambuí e o Paranoá se dá pela presença de um paraconglomerado basal da Formação Jequitaí, importante guia estratigráfico regional (Oliveira, 1967).

\subsubsection{Suíte Alcalina de Peixe}

A Suíte Alcalina de Peixe, ou Complexo Alcalino de Peixe (Barbosa et al., 1969) é um corpo de forma elíptica, com $30 \mathrm{~km}$ de comprimento e $6,5 \mathrm{~km}$ de largura orientado NS, de rochas plutônicas em contato intrusivo com os metassedimentos do Grupo Serra da Mesa. É composto principalmente por biotita-nefelina sienitos bandados e foliados a maciços, originados de magmas insaturados que evoluíram a partir de magmas originados em manto litosférico metassomatizado, com cristalização há 1,5 Ga (Kitajima, 2002). As rochas saturadas e supersaturadas (granitos e feldspato alcalino sienitos) foram formadas por magmas independentes que se desenvolveram a diferentes profundidades e distintos graus de metassomatismo ou ainda por diferentes percentuais de fusão parcial. A Suíte foi submetida a processos metamórficos no fim do Brasiliano e a uma nova atividade ígnea que posicionou um pegmatito diorítico portador de coríndon com idade U-Pb em zircão de 0,6 Ga (Kitajima, 2002). 


\subsection{GRUPO ARAÍ}

\subsubsection{Evolução do conhecimento}

As primeiras referências ao Grupo Araí provêm do Projeto Brasília-Goiás (Barbosa et al., 1969), durante o qual coube a Robert C. Dyer, um dos componentes da equipe, sua proposição formal. Dyer (1970) subdivide o grupo em dez unidades litoestratigráficas, incluindo as formações Arraias (unidades 1 a 3 ) e Traíras (unidades 4 a 10). A primeira, depositada discordantemente sobre o embasamento, é composta por metassedimentos psamíticos, lentes de metassiltitos e corpos descontínuos de metaconglomerados, com ocorrências locais de efusivas básicas e ácidas, sendo depositada em ambiente predominantemente fluvial. A segunda é uma sequência psamo-pelito-carbonatada depositada em ambiente marinho.

Araújo \& Alves (1979), na realização de mapeamento geológico na escala 1:50.000 em parte da área de ocorrência desse grupo, dividiram as rochas cartografadas como pertencentes ao Grupo Araí por Barbosa et al. (1969) em treze subunidades. Porém apenas as seis subunidades inferiores foram creditadas a este grupo. As demais subunidades classificadas por Dyer (1970) como pertencentes ao Araí (unidades 7 a 10) foram atribuídas ao Grupo Bambuí devido à existência de uma discordância entre as subunidades 6 (unidade 6 do Grupo Araí) e 7 (unidade 1 do Grupo Bambuí) e, mais tarde, atribuídas ao Grupo Paranoá por Braun (1980). Este mesmo autor reclassifica o conjunto das dez unidades de Dyer (1970) à categoria de Supergrupo Araí e o subdivide em cinco subunidades. Seguindo o caráter estratigráfico, Marini et al. (1976), em estudos de âmbito regional, descreve a formação Arraias como indivisa, constituída das seguintes litologias, da base para o topo: quartzito finos brancos bem estratificados, com níveis micáceos, contendo intercalações decimétricas de conglomerado fino e leitos xistosos com espessura centimétrica, localmente calcíferos; camada decamétrica de quartzo-muscovita xisto contendo bastante magnetita em cristais octaédricos milimétricos e muitos veios e lentes de quartzo de segregação; quartzito fino micáceo e laminado, devido a intercalações centimétricas-decimétricas de camadas com cores de alteração cinza escuro, rosa e branco, contendo níveis conglomeráticos. Posteriormente, Andrade \& Danni (1978), em trabalho de semi-detalhe na região da Serra Branca, delimitaram três unidades na Formação Arraias: conglomerados e quartzitos; sericita-quartzo xistos; quartzitos. As unidades 
cartografadas por esses autores são bastante semelhantes às descritas por Marini et al. (1976), porém com a ausência de conglomerados na unidade quartzítica do topo da formação.

Martins (1999) define dois conjuntos estratigráficos principais no Grupo Araí dando enfoque ao ambiente deposicional associado: a Sequência Continental, associada aos sistemas deposicionais fluvial, eólico e fluvio-deltáico, abrangendo a porção basal do grupo (Formação Arraias) e a Sequência Transicional-Marinha, correlacionada a sistemas deposicionais litorâneos e de plataforma rasa e aberta, se tornando progressivamente marinha em direção ao topo (Formação Traíras). Em contrapartida, Dardenne et al. (1999) dividiram o Grupo Araí em três unidades principais a relacionadas às fases do rifte: i) Unidade Continental Basal (fase prérifte), composta por quartzitos fluviais e eólicos; ii) Unidade Continental Intermediária (fase rifte), composta por brechas e conglomerados intraformacionais na base e quartzitos grossos com níveis conglomeráticos no topo; e, iii) Unidade Marinha Superior (fase pós-rifte), constituída de metassiltitos intercalados com quartzitos finos e acompanhada de uma transgressão marinha regional.

Marques (2010), em análise litoestratigráfica e estudos de geoquímica e geocronologia dos grupos Araí e Serra da Mesa e de seus embasamentos na região sudeste do Tocantins, classifica o Grupo Araí como uma megassequência de primeira ordem com quatro estágios bem definidos: pré-rifte, sin-rifte, transicional e pós-rifte. Por fim, Tanizaki (2013), em análise sedimentar e tectono-estratigráfica subdivide o Grupo Araí em quatro unidades (Figura 2.4): Água Morna, Arraias, Caldas e Traíras; tendo em vista a necessidade de se efetuar uma integração de dados de fontes e áreas diversas com foco sedimentológico/estratigráfico, com base no Código Brasileiro de Nomenclatura Estratigráfica (Petri et al. 1986a; Petri et al. 1986b). A Formação Água Morna representa um sistema deposicional fluvial entrelaçado, instituído em uma bacia do tipo sag-intracontinental na fase pré-rifte da bacia, submetida a processos de subsidência termal. A Formação Arraias constitui espesso pacote de sedimentos continentais, caracterizados nos tratos de sistema da fase rifte, relacionados essencialmente com a subsidência mecânica da bacia. A Formação Caldas compõe a sequência deposicional transicional do Grupo Araí. A Formação Traíras representa a sequência marinha desenvolvida no decurso da subsidência flexural. 


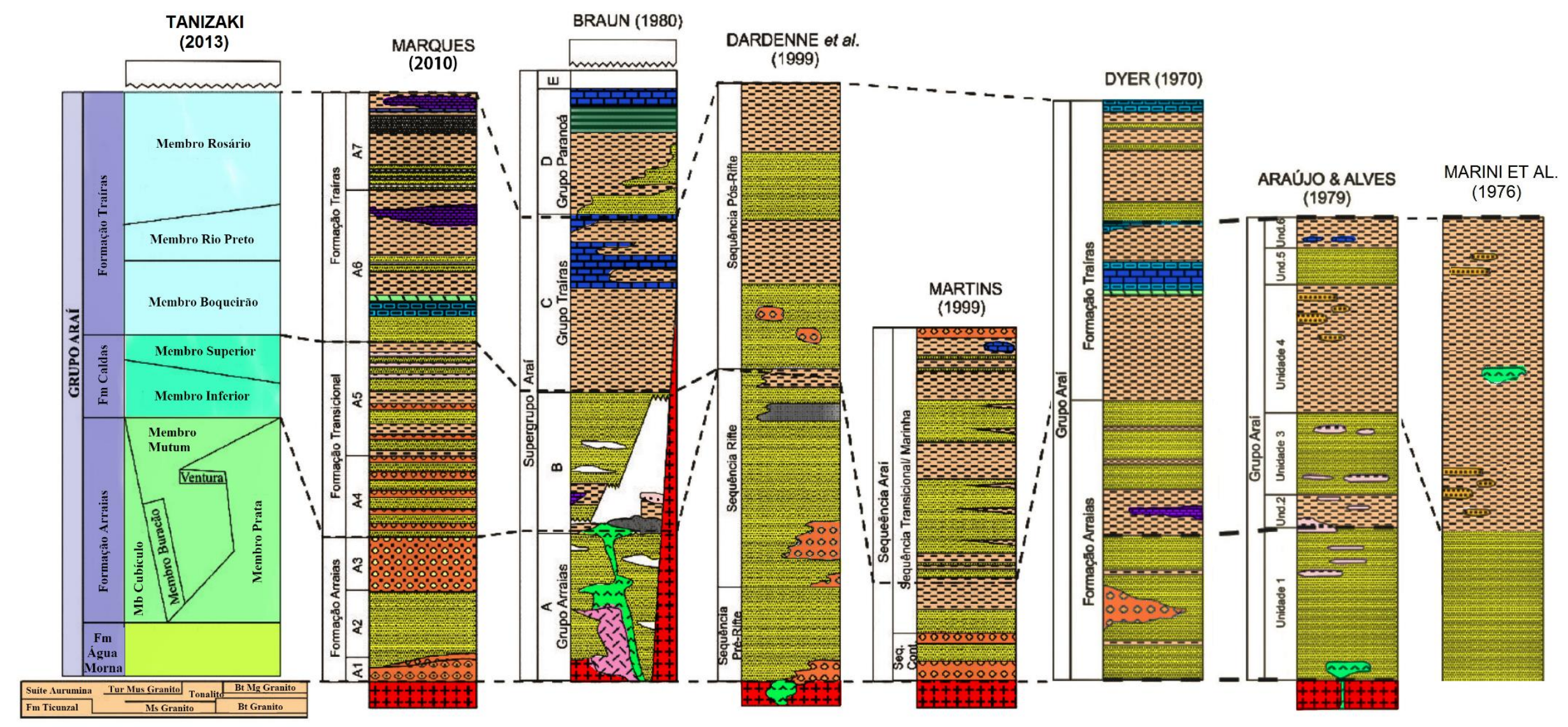

Figura 2.4. Correlação estratigráfica das propostas de Dyer (1970), Marini et al. (1976), Araújo \& Alves (1979), Braun (1980), Dardenne et al. (1999), Martins (1999), Marques (2010) e Tanizaki (2013). Modificado de Tanizaki (2013). 
Marini et al. (1984a) define a idade do Grupo Araí como pertencente ao Mesoproterozoico. Estudos isotópicos a partir de datações U-Pb em zircões de metarriolitos que ocorrem na sucessão basal do Grupo Araí (Pimentel et al., 1991; Pimentel \& Fuck 1991) e de dados isotópicos em granitos anorogênicos e vulcânicas ácidas (Pimentel \& Botelho 2001) permitiram datar a idade da deposição dessa unidade em 1,771 $\pm 0,002 \mathrm{Ga}$, o que significa que estas rochas vulcânicas seriam do Paleoproterozoico tardio, indicando sua contemporaneidade com o Supergrupo Espinhaço, no Cráton do São Francisco. A partir destes trabalhos o Grupo Araí é atribuído ao Paleo/mesoproterozoico (Pimentel et al., 1999; Pimentel et al., 2000). A idade de 1,771 Ga datada por Pimentel \& Botelho (2001) se encontra presente no Supergrupo Espinhaço representada por vulcânicas com idade U-Pb de 1,8-1,7 Ga na Formação Rio dos Remédios (BA), no Granito Borrachudos (MG) e no vulcanismo associado (Babinski et al., 1999; Schobbenhaus et al., 1994). As intrusões graníticas da Suíte Serra da Mesa, datadas em 1,56 Ga, também confirmam a contemporaneidade do rifte Araí ao rifte Espinhaço, podendo ser correlacionadas a rochas vulcânicas da Formação Bomba do Sintema Pajeú com idade U$\mathrm{Pb}$ de 1,57 Ga (Danderfer et al., 2009).

Massucato (2003), através de estudos estruturais, caracteriza o embasamento na porção do Grupo Araí pela observação de foliações. Foram reconhecidas cinco foliações distintas, separadas em três eventos deformacionais. O primeiro evento apresenta uma foliação gerada em resposta a uma compressão NS, com idade em 1,5 Ga, segundo as datações utilizando-se o método ${ }^{40} \mathrm{Ar} /{ }^{39} \mathrm{Ar}$, obliterada aparentemente pela abertura parcial do sistema K-Ar durante o ciclo Brasiliano. Tal fato permite inferir que a deformação, responsável pela geração do primeiro evento, pode ter pertencido ao ciclo Transamazônico $(2,2-2,0 \mathrm{Ga})$, segundo o autor. O segundo evento apresenta uma compressão de direção aproximadamente $\mathrm{EW}$, datado em 1,4 Ga, perturbada devido ao encaixe dos corpos graníticos da fase rifte ou, ainda, devido à influência do Brasiliano sobre as rochas da região. Este evento também ocorre provavelmente relacionado ao ciclo Transamazônico. O terceiro evento foi responsável por três foliações distintas, capazes de admitir uma compressão EW que pode ter ocorrido em 700-400 Ma. A estruturação apresentada para o terceiro evento é concordante com uma tectônica do tipo thickskinned, com embasamento mediamente a pouco envolvido.

Fonseca et al. (1995), Giustina \& Barbosa (2005) e Alvarenga et al. (2007b), em alternativa às ideias de Massucato (2003), propuseram apenas dois eventos, de natureza compressiva, Transamazônico e Brasiliano, intercalados por uma fase distensiva rúptil no Estateriano. 
Fonseca (1996), na porção setentrional da Faixa Brasília, a qual o Grupo Araí está diretamente envolvido, descreve sistemas de falhas e fraturas de alto ângulo, orientados NE e NW, muitas vezes individualizados em zonas de cisalhamento (Figura 2.5). Estes sistemas foram regionalmente classificados pelo autor em: (i) Sistema Cavalcante-Teresina de Goiás; (ii) Sistema Teresina de Goiás-Nova Roma-Monte Alegre-Campos Belos; (iii) Sistema ArraiasCampos Belos e (iv) Sistema São Jorge-Alto Paraíso-Cormari.

O sistema Cavalcante-Teresina de Goiás abrange um conjunto de falhas transcorrentes verticais, afetando rochas do embasamento e do Grupo Araí. Este sistema está vinculado à norte com o sistema Teresina de Goiás-Nova Roma, com inflexão das estruturas para o norte, assumindo geometria frontal. As rochas envolvidas neste sistema consistem essencialmente granitoides e quartzitos. O sistema Teresina de Goiás - Nova Roma - Monte Alegre - Campos Belos descreve um conjunto de falhas reversas, com embasamento envolvido, de orientação preferencialmente meridiana. As estruturas do Sistema Teresina de Goiás-Nova Roma são essencialmente falhas reversas de alto ângulo, com terrenos do embasamento sobrepostos ao Grupo Araí, e, mais a leste, o Grupo Araí sobre o Grupo Bambuí. Este sistema se prolonga intermitentemente seguindo direção NS até Monte Alegre e a região de Campos Belos, onde sofre interferência com o Sistema Campos Belos-Arraias, orientado NW. O Sistema Campos Belos-Arraias compõe um sistema de falhas oblíquas que opera a partir da região de Campos Belos em direção à cidade de Arraias. É descrito por um conjunto de falhas de alto ângulo com movimentação reversa para leste, com orientação geral N30-40W, as quais afetam os granitoides do embasamento e as rochas do Grupo Araí. Essas falhas transcorrentes truncam as falhas NS e NE do Sistema Teresina-Nova Roma-Monte Alegre, estabelecendo assim uma relação cronológica entre os diferentes tipos de falhas: as falhas frontais a dominante NS-NNE anteriores às falhas transcorrentes sinistrais NW, mais tardias. Esse fato é bem comprovado a sul de Cavalcante, no sistema transcorrente São Jorge-Alto Paraíso-Cormari. O Sistema São Jorge-Alto Paraíso-Cormari é um sistema de falhas ENE com alto ângulo de mergulho, truncando rochas do Grupo Araí, Paranoá e Bambuí. É marcado por foliação vertical e lineações minerais orientadas segundo a direção da foliação. Indicadores cinemáticos indicam um sistema dextral.

Tanizaki (2013) também descreve em seu trabalho zonas de cisalhamento bem marcadas distribuídas na região de influência do Grupo Araí. Essas zonas incluem o Sistema CavalcanteTeresina e o Sistema Arraias-Campos Belos, os mesmos descritos por Fonseca (1996), e também o Sistema Colinas do Sul, que constitui um conjunto de falhas transcorrentes verticais 
de cinemática dextral, paralela ao Sistema São Jorge-Alto Paraíso e o Sistema Rio Maranhão, com trend NS que limita a área de antepaís interno do núcleo metamórfico.

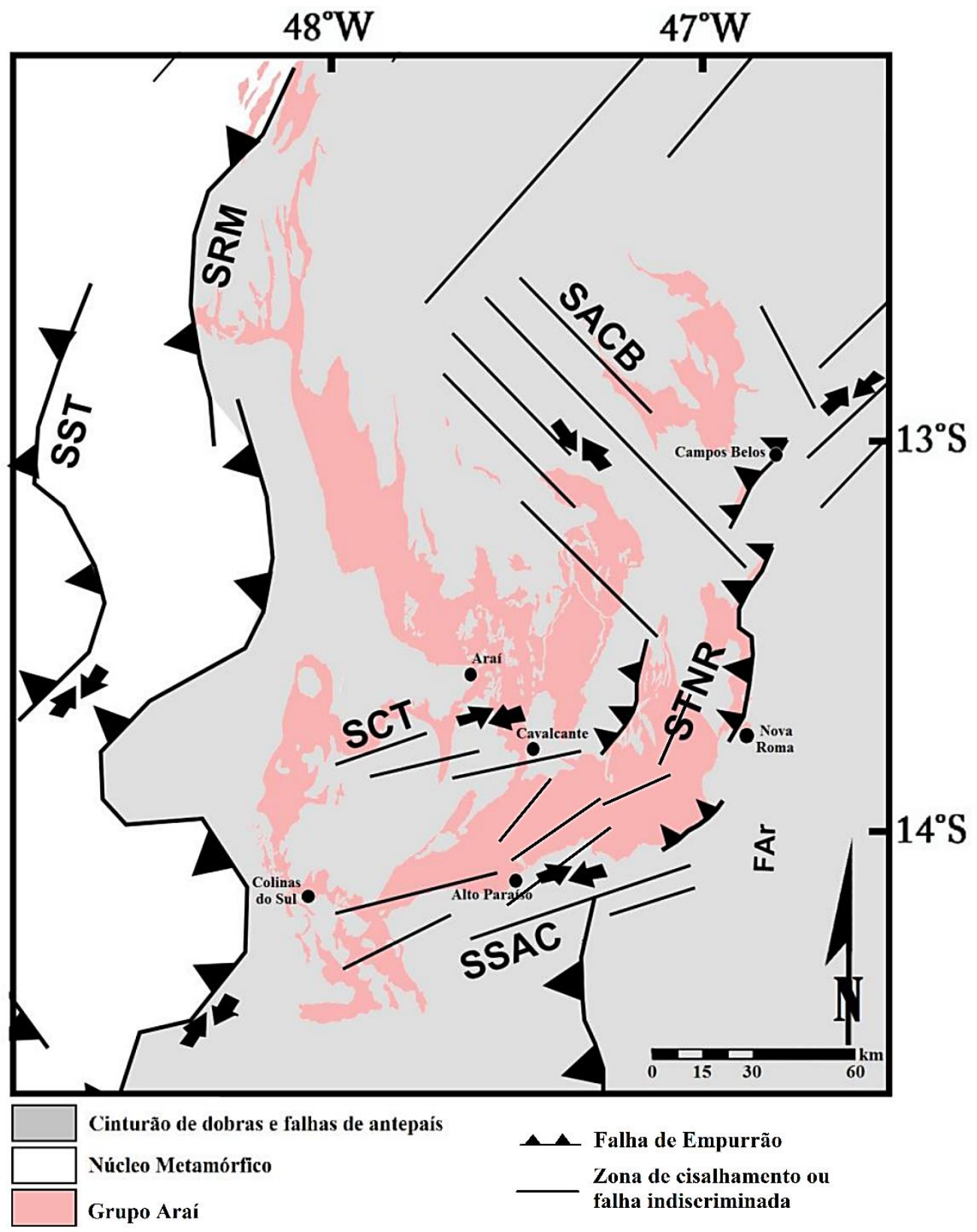

Figura 2.5. Mapa simplificado evidenciando os sistemas de falhas na região de estudo segundo Fonseca (1996). SRM - Sistema Rio Maranhão, SACB - Sistema Arraias-Campos Belos, STNR - Sistema Teresina de Goiás-Nova Roma-Monte Alegre-Campos Belos, SSAC - São Jorge-Alto Paraíso-Cormari e SCT - Sistema CavalcanteTeresina.

Almeida (2009) faz a interpretação geológica do Rifte Araí a partir de imagens R99SAR e de dados geofísicos magnéticos e gamaespectrométricos entre as cidades de Cavalcante, Monte Alegre de Goiás e Nova Roma. Na interpretação geofísica, foram gerados produtos magnéticos tais como o Campo Magnético Anômalo, Primeira Derivada Vertical, Amplitude 
do Gradiente Horizontal Total (AGHT), Amplitude do Sinal Analítico e Inclinação do Sinal Analítico (ISA ou Tilt Derivative), além dos produtos gamaespectrométricos Canal de Contagem Total (CT), Canais individuais do Potássio, Tório e Urânio, Mapa de Razões e Imagem Ternária. No mapa da Amplitude do Sinal Analítico foi possível separar os domínios magnéticos e individualizar os maciços graníticos da Suíte Pedra Branca (Figura 2.6).
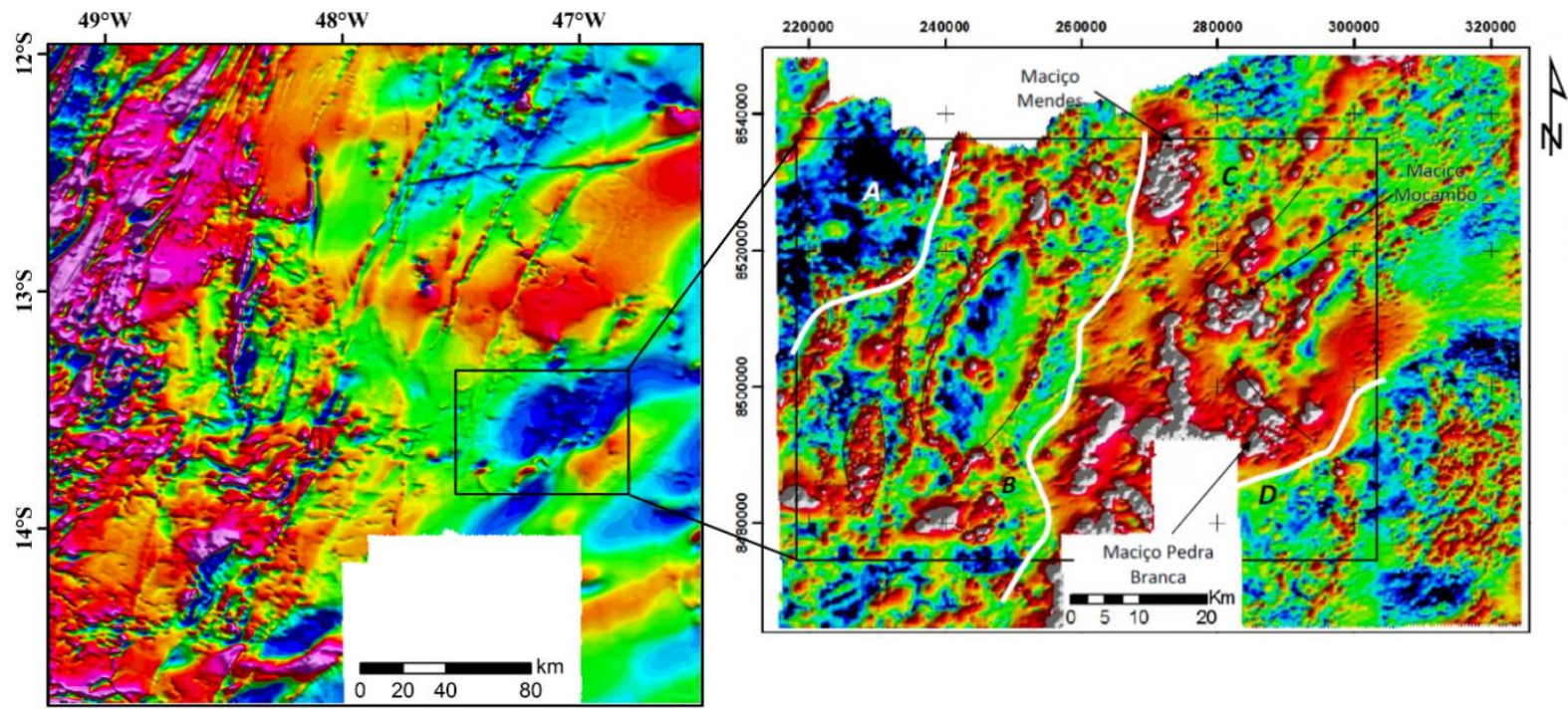

Figura 2.6. (a) Mapa magnético integrado neste trabalho, onde o polígono preto representa a localização de (b) Análise da Amplitude do Sinal Analítico de Almeida (2009) com as subdivisões dos grandes domínios magnéticos (A, B, C e D) e dos maciços graníticos da Suíte Pedra Branca.

\subsubsection{Síntese da evolução tectono-sedimentar}

As rochas do Grupo Araí estão relacionadas a um evento de extensão continental desenvolvido na região central do Brasil (Figura 2.7). Este evento de rifteamento afetou essencialmente as rochas da Formação Ticunzal e da Suíte Aurumina, já deformadas pela Orogênese Transamazônica (2,2-2,0 Ga), e controlou a formação e sedimentação de duas bacias-rifte correlatas representadas, a oeste pelo rifte Araí e, a leste pelo rifte Espinhaço (Brito Neves et al., 1996, 2014). É um período marcado também pela intrusão dos corpos máficosultramáficos de Niquelância, Barro alto e Canabrava (Nilson et al., 1994). 


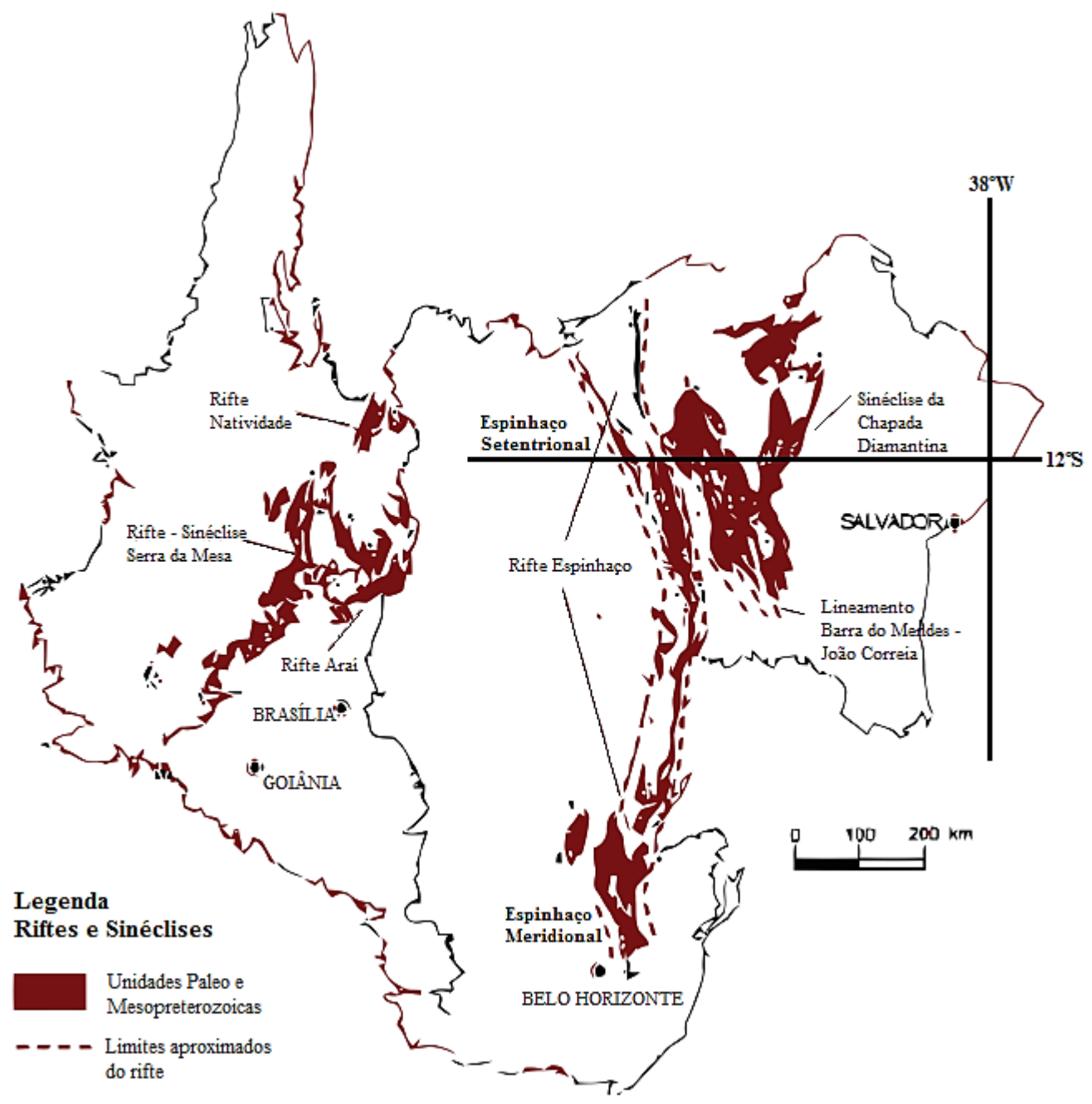

Figura 2.7. Rifteamentos do Paleo e Mesoproterozoico em parte do Brasil. Fonte: Delgado et al. (2003).

O Grupo Araí engloba a porção supracrustal da bacia-rifte a oeste, que evoluiu em resposta a uma extensão de direção NNE-SSW, com início antes de 1,77 Ga e término entre 1,61-1,57 Ga, resultante do quebramento dos terrenos paleoproterozoicos formados durante a Orogênese Transamazônica (Alvarenga et al., 2000). Essas forças distensivas teriam provocado a abertura do rifte Araí (Figura 2.8) a partir de antigas linhas de fraqueza, com a formação de uma bacia de subsidência lenta (Schobbenhaus, 1993) que teria ocorrido após uma fase de arqueamento crustal (Marini et al., 1981). Os falhamentos regionais gerados durante esse período de extensão são profundos, podendo chegar à parte superior do manto (Alvarenga et al., 2007b).

No estágio inicial do rifte, parte das falhas geradas devido à intumescência do manto e estiramento da crosta desenvolveram escarpas, formando um graben ensiálico com a implantação da sedimentação de origem continental, em leques aluviais e rios entrelaçados associados a ambiente desértico (Schobbenhaus, 1993; Alvarenga et al., 2007b; Marques, 
2010). As idades modelo de zircões detríticos apresentadas por Pimentel \& Botelho (2001) é de 2,4 a 2,16 Ga, produtos da erosão de crosta paleoproterozoica recém estabilizada após a Orogênese Transamazônica.

$\mathrm{Na}$ fase sin-rifte predomina a subsidência mecânica, com deposição de sedimentos conglomeráticos em leques aluviais e arenitos fluviais, podendo sofrer intercalações de vulcânicas ácidas e vulcanoclásticas pontualmente distribuídas ao longo da sequência continental. Basaltos continentais também podem ser encontrados intercalados a quartzitos e siltitos, sempre recobrindo a sequência vulcânica ácida. Localmente, ocorre fusão parcial da crosta e provavelmente do manto devido ao sistema de falhas profundo, originando os processos magmáticos que conduziram à formação dos granitos estaníferos anorogênicos da Suíte Pedra Branca e ao vulcanismo bimodal registrado na base do Grupo Araí, ambos datados com ocorrência em cerca de 1,77 Ga (Alvarenga et al., 2007b).

A fase transicional do rifte se estabelece com a introdução da sedimentação marinha na bacia, havendo mudança no regime de subsidência que passa a ser predominantemente flexural/termal. Devido às baixas taxas de subsidência ocorre sedimentação marinha e continental em praias arenosas, praias de cascalhos (storm beachs), possíveis deltas e depósitos de planície de maré (Marques, 2010).

A fase pós-rifte é marcada por depressão térmica e altas taxas de subsidência, com a expansão da bacia fora dos limites do rifte original. Os grupos Serra da Mesa e Natividade podem ser correlacionados a essa fase da Bacia Araí. A sedimentação é caracterizada pela deposição de sedimentos psamíticos e pelito-carbonáticos em uma sequência transgressiva marinha de ambientes litorâneo e de plataforma aberta (sinéclise marginal). O fim dos processos de sedimentação do Grupo Araí parece ter ocorrido por volta de 1,6-1,56 Ga, contemporâneo às intrusões graníticas relacionadas à Suíte Serra da Mesa, que podem estar associadas a uma reativação tectônica do embasamento do rifte Araí (Pimentel \& Botelho, 2001; Rossi et al., 1992; Dardenne et al., 2003).

Um período de quietude tectônica se estabelece após o processo de rifteamento, entre 1,3-1,25 Ga. A partir desse momento ocorre a formação da sequência vulcanossedimentar de Palmeirópolis e o Complexo máfico-ultramáfico de Canabrava, representando um novo evento de extensão crustal, ao qual está associada a instalação de um ambiente de margem passiva onde são depositados os sedimentos do Grupo Paranoá, em 1350-950 Ma (Dardenne, 1978b e 1979; Pimentel et al., 2004a). 

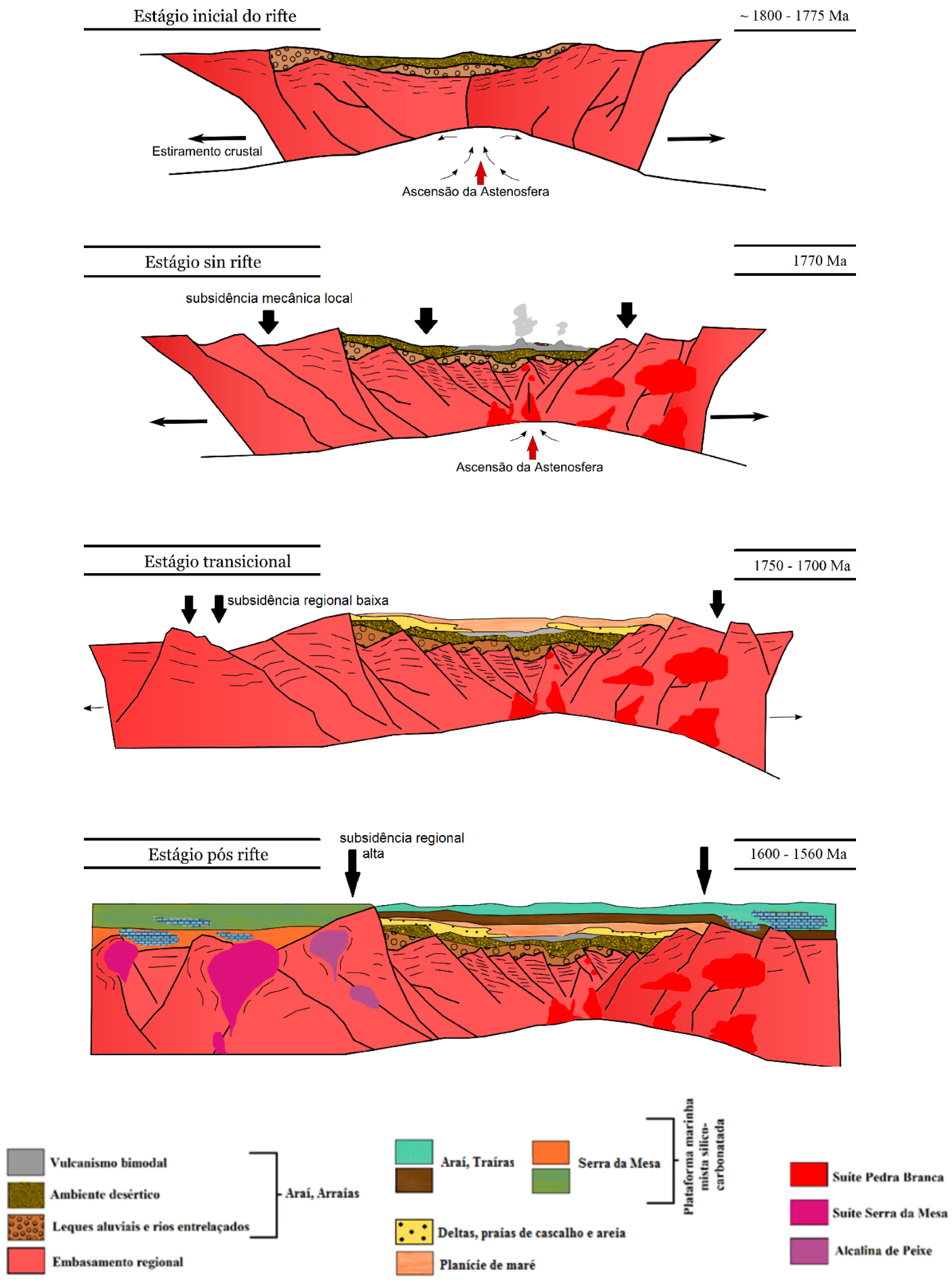

Figura 2.8. Evolução do rifte Araí e deposição dos sedimentos dos grupos Araí e Serra da Mesa. Figura adaptada segundo modelo teórico de Marques (2010). 
Com ocorrência entre 770-520 Ma, a Orogenia Brasiliana caracterizou uma etapa de convergência de fragmentos continentais que resultou na aglutinação do supercontinente Gondwana (Unrung, 1997). Esse evento orogenético afetou essencialmente as rochas do embasamento cristalino e do Grupo Araí na porção setentrional da Faixa Brasília, sendo esta porção classificada como antepaís interno, com dobras e falhas de empurrão com vergência para leste (Fonseca et al., 1995; Martins-Neto \& Alkmim, 2001).

No Brasiliano as falhas normais, antes relacionadas à fase rifte, foram transformadas em falhas compressivas com transporte tectônico de oeste para leste e, subordinadamente, de norte para sul. Como exemplo de estruturas do rifte que sofreram inversão em seu regime estrutural têm-se a falha identificada a leste da Serra da Pedra Branca e as falhas que controlam o leito do Rio Paranã no corte do Grupo Araí (Alvarenga et al., 2002, 2007b; Botelho et al., 2006b).

As rochas do Grupo Araí sofreram metamorfismo extremamente fraco, sendo anquimetamórficas ou de grau xisto verde baixo (Dardenne, 2000). Essas rochas são separadas do Grupo Serra da Mesa (fácies anfibolito) pelo sistema de falhas Rio Maranhão, que foi responsável pela exumação dos corpos granulíticos do Complexo Canabrava e a sequência vulcanossedimentar de Palmeirópolis por processo de underthrusting (D’el-Rey Silva et al., 2008, 2011). Por último, predomina a tectônica de blocos com extensas zonas de cisalhamento, que pode ter sido responsável pela reativação de estruturas pré-formadas no rifte (ex. Zona de Cisalhamento Caldas) (Marques, 2010). 


\section{Capítulo 3}

\section{TEORIA GRAVIMÉTRICA E MAGNÉTICA}

O conhecimento teórico acerca dos métodos potenciais e suas ferramentas matemáticas contribui de forma essencial para a compreensão das respostas físicas das formações rochosas, evidencia possíveis restrições metodológicas e contribui para a melhor escolha das ferramentas a serem utilizadas. Este capítulo aborda a fundamentação física relacionada a campos potenciais a partir de revisão teórica, primeiramente com as noções gerais de cada método (magnético e gravimétrico), a teoria do potencial gravitacional e magnético, as constantes físicas relacionadas à variação desses campos potenciais com enfoque geológico - retirados de Hinze et al. (2013) e Blakely (1995) - e correções/reduções aplicadas aos dados geofísicos - retiradas de diferentes bibliografias.

A atração gravitacional terrestre e seu campo magnético são, ambos, campos vetoriais. Isso significa que esses campos são caracterizados por três funções no espaço e no tempo, ou seja, as componentes do campo se dão em três direções ortogonais entre si. Um campo vetorial é caracterizado por suas linhas de campo (ou linhas de fluxo), cuja tangente fornece a direção do campo num dado ponto. Os tópicos que se seguem abordam com mais detalhes esses campos potenciais e os métodos geofísicos que se utilizam destes campos para obtenção de contrastes de propriedades físicas no estudo da Terra.

\subsection{GRAVIMETRIA}

\subsubsection{Introdução}

A gravimetria é um método passivo de exploração, ou seja, não precisa emitir qualquer sinal para obter resposta. Se baseia na medição das variações do campo gravitacional terrestre, causadas por diferenças laterais de densidade das rochas em subsuperfície. Esse campo monopolar é sempre presente e pode variar tanto espacialmente quanto temporalmente, sofrendo mudanças em seus valores ao longo do tempo e gerando anomalias a partir de condições de subsuperfície locais. O campo gravitacional medido pode ser influenciado por uma grande variedade de fontes, tais como: terreno, fontes superficiais, fontes geológicas, 
instrumentação e fontes planetárias. Assim, para produzir medições interpretáveis, estas variações devem ser removidas a partir dos dados observados (Hinze et al., 2013).

O método gravimétrico foi o primeiro método geofísico a ser utilizado na exploração de óleo e gás (Nabighian et al., 2005). Tradicionalmente, o método tem sido usado na caracterização regional para determinar a arquitetura da crosta, delimitação de bacias e na identificação de regiões potencialmente favoráveis para a exploração de recursos e desenvolvimento de modelos de exploração conceitual (Hinze et al., 2013).

\subsubsection{Fundamentos da Gravimetria}

O campo gravitacional é causado pelo fenômeno fundamental da gravitação, responsável pela atração de massa entre dois corpos, um em direção ao outro. A massa de um corpo é uma propriedade determinada pelo seu volume, conteúdo atômico, e arranjo dos átomos. Em geofísica, a massa é substituída pelo produto da densidade e o volume do corpo. Assim, a densidade é o parâmetro operativo do método gravimétrico.

Newton mostrou que a força gravitacional é inversamente proporcional à distância entre dois corpos (Figura 3.1). No caso de fontes com dimensões pequenas se comparadas à sua separação como, por exemplo, os planetas que giram em torno do Sol, a força é inversamente proporcional ao quadrado da distância entre o centro dos objetos. Assim, se a distância entre corpos é dobrada, a força sobre elas é reduzida a um quarto.

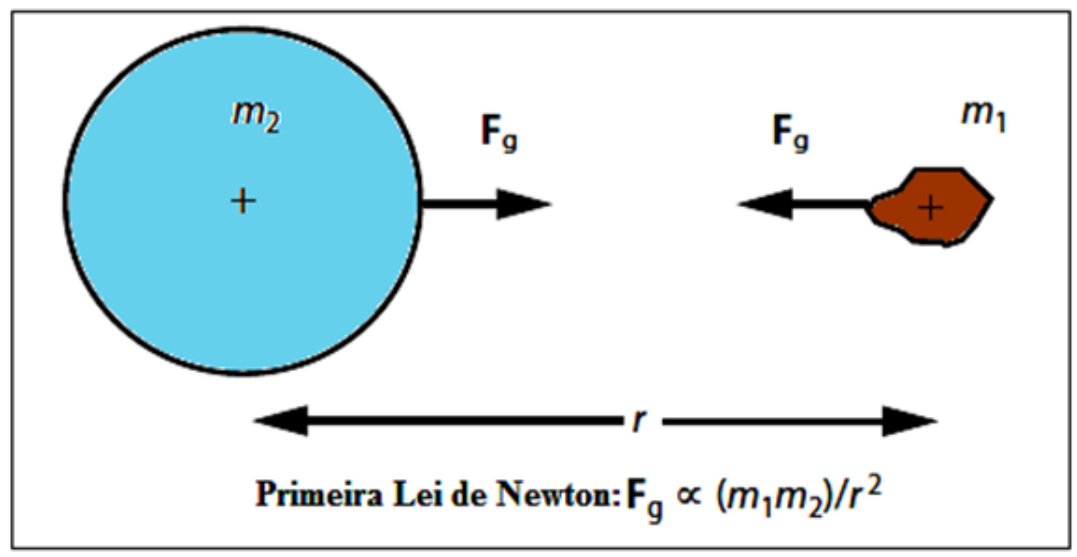

Figura 3.1. Ilustração de dois corpos atraídos um em direção ao outro com uma força gravitacional $F_{\mathrm{g}}$ proporcional ao produto das suas massas $m_{1}$ e $m_{2}$ e inversamente proporcional ao quadrado da distância $r$ entre os centros das massas (modificado de Hinze et al., 2013). 
Em coordenadas cartesianas, a força entre uma partícula de massa $m$, centrada em um ponto $\mathrm{Q}=\left(\mathrm{x}^{\prime}, \mathrm{y}^{\prime}, \mathrm{z}^{\prime}\right)$, e uma partícula de massa $m_{0} \mathrm{em} \mathrm{P}=(\mathrm{x}, \mathrm{y}, \mathrm{z})$, é dada por:

$$
F=G \frac{m \cdot m_{0}}{r^{2}}
$$

onde $r=\left[\left(x-x^{\prime}\right)^{2}+\left(y-y^{\prime}\right)^{2}+\left(z-z^{\prime}\right)^{2}\right]^{\frac{1}{2}}$ e $G$ é a constante gravitacional de Newton.

Combinando a equação (3.1) com a Segunda Lei da Mecânica, que enuncia que a força resultante $F$, sobre um corpo de massa $m$ gera uma aceleração $a$, a atração gravitacional pode ser descrita por:

$$
\vec{g}=G \frac{m}{r^{2}} \hat{\mathbf{r}}
$$

onde $\hat{r}$ é um vetor unitário direcionado do centro da massa $m$ ao ponto de observação $P$. A atração gravitacional $g$, como descrita em (3.2), é um campo irrotacional pois:

$$
\nabla \times \mathbf{g}=0
$$

Assim, a atração gravitacional, ou campo gravitacional, é um campo conservativo e pode ser representada pelo gradiente do potencial escalar $U$, onde $U$ é representado por:

$$
U=G \frac{m}{r}
$$

\subsubsection{Teoria do potencial gravitacional}

Do Teorema de Helmholtz, um campo vetorial é conservativo se o trabalho realizado ao movimentar um objeto de massa $m$ através do campo independe do caminho percorrido, ou seja, depende apenas da sua distância final. Nesse caso, um campo $F$ pode ser representando como o gradiente de um escalar $U$, denominado potencial de $F$.

A força gravitacional é um vetor cuja direção se dá ao longo da linha que une o centro de duas massas. A força que dá origem a um campo conservativo é derivada de uma função potencial escalar $U(\mathrm{x}, \mathrm{y}, \mathrm{z})$ denominada "potencial tridimensional" ou "neewtoniano", dada, em referencial cartesiano, por:

$$
\nabla U(x, y, z)=\frac{-F(x, y, z)}{m}=-g(x, y, z)
$$

Em coordenadas esféricas, o potencial gravitacional pode ser descrito em termos de: 


$$
U(r, \theta, \phi)=\int_{\infty}^{r}(\nabla U) \cdot d r=-\int_{\infty}^{r} g \cdot d r
$$

Pelo Teorema da Divergência de Gauss tem-se $E$ representando uma região sólida simples e $S$ a superfície fronteira de $E$, com componente normal do campo $g_{n}$ orientada positivamente (para fora). Seja $g$ um campo vetorial cujas componentes tenha derivadas parciais contínuas em uma região aberta que contenha $E$, tem-se que o fluxo externo de um campo vetorial $g$ que passa através de uma superfície fechada é igual a integral do volume da divergência sobre a região dentro da superfície:

$$
\int_{S} g_{n} d s=\int_{E} \nabla \cdot g d e
$$

Para os casos onde não há matéria no interior da superfície causando atração, as integrais se anulam e $\nabla \cdot g=0$. Da equação (3.5), a força gravitacional é o gradiente do potencial escalar $U$ e, assim:

$$
-\nabla \cdot g=\nabla \cdot \nabla U=\nabla^{2} U=0
$$

Isto significa que o potencial no espaço satisfaz a equação de Laplace $\nabla^{2} U=\frac{\partial^{2} U}{\partial x^{2}}+\frac{\partial^{2} U}{\partial y^{2}}+\frac{\partial^{2} U}{\partial z^{2}}=0$. Por $g=-\partial U / \partial z$, assumindo a leitura nos valores de gravidade na componente vertical do campo, e assumindo que qualquer derivativa da solução da equação diferencial também é uma solução, tem-se:

$$
\nabla^{2} g=0
$$

Para casos onde há uma partícula de massa no centro de uma esfera de raio $r$, é possível afirmar que:

$$
\int_{S} g_{n} \cdot d s=\left(\frac{-G m}{r^{2}}\right)=-4 \pi G m
$$

Se a superfície recobre várias massas, com uma massa total $M$, tem-se:

$$
\int_{E} \nabla \cdot g d e=\int_{S} g_{n} \cdot d s=-4 \pi G M
$$

Simplificando a integral para volumes muito pequenos, pode-se escrever:

$$
\nabla \cdot g=-4 \pi G \rho
$$


onde $\rho$ representa o valor de densidade, e a equação

$$
\nabla^{2} U=-4 \pi G \rho
$$

é a equação de Poisson. As equações (3.8) e (3.13) determinam que um campo potencial satisfaz a equação de Laplace no espaço e a de Poisson numa região contendo massa. Essas equações implicam que diferentes distribuições de massa podem produzir campos potenciais idênticos, gerando ambiguidade na interpretação (Skeels, 1947).

Das equações (3.11) e (3.12) assume-se que

$$
\int_{E}(-4 \pi G \rho) d e=\int_{S} g_{n} d s
$$

isto é, a componente gravitacional perpendicular à superfície fornece a densidade superficial equivalente. Para uma superfície equipotencial representaria simplesmente o campo gravimétrico total.

\subsubsection{Reduções Gravimétricas}

Antes que os resultados de uma aquisição gravimétrica possam ser interpretados em termos geológicos é necessário que o dado bruto de gravidade coletado passe por essa conversão a um datum comum, a superfície geoidal, a fim de remover os efeitos que não possuem interesse geológico. Esse processo é conhecido como "redução de dados gravimétricos" ou "redução ao geoide".

A diferença entre os valores de gravidade observados $\left(\mathrm{g}_{\mathrm{obs}}\right)$ e o valor de gravidade teórico derivado da Fórmula Internacional de Gravidade ou IGF (International Gravity Formula) para uma dada localização ou uma estação base é conhecida como anomalia gravimétrica. De forma simplificada, uma anomalia gravimétrica será a atração gravitacional observada deduzida da atração gravitacional do geoide de referência. Por definição, o geoide corresponde à superfície equipotencial gravimétrica do nível médio dos mares (Blakely, 1995).

O elipsoide de referência é uma formulação matemática que se aproxima da superfície do nível médio dos mares (geoide), com toda a massa rochosa acima dessa superfície removida. Para reduzir o valor de gravidade ao elipsoide de referência e obter a anomalia de interesse, todas as acelerações que não forem relacionadas exclusivamente à massa que preenche o espaço entre a superfície e o elipsoide devem ser removidas através das seguintes correções: 


\subsubsection{Correção da deriva instrumental}

A mudança nas leituras do gravímetro com o tempo, ocasionadas pelas deformações anelásticas da mola e dilatações/compressões devido à variação da temperatura produzem uma variação aparente nas medidas do campo gravitacional em uma dada estação, conhecida como deriva (ou drift) instrumental. Esse efeito pode ser removido simplesmente efetuando a repetição de medidas em uma mesma estação em diferentes horas do dia, tipicamente em intervalos de 1-2 horas. A diferença entre medidas sucessivas são plotadas a fim de produzir uma curva de deriva instrumental que será removida dos dados observados. A correção da deriva é realizada ao extrair, em módulo, a variação linear de cada ponto amostrado (Reynolds, 1997).

\subsubsection{Correção dos efeitos de maré}

Os instrumentos de medição dos valores de gravidade possuem sensibilidade tal que conseguem registrar variações gravimétricas decorrentes da atração gravitacional da lua e do sol sobre as massas oceânicas. A influência das marés irá variar de acordo com a posição desses astros no espaço celeste ao longo do tempo, que irão distorcer o formato da Terra, ocasionando variações na distância entre sua superfície e o centro. Esses efeitos dependem das variáveis latitude (sendo maiores em baixas latitudes) e tempo (com períodos de, no mínimo, 12 horas) e podem ocasionar alterações nos valores de aproximadamente 0,3 mGal. (Blakely 1995; Reynolds 1997). Contudo as marés são previsíveis e periódicas e seus efeitos podem ser monitorados e corrigidos em softwares a partir da localização e tempo. Leituras repetidas na mesma estação permitem as estimativas necessárias para a correção de maré sobre o intervalo de tempo necessário. Fornecido o fuso horário e a hora da aquisição registrados pelo gravímetro, todas as leituras são corrigidas para as marés terrestres devido à posição do sol e da lua no momento e local da observação. As previsões periódicas para o cálculo são fornecidas pelo Dominion Observatory of Canada (Geosoft, 2010). A Figura 3.2 apresenta a variação nos valores da leitura gravimétrica causada pelos efeitos de deriva instrumental e maré. 


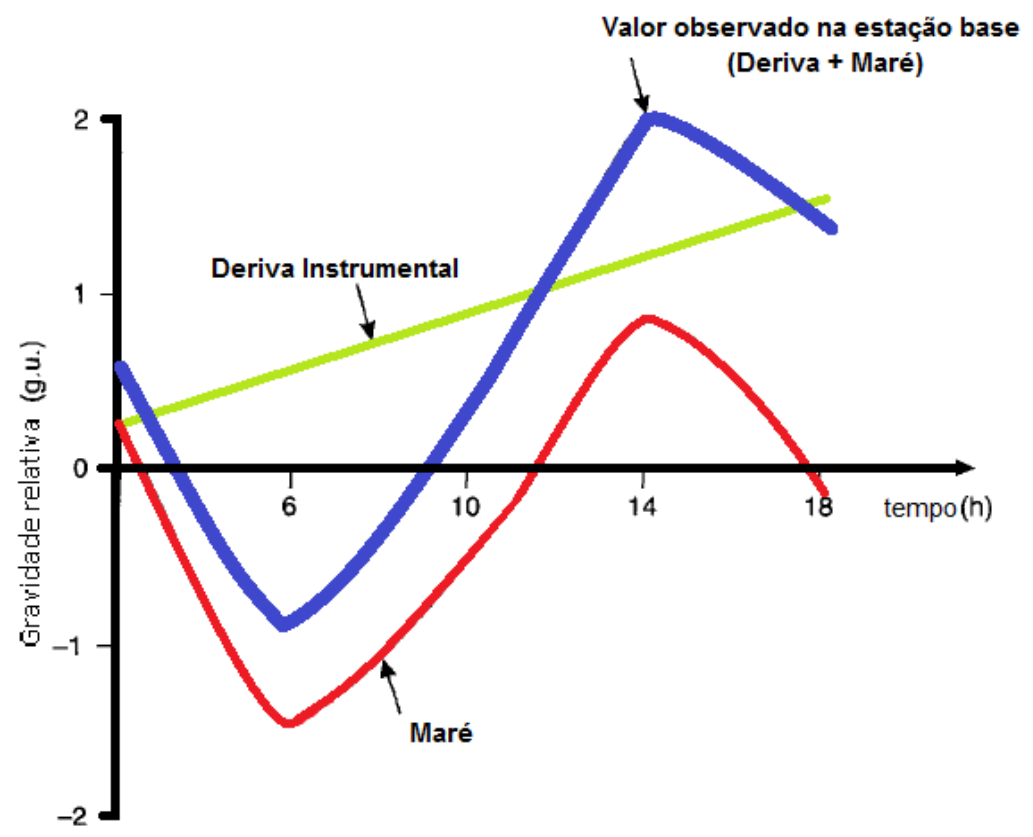

Figura 3.2. Gráfico ilustrando os efeitos de maré e deriva instrumental na aceleração da gravidade (retirado de Reynolds, 1997).

\subsubsection{Correção de latitude}

Tanto a rotação da Terra quanto seu achatamento produzem diferenças nos valores de gravidade que variam conforme a latitude. A aceleração centrífuga devido a rotação terrestre é máxima no equador e inexiste nos polos. Em contrapartida, a aceleração gravitacional possuirá valores maiores nos polos, onde o geoide se encontra mais próximo do centro de massa terrestre, e menores no equador. A partir desse pressuposto, a correção de latitude é feita na subtração da gravidade teórica $\left(g_{\phi}\right)$ dos valores observados ( $\left.\mathrm{g}_{\mathrm{obs}}\right)$. De acordo com o World Geodetic System 1984 (Blakely, 1995), a gravidade teórica é dada pela fórmula:

$$
g_{\phi}=978032,67714 \frac{1+0,00193185138639 \sin ^{2} \phi}{\sqrt{1-0,00669437999013 \sin ^{2} \phi}}
$$

O valor de $g_{\phi}$ é dado em mGal e $\phi$ representa a latitude em graus.

\subsubsection{Correção ar livre}

Uma vez que a gravidade varia inversamente ao quadrado da distância, é necessário corrigir as mudanças na elevação entre estações para ajustar a diferença de altitude das medidas em relação ao geoide. A correção ar livre não leva em consideração a matéria envolvida entre a estação e o datum de referência. Essa correção é inferida calculando-se a diferença da 
aceleração gravitacional entre o nível médio dos mares e a estação observada a uma atitude $h$, em metros (Figura 3.3a) (Telford et al. 1990, Luiz \& Silva 1995, Blakely 1995).

Sabendo-se que a gravidade no nível de referência é dada pela equação (3.2), a aceleração da gravidade a uma altitude $h$ será:

$$
\left|g_{h}\right|=\left|\frac{G M}{(r+h)^{2}}\right|
$$

Assim, calculando a variação da gravidade entre o geoide e o ponto de observação, encontra-se a correção ar livre, dada por:

$$
C_{A L}=\Delta g=\left|g-g_{h}\right| \approx \frac{G M}{r^{3}}=0,3086 h
$$

A quantidade calculada aplicando-se as correções de latitude e ar livre é denominada Anomalia Ar Livre $\left(g_{A L}\right)$ e é dada pela seguinte fórmula:

$$
g_{A L}=g_{o b s}-g \phi+C_{A L}
$$

onde $g_{o b s}$ é o valor gravimétrico medido em campo (removido os efeitos de drift e maré), $g_{\phi}$ é a correção de latitude e $C_{A L}$ é a correção ar livre.

\subsubsection{Correção Bouguer}

Essa correção leva em consideração o material rochoso entre a estação e o nível do mar, ignorado anteriormente no cálculo da correção ar livre. Assim, é feito o cálculo do empuxo gravitacional exercido por uma placa rochosa infinita de espessura $h$ (em metros) e densidade média $\rho\left(\mathrm{mg} / \mathrm{m}^{3}\right)$ (Figura 3.3b). Em áreas continentais é comum utilizar o valor de $2,67 \mathrm{mg} / \mathrm{m}^{3}$ e em áreas oceânicas de 2,80 mg/m³ (Blakely, 1995).

A correção Bouguer é dada, para áreas continentais, por:

$$
C_{B}=2 \pi G \rho h=0,04191 \rho h=0,1119 h
$$

\subsubsection{Correção de terreno}

Em áreas onde há considerável variação na elevação, particularmente próxima à qualquer estação gravimétrica, deve-se aplicar a correção de terreno. Colinas acima do níveis das medidas das estações exercem uma atração ascendente sobre o gravímetro enquanto depressões exercem o efeito oposto sobre as medições (Figura 3.3c). 
Existem várias técnicas para calcular a correção de terreno. Todas elas requerem conhecimento detalhado do relevo próximo à estação através de um modelo digital de terreno ou por mapa topográfico que cubra além dos limites da área da aquisição, com linhas de contorno espaçadas em 10 metros ou menos. A "Carta de Hammer", o procedimento mais conhecido, envolve a divisão da área em compartimentos cuja elevação será comparada à elevação do ponto de aquisição. O formato mais usual é utilizar círculos concêntricos e linhas radiais, definindo setores cujas áreas aumentam com a distância ao ponto de medição. O efeito gravitacional em cada setor é calculado por:

$$
\partial g_{T}(r, \theta)=G \rho \theta\left\{\left(r_{0}-r_{i}\right)+\left(r_{i}^{2}+\Delta z^{2}\right)^{\frac{1}{2}}-\left(r_{0}{ }^{2}+\Delta z^{2}\right)^{\frac{1}{2}}\right\}
$$

onde $G$ é a constante gravitacional, $\rho$ é a densidade, $\theta$ é o ângulo de abertura do setor em radianos, $\Delta z=\left|z_{s}-z_{a}\right|$, em que $z_{s}$ é a elevação da estação e $z_{a}$ é a elevação média do setor, $r_{0}$ e $r_{i}$ são os raios interno e externo do setor.

A correção de terreno será a soma da contribuição de todos os setores (Telford et al., 1990):

$$
C_{T}=\sum_{r} \sum_{\theta} \partial g_{T}(r, \theta)
$$

A correção de terreno se relaciona de forma direta à atração gravitacional das massas e, para a maioria dos geocientistas, a anomalia Bouguer só está completa com sua presença (Telford et al., 1990, Luiz \& Silva 1995, Shiraiwa \& Ussami, 2002). Dessa forma, a anomalia Bouguer completa é representada pela Equação (3.22):

$$
g_{B}=g_{\text {OBS }}-g_{\theta}+C_{A L}-C_{B}+C_{T}
$$

(a)

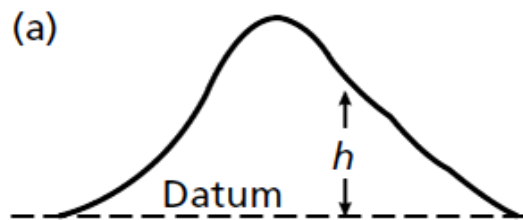

(b)

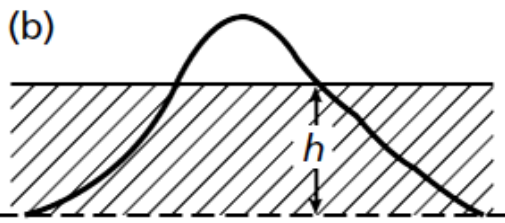

(c)

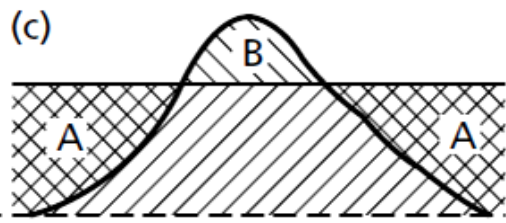

Figura 3.3. (a) Correção ar livre para uma altura $h$ acima do datum utilizado, (b) Correção Bouguer, considerando uma placa infinita de espessura $h$ e (c) Correção de Terreno, considerando a falta ou excesso de massa entre o ponto medido e suas adjacências (fonte: Kearey et al., 2009). 


\subsubsection{Densidade das rochas e minerais}

O método gravimétrico explora as variações laterais de densidade nas rochas. A densidade, uma propriedade escalar, é a mais simples das propriedades geofísicas e mais facilmente medida com uma precisão de primeira ordem sem a necessidade de instrumentação sofisticada.

As rochas sedimentares tendem a ser menos densas que as rochas ígneas e metamórficas (com densidade média entre $2,1 \pm 0,3 \mathrm{mg} / \mathrm{m}^{3}$ ), influenciadas primariamente pela quantidade de espaço poroso presente na rocha. Outros fatores que afetam a densidade de material sedimentar são a composição, cimentação, idade e profundidade de soterramento, tectonismo e preenchimento dos poros por fluidos.

As variações nos valores de densidade dependem do material que a rocha é feita e do grau de consolidação. Sedimentos soterrados por um longo intervalo de tempo se consolidam e podem litificar, resultando na redução da porosidade e aumento da densidade.

Em contraste às rochas sedimentares, as rochas ígneas tendem a ser mais densas, apesar de haverem casos em que os valores de densidade podem ser mais baixos, como em rochas vulcânicas com porosidade elevada. A densidade das rochas ígneas tende a aumentar com a diminuição no conteúdo de sílica. Assim, rochas ígneas básicas geralmente são mais densas do que as ígneas ácidas. Da mesma forma, rochas plutônicas tendem a ser mais densas do que suas vulcânicas equivalentes (Reynolds, 1997).

Nas rochas metamórficas, os valores de densidade tendem a aumentar com a diminuição da acidez e com o aumento no grau de metamorfismo. Isto ocorre devido ao preenchimento do espaço poroso e recristalização da rocha em uma forma mais densa.

A porosidade em rochas ígneas e metamórficas é pouco significativa, a menos que essas rochas possuam alto grau de fraturamento. Processos secundários, físicos e químicos, podem alterar a densidade das rochas, causando fraturamento, presença de soluções ou espaço vazio intersticial. Tipicamente, rochas cristalinas ou bastante litificadas têm espaço vazio mínimo, geralmente inferior a 1\%. As rochas cristalinas da crosta continental, em geral, tornam-se mais máficas com a profundidade, e, portanto, os valores de densidade tendem a aumentar com a profundidade para além do efeito do aumento da pressão litostática (Hinze et al., 2013). 


\subsection{MAGNETOMETRIA}

\subsubsection{Introdução}

A magnetometria é um método geofísico de ampla aplicação. Levantamentos terrestres e aéreos são utilizados em praticamente todas as escalas possíveis e para uma série de propósitos. Levantamentos magnéticos regionais e de detalhe continuam sendo uma ferramenta primária na procura de minérios, tais como ferro, metais preciosos, diamantes, molibdênio, e titânio (Nabighian et al., 2005). Com o advento de magnetômetros aerotransportados precisos durante a Segunda Guerra Mundial, o uso do método mudou de foco em estudos localizados, em grande parte para fins de exploração mineral, a uma ferramenta regional para mapear a espessura de bacias sedimentares e sua estruturação geológica e a natureza de rochas cristalinas em subsuperfície.

Tal como na gravimetria, o método magnético é um método passivo de exploração. O campo magnético é dipolar e sempre presente, sujeito a variações tanto espaciais quanto temporais. O método consiste em relacionar anomalias no campo magnético terrestre às diferenças nas propriedades magnéticas das rochas devido, principalmente, à presença de minerais ferromagnéticos, que alteram fortemente a intensidade do campo magnético.

\subsubsection{Fundamentos da magnetometria}

O campo magnético terrestre é o somatório das várias componentes magnéticas, derivadas tanto do interior da Terra como de seu exterior. A componente principal do campo magnético terrestre é gerada por correntes elétricas associadas a movimentos convectivos em seu núcleo externo e é responsável por cerca de $98 \%$ ou mais do campo geomagnético. Sobreposto aos campos principal e externo, está o campo gerado pelo contraste litológico de magnetização em subsuperfície, que é o foco de interesse na exploração, utilizado para ajudar a determinar parâmetros tais como a composição, estrutura e propriedades térmicas da crosta e manto superior (Hinze et al., 2013).

A teoria do magnetismo envolve campos que exercem uma força sobre corpos magnetizados e materiais eletricamente condutivos. Ao contrário do fenômeno monopolar da gravitação o magnetismo é dipolar, isto é, um campo magnético possui dois polos, positivo e negativo e não existem pólos magnéticos livres, ou seja, não existem monopolos. Haverá sempre um pólo magnético positivo formando par com um pólo magnético negativo. 
A força exercida entre pólos magnéticos de um ímã é proporcional ao inverso do quadrado da distância de separação entre eles (Equação 3.24). A relação entre a força magnética e os polos foi primeiro investigada por Coulomb no final do século XVIII e, pouco depois, foi colocada em termos matemáticos por Poisson. Esta lei empírica, conhecido como Lei de Coulomb, é semelhante em estrutura à lei da força gravitacional de Newton e afirma que:

$$
F_{M}=C_{m} \frac{p_{1} p_{2}}{r^{2}}
$$

em que $p_{1}$ e $p_{2}$ são polos pontuais magnéticos com os respectivos valores das cargas representadas por $p$ e $r$ é a distância entre eles. $C_{m}$ é a constante magnética correspondente a $\frac{1}{\mu}$ onde $\mu$ é a permeabilidaee magnética. Embora não ocorram de fato polos magnéticos livres, muitas propriedades magnéticas podem ser resolvidas em termos de polos magnéticos fictícios.

Por conveniência utiliza-se no método magnético, ao invés da força, o campo magnético $H$, definido como a força que experimenta um polo magnético devido à presença no espaço de outro polo magnético considerado, ou

$$
H=\frac{F_{M}}{p_{1}}=C_{m} \frac{p}{r_{2}}
$$

onde $p_{l}$ é um polo fictício a um ponto no espaço, em que $H$ é especificado. Supõe-se $p>p_{l}$, de tal forma que $p_{l}$ não perturba o campo $H$ (Blakely, 1995).

Os materiais podem adquirir uma componente de magnetização, na presença de um campo magnético externo. Para os campos magnéticos de baixa amplitude, digamos da ordem do campo magnético terrestre, essa magnetização induzida é proporcional em magnitude e é paralela (ou antiparalela) ao campo externo, isto é,

$$
M=k H
$$

onde $k$ é a constante de proporcionalidade, denominada susceptibilidade magnética, um valor adimensional que indica o grau de magnetização a ser induzida em determinado material na presença de um campo magnético externo. $\mathrm{O}$ vetor intensidade de magnetização $M$ é definido como a soma vetorial entre a intensidade de magnetização induzida e a intensidade de magnetização remanente (Reynolds, 1997), numa relação:

$$
\vec{M}_{T}=\vec{M}_{I}+\vec{M}_{R}
$$


onde $\vec{M}_{T}$ é a magnetização total do corpo, $\vec{M}_{I}$ é a magnetização induzida e $\vec{M}_{R}$ a magnetização remanente.

A Razão de Köenigsberg é a relação entre as magnetizações induzida e remanente (Blakely, 1995), dada por:

$$
Q=\frac{M_{R}}{M_{I}}
$$

A indução magnética B é o campo total, incluindo os efeitos de magnetização, e pode ser escrita como:

$$
B=\mu_{0}(H+M)=\mu_{0}(1+k) H
$$

onde $\mu_{0}$ é a permeabilidade magnética no vácuo, dada por $4 \pi \times 10^{-7} \mathrm{~Wb} / \mathrm{A} . \mathrm{m}$ (Telford et al., 1990).

\subsubsection{Teoria do potencial magnético de um dipolo pontual}

As relações de campo potencial para o campo gravitacional também se fazem verdadeiras para o campo magnético, onde a força entre os corpos é tanto atrativa quanto repulsiva e depende da distância entre os corpos.

Um dipolo magnético consiste de dois polos opostos de força $p$, separados por uma distância infinitesimal $l$, com potencial $V$ e distância $r$, dados por:

$$
V(r)=\left(\frac{1}{r_{1}}-\frac{1}{r_{2}}\right) C_{m}
$$

onde $r_{1}$ e $r_{2}$ são as distâncias a $r$ dos polos norte (positivo) e sul (negativo), respectivamente. Generalizando a equação em termos de $r$, ao invés de $r_{1}$ e $r_{2}$ e, de acordo com a figura XX:

$$
r_{1}^{2}=r_{2}^{2}+\left(\frac{l}{2}\right)^{2}-(l \times r) \cos \Theta
$$

E, dividindo por $r^{2}$ :

$$
\left(\frac{r_{1}}{r^{2}}\right)=1+\left(\frac{l}{2 r}\right)^{2}-\left(\frac{l}{r}\right) \cos \Theta
$$

Resolvendo para $\left(r_{1} / r\right)$ e expandindo com o teorema binomial, tem-se: 


$$
\begin{aligned}
\frac{r_{1}}{r}= & \left(1+\left[\left(\frac{l}{2 r}\right)^{2}-\left(\frac{l}{r}\right) \cos \Theta\right]\right)^{\frac{1}{2}} \\
= & 1-\frac{1}{2}\left[\left(\frac{l}{2 r}\right)^{2}-\left(\frac{l}{r}\right) \cos \Theta\right] \\
& +\frac{\left(-\frac{1}{2}\right)\left(-\frac{3}{2}\right)}{2 !}\left[\left(\frac{l}{2 r}\right)^{2}-\left(\frac{l}{r}\right) \cos \Theta\right]^{2}+\cdots \\
\simeq & 1+\left(\frac{l}{2 r}\right) \cos \Theta+\left(\frac{l}{2 r}\right)^{2}\left(\frac{3 \cos \Theta-1}{2}\right)
\end{aligned}
$$

onde os termos de ordem maior que $(l / r)^{2}$ foram negligenciados, pois $l>>r$. Assim:

$$
\frac{r_{2}}{r} \simeq 1-\left(\frac{l}{2 r}\right) \cos \Theta+\left(\frac{l}{2 r}\right)^{2}\left(\frac{3 \cos \Theta-1}{2}\right)
$$

E o potencial magnético escalar do dipolo se torna:

$$
V(r) \simeq(p \times l) \frac{\cos \Theta}{r^{2}} C_{\mathrm{m}}=\frac{\mathbf{j} \cdot \hat{\mathbf{r}}}{r^{2}} C_{\mathrm{m}}=\mathbf{j} \cdot \nabla\left(\frac{1}{r}\right) C_{\mathrm{m}}
$$

onde o produto vetorial envolve o momento dipolar $j$ dirigido de $-p$ a $+p$ com magnitude $j=(p \times l)$ e $\hat{r}$ é o vetor unitário, com componentes $\hat{r}_{x}=(r \times \cos \alpha) \hat{e}_{x}, \hat{r}_{y}=(r \times \cos \beta) \hat{e}_{y}$ e $\hat{r}_{z}=(r \times \cos \gamma) \hat{e}_{z}$, onde os cossenos na direção de $r$ satisfazem a condição $\cos ^{2} \alpha+\cos ^{2} \beta+\cos ^{2} \gamma=1$ e $|\hat{r}|=|\hat{e}|=1$. 


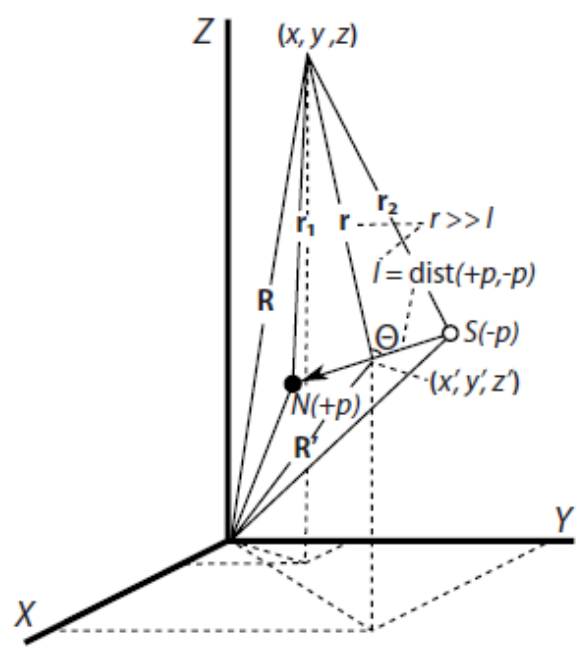

Figura 3.4. Arranjo espacial norte $(\mathrm{N})$ ou positivo $(+\mathrm{p})$ e sul $(\mathrm{S})$ ou negativo $(-\mathrm{p})$ apontando polos magnéticos separados pela distância 1 infinitesimal, definindo um dipolo magnético pontual. O dipolo está localizado em ( $\mathrm{x}$ ', y', z') com distância $r$ ao ponto de observação ( $x, y, z)$ de tal modo que $R=R$ - R' no sistema de coordenadas cartesiano centrado na Terra. Fonte: Hinze et al. (2013).

\subsubsection{Reduções Magnéticas}

A redução de dados magnéticos é necessária para remover todas as causas de variação magnética que não sejam as decorrentes dos efeitos magnéticos das observações de interesse, isto é, fontes não geológicas. São basicamente duas correções, a correção da variação diurna e a remoção do campo geomagnético de referência (IGRF). Pode ser feita a correção topográfica, no entanto não é usual, pois o gradiente vertical do campo geomagnético é muito baixo, de cerca de $0,03 \mathrm{nT} / \mathrm{m}$ nos polos e $-0,015 \mathrm{nT} / \mathrm{m}$ no equador (Kearey et al. 2009). Assim, não se faz necessária esta correção e pode ser descartada, não sendo necessário um preciso levantamento topográfico em estudos de distribuição espacial da magnetização.

Após as correções, removidas as fontes indesejáveis ao estudo geológico, resta apenas a parte do campo provocada pelas irregularidades rochosas. Este campo é denominado de campo magnético anômalo e é utilizado em grande parte na interpretação geofísica em diversas situações.

\subsubsection{Correção da variação diurna}

As variações diurnas são pequenas variações no campo magnético terrestre ao longo do dia devido à incidência da radiação solar, que controla a atividade de correntes elétricas na ionosfera. A variação é da ordem de 20 a 60 nT, exceto durante períodos de forte bombardeio 
corpuscular da Terra pelo Sol durante tempestades magnéticas, onde as variações são erráticas e podem atingir valores maiores (Hinze et al., 2013).

A variação diurna afeta diretamente os levantamentos geofísicos. O primeiro passo na remoção é monitorá-la para que possa ser removida antes da interpretação. A variação diurna durante um levantamento aeromagnético pode ser avaliada organizando inúmeros pontos de crossovers (amarração das linhas de voo e de controle). A análise das diferenças nas leituras em cada passagem por sobre esses pontos, que representa a alteração no campo ao longo de diferentes períodos de tempo, permite que todo o levantamento possa ser corrigido da variação diurna sem a necessidade de um instrumento de base, a partir de análises estatísticas de discrepâncias nas anomalias magnéticas nos pontos de intersecção (Kearey et al., 2009). Recentemente, gradiômetros verticais e horizontais vêm sendo utilizados para remover os efeitos temporais de ambos levantamentos aéreo e marinho (Hardwick, 1984; Eggers \& Thompson, 1984).

\subsubsection{Remoção do campo geomagnético de referência (IGRF)}

O campo geomagnético sofre mudanças em seu comportamento a longo prazo, tanto em direção como em magnitude, denominadas de variação secular. A sua taxa de modificação é da ordem de 80 nT/ano, porém são variações inconstantes em posição e tempo. Sua origem interna e variação rápida em relação ao tempo geológico defendem uma fonte principal com origem no núcleo externo líquido bem correntes fluidas secundárias. Remover o IGRF (International Geomagnetic Reference Field) significa remover o campo geomagnético de referência, ou seja, um modelo matemático em expansões de harmônicos esféricos que representa o campo magnético terrestre com origem no núcleo e inclui termos temporais para corrigir as variações seculares (Blakely, 1995; Hinze et al., 2013). A cada meia década desde 1965 um Campo Geomagético de Referência é calculado e adotado internacionalmente, com base em observatórios magnéticos e medidas de levantamento e, nos últimos anos, as observações do campo magnético terrestre a partir de observações de satélites (Langel \& Hinze, 1998; Olsen et al., 2007).

\subsubsection{Magnetismo das rochas e minerais}

O magnetismo tem origem atômica e deve-se a três fatores: (i) o momento magnético dos núcleos: muito pequeno e portanto desprezível, (ii) elétrons orbitantes: momentos orbitais fazem a interligação dos momentos de spin e a estrutura cristalina e (iii) momento magnético 
de elétrons (momento de spins): explicam a maior parte das propriedades magnéticas de

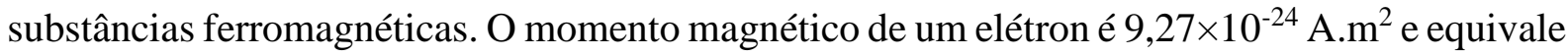
a um "magneton de Bohr" (Tarling \& Hrouda, 1993).

Os materiais podem exibir diferentes comportamentos quando apresentados a um campo magnético externo (Figura 3.5). Na maioria das substâncias, quando não há nenhum campo magnético atuante, os momentos magnéticos de spins de átomos adjacentes são distribuídos aleatoriamente não havendo, em geral, magnetização.

$\mathrm{O}$ diamagnetismo ocorre quando materiais magneticamente neutros adquirem magnetização antiparalela ao campo magnético indutor $H$, exibindo valores negativos de susceptibilidade, da ordem de $10^{-6}(\mathrm{SI})$. Sua magnetização irá depender do campo magnético aplicado numa relação linear e se reduz a zero quando o campo é removido, uma situação característica de átomos com as camadas eletrônicas completas e momentos magnéticos compensados. Os materiais diamagnéticos mais comuns são a grafita, mármore, quarto e halita.

O paramagnetismo irá ocorrer quando o momento magnético se alinha na mesma direção do campo indutor $H$ devido a momentos de spin e momentos orbitais descompensados (camadas atômicas incompletas). Na ausência do campo o momento magnético final é igual a zero, devido ao efeito desorganizador de movimentos termais. No entanto, na presença de um campo magnético, os materiais irão apresentar susceptibilidade magnética positiva e fraca, com ordem de grandeza entre $10^{-5}$ e $10^{-3}(\mathrm{SI})$, que decresce inversamente ao aumento da temperatura, de acordo com a Lei de Curie-Weiss. Assim, a magnitude do paramagnetismo é inversamente proporcional à temperatura. Portadores de paramagnetismo, como os íons $\mathrm{Fe}^{2+}, \mathrm{Fe}^{3+}$, e $\mathrm{Mn}^{2+}$ irão gerar minerais formadores de rochas comuns como a biotita, piroxênio, anfibólio, olivina, e granada, apresentando comportamento tipicamente paramagnético.

O ferromagnetismo é característico de materiais nos quais os momentos magnéticos apresentam mesma direção do campo aplicado e retém o seu alinhamento magnético após a remoção do campo. Alguns elementos como o ferro, cobalto e o níquel, apresentam interações magnéticas tão fortes que seus momentos se alinham paralelamente por contínuas regiões, denominadas domínios. Esses domínios magnéticos geralmente possuem dimensões da ordem de $10^{-6} \mathrm{~m}$. O ferromagnetismo irá desaparecer quando a temperatura é elevada acima da temperatura Curie apresentando, posteriormente, um comportamento paramagnético.

Nos óxidos de ferro, a presença do oxigênio muda o sinal das forças de troca e os momentos adjacentes são antiparalelos. O antiferromagnetismo ocorre quando os momentos, alinhados antiparalelos uns aos outros e com igual magnitude, se cancelam totalmente, com momento 
magnético resultante nulo ou muito próximo desse valor. A hematita é um exemplo de mineral que exibe comportamento tipicamente antiferromagnético. O ferrimagnetismo ocorre quando os momentos numa direção excedem os da direção oposta. Materiais ferrimagnéticos, que possuem as mesmas propriedades das substâncias ferromagnéticas, são a forma mais comum de magnetismo causador de anomalias nas formações rochosas. A magnetita é o principal componente ferrimagnético de ocorrência natural na Terra. Ela tem uma susceptibilidade magnética muito maior do que as substâncias paramagnéticas devido às interações entre os átomos adjacentes e seus momentos magnéticos na direção do campo magnético externo aplicado (Hinze et al., 2013; Reynolds, 1997 e Telford et al., 1990).

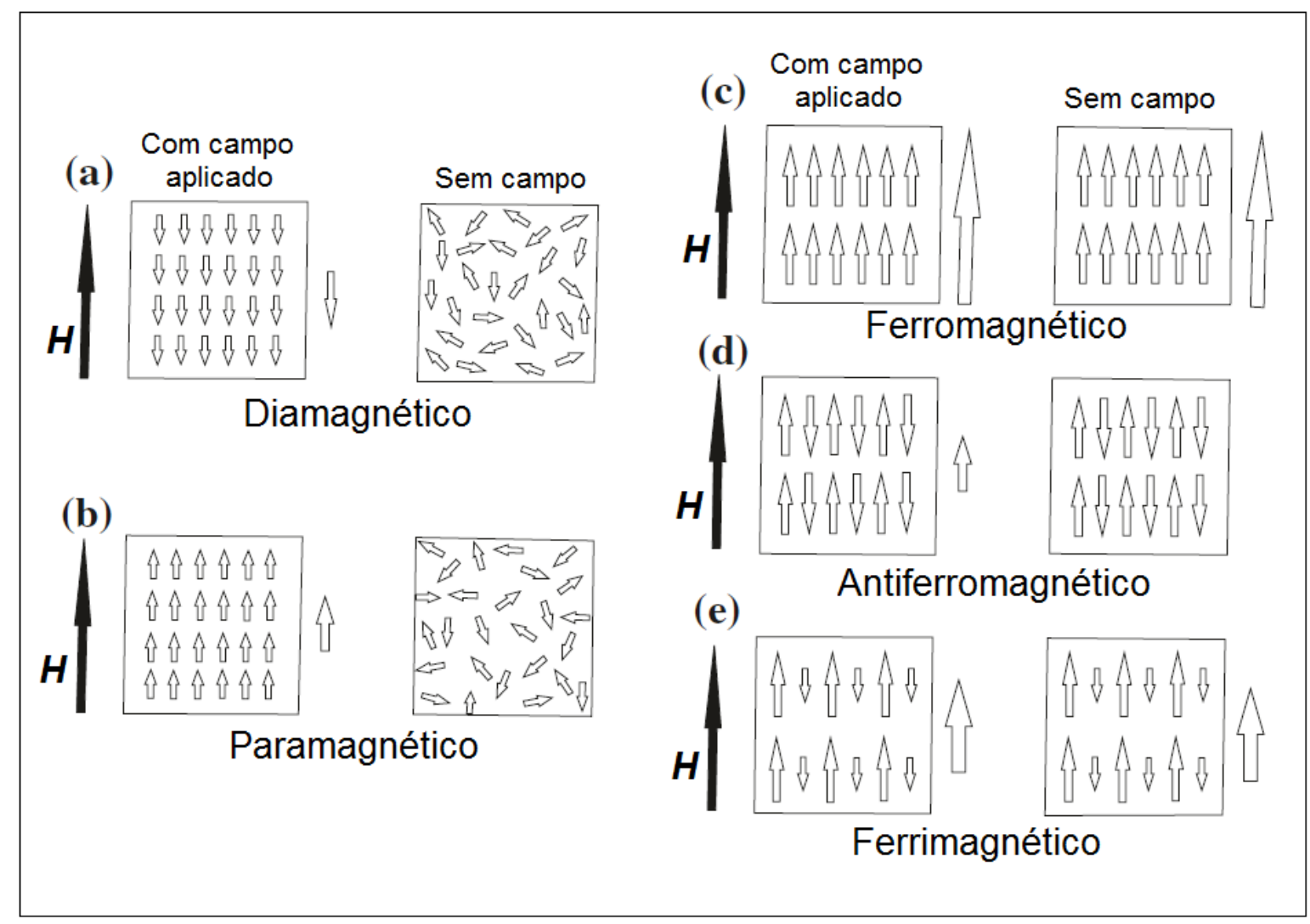

Figura 3.5. Magnetização (seta branca à direita dos quadrados) que uma substância adquire na presença e ausência de um campo magnético aplicado (seta preta). Modificado de Tarling \& Hrouda (1993).

\subsubsection{Susceptibilidade magnética de rochas e minerais}

Várias propriedades magnéticas são atribuídas aos diferentes tipos de rochas, minerais e outros materiais. A mais comum e que tem significado mais geral para a exploração geofísica é a susceptibilidade magnética. Esta propriedade controla a magnetização induzida em rochas e outros materiais e é a principal propriedade dos materiais diamagnéticos e paramagnéticos, 
bem como um parâmetro crítico de materiais ferrimagnéticos (Hinze et al., 2013). Rochas com significante concentração de minerais ferro/ferrimagnéticos, principalmente magnetita, titanomagnetita e pirrotita, tendem a possuir altos valores de susceptibilidade magnética. Os minerais paramagnéticos também podem influenciar, em menores proporções, na susceptibilidade de uma rocha, especialmente em rochas máficas cristalinas (Clark \& Emerson, 1991). Consequentemente, rochas básicas e ultrabásicas irão apresentar altos valores de susceptibilidade, ao passo que rochas ígneas ácidas e metamórficas possuirão valores intermediários a baixos e rochas sedimentares apresentarão baixos valores, em geral.

Além da composição mineralógica de uma rocha, outros fatores também influenciam seus valores de susceptibilidade, tais como o alinhamento e formato dos grãos magnéticos dispersos na rocha - trama magnética (Reynolds, 1997). A quantidade de minerais magnéticos em uma rocha será função, principalmente, de sua composição química combinada a fatores tais como pressão e temperatura em sua história geológica. Esses fatores influenciam o particionamento de Fe em espécies minerais diferentes.

Separando os processos geológicos em primários (a formação das rochas) e secundários (processos de diagênese, metamorfismo, metassomatismo, deformação e intemperismo) Isles \& Rankin (2013) afirmam que processos secundários podem ter maior impacto na susceptibilidade magnética predominante em uma formação rochosa do que processos primários. 


\section{Capítulo 4}

MATERIAIS E MÉTODOS

Este capítulo tem por finalidade a exposição dos materiais e métodos utilizados na presente dissertação como ferramenta para a obtenção dos resultados finais a partir da interpretação geofísica e geológica. Ele inclui os detalhes da campanha de campo realizada nesse estudo, que contou com a aquisição de dados geofísicos e geológicos estruturais, além de explicar de forma detalhada acerca do levantamento gravimétrico e geodésico realizado. Por fim, descreve as etapas de processamento dos dados gravimétricos e magnéticos além de fornecer um visão geral acerca das técnicas de realce de anomalias utilizadas na posterior interpretação dos dados.

As rotinas de tratamentos dos dados aeromagnéticos e de gravimetria terrestre foram todas realizadas no Laboratório de Geofísica Aplicada (LGA) do Instituto de Geociências da Universidade de Brasília (IG-UnB). Todos os dados aerogeofísicos foram disponibilizados na forma de banco de dados e com a condição de uso restrito a propósitos acadêmicos.

\subsection{RECONHECIMENTO GEOLÓGICO DE CAMPO}

Foi realizada campanha de campo com duração de cinco dias, entre 15 e 19 de fevereiro de 2016, incluindo levantamento gravimétrico terrestre e obtenção de medidas estruturais em afloramentos da região. Foram coletadas 8 amostras de rocha ao longo das linhas de aquisição dos dados gravimétricos. Como suporte à interpretação geofísica, foram realizados ensaios de densidade nas amostras coletadas em campo, com objetivo de representar a densidade relativa geral das principais unidades geológicas que cruzam o perfil. Não foi possível coletar amostras do embasamento devido ao mesmo ser bastante trabalhado pela erosão na região, aflorando apenas em lajedos "colinosos". As análises foram feitas no laboratório de Geoquímica do IG/UnB com balança de precisão de $0,01 \mathrm{~g}$ e becker graduado com intervalo de $0,1 \mathrm{ml}$. O procedimento adotado utiliza o peso da amostra e o volume de líquido deslocado por ela, o qual será igual ao seu próprio volume, de acordo com o princípio de Arquimedes. Previamente ao início do ensaio, as amostras selecionadas foram serradas em 
forma de cubos de modo que fosse possível inserí-las no becker. As amostras muito porosas foram envolvidas em papel parafina, o qual previamente mediu-se a massa, descontada do resultado final. Os resultados (Tabela 4.1) serviram como base para a escolha dos valores para a modelagem gravimétrica, levando em conta o fato de serem amostras em superfície e possivelmente mais intemperizadas.

Em adição, foram obtidas 30 medidas estruturais na área de estudo em afloramentos ao longo de rodovias asfaltadas e não asfaltadas, relacionadas a juntas e falhas com direções preferenciais em N10E, N20-40E e N70W. Secundariamente, as direções N10-60E e N20-50W (figuras 4.1 e 4.2). Parte das estruturas medidas estão associadas ao Sistema CavalcanteTeresina e Sistema Teresina-Nova Roma, com falhas NE-NNE predominantes, e falhas NW tardias. As feições N20-40E estão relacionadas principalmente à deformação do Brasiliano. As fraturas N20-50W são comumente encontradas no Domínio Rifte e Pós-rifte do Grupo Araí, descritos por Alvarenga et al. (2007b), que separaram as estruturas da região por Domínios Geotectônicos.

Tabela 4.1. Valores de densidade relativa de amostras coletadas em trabalho de campo (Os pontos visitados se encontram no Anexo 1).

\begin{tabular}{|c|c|c|c|c|}
\hline \multirow{2}{*}{ Identificação } & \multicolumn{2}{|c|}{ Localização } & \multirow{2}{*}{$\begin{array}{c}\text { Densidade } \\
\text { relativa }\left(\mathrm{g} / \mathrm{cm}^{3}\right)\end{array}$} & \multirow{2}{*}{ Descrição } \\
\hline & Latitude & Longitude & & \\
\hline A1 & -14.2423 & -47.4882 & 2,4293 & Metassiltito do Grupo Paranoá (MPpa2) \\
\hline $\mathrm{A} 2$ & -14.1886 & -47.5044 & 2,6502 & Quartzito do Grupo Paranoá (MPpa1) \\
\hline A4 & -13.9285 & -47.4336 & 2,5168 & Quartzito do Grupo Araí (Formação Arraias) \\
\hline A5 & -13.9193 & -47.4195 & 2,6710 & $\begin{array}{l}\text { Quartzito micáceo protomilonítico (Formação } \\
\text { Arraias) }\end{array}$ \\
\hline A6 & -13.8303 & -47.4216 & 2,4813 & Quarzto-muscovita xisto (Formação Ticunzal) \\
\hline A8 & -13.6945 & -47.4657 & 2,6565 & Quarzto-muscovita xisto (Formação Ticunzal) \\
\hline A9 & -13.6921 & -47.4659 & 2,4603 & $\begin{array}{l}\text { Quartzito fraturado do Grupo Araí (Formação } \\
\qquad \text { Arraias) }\end{array}$ \\
\hline A11 & -13.8768 & -48.1830 & 2,7361 & Xisto grafitoso dobrado (Grupo Serra da Mesa) \\
\hline
\end{tabular}




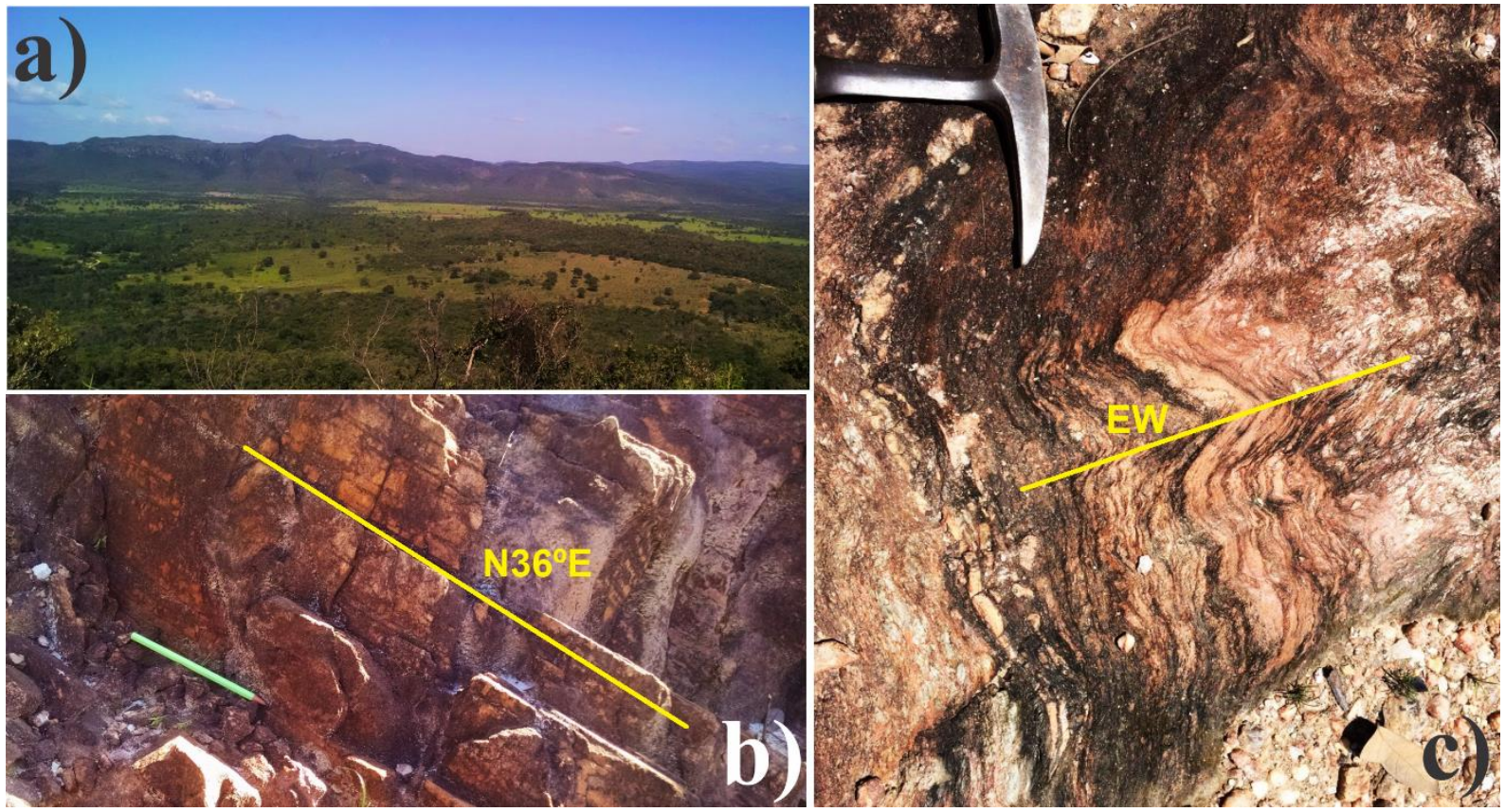

Figura 4.1. (a) Vista panorâmica do contato entre embasamento regional arrasado e Grupo Araí (chapadão e serras de composição quartzítica). Fotografia retirada em frente ao ponto A9 (Tabela 4.1). (b) Quartzito fraturado da Formação Arraiais correspondente ao ponto A9 (Tabela 4.1). Afloramento nas proximidades da cidade de Cavalcante (GO). (c) Dobras com plano axial de direção EW em xistos grafitosos observadas na região de contato entre os grupos Serra da Mesa e Araí, correspondentes ao ponto A11 (Tabela 4.1).

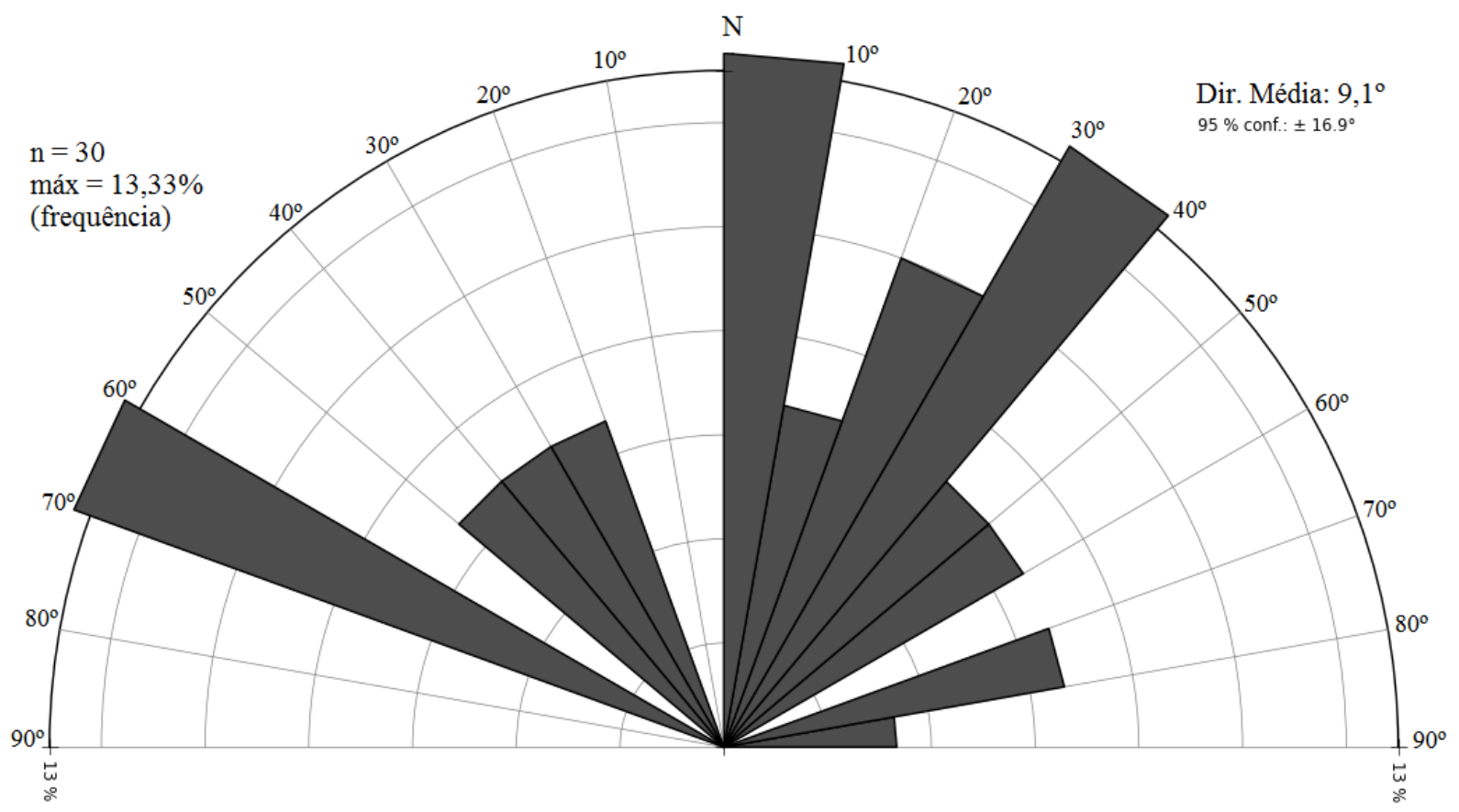

Figura 4.2. Roseta com as direção coletadas em juntas e falhas durante o reconhecimento de campo. As direções preferenciais são N10E , N20-40E e N70W. Secundariamente, as direções N10-60E e N20-50W. 


\subsection{AQUISIÇÃO DE DADOS GRAVIMÉTRICOS}

A aquisição dos dados gravimétricos terrestres foi realizada ao longo de estradas asfaltadas e de terra nas proximidades de Cavalcante (GO), Alto Paraíso (GO) e Colinas do Sul (GO). Foram adquiridos, simultaneamente, dados gravimétricos e geodésicos com o gravímetro Scintrex CG5 (SN 071140317) pertencente ao IG/UnB, com espaçamento entre cada estação de aproximadamente $800 \mathrm{~m}$, num total de 122 pontos amostrados. A base da primeira linha gravimétrica, pertencente ao Banco de Dados Geodésicos do IBGE (identificação EG 8077301 ou RN 1706-F), se encontra localizada na Paróquia Nossa Senhora das Graças, em Alto Paraíso de Goiás, com marco estabelecido em frente à torre do sino. A base gravimétrica da segunda linha, também pertencente ao IBGE (identificação EG 8063762 ou RN2269-N) se encontra fixa próxima ao mastro da bandeira da Escola Municipal Maria Auxiliadora, em Colinas do Sul.

Para a aquisição dos dados geodésicos foi utilizado o receptor GNSS/RTK (Global Navigation Satellite System/Real Time Kinematic) Trimble R4 ajustado para o modo cinemático (stop and go) (Figura 4.3). Nesse estilo de levantamento as coordenadas são de interesse apenas quando o receptor se encontra em modo estacionário (modo stop), porém o receptor continua a rastrear satélites enquanto em movimento (modo go) de um ponto de coleta ao próximo (Gleason \& Gebre-Egziabher, 2009). Normalmente, é adotado um procedimento de inicialização que consiste em posicionar o receptor no primeiro ponto da aquisição e deixá-lo rastreando aos observáveis por um tempo mínimo (usualmente 30 minutos). Em seguida, os demais pontos são observados com um tempo mais curto (5 minutos). A estação base utilizada para o processamento dos dados geodésicos foi a estação de Uruaçu (GO) - GOUR, pertencente à Rede Brasileira de Monitoramento Contínuo do IBGE (RBMC-IBGE).

A modelagem gravimétrica que será apresentada no Capítulo 5 foi feita a partir desta aquisição de campo, cuja coleta de dados do perfil de direção NS se deu em parte da rodovia GO-118 e GO-241 (Figura 1.1), seguindo mais adentro em uma estrada de terra de fazendas próximas (Figura 4.4). Essa linha de aquisição possui um gap de aproximadamente 7 km devido às dificuldades de acesso e topografia irregular e acentuada. É importante ressaltar que a linha escolhida para o perfil gravimétrico levou em consideração a facilidade de acesso e transporte do gravímetro. Dessa forma, não foi possível cortar a região do rifte onde ocorrem as intrusões graníticas da Subprovíncia Paranã ( 1,7 Ga) e também alguns dos expressivos cisalhamentos que caracterizam a região do rifte, elementos estes que possuem grande importância para o entendimento da evolução da bacia. Apesar disso, esse modelo pode melhorar o entendimento 
no que diz respeito à profundidade da cobertura sedimentar e ao arranjo estrutural nessa porção da bacia.
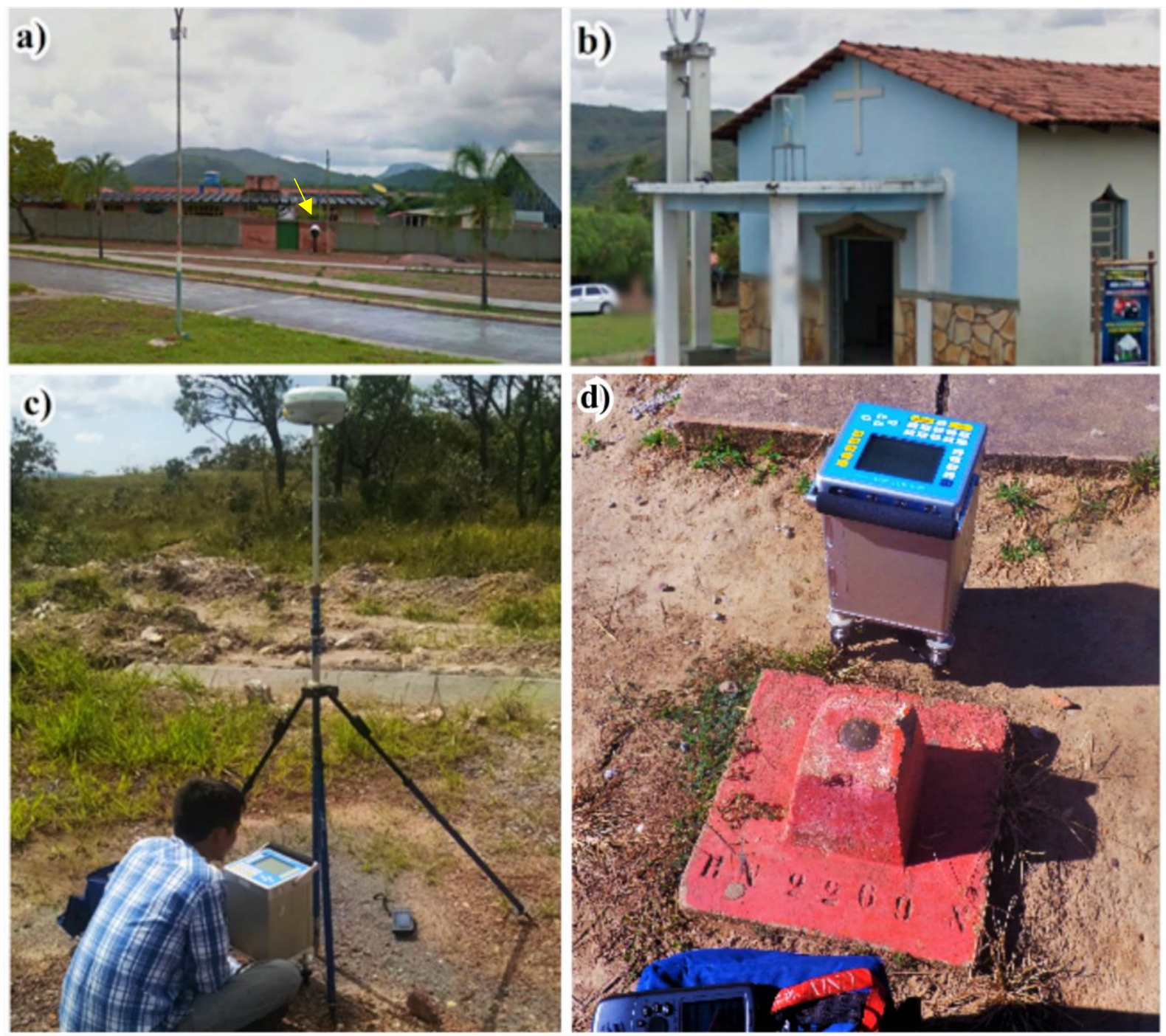

Figura 4.3. Locais contendo as bases gravimétricas utilizadas nesse estudo: (a) Escola Municipal Maria Auxiliadora - Colinas do Sul/GO e (b) Paróquia Nossa Senhora das Graças - Alto Paraíso/GO. Em (c), exemplo de estação de aquisição simultânea de dados gravimétricos e geodésicos utilizando o gravímetro Scintrex CG5 e receptor GNSS/RTK Trimble R4. (d) Base gravimétrica situada na Escola Municipal Maria Auxiliadora, utilizada na aquisição dos dados terrestres na região de Colinas do Sul. 


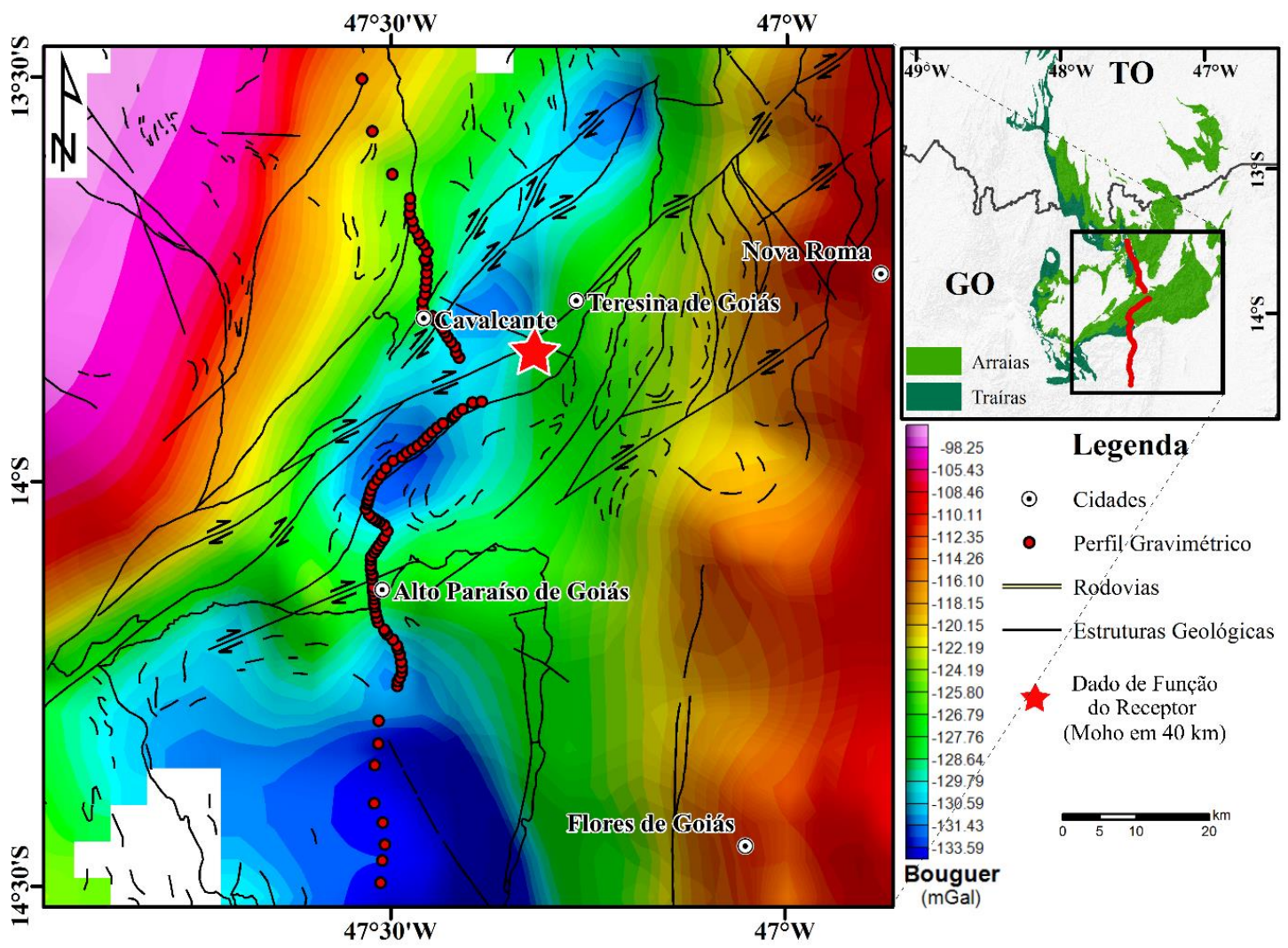

Figura 4.4. Localização do perfil gravimétrico utilizado na modelagem 2D apresentada na Figura 5.23 e estruturas mapeadas com base no mapa na escala 1:1.000.000 000 de Lacerda Filho et al. (2004) e Souza et al. (2004).

\subsection{PRÉ-PROCESSAMENTO DOS DADOS}

\subsubsection{Dados Magnéticos}

Seis levantamentos aeromagnéticos foram utilizados neste trabalho (Figura 4.5), os quais encontram-se detalhados na Tabela 4.2. Os dados aeromagnéticos provenientes desses levantamentos possuem as seguintes características: (i) englobam uma área que integra diferentes zonas UTM, (ii) os levantamentos dos projetos Serra da Mesa e PGBC são da década de 70 e possuem uma tecnologia já ultrapassada que enfrenta alguns problemas como a indisponibilidade de Sistemas de Posicionamento Global (GPS) para a navegação da aeronave, enquanto que os outros levantamentos utilizados são de aquisição recente e possuem alta resolução, (iii) todos os levantamentos foram adquiridos com linhas de voo na direção N-S exceto o Projeto Serra da Mesa, que possui direção das linhas de voo NW-SE,

diferindo da direção dos outros aerolevantamentos utilizados, (iv) os dados originais se encontram em diferentes projeções cartográficas. 
Tabela 4.2. Especificações técnicas dos aerolevantamentos geofísicos utilizados.

\begin{tabular}{|c|c|c|c|c|c|c|c|}
\hline Nome & Identif. & Contratante & Ano & $\begin{array}{l}\text { Amostra- } \\
\text { gem }\end{array}$ & $\begin{array}{l}\text { Altura } \\
\text { Voo }\end{array}$ & $\begin{array}{c}\text { Linha } \\
\text { Voo }\end{array}$ & $\begin{array}{c}\text { Linha } \\
\text { Controle }\end{array}$ \\
\hline Projeto Serra da Mesa & 1014 & $\begin{array}{l}\text { DNPM/ } \\
\text { CNEM }\end{array}$ & 1973 & $1 \mathrm{~s}$ & $135 \mathrm{~m}$ & $\begin{array}{l}\text { NW-SE } \\
1 \mathrm{~km}\end{array}$ & $\begin{array}{l}\text { NE-SW } \\
20 \mathrm{~km}\end{array}$ \\
\hline $\begin{array}{c}\text { Projeto Geofísico } \\
\text { Brasil-Canadá }\end{array}$ & 1020 & DNPM & 1975 & $1 \mathrm{~s}$ & $170 \mathrm{~m}$ & $\begin{array}{l}\mathrm{N}-\mathrm{S} \\
2 \mathrm{~km}\end{array}$ & $\begin{array}{l}\mathrm{E}-\mathrm{W} \\
14 \mathrm{~km}\end{array}$ \\
\hline $\begin{array}{c}\text { Projeto Complemento do } \\
\text { Tocantins }\end{array}$ & 1071 & CPRM & $\begin{array}{l}2006 / \\
2007\end{array}$ & $0,1 \mathrm{~s} / 1 \mathrm{~s}$ & $100 \mathrm{~m}$ & $\begin{array}{c}\mathrm{N}-\mathrm{S} \\
0,5 \mathrm{~km}\end{array}$ & $\begin{array}{c}\mathrm{E}-\mathrm{W} \\
10 \mathrm{~km}\end{array}$ \\
\hline Projeto Tocantins & 1073 & $\begin{array}{l}\text { MME/ANP/ } \\
\text { CPRM }\end{array}$ & $\begin{array}{l}2005- \\
2007\end{array}$ & $0,1 \mathrm{~s} / 1 \mathrm{~s}$ & $100 \mathrm{~m}$ & $\begin{array}{c}\mathrm{N}-\mathrm{S} \\
0,5 \mathrm{~km}\end{array}$ & $\begin{array}{l}\mathrm{E}-\mathrm{W} \\
10 \mathrm{~km}\end{array}$ \\
\hline $\begin{array}{c}\text { Proj. Arco Magmático de } \\
\text { Mara Rosa }\end{array}$ & 3008 & $\begin{array}{l}\text { Gov. Goiás/SIC- } \\
\text { MME/CPRM }\end{array}$ & 2004 & $0,1 \mathrm{~s} / 1 \mathrm{~s}$ & $100 \mathrm{~m}$ & $\begin{array}{c}\mathrm{N}-\mathrm{S} \\
0,5 \mathrm{~km}\end{array}$ & $\begin{array}{l}\mathrm{E}-\mathrm{W} \\
5 \mathrm{~km}\end{array}$ \\
\hline $\begin{array}{c}\text { Proj. Paleo- } \\
\text { Neoproterozoico do } \\
\text { Nordeste do Goiás }\end{array}$ & 3013 & $\begin{array}{l}\text { Gov. Goiás/SIC- } \\
\text { MME/CPRM }\end{array}$ & 2006 & $0,1 \mathrm{~s} / 1 \mathrm{~s}$ & $100 \mathrm{~m}$ & $\begin{array}{c}\mathrm{N}-\mathrm{S} \\
0,5 \mathrm{~km}\end{array}$ & $\begin{array}{l}\mathrm{E}-\mathrm{W} \\
5 \mathrm{~km}\end{array}$ \\
\hline
\end{tabular}

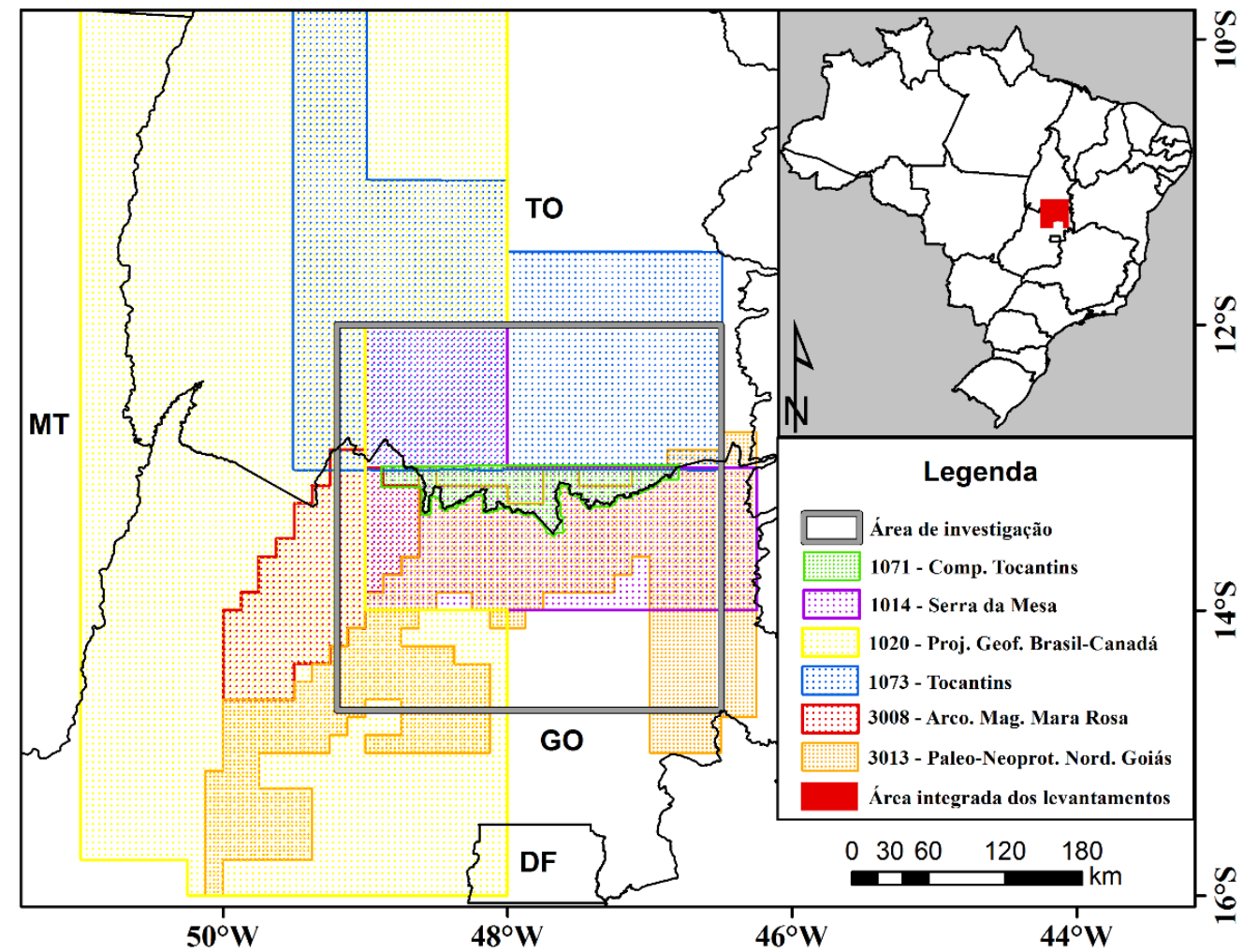

Figura 4.5. Mapa da localização dos projetos aerogeofisicos utilizados em relação à presente área de estudo.

Essas diferentes caraterísticas para cada levantamento dificultam sua integração espacial, sendo necessária a divisão do processamento em duas etapas: pré-processamento e processamento. $\mathrm{O}$ pré-processamento consiste na padronização dos parâmetros relacionados à interpolação de diferentes levantamentos e na aplicação de técnicas que minimizem os efeitos relacionados ao tipo de levantamento e às possíveis interferências no campo potencial que prejudiquem o cálculo das anomalias gravimétricas e magnéticas associadas a fontes geológicas. É importante ressaltar que uma pequena porção da área de estudos é recoberta 
apenas pelos levantamentos mais antigos da década 70 e que a parte sul não é recoberta por nenhum levantamento de dados aeromagnéticos.

Devido às diferenças na aquisição dos aerolevantamentos utilizados nesse estudo, cada um deles foi processado de maneira diferente (Tabela 4.3). Para os levantamentos mais antigos (Serra da Mesa e PGBC) foram necessárias etapas específicas de pré-processamento. Para cada levantamento foram realizadas as seguintes etapas de pré-processamento, aplicadas de acordo com sua necessidade em cada projeto geofísico, explanadas logo em seguida:

Tabela 4.3. Etapas de pré-processamento nos dados aeromagnéticos dos diferentes levantamentos (enumeração está de acordo com o texto subsequente).

\begin{tabular}{ccccccc}
\hline Etapa & $\begin{array}{c}\text { Serra da } \\
\text { Mesa (1014) }\end{array}$ & $\begin{array}{c}\text { PGBC } \\
(\mathbf{1 0 2 0})\end{array}$ & $\begin{array}{c}\text { Complemento } \\
\text { Tocantins } \\
(\mathbf{1 0 7 1})\end{array}$ & $\begin{array}{c}\text { Tocantins } \\
(\mathbf{1 0 7 3 )}\end{array}$ & $\begin{array}{c}\text { Arco Mag. } \\
\text { Mara Rosa } \\
(\mathbf{3 0 0 8})\end{array}$ & $\begin{array}{c}\text { Paleo-Neop. } \\
\text { Nord. Goiás } \\
(\mathbf{3 0 1 3})\end{array}$ \\
\hline I & $\times$ & $\times$ & $\times$ & $\times$ & $\times$ & $\times$ \\
II & $\times$ & $\times$ & $\times$ & $\times$ & $\times$ & $\times$ \\
III & $\times$ & $\times$ & $\times$ & & & \\
IV & $\times$ & $\times$ & $\times$ & $\times$ & $\times$ & $\times$ \\
VI & $\times$ & $\times$ & $\times$ & $\times$ & $\times$ & $\times$ \\
VII & $\times$ & $\times$ & $\times$ & $\times$ & & \\
\hline
\end{tabular}

\section{I) CONVERSÃO DA PROJEÇÃO CARTOGRÁFICA}

Cada levantamento aerogeofísico utilizado neste trabalho foi cedido originalmente com projeções distintas. Os dados digitalizados dos projetos Serra da Mesa (1014) e PGBC (1020) foram cedidos na Projeção Equatorial de Mercator (Equatorial Mercator Projection - EM). Os projetos Complemento do Tocantins (1071) e Arco Magmático de Mara Rosa (3008) foram cedido na projeção Universal Transversa de Mercator - UTM, Datum WGS84 (Zona 22S). O Projeto Aerogeofísico Tocantins foi cedido na projeção Universal Transversa de Mercator UTM, Datum WGS84, com meridiano central $48^{\circ} \mathrm{W}$ e fator de escala para meridiano central igual a 0,9996 e o Projeto Paleo-Neoproterozoico do Nordeste de Goiás (3013) foi cedido na projeção Universal Transversa de Mercator - UTM, Datum WGS84, com meridianos centrais $45^{\circ} \mathrm{W}$ e $51^{\circ} \mathrm{W}$ e fator de escala para meridiano central igual a $0,9996$.

Por ser uma área de investigação que compreende mais de um fuso e que, consequentemente, se encontra entre duas zonas UTM, todos os dados foram padronizados e convertidos para coordenadas geográficas, Datum WGS84, que satisfaz às limitações de cada levantamento. Para a aplicação de técnicas que necessitam de coordenadas em metros para o cálculo de profundidades de fontes foi utilizada coordenada específica na projeção Policônica - Datum WGS 84, com meridiano central em $47,6^{\circ} \mathrm{W}$. 


\section{II) CONTROLE DE QUALIDADE}

O dado bruto deve ser visualmente inspecionado quanto às inconsistências que possam prejudicar sua análise, tal como a presença de "picos" (spikes) no sinal (variações anômalas e abruptas em um pequeno espaço de tempo do valor medido, gerados por interferências eletroeletrônicas), gaps ou qualquer outra irregularidade nos dados. Algumas formas de identificar e eliminar esses problemas envolvem a análise da distribuição das linhas de aquisição, juntamente com a visualização dos perfis empilhados e também o teste da quarta diferença nos dados.

A fim de verificar a consistência dos dados foram feitas a análise ao longo das linhas de voo e perfis empilhados (Figura 4.6) além do teste da quarta diferença para os dados dos projetos Serra da Mesa (1014) e PGBC (1020). Os outros aerolevantamentos já foram fornecidos com esta etapa de pré-processamento realizada.

Os mapas das linhas de voo para cada aerolevantamento foram plotados a fim de verificar sua distribuição em malha regular (Figura 4.6a). O padrão para as linhas de voo de ambos os levantamentos não apresentou grandes problemas, exceto em alguns pontos com má localização, posteriormente removidos. Os desvios eventuais nas linhas dos levantamentos devem-se ao tipo de navegação destes aerolevantamentos, controlada pelo sistema Doppler e recuperada a partir de fotografias colhidas durante o voo com câmeras 35 mm - DNPM 1981. Esta técnica de navegação é antiga e pouco precisa, causando desvios mensuráveis entre as linhas planejadas e sobrevoadas. Os perfis empilhados foram plotados (Figura 4.6b) a fim de verificar a presença de valores espúrios que podem não estar associados diretamente ao sinal do campo magnético, para posteriormente serem removidos pela análise da quarta diferença. A quarta diferença é numericamente equivalente à quarta derivada do campo magnético anômalo registrado em cada linha da aquisição e possui a função de ressaltar sinais de alta frequência, alta amplitude e curto comprimento de onda que não possuem relação com o sinal adjacente para que possam ser removidos. É calculada a partir da relação:

$$
4^{\text {th }} \text { diff }=T_{-2}-4 T_{-1}+6 T_{0}-4 T_{+1}+T_{+2} / 16
$$

onde $T_{-2}, T_{-1}, T_{0}, T_{+1}$ e $T_{+2}$ são cinco leituras consecutivas centradas sobre a leitura $T_{0}$ (Reeves, 2005).

A análise da quarta diferença no sinal dos aerolevantamentos Serra da Mesa (1014) e PGBC (1020) permitiu que os dados espúrios fossem destacados como picos (Figura 
4.7), sendo removidos do banco e, posteriormente, interpolados pela técnica da mínima curvatura.
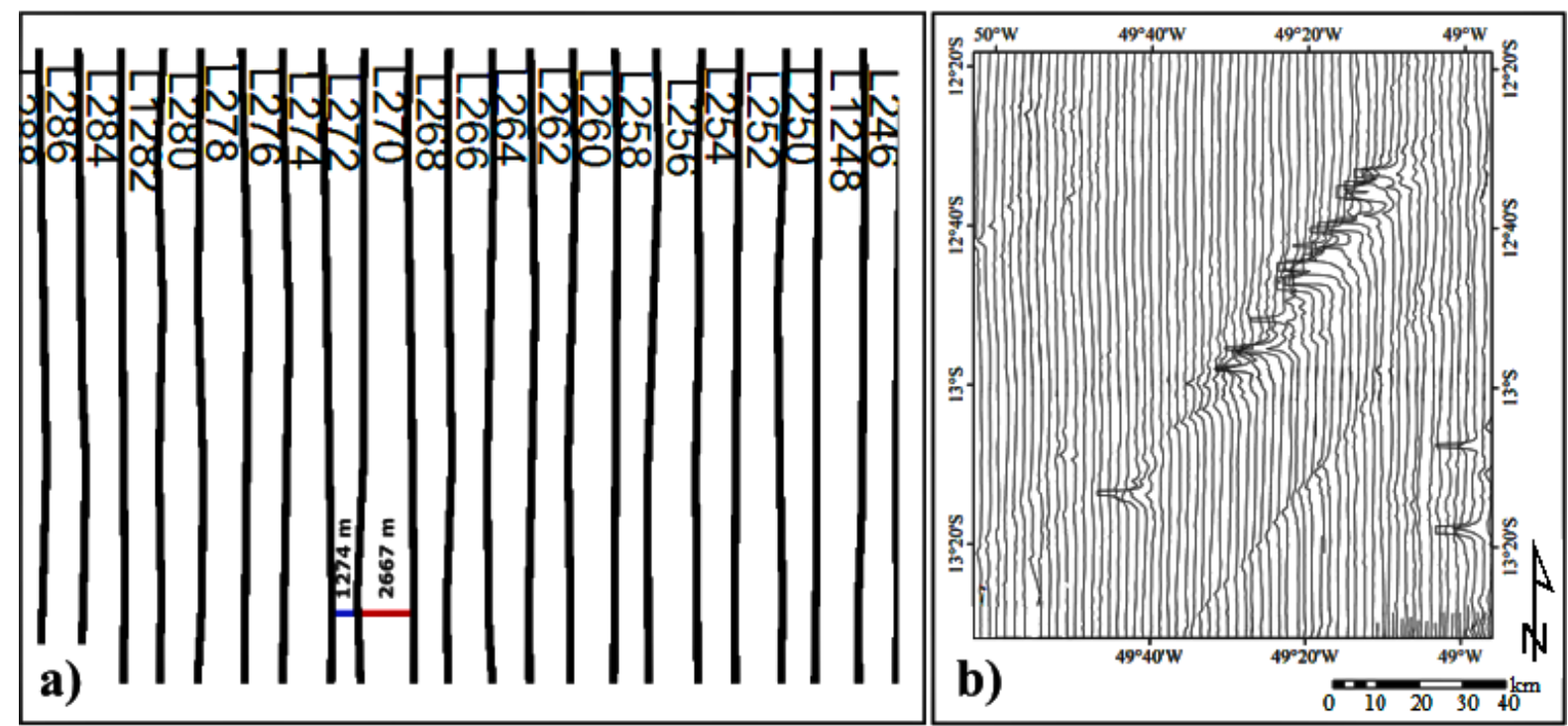

Figura 4.6. (a) Linhas de voo de uma porção do levantamento PGBC, que possui espaçamento de $2 \mathrm{~km}$. É possível visualizar desvios mensuráveis no trajeto da aeronave. (b) Exemplo dos perfis empilhados do campo magnético anômalo de parte do levantamento para a verificação de valores espúrios, picos anômalos não associados diretamente ao sinal do campo magnético.

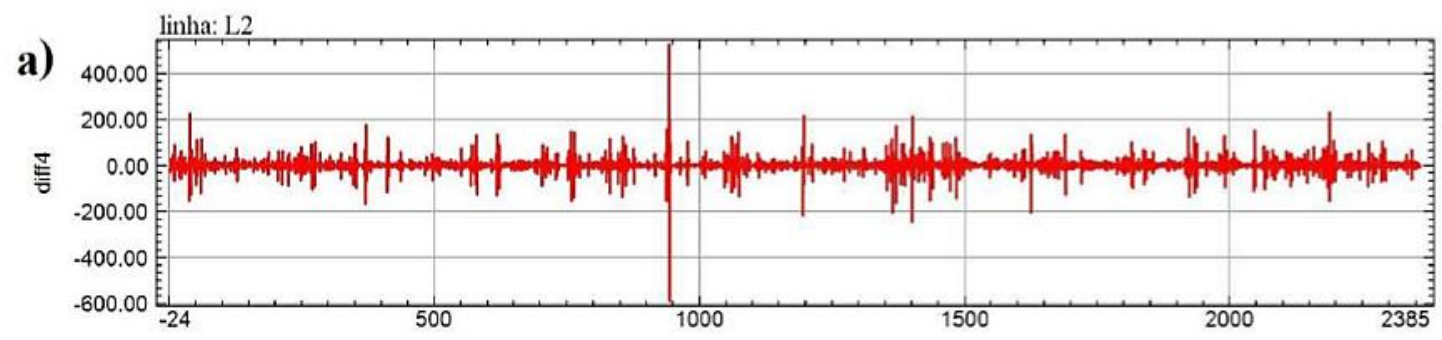

b)

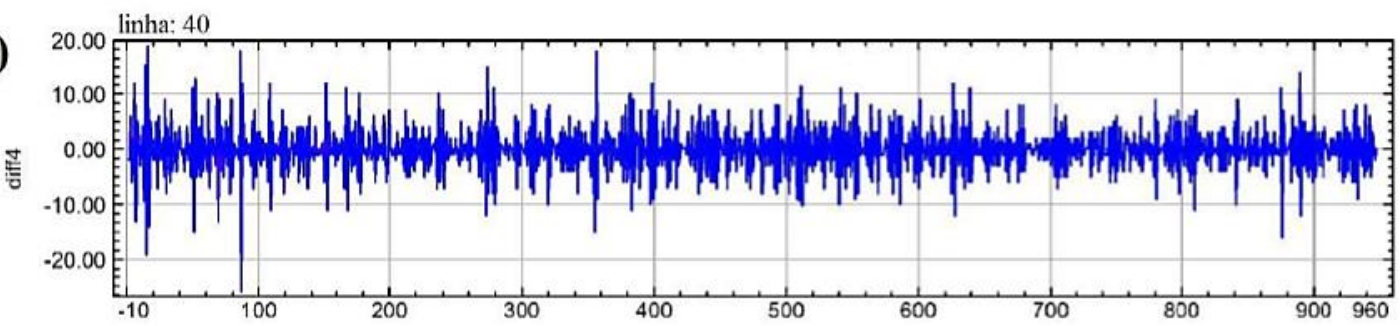

Figura 4.7. Exemplos de dados espúrios ressaltados com a técnica da análise da quarta diferença do campo magnético anômalo em: (a) Projeto Serra da Mesa (1014) e (b) PGBC (1020). 


\section{III) INTERPOLAÇÃO EM MALHA REGULAR}

A interpolação de dados 2D em malha regular a ser utilizada depende, sobretudo, da distribuição espacial dos dados coletados. Por serem provindos de aerolevantamentos, os dados encontram-se distribuídos em linhas grosseiramente espaçadas de forma paralelas, de acordo com a trajetória do avião. A técnica de gridagem bidirecional se mostra eficaz para dados com este tipo de característica pois tende a reforçar as tendências perpendiculares à direção das linhas de aquisição. O processo de gridagem se divide em duas etapas. Primeiro é feita a interpolação ao longo das linhas de aquisição originais a fim de se obter valores utilizados na segunda parte, a interpolação perpendicular na intersecção com as linhas de voo, de forma a gerar um valor para cada ponto requerido do grid (Reeves, 2005). Este método de interpolação foi utilizado para todos os levantamentos empregados no presente trabalho. Foi escolhido um valor de $1 / 4$ do espaçamento entre as linhas de voo para a célula unitária do grid (Vasconcelos et al., 1990; Blum, 1999), respeitando o Teorema da Amostragem (Davis, 1986), de forma a evitar a perda de informação e o aparecimento do efeito de aliasing nos dados.

\section{IV) REMOÇÃO DO IGRF}

A remoção do IGRF foi aplicada aos dados mais antigos - levantamentos Serra da Mesa (1014) e PGBC (1020) (Figura 4.8) - a qual não foi realizada nos dados originais. Esta etapa de processamento, citada com maiores detalhes no Capítulo 3, busca remover a contribuição no sinal magnético proveniente do núcleo terrestre que não se faz interessante ao mapeamento geológico. Com a retirada do IGRF, o sinal magnético resultante apresenta apenas proveniência de fontes crustais acima da superfície Curie - o campo magnético anômalo, aquele que contém apenas as assinaturas anômalas que podem ter significado para o estudo geofísico-geológico. $\mathrm{O}$ campo magnético anômalo é o ponto de partida na geração dos principais produtos utilizados neste trabalho. 


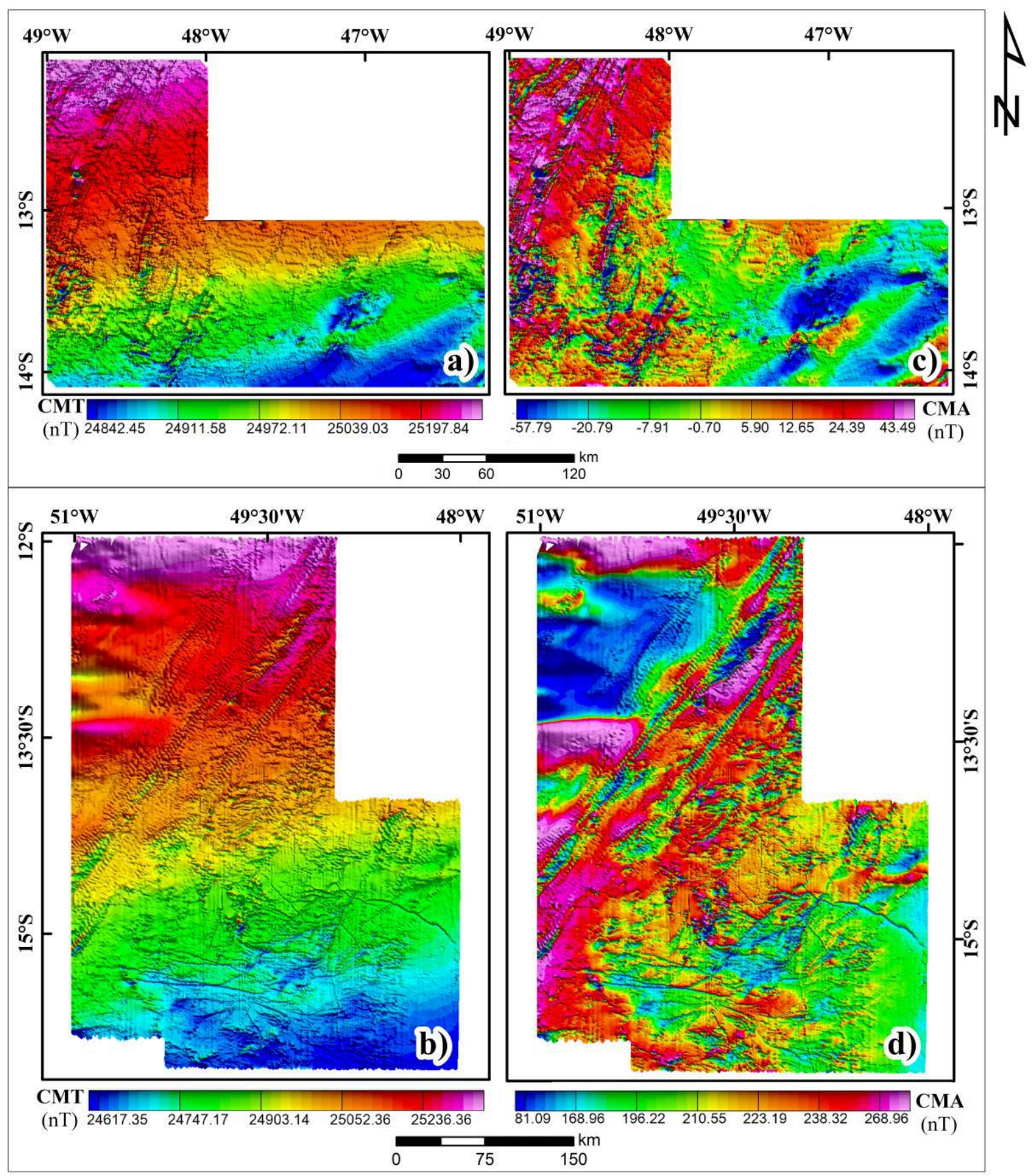

Figura 4.8. Mapas do campo magnético total (CMT) dos levantamentos (a) Serra da Mesa e (b) PGBC e mapas do campo magnético anômalo (CMA) após a remoção do IGRF, respectivamente, em (c) e (d).

\section{V) MICRONIVELAMENTO}

O micronivelamento é um processo de filtragem realizado em dados espaciais de forma a reduzir ou remover os efeitos não-geológicos provocados por ruídos com grandes comprimentos de onda ao longo das linhas de voo (Geosoft, 2010). Após o processo de interpolação dos grids e remoção do IGRF nos levantamentos PGBC (1020) e Serra da Mesa 
(1014) verificou-se, respectivamente, a presença de erros residuais lineares na direção das linhas de voo, tornando-se necessária a realização da etapa de micronivelamento. Existem várias técnicas de micronivelamento aplicadas a dados aerogeofísicos, como a descrita por Minty (1991). O micronivelamento aplicado a este trabalho tem como base a técnica desenvolvida por Urquhart (1988), utilizando o módulo MAGMAP do software Oasis Montaj na aplicação de um filtro de decorrugação no domínio de Fourier (Figura 4.9). Este processo envolve as seguintes etapas:

(i) Aplicação de um filtro Butterworth passa-alta na direção perpendicular ao ruído, definido como quatro vezes a separação da linha, de forma a passar comprimentos de onda na ordem de duas a quatro separações de linha, tal como a resultante em um erro de nivelamento linha-a-linha.

(ii) Filtro de cosseno direcional na mesma direção das linhas de voo, ajustado para passar comprimentos de onda apenas na direção das linhas;

(iii) Subtração dos grids de erro produzidos em (i) e (ii), corrigido do sinal geológico, do grid original, resultando em um conjunto de dados magnéticos micronivelados.

A fim de se obter o melhor resultado de decorrugação foram realizados testes empíricos referentes à determinação de comprimento de onda de corte, ordem do filtro (grau de suavização) e grau da função cosseno. 


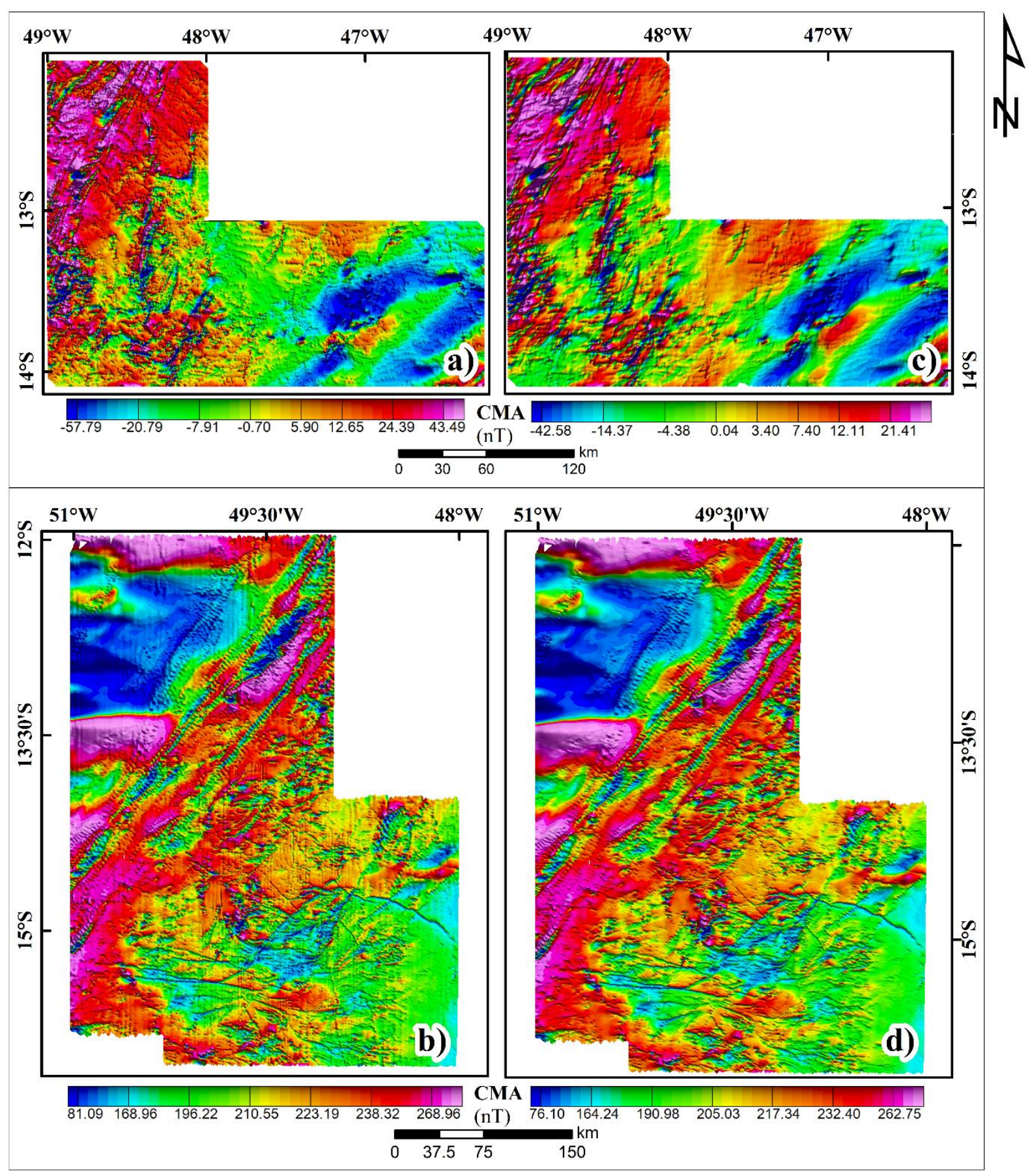

Figura 4.9. Mapas do campo magnético anômalo dos levantamentos (a) Serra da Mesa (1014) e (b) PGBC (1020) e mapas do campo magnético anômalo micronivelado, respectivamente, em (c) e (d).

\section{VI) CONTINUAÇÃO ASCENDENTE}

Dado os diferentes parâmetros de aquisição e resolução dos projetos aerogeofísicos (Tabela 4.2), houve a necessidade de realizar continuação ascendente nos dados de forma a homogeneizar o sinal magnético para uma mesma altura, de tal maneira que as elevações dos 
dados adquiridos a diferentes alturas de voo sejam normalizadas para a maior altura de voo entre os levantamentos $(150 \mathrm{~m})$. Essa necessidade se dá pelo fato de o sinal magnético provindo de fontes rasas apresentar menores dimensões e diminuir mais rapidamente do que aquele relacionado a fontes profundas, provocando diferenças perceptíveis no sinal magnético em levantamentos a diferentes alturas de aquisição. Ao realizar a continuação ascendente as fontes rasas são suavizadas, mas nunca removidas dos dados filtrados (Isles \& Rankin, 2013). O filtro de continuação ascendente foi aplicado ao mapa do campo magnético anômalo dos levantamentos 1071, 1073, 3008 e 3013, continuados 50 metros para cima, e no levantamento 1014, continuado 15 metros para cima.

\section{VII) INTEGRAÇÃO DOS PROJETOS}

A fim de gerar uma malha regular contendo todos os projetos aerogeofísicos foi feita a junção dos dados magnéticos a partir da técnica de Sutura (Suture Method) disponível no software Oasis Montaj v8.5. Esta técnica é eficaz especialmente em grids contendo uma estreita área de sobreposição, por onde será inserida uma linha de sutura gerada pela técnica (Figura 4.10). A área fora da sobreposição permanece inalterada. (Johnson et al., 1999). Ao longo da linha de sutura, uma incompatibilidade nos valores pode ser corrigida ajustando os valores incompatíveis dos grids em ambos os lados da linha de sutura como, por exemplo, em um ponto da linha em que o valor para um grid 1 é maior do que o valor para um grid 2, usa-se o valor médio para eliminar as discrepâncias. Esta técnica utiliza a abordagem de sutura multifrequencial para corrigir os valores, assegurando uma transição suave entre os grids (Geosoft, 2010).

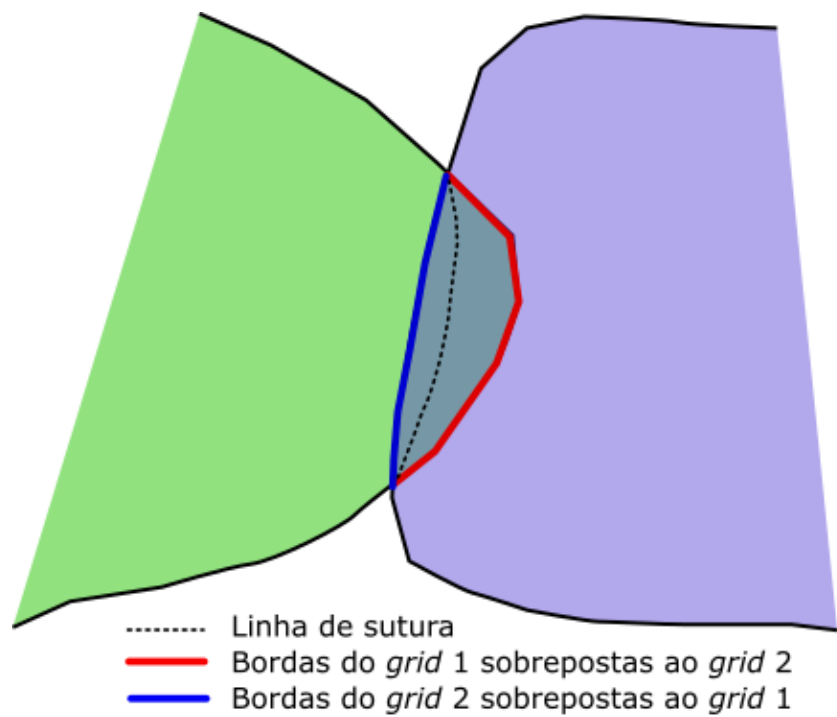

Figura 4.10. Esquema simplificado da definição do método de Sutura (com base em Johnson et al., 1999). 
Devido à diferença no espaçamento das linhas de voo (LV) dos levantamentos $1020 \mathrm{e}$ 1014 com relação aos demais (Tabela 4.2), a junção dos dados magnéticos foi conduzida em duas etapas. Na primeira, todos os grids foram integrados com célula de interpolação igual a $125 \mathrm{~m}$, de forma a gerar um mapa de anomalias magnéticas de maior resolução. As regiões interpoladas que possuíam apenas recobrimento dos levantamentos 1020 e 1014 não acompanham a mesma qualidade do restante do grid devido ao fato de serem levantamentos antigos com técnicas de aquisição ultrapassadas que não permitem visualização dos dados com a mesma qualidade dos demais. Porém esta malha com maior resolução ainda se faz útil na aplicação a produtos que necessitam de maior detalhe, como o traçado dos lineamentos (Figura 4.11a). Na segunda etapa, foi feita a junção com célula de interpolação igual a 500m, acompanhando o valor utilizado na interpolação do levantamento 1020 (maior espaçamento entre as LV), de forma a gerar um grid de menor resolução, mais suave, utilizado nas demais técnicas de análise (Figura 4.11b). 

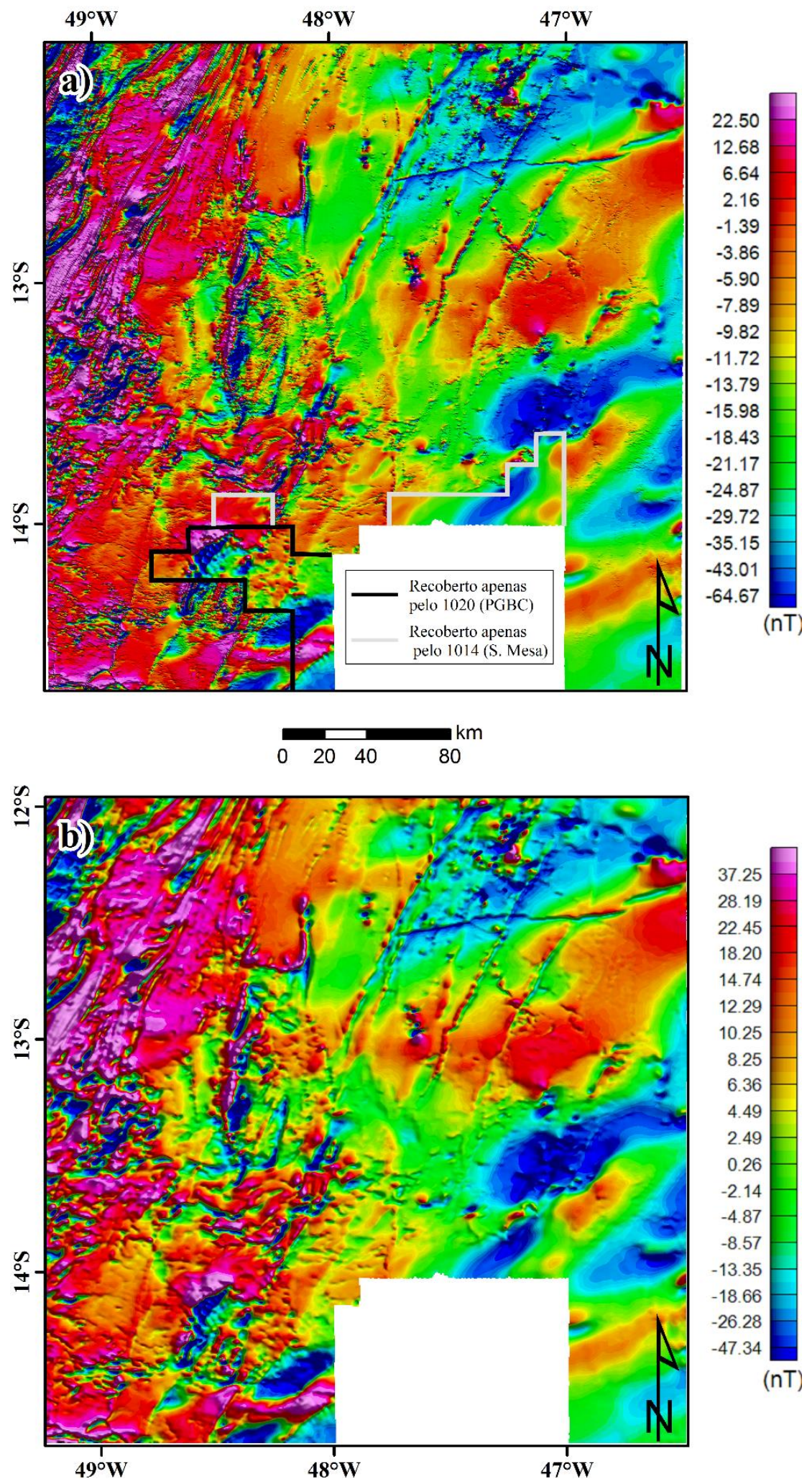

Figura 4.11. a) Mapa do campo magnético anômalo de maior resolução (célula unitária de 125m) e b) Mapa do campo magnético anômalo de menor resolução (célula unitária de 500m). A linha preta indica os limites do mapa recobertos apenas pelo projeto 1020 (PGBC) e a linha cinza indica os limites recobertos apenas pelo projeto 1014 (Serra da Mesa). Devido a ausência de aerolevantamentos recobrindo a parte sul da área estudada, não foi possível a interpolação de dados magnéticos nessa porção. 


\subsubsection{Dados Gravimétricos}

Os dados gravimétricos utilizados neste trabalho compreendem um banco de dados compilado por Vidotti et al. (1998) contendo estações gravimétricas provenientes de levantamentos realizados por várias instituições, tais como o Instituto Brasileiro de Geografia e Estatística (IBGE), Instituto de Astronomia, Geofísica e Ciências Atmosféricas, Universidade de São Paulo (IAG/USP) e Instituto de Geociências, Universidade de Brasília (IG/UnB), além das estações adquiridas neste trabalho. Todos os dados fornecidos e coletados possuem valores de Anomalias Free Air e Bouguer Completa.

Os dados da aquisição feita exclusivamente para este trabalho passaram pelas etapas de redução detalhadas no Capítulo 3. Na interpolação de todos os dados foi utilizado o método da curvatura mínima, com tamanho da célula de $5 \mathrm{~km}$. A curvatura mínima aplicada a dados aleatórios, como é o caso de aquisições terrestres onde os pontos são, em sua maioria, coletados ao longo de rodovias e estradas não pavimentadas, se mostra uma técnica de interpolação rápida e satisfatória. Nesta técnica, a superfície de interpolação se assemelha a uma fina camada linear e elástica que passa através de cada um dos valores considerados, com leve aumento ou estiramento. O método é caracterizado como um processo de interpolação não exato a partir de diversas iterações ao longo do grid, gerando uma superfície suavizada que atravessa todos os dados. Como consequência, os dados nem sempre irão respeitar seu valor real, pois em cada iteração os valores dos nodos são recalculados, havendo sucessivas mudanças em seu valor inicial, até que apresentem um número menor que um valor máximo residual, ou que um certo número de iterações seja satisfeito (Geosoft, 2010). O mapa de Anomalia Bouguer, juntamente com as estações gravimétricas utilizada neste estudo são apresentados na Figura 4.12. 


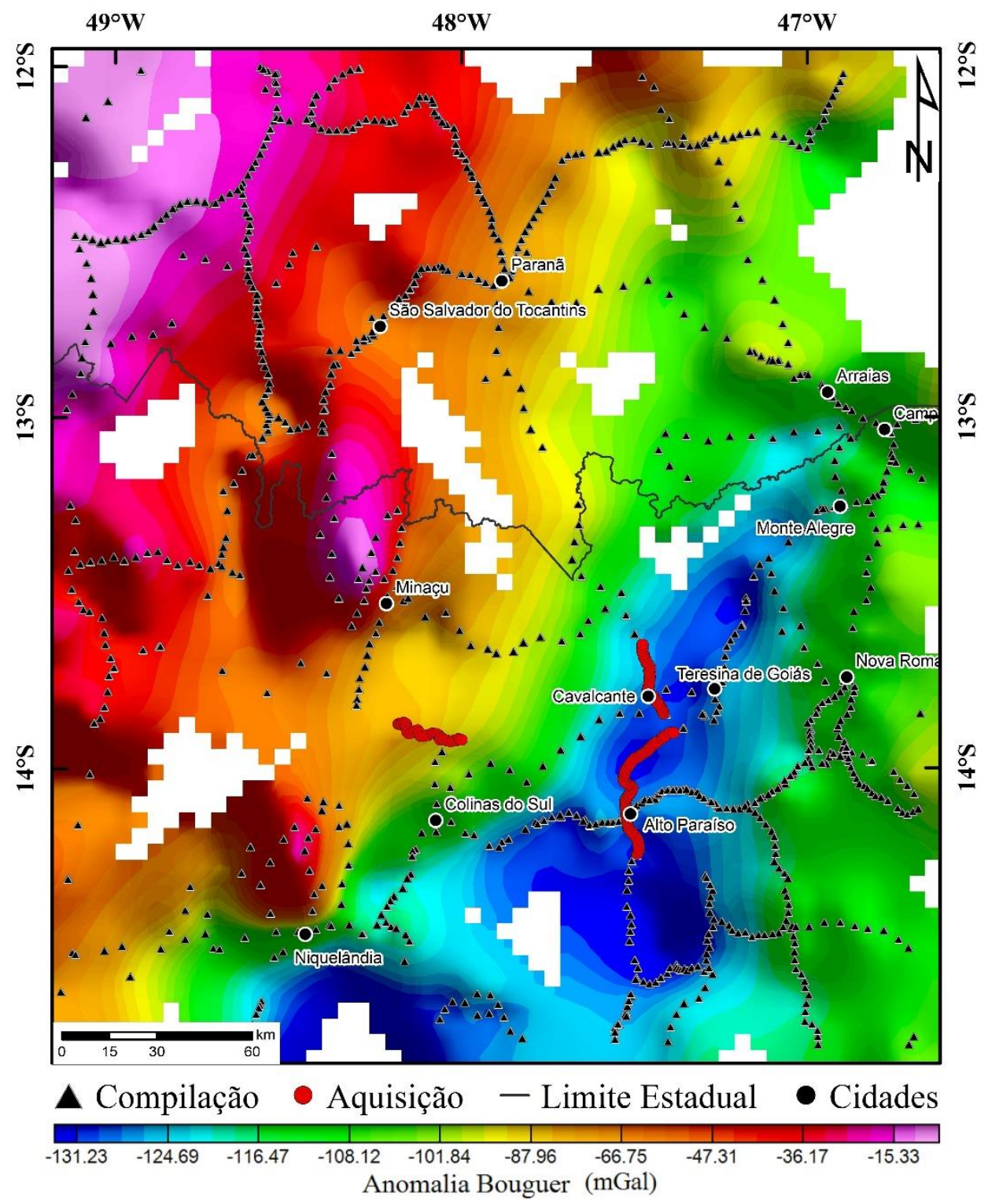

Figura 4.12. Mapa de Anomalia Bouguer de dados terrestres e localização das estações utilizadas neste estudo.

\subsection{PROCESSAMENTO E TÉCNICAS DE REALCE}

O processamento dos dados e as técnicas de realce de anomalias são etapa fundamental na caracterização geofísica e interpretação geológica. Podem ser realizados através de filtragem no domínio espacial (lineares ou não-lineares) e/ou no domínio de Fourier (número de onda ou frequência espacial).

Para o processamento e interpretação dos dados magnéticos foi utilizado como base primária o campo magnético anômalo (i.e. o campo magnético total reduzido do IGRF) micronivelado, tendo em vista características que dificultam a redução ao polo na região deste 
estudo, que serão abordadas de forma mais detalhada na seção 4.2.1. Para os dados gravimétricos foi utilizada como base a Anomalia Bouguer Completa, gerada a partir de correções das variações do campo gravitacional terrestre não relacionadas aos contrastes de densidade das rochas (reduções gravimétricas). Estes procedimentos foram realizados com o software Oasis Montaj v8.5. As rotinas de processamento dos dados são apresentadas de forma simplificada no fluxograma da Figura 4.13.

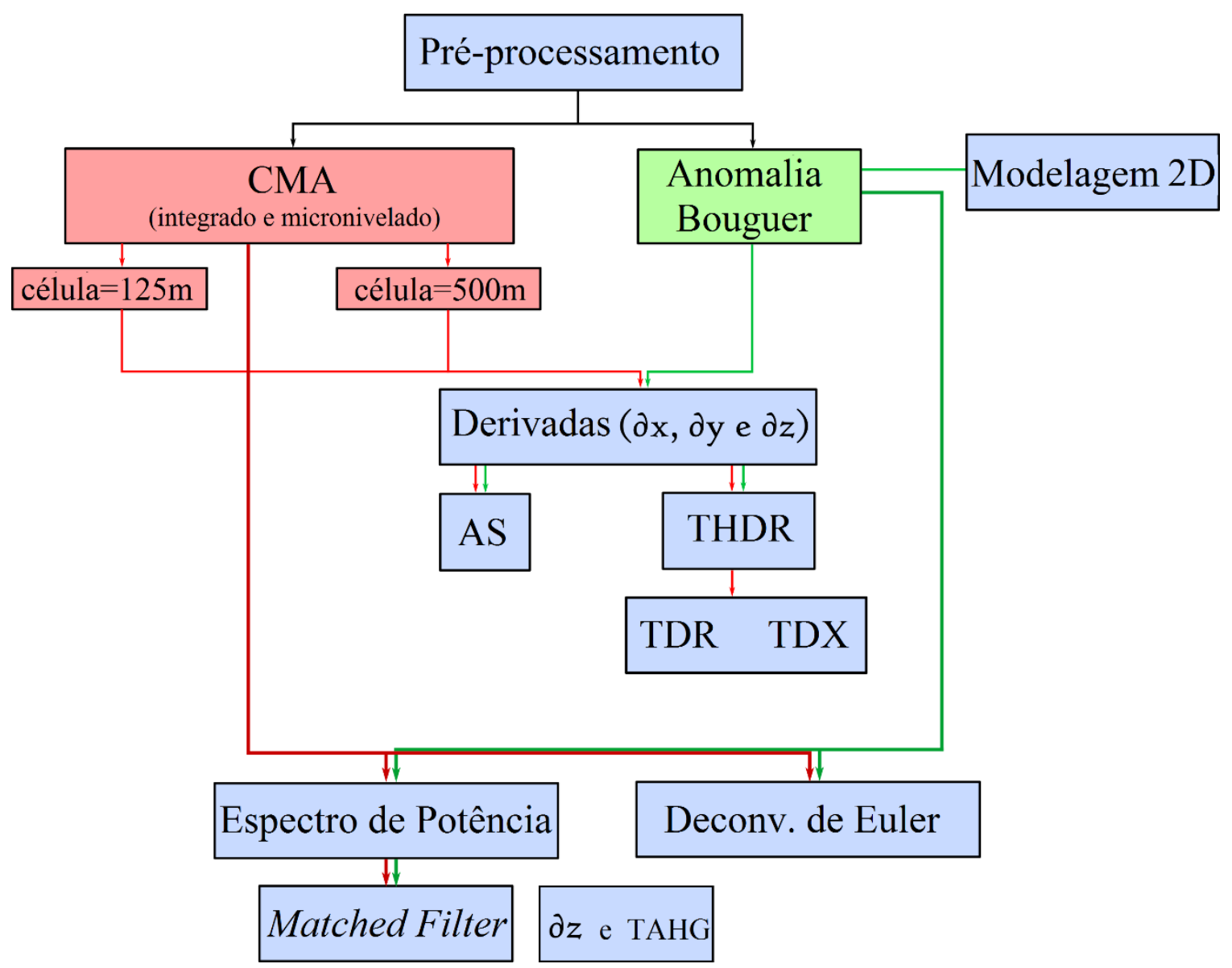

Figura 4.13. Fluxograma exemplificado evidenciando a sequência de processamento dos dados magnéticos e gravimétricos.

\subsubsection{Redução ao Polo}

A redução ao polo (RTP) (Baranov, 1957; Baranov \& Naudy, 1964) é uma técnica de processamento que permite imagear a geometria de unidades rochosas de forma mais eficaz do que na aplicação do campo magnético anômalo. Sua aplicação consiste em transformar dados medidos a qualquer inclinação do campo magnético como se observados nos polos magnéticos $\left(\mathrm{I}=90^{\circ}\right)$, fazendo com que uma anomalia antes dipolar sofra uma alteração, centralizando o pico 
de amplitude no centro do corpo causativo. Em outras palavras, a RTP desloca lateralmente anomalias de forma a serem localizadas ao longo das respectivas fontes e altera a sua forma de modo que fontes simétricas gerem anomalias simétricas (Blakely, 1995). Pode ser escrita em termos de:

$$
L(\theta)=\frac{1}{[i \cos (I) \cos (D-\theta)+\sin (I)]^{2}}
$$

onde $\theta$ é a direção do número de onda, I é a inclinação magnética e $\mathrm{D}$ é a declinação magnética, com uma componente de amplitude (o termo $\sin (\mathrm{I})$ ) e uma componente de fase (o termo $i \cos (\mathrm{I})$ $\cos (\mathrm{D}-\theta))$

No entanto, existem situações que limitam o uso da técnica, podendo produzir dados errôneos ou enganosos. Em baixas latitudes $\left(\mathrm{I}<20^{\circ}\right)$ a RTP se torna instável pois o cálculo envolve a divisão por números cada vez menores conforme a inclinação do campo diminui. Essa instabilidade tipicamente se manifesta como uma falsa tendência nos dados paralela à declinação campo da Terra (i.e. o norte magnético). Além disso, nos casos em que os corpos rochosos retêm uma forte componente de magnetização remanente (ou outras formas nãoinduzidas de magnetização), a aplicação da RTP para as anomalias ao longo destes corpos é teoricamente inválida, porém corpos magnetizados com remanência raramente são as fontes dominantes de anomalias magnéticas em uma área de pesquisa e, em geral, pode-se aplicar a técnica de RTP e obter resultados satisfatórios (Isles \& Rankin, 2013).

A área do presente estudo encontra-se em baixas latitudes magnéticas e também possui forte remanência constatada, de forma inicial, por diversas anomalias dipolares invertidas em relação ao comportamento esperado para uma anomalia puramente induzida na mesma coordenada geográfica e que não possuem, necessariamente, o mesmo vetor remanência. Este comportamento foi observado também por Almeida (2009) na região da Suíte Pedra Branca, referente à uma fonte provavelmente profunda. A Figura 4.14 apresenta essa anomalia dipolar invertida comparada ao comportamento de anomalias puramente induzidas a uma inclinação do campo magnético de aproximada de $15^{\circ}$. 

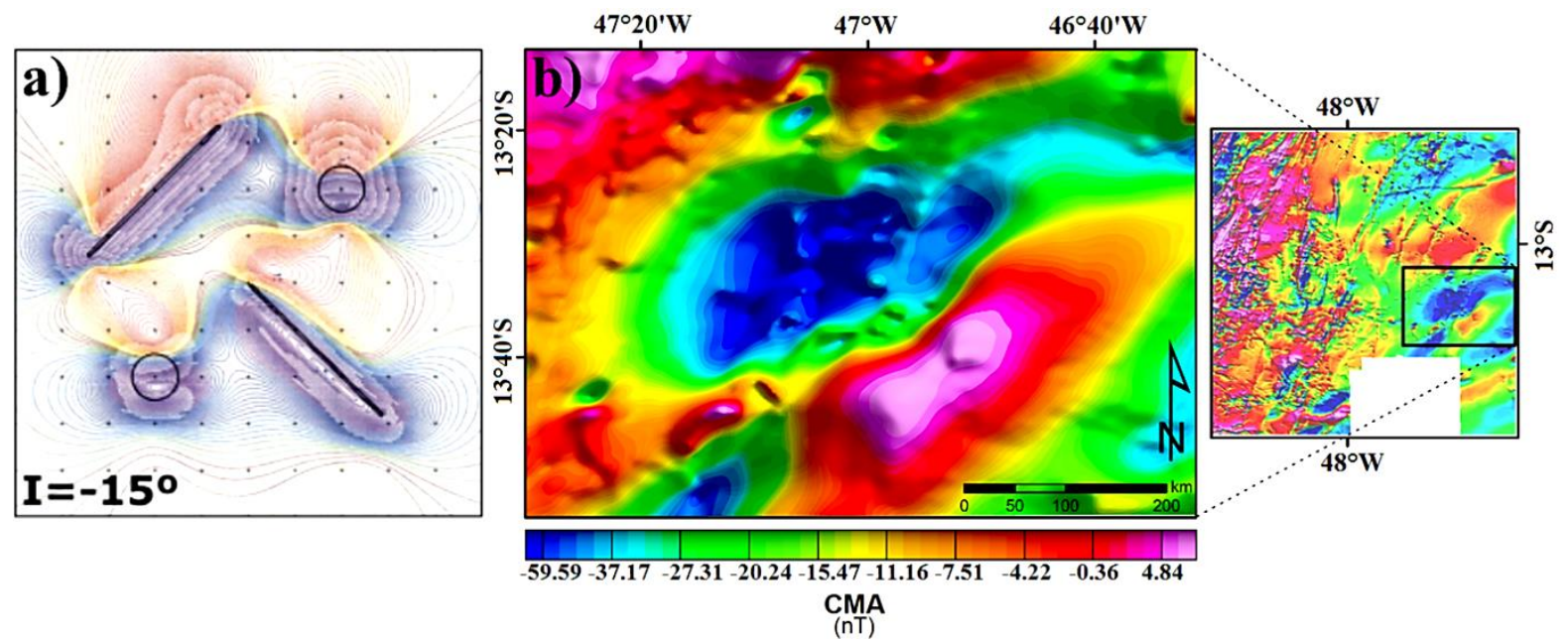

Figura 4.14. (a) Modelo de estudo mostrando o impacto da inclinação igual a $15^{\circ}$ no hemisfério sul no reconhecimento da geometria de fontes causadoras no campo magnético anômalo (adaptado de Isles \& Rankin, 2013) e (b) Anomalia dipolar invertida na área de estudo em relação a um comportamento esperado para uma anomalia puramente induzida, representando a possível presença de remanência na região.

Foram testados algoritmos de redução ao polo, incluindo aqueles que consideram baixas latitudes e presença de magnetização remanente, no entanto não foi possível encontrar uma metodologia que suprisse os problemas apresentados para a área estudada de forma satisfatória. Os algorítmos utilizados incluem a Redução ao Polo convencional com correção de amplitude (Grant \& Dodds, 1972) e a Redução ao Polo Diferencial (Cooper \& Cowan, 2005) disponibilizados no sistema de processamento MAGMAP do software Oasis Montaj v8.5, e Redução ao Polo pelo método MaxiMin (Fedi et al., 1994; Cordani \& Shukowsky, 2009), desenvolvido em ambiente MATLAB.

A Redução ao Polo aplicada a toda região de estudo, de forma a facilitar a análise das anomalias, não foi satisfatória e foi descartada das etapas de processamento, visto que nem todas as anomalias conseguiram ser reduzidas com amplitude máxima no centro dos corpos, permanecendo dipolares ou, se reduzidas, não foram eficazes a toda a área. Este comportamento já era previsto visto que é uma área que abrange uma geologia complexa e com diferentes registros de magnetização. Devido a estes fatores, optou-se por utilizar o mapa do campo magnético anômalo como base para os produtos de realce de anomalias e estimativa de profundidades. 


\subsubsection{Derivadas direcionais}

As derivadas de primeira e segunda ordem nas direções x,y e z realçam anomalias de alta frequência e podem ser calculadas tanto no domínio espacial quanto no domínio da frequência, sendo as derivadas horizontais computadas mais facilmente no domínio espacial (Nabighian et al., 2005).

As derivadas horizontais realçam feições nas direções x e y, acentuando o gradiente lateral da propriedade física investigada na direção escolhida, ou seja, na localização de extremidades de fontes (Simpson et al., 1986). Também são úteis na obtenção de novos produtos que necessitem do gradiente lateral, tais como no Gradiente Horizontal Total e Deconvolução de Euler.

A derivada vertical enfatiza características próximas à superfície e estreita a largura da anomalia, localizando assim fontes de forma mais precisa (Cooper \& Cowan, 2004). A primeira derivada vertical é um filtro passa-alta amplamente utilizado, pois é robusto em computação, possui resultados confiáveis e facilmente interpretáveis (Isles \& Rankin, 2013). Também é utilizada como base na obtenção de produtos tais como o Sinal Analítico e Derivada Tilt.

\subsubsection{Gradiente Horizontal Total (THDR)}

Primeiramente descrito por Cordel \& Grauch (1985), a técnica visa a detecção de bordas de corpos anômalos aplicada a dados magnéticos e gravimétricos. É descrita em termos de:

$$
T H D R=\sqrt{\left(\frac{\partial B}{\partial x}\right)^{2}+\left(\frac{\partial B}{\partial y}\right)^{2}}
$$

onde $\frac{\partial B}{\partial x} \mathrm{e} \frac{\partial B}{\partial y}$ indicam as derivadas horizontais nas direções x e y, respectivamente.

Este filtro possibilita distinguir mudanças laterais abruptas de densidade/susceptibilidade magnética, representadas pelos maiores gradientes. Ele destaca as altas frequências no sinal, posicionando os picos das anomalias nas bordas dos corpos ou bem próximas a elas, com valores mínimos em sua porção central, porém o sinal é atenuado com o aumento da profundidade (Ferreira et al., 2013). 


\subsubsection{Sinal Analítico (AS)}

O conceito de Sinal Analítico aplicado a anomalias magnéticas foi desenvolvido, em duas dimensões, por Nabighian (1972). Este produto, de forma genérica, centraliza a anomalia de um corpo magnético independentemente da orientação da magnetização do corpo (Isles \& Rankin, 2013), isto é, o Sinal Analítico 2D irá mapear de forma eficaz corpos mesmo localizados em baixas inclinações magnéticas ou na presença de magnetização remanente, pois é independente das características direcionais da magnetização de origem, o que não se estende ao caso 3D (Li, 2006). Para este, a forma e o valor absoluto do Sinal Analítico são também dependentes das direções de magnetização e do valor do campo, além de outros fatores como a profundidade do topo da borda abaixo do nível da observação e de seu mergulho, que determinam o deslocamento sofrido pela anomalia em relação ao centro do corpo. Nos casos 3D mais comuns, as localizações do gradiente total são sempre desfasadas de seus limites reais. Os melhores resultados são obtidos para diques verticais e de espessura relativamente baixa (Li, 2006).

Segundo Roest et al. (1992), a expressão do Sinal analítico deriva dos três gradientes ortogonais do campo magnético total $B$, segundo a equação:

$$
|A S|=\sqrt{\left(\frac{\partial B}{\partial x}\right)^{2}+\left(\frac{\partial B}{\partial y}\right)^{2}+\left(\frac{\partial B}{\partial z}\right)^{2}}
$$

onde $\frac{\partial B}{\partial x}, \frac{\partial B}{\partial y} \mathrm{e} \frac{\partial B}{\partial z}$ são as derivadas de primeira ordem do campo magnético $\mathrm{M}$ nas direções $\mathrm{x}, \mathrm{y}$ e $z$, respectivamente.

\subsubsection{Derivada Tilt (TDR)}

A Derivada Tilt, ou Tilt Angle é representada pelo arco tangente da razão entre a primeira derivada vertical e o Gradiente Horizontal Total (Miller \& Singh, 1994; Verduzco et al., 2004), segundo a equação:

$$
T D R=\tan ^{-1}\left[\frac{\left(\frac{\partial B}{\partial z}\right)}{T H D R}\right]
$$


onde $\frac{\partial B}{\partial z}$ indica a derivada vertical de primeira ordem e THDR, o Gradiente Horizontal Total. Devido à natureza da função arco tangente, todos os valores da Derivada Tilt se restringem à uma variação entre $-\pi / 2$ e $\pi / 2$, independentemente da amplitude da derivada vertical ou do valor absoluto do Gradiente Horizontal Total (Cooper \& Cowan, 2006). Este filtro se assemelha a um filtro de controle de ganho automático (AGC): ambos tendem a igualar a amplitude final das anomalias, ou seja, tanto anomalias rasas como profundas irão manifestar-se de forma semelhante em um perfil ou grid (Verduzco et al., 2004).

\subsection{6. Ângulo Tilt Horizontal (Horizontal Tilt Angle - TDX)}

Esta técnica, introduzida por Cooper \& Cowan (2006), tem a função de detectar as bordas de corpos anômalos e é dada pela normalização do Gradiente Horizontal Total (THDR) pela derivada vertical do campo magnético anômalo ( $\frac{\partial B}{\partial z}$ ), dada por:

$$
T D X=\tan ^{-1}\left(\frac{T H D R}{\left|\frac{\partial B}{\partial z}\right|}\right)
$$

Segundo os autores, este produto é capaz de ressaltar tanto a borda de corpos relacionados a profundidades mais rasas quanto aqueles mais profundos e também delineia fielmente sua geometria. O TDX tem um gradiente muito mais nítido sobre as bordas dos corpos magnetizados.

\subsection{7. Ângulo Tilt do Gradiente Horizontal Total (TAHG)}

O TAHG (Ferreira et al., 2013) é uma técnica de detecção de bordas baseada no realce do THDR de anomalias magnéticas utilizando o TDR. O TAHG é obtido tomando o arco tangente da derivada vertical do THDR dividida pelo módulo do THDR, dada pela equação:

$$
T A H G=\tan ^{-1}\left(\frac{\frac{\partial T H D R}{\partial z}}{\sqrt{\left(\frac{\partial T H D R}{\partial x}\right)^{2}+\left(\frac{\partial T H D R}{\partial y}\right)^{2}}}\right)
$$


Os principais atributos deste método são de fornecer amplitudes máximas nas bordas das fontes e equalizar os sinais provenientes de fontes rasas e profundas. O TAHG produz resultados semelhantes ao método de transformação TDX, mas as anomalias resultantes são ainda menos dependentes da profundidade das fontes e seus valores máximos são posicionadas muito próximas às bordas, mesmo para fontes mais profundas.

\subsubsection{Espectro Radial de Potência}

Introduzido por Spector \& Grant (1970), aplicado a um conjunto de prismas variando em profundidade, comprimento, largura e magnetização, o espectro radial de potência contribui para a criação de um modelo estatístico com base na análise do logaritmo da densidade de energia espectral pelo número de onda. O mapa da intensidade do campo magnético anômalo de uma área consiste da sobreposição de um grande número de anomalias individuais causadas por corpos rochosos distintos com diferentes dimensões e magnetizações, a maioria das quais se sobrepõem. Observando segmentos com inclinações constantes no espectro, é possível identificar amostras estatísticas de fontes magnéticas ou camadas de fontes equivalentes em diferentes profundidades.

No espectro radial de potência, a profundidade média h para cada camada magnética é simplesmente a metade do valor de inclinação de cada reta, ou para números de onda em

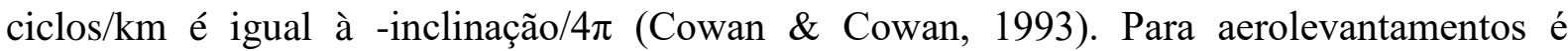
necessário subtrair o valor da altura de voo das respostas de profundidade obtidas. Para este trabalho a altura subtraída corresponde a $150 \mathrm{~m}$.

Para a geração e análise do espectro utilizou-se a rotina de processamento de Phillips (2007), contida no pacote disponibilizado pela USGS como executável do software Oasis Montaj. Os parâmetros de amostragem foram respeitados, segundo o número de Nyquist, definido como a maior frequência espacial a ser analisada de forma que não incorpore possíveis ruídos à análise. Como descrito por Davis (1986), o número de Nyquist é dado por:

$$
f_{n}=\frac{1}{2 \Delta x}
$$

onde $f_{n}$ é a frequência espacial Nyquist e $\Delta x$ é o intervalo de amostragem.

Intervalos de dados que ultrapassam esse valor foram removidos da análise do espectro, pois números de onda maiores que duas vezes a maior distância entre as amostras não podem ser discriminados corretamente no sinal, sendo considerados como ruídos aleatórios. Uma boa 
determinação para cada profundidade irá depender da equação obtida para a regressão linear de cada reta, com coeficiente de determinação $\mathrm{R}^{2}$ sendo o mais próximo possível de 1 .

\subsubsection{Matched Filter}

O Matched Filter é uma técnica de filtragem no domínio de Fourier que utiliza parâmetros do modelo determinados a partir do logaritmo natural do espectro de potência, conforme descrito no item anterior, na concepção dos filtros apropriados para a separação de fontes com padrão magnético distinto, a diferentes profundidades. Estas fontes mostram características lineares no espectro e podem sem separadas apropriadamente com um filtro passa-banda na forma:

$$
\text { Filt }_{j}(|k|)=\frac{B_{j} k^{n_{j}} e^{-|k| z_{j}}}{\sum_{i=1}^{N} B_{i}|k|^{n_{i}} e^{-|k| z_{i}}}
$$

onde $|\mathrm{k}|$ é o número de onda radial $|k|=\sqrt{{k_{x}{ }^{2}+k_{y}{ }^{2}}^{2}}$ para as direções x e y, B é uma constante proporcional à amplitude do sinal contraste de magnetização ou densidade no interior da camada, z é a profundidade da camada e n é o equivalente ao tipo da camada, sendo $n=1$ para uma camada dipolar magnética, $n=0$ para uma camada magnética de semiespaço ou camada de densidade e $n=-1$ para camada semiespaço de densidade. $O$ numerador da equação acima representa o espectro de amplitude da camada \#j e o denominador, o espectro de amplitude modelado de todas as outras camadas equivalentes (Phillips, 2001).

Esta técnica é capaz de separar, de forma semiquantitativa, sinais de fontes a diferentes profundidades, pertencentes a distintos conteúdos rochosos, tais como o pacote sedimentar, embasamento, interface crosta/manto, superfície Curie, limite dúctil-rúptil. Além disso, tem se mostrado ferramenta útil na análise de bacias sedimentares.

\subsubsection{Deconvolução de Euler}

A Deconvolução de Euler, introduzida inicialmente por Thompson (1982) e estendida para o caso 3D por Reid et al. (1990), constitui um método de interpretação que fornece estimativas rápidas de posição e profundidade de determinadas fontes magnéticas e gravimétricas. A equação de Euler 3-D é dada na forma: 


$$
\left(x-x_{0}\right) \frac{\partial T}{\partial x}+\left(y-y_{0}\right) \frac{\partial T}{\partial y}+\left(z-z_{0}\right) \frac{\partial T}{\partial z}=N(B-T)
$$

onde $\left(\mathrm{x}_{0}, \mathrm{y}_{0}, \mathrm{z}_{0}\right)$ é a posição da fonte magnética cujo campo total $\mathrm{T}$ é medido para a posição (x, $\mathrm{y}, \mathrm{z}$ ). O campo total tem um valor regional de B. O grau de homogeneidade $\mathrm{N}$ pode ser interpretado como um índice estrutural (SI) (Tabela 4.4) que caracteriza a geometria da fonte, o qual é a medida da razão da mudança, como a distância, de um campo potencial.

Tabela 4.4. Índices estruturais como sugeridos por Reid et al. (2014).

\begin{tabular}{ccc}
\hline Modelo & SI Magnético & SI gravimétrico \\
\hline Esfera & 3 & 2 \\
Chaminé, cilindro, pipe & 2 & 1 \\
Soleira, dique & 1 & 0 \\
Contato, falha & $0^{\mathrm{a}}$ & $-1^{\mathrm{a}}$ \\
Contato de profundidade infinita & 0 & Sem aplicação $^{\mathrm{b}}$ \\
\hline
\end{tabular}

axige a definição estendida do SI como proposto por Stavrev \& Reid $(2007,2010)$ e um processo de desconvolução não-linear.

${ }^{\mathrm{b}} \mathrm{A}$ anomalia de gravidade é infinita.

Para a aplicação da Deconvolução de Euler foram testadas as técnicas de Deconvolução Padrão e Localizada, ambas disponibilizadas como ferramenta da extensão Euler 3D do software Oasis Montaj v8.5. A Deconvolução Padrão de Euler move uma janela quadrada de tamanho fixo (previamente estabelecido) pelo grid e calcula as soluções para a Equação de Euler (4.10) com base no índice estrutural escolhido para cada janela. Existem tipicamente muitas soluções, desta forma uma solução é gravada se a incerteza da profundidade calculada é menor do que uma tolerância especificada pelo intérprete e se a solução está dentro de uma distância de limitação do centro da janela de dados (Geosoft, 2010).

Diferentemente do método utilizado pela Deconvolução Padrão, onde todas as localizações dos grids são testadas e somente aquelas localizações com soluções válidas que passam pelo critério de entrada são retidas, gerando inúmeras soluções, o método da Deconvolução Localizada de Euler se inicia pela geração do grid do Sinal Analítico, encontrando picos no Sinal Analítico e estimando um tamanho de janela usando as localizações dos pontos de inflexão adjacentes. O algoritmo de detecção de picos no Sinal Analítico é feito com base na técnica desenvolvida por Blakely \& Simpson (1986). Esta técnica olha para cada célula do grid a ser considerada e compara seu valor com os valores de oito células mais próximas em quatro direções (ao longo da linha, coluna, e ambas as diagonais). A definição do que constitui um pico pode ser controlada através do "Nível de detecção de picos" (índice de Blakely). É possível aumentar ou diminuir o número de alvos escolhidos apenas aumentando 
ou diminuindo o índice de Blakely. São quatro índices, a depender do número de direções a serem analisadas. Após a marcação dos picos, estas localizações são utilizadas para a Deconvolução de Euler Localizada.

Observando os critérios estabelecidos por Reid et al. (2014), a técnica da Deconvolução Padrão foi a que apresentou melhor resposta para a região de estudo. Foram feitos vários testes com diferentes janelas e índices estruturais. Os parâmetros escolhidos foram aqueles que melhor eliminaram soluções que se encontravam lateralmente longe da janela, fora da área de curvatura positiva no Sinal Analítico, de baixa confiabilidade (a partir das estatísticas das soluções) ou muito distantes de uma nuvem de soluções.

Para os dados gravimétricos a Deconvolução foi aplicada ao mapa da Anomalia Bouguer, utilizando índice estrutural igual a 1 e janela 10x10. Para os dados magnéticos, foi aplicada ao mapa do campo magnético anômalo com índice estrutural de 0,1 e 2 e janela 10x10.

\subsubsection{Modelagem direta 2D de dados gravimétricos}

Devido à complexidade geológica e estrutural da área de estudo, além dos fatores relacionados ao campo magnético como a forte remanência constatada e a localização em baixas latitudes, optou-se por realizar a modelagem apenas do sinal gravimétrico das linhas obtidas em campo, sendo reaproveitados alguns pontos dos dados gravimétricos fornecidos de estudos anteriores para completar o alcance lateral das linhas.

Para a construção do modelo, utilizou-se o programa GM-SYS Profile, dentro da plataforma Oasis Montaj v8.5. O modelo bidimensional adotado propõe variações geológicas em profundidade (componente $\mathrm{Z}$ ) e na direção de aquisição da linha (componente $\mathrm{X}$ ), não sofrendo mudanças na direção Y. Estas superfícies presumivelmente se estendem ao infinito nesta direção. A modelagem gravimétrica direta envolve a criação de um modelo geológico hipotético, ajustando-o à anomalia gravimétrica correspondente. $\mathrm{O}$ objetivo é construir um modelo geológico bidimensional, com base na intuição geofísica e geológica da área de estudo, utilizando-se de informações prévias acerca da região, de forma a obter um modelo o mais próximo possível da realidade (Blakely, 1995). Deve-se comparar a anomalia calculada à observada, de acordo com o ajuste dos parâmetros do modelo, tais como densidade, magnetização e profundidade das fontes, a fim de aproximar ao máximo a curva das duas anomalias, até que o ajuste final seja satisfatório. 


\section{Capítulo 5}

\section{RESULTADOS E INTERPRETAÇÕES GEOFÍSICAS}

A interpretação dos resultados obtidos pelos métodos magnético e gravimétrico foi feita com base nos mapas do campo magnético anômalo e da anomalia Bouguer, respectivamente. A partir desses mapas, foram gerados os demais produtos para a análise. Todos os produtos utilizados na interpretação foram incorporados em um banco de dados no software ArcGIS v.10.2 de forma a facilitar a integração entre os métodos e a interpretação conjunta dos dados.

As etapas de interpretação e integração dos produtos referentes aos dados magnéticos e gravimétricos envolveram principalmente a análise qualitativa, incluindo a observação dos traçados dos lineamentos em diferentes profundidades (figuras 5.10 a 5.15), a localização das soluções de Euler (figuras 5.16 a 5.18), a análise da distribuição espacial das anomalias de forma conjunta a todos os grids, e sua correlação com o arcabouço estrutural do rifte e regiões adjacentes. Com essas informações foi produzido um mapa do arranjo magnético-estrutural interpretado (Figura 5.20), correlacionando à geologia conhecida da área de estudo. Adicionado à essas informações e utilizando as respostas de profundidade encontradas com esses produtos foi produzido um modelo geológico estrutural 2D (Figura 5.23) de dados gravimétricos transpassando a região do rifte.

\subsection{MATCHED FILTER}

\subsubsection{Espectro radial de potência dos dados magnéticos e gravimétricos}

Com o intuito de se obter valores de profundidades no que diz respeito a fontes com assinaturas distintas, em diferentes níveis crustais, foi realizado o espectro radial de potência nos dados aeromagnéticos e de gravimetria terrestre. O número de Nyquist utilizado na análise magnética compreende um valor de $1 \mathrm{~km}^{-1}$, utilizando a equação (4.7) onde $\Delta x$ corresponde ao maior espaçamento entre as amostras. Da mesma forma, para os dados gravimétricos esse valor corresponde a $0,16 \mathrm{~km}^{-1}$, representado pelo tamanho da célula unitária do grid. A análise do espectro de potência aplicado aos dados do campo magnético anômalo para a área deste estudo 
indicou quatro níveis de profundidade (Figura 5.1) em: 21,8 km; 6,6 km; 1,6 km e 0,5 km. As bandas do espectro correspondentes a cada segmento de reta, representando o topo de fontes a uma profundidade específica, são apresentadas na Tabela 5.1.

Tabela 5.1. Características da resposta do espectro radial de potência aplicado aos dados magnéticos para cada profundidade associada.

\begin{tabular}{ccc}
\hline PROFUNDIDADES $(\mathbf{k m})$ & $\begin{array}{c}\text { COMPRIMENTO DE ONDA } \\
\text { MÍNIMO }(\mathbf{k m})\end{array}$ & $\begin{array}{c}\text { COMPRIMENTO DE ONDA } \\
\text { MÁXIMO }(\mathbf{k m})\end{array}$ \\
\hline $\mathbf{0 , 5}$ & 1,00 & 5,20 \\
$\mathbf{1 , 6}$ & 5,20 & 30,12 \\
$\mathbf{6 , 6}$ & 30,12 & 70,42 \\
$\mathbf{2 1 , 8}$ & 70,42 & $\infty$ \\
\hline
\end{tabular}

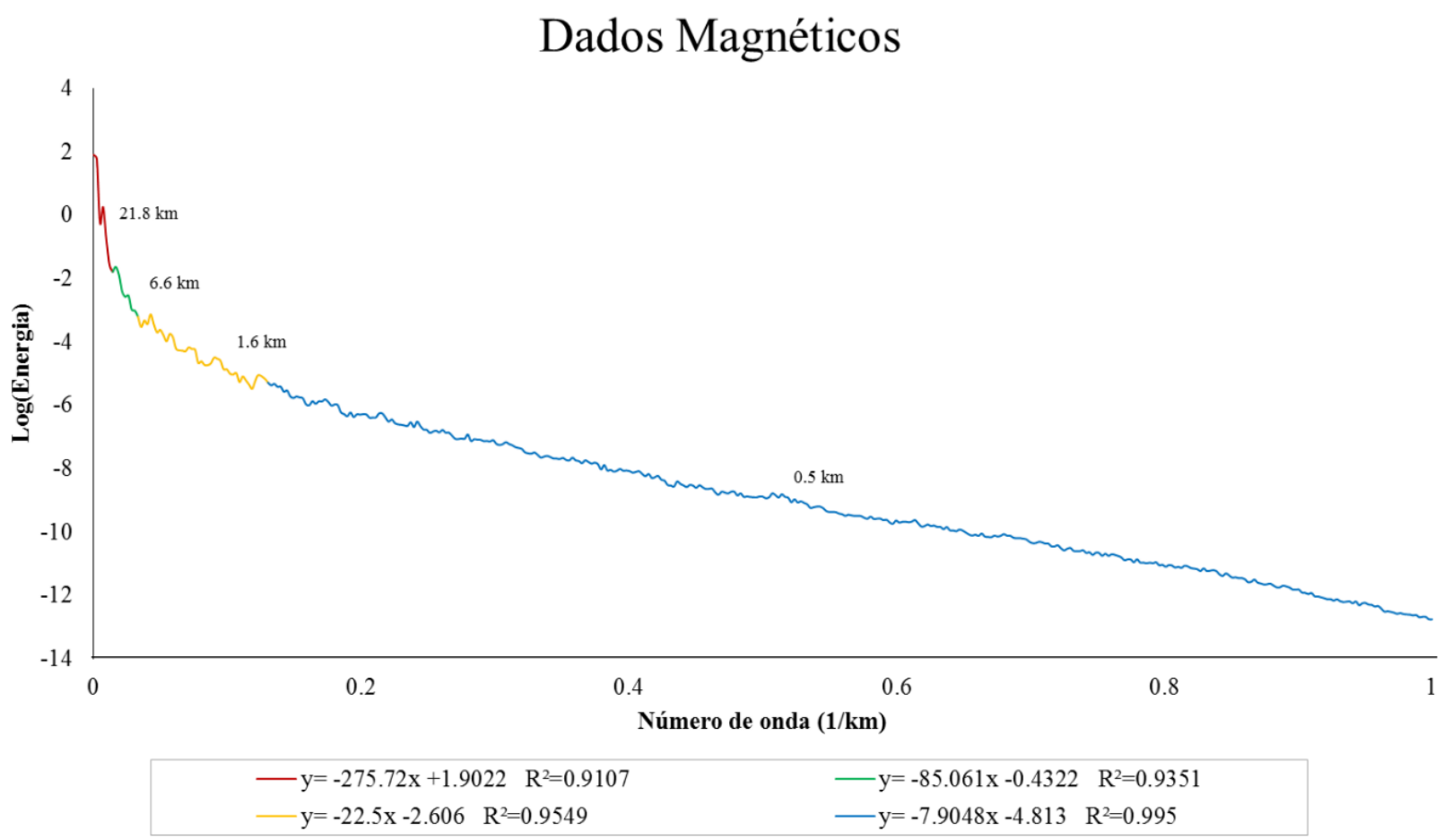

Figura 5.1. Espectro radial de potência obtido a partir do mapa do campo magnético anômalo, onde cada segmento assinalado com cor diferente representa uma profundidade de topo de fontes distinta. A equação de cada reta ajustada é amostrada, onde $\mathrm{R}^{\mathbf{2}}$ indica o melhor ajuste para cada reta.

A análise do espectro de potência aplicado ao mapa de anomalias Bouguer para a área de estudo também indicou quatro níveis de profundidades (Figura 5.2) em: 37 km; 12,5 km; 6 km e 1,8 km. A detecção de interface em $37 \mathrm{~km}$ revela caráter profundo detectável apenas na análise gravimétrica, visto que, de maneira geral, em profundidades maiores que $30 \mathrm{~km}$ as 
rochas perdem suas propriedades magnéticas (Blum \& Pires, 1996). As bandas do espectro correspondentes a cada segmento de reta são apresentadas na Tabela 5.2.

Tabela 5.2. Características da resposta do espectro radial de potência aplicado aos dados gravimétricos para cada profundidade associada.

\begin{tabular}{ccc}
\hline PROFUNDIDADES $(\mathbf{k m})$ & $\begin{array}{c}\text { COMPRIMENTO DE ONDA } \\
\text { MÍNIMO }(\mathbf{k m})\end{array}$ & $\begin{array}{c}\text { COMPRIMENTO DE ONDA } \\
\text { MÁXIMO }(\mathbf{k m})\end{array}$ \\
\hline $\mathbf{1 , 8}$ & 6,06 & 9,00 \\
$\mathbf{6}$ & 9,00 & 15,57 \\
$\mathbf{1 2 , 5}$ & 15,57 & 57,80 \\
$\mathbf{3 7}$ & 57,80 & $\infty$ \\
\hline
\end{tabular}

\section{Dados Gravimétricos}

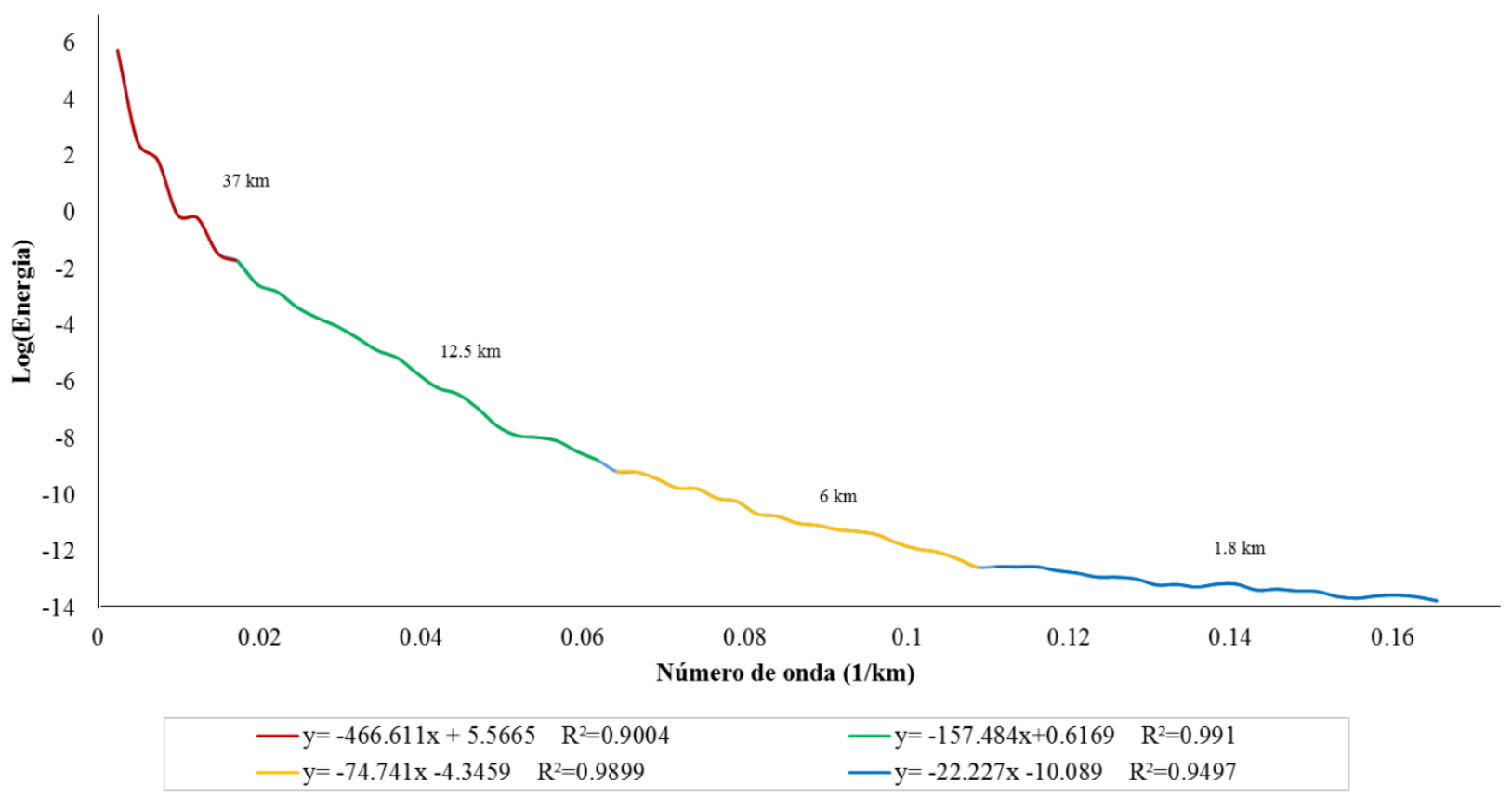

Figura 5.2. Espectro radial de potência obtido a partir do mapa do campo magnético anômalo, onde cada segmento assinalado com cor diferente representa uma profundidade de topo de fontes distinta. A equação de cada reta ajustada é amostrada, onde $\mathrm{R}^{2}$ indica o melhor ajuste para cada reta.

A realização do espectro de potência para toda a área de estudo incorpora diferentes comprimentos de ondas sobrepostos, pertencente a anomalias com significado geológico distinto. É válido ressaltar que cada uma dessas janelas de profundidade destaca uma gama de fontes magnéticas, mas espera-se que a profundidade dominante esteja próxima da 
profundidade nominal calculada a partir do espectro. Fontes muito mais rasas ou profundas em relação a esta profundidade nominal serão mal representadas naquele intervalo.

A partir da separação de $n$ componentes do espectro radial de potência, representando diferentes profundidades, por meio da observação da inclinação de múltiplas retas ajustadas ao espectro (Figura 5.1), a técnica do Matched Filter aprimorada por Phillips (2001) foi utilizada para evidenciar, no mapa de anomalias magnéticas, diferentes níveis de profundidade na área de estudo, reconhecendo cerca de quatro profundidades em bandas com diferentes comprimentos de onda. $\mathrm{O}$ ajuste das retas das profundidades em comparação ao espectro se encontra descrito na Figura 5.3a e as respostas encontradas para a análise do Matched Filter dos dados é evidenciada na Figura 5.4.
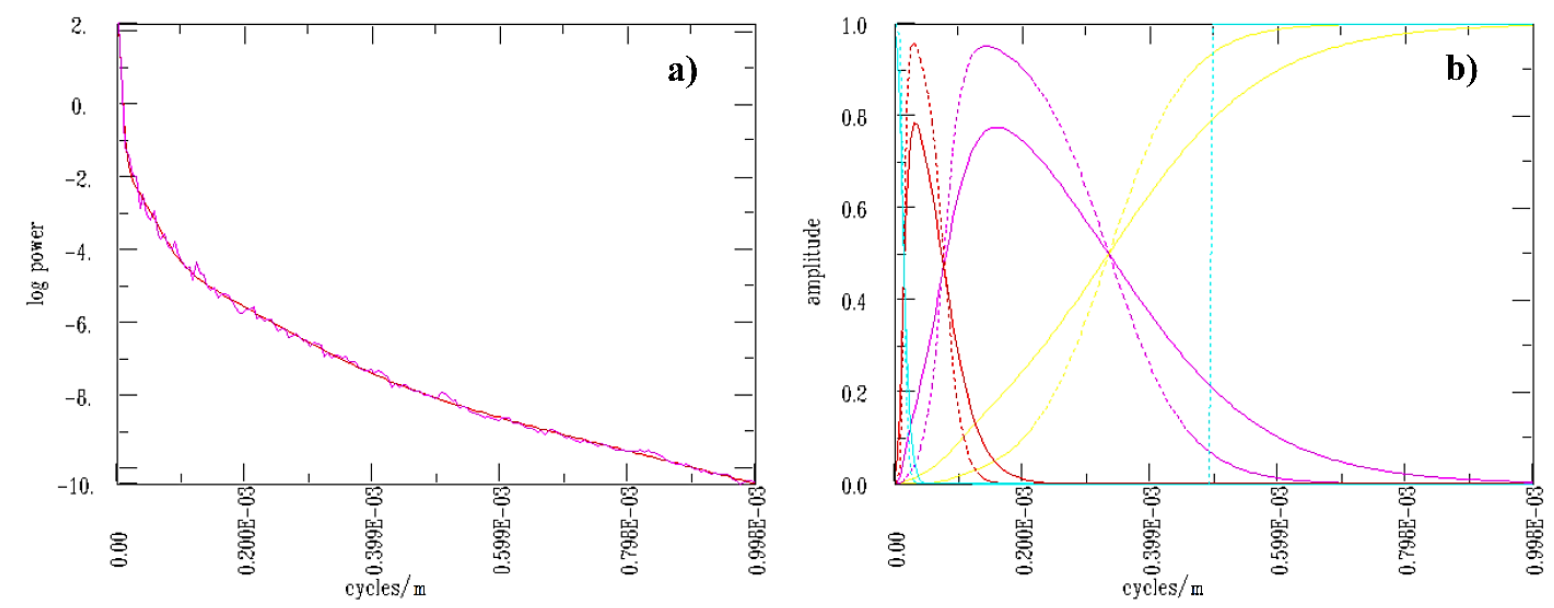

Figura 5.3. (a) Ajuste das retas ao espectro de potência pelo Matched Filter, onde a linha mais suave representa o sinal ajustado à linha menos suave, que corresponde ao logaritmo da energia pela frequência espacial. (b) Filtros utilizados para a separação das bandas relacionadas às diferentes profundidades encontradas no espectro. 

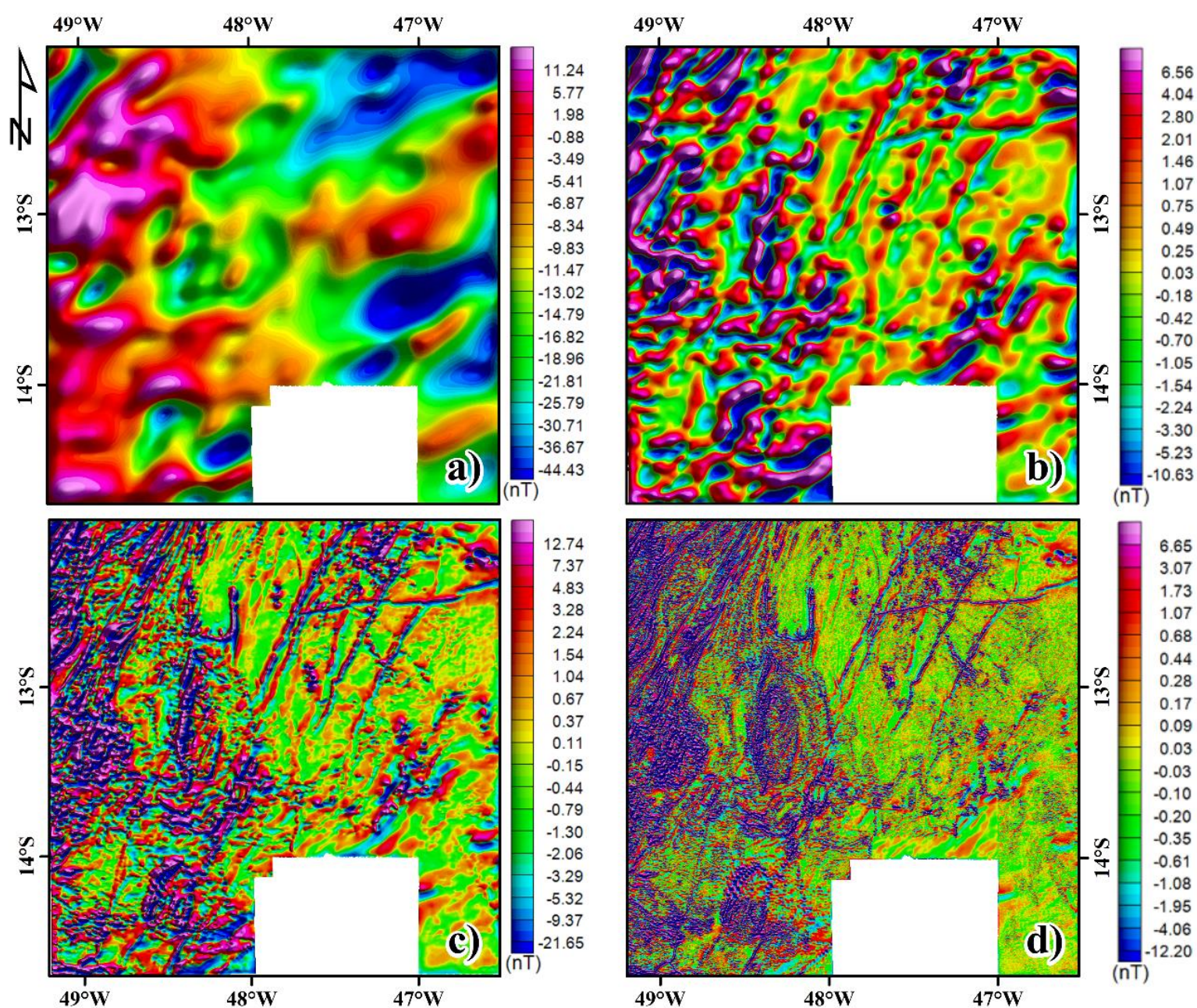

$\mathrm{km}$

Figura 5.4. Resultados do Matched Filter aplicado ao mapa do campo magnético anômalo, onde os mapas com diferentes bandas de frequência retomam a profundidade de fontes com topo em (a) 21,8 km; (b) 6,6 km; (c) 1,6 $\mathrm{km}$ e (d) $0,5 \mathrm{~km}$.

\subsubsection{Matched Filter aplicado a sub-áreas}

Devido à diversidade geológica e tectônica na área de estudo e a fim de refinar as respostas de profundidade, foi realizada a análise do espectro radial de potência a partir da geração de malhas individualizadas pela técnica do Matched Filter aplicada a sub-áreas de mesmo tamanho, parcialmente sobrepostas, em porções do mapa que abrangem o Grupo Araí (Figura 5.5), de forma a minimizar a interferência de sinal magnético proveniente de outras fontes, tais quais as associadas às falhas Rio Maranhão, Rio dos Bois e a região de influência do Lineamento Transbrasiliano, que possuem assinaturas magnéticas marcantes, capazes de interferir no sinal relacionado às fontes magnéticas da bacia-rifte. A análise envolveu as 
seguintes etapas: (i) delimitação e escolha das sub-áreas em regiões que englobam todo o Grupo Araí a fim de observar o comportamento das fontes magnéticas provenientes da região da bacia; (ii) cálculo individual do espectro radial de potência de cada sub-área do grid do campo magnético anômalo pelo pacote do Matched Filter (Phillips, 2001); (iii) ajuste de retas na curva do espectro, representando camadas de fontes magnéticas distintas com topo a diferentes profundidades, onde as camadas mais rasas são limitadas em profundidade (camada magnética dipolar) e a camada mais profunda é modelada como semi-espaço (halfspace); (iv) repetição do procedimento a fim de diminuir os erros sistemáticos observacionais (4 vezes em cada subárea) e (iv) junção de todos os resultados de profundidades observados (Tabela 5.3), separando as famílias de fontes em um histograma e gráfico de profundidades gerados a partir dos resultados (figuras 5.6a e 5.7). É importante ressaltar que a altura de voo foi subtraída de todos os resultados, que no grid já continuado para cima, corresponde a $150 \mathrm{~m}$.

Os valores de profundidades estimados pelo Matched Filter para as sub-áreas investigadas foram analisados estatisticamente por meio do histograma de densidades, apresentado na Figura 5.6a, e por meio do gráfico de profundidades observado na Figura 5.7. Foram observadas populações de profundidade mais significativa, com conjuntos de valores mais comuns, e uma minoria sem ocorrência significativa, que não se ajusta a qualquer população. Para a estimativa de populações estatísticas de profundidade associadas a uma mesma reta foi realizado o cálculo da média ponderada das profundidades observando apenas as populações significativas, desconsiderando para o cálculo os valores aleatórios. As médias ponderadas foram separadas em três profundidades, de acordo com a marcação do mesmo número de retas no espectro de cada sub-área. As profundidades magnéticas encontradas são de $0,36 \mathrm{~km} ; 1,85 \mathrm{~km}$ e $7,53 \mathrm{~km}$. 


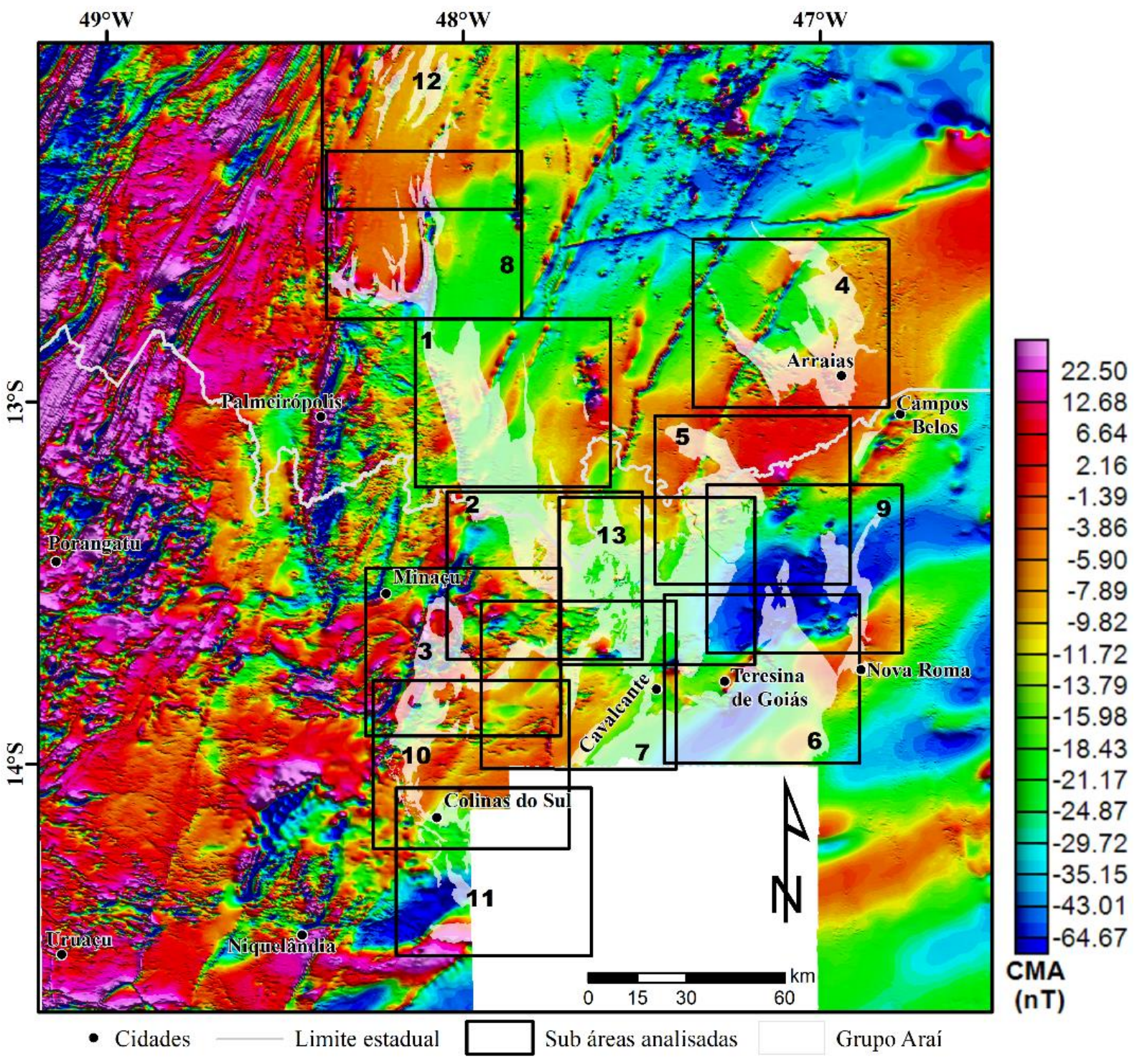

Figura 5.5. Localização das sub áreas analisadas com a técnica do Matched Filter, sobrepostas ao mapa do campo magnético anômalo. As sub-áreas representam um total de 13 e foram numeradas aleatoriamente de acordo com o recorte do grid e ajuste aos limites do Grupo Araí a fim de obter um recobrimento total do mesmo. 
Tabela 5.3. Resultados das profundidades observadas para cada sub-área.

\begin{tabular}{|c|c|c|c|c|c|c|c|c|c|c|c|c|}
\hline \multirow{2}{*}{ Sub-área } & \multicolumn{4}{|c|}{ Profundo (m) } & \multicolumn{4}{|c|}{ Intermediário (m) } & \multicolumn{4}{|c|}{ Raso (m) } \\
\hline & $\mathbf{1}^{\mathrm{a}}$ & $2^{\mathrm{a}}$ & $3^{a}$ & $4^{a}$ & $\mathbf{1}^{\mathbf{a}}$ & $2^{\mathbf{a}}$ & $3^{\mathbf{a}}$ & $4^{a}$ & $\mathbf{1}^{\mathbf{a}}$ & $2^{\mathbf{a}}$ & $3^{a}$ & $4^{a}$ \\
\hline 1 & 8347 & 5884 & 6288 & 9582 & 2087 & 1555 & 1729 & 1793 & 376 & 351 & 369 & 373 \\
\hline 2 & 8601 & 7193 & 7839 & 6670 & 1361 & 1628 & 1623 & 1579 & 285 & 318 & 308 & 311 \\
\hline 3 & 5266 & 4180 & 5495 & 6601 & 1586 & 1543 & 1664 & 1711 & 346 & 353 & 357 & 354 \\
\hline 4 & 7405 & 7098 & 6388 & 8013 & 1476 & 1231 & 1318 & 1521 & 357 & 358 & 356 & 360 \\
\hline 5 & 9837 & 9808 & 10057 & 9602 & 1944 & 1870 & 1901 & 1838 & 353 & 336 & 337 & 332 \\
\hline 6 & 8816 & 10293 & 10147 & 9882 & 1820 & 2173 & 2274 & 2078 & 383 & 387 & 400 & 390 \\
\hline 7 & 5273 & 6877 & 6729 & 6776 & 1596 & 1707 & 1786 & 1932 & 359 & 339 & 343 & 346 \\
\hline 8 & 9447 & 10068 & 9714 & 9425 & 2631 & 2563 & 2701 & 2536 & 401 & 400 & 402 & 401 \\
\hline 9 & 9102 & 8600 & 8681 & 9477 & 2168 & 1887 & 1941 & 2144 & 388 & 375 & 377 & 379 \\
\hline 10 & 4399 & 4323 & 5401 & 4882 & 1540 & 1575 & 1848 & 1851 & 364 & 387 & 436 & 418 \\
\hline 11 & 5559 & 5424 & 6187 & 4602 & 1668 & 1497 & 2031 & 957 & 438 & 408 & 522 & 340 \\
\hline 12 & 8231 & 6677 & 9672 & 6011 & 1886 & 2021 & 2043 & 1985 & 407 & 407 & 410 & 408 \\
\hline \multirow[t]{2}{*}{13} & 7353 & 7854 & 6436 & 7877 & 2141 & 2622 & 1694 & 2262 & 401 & 399 & 370 & 374 \\
\hline & \multicolumn{2}{|c|}{$\begin{array}{c}\text { Amplitude }= \\
6113\end{array}$} & \multicolumn{2}{|c|}{$\begin{array}{c}\text { Desvio Padrão }= \\
1813\end{array}$} & \multicolumn{2}{|c|}{$\begin{array}{c}\text { Amplitude = } \\
1744\end{array}$} & \multicolumn{2}{|c|}{$\begin{array}{c}\text { Desvio Padrão }= \\
361\end{array}$} & \multicolumn{2}{|c|}{$\begin{array}{c}\text { Amplitude }= \\
237\end{array}$} & \multicolumn{2}{|c|}{$\begin{array}{c}\text { Desvio Padrão }= \\
38\end{array}$} \\
\hline
\end{tabular}



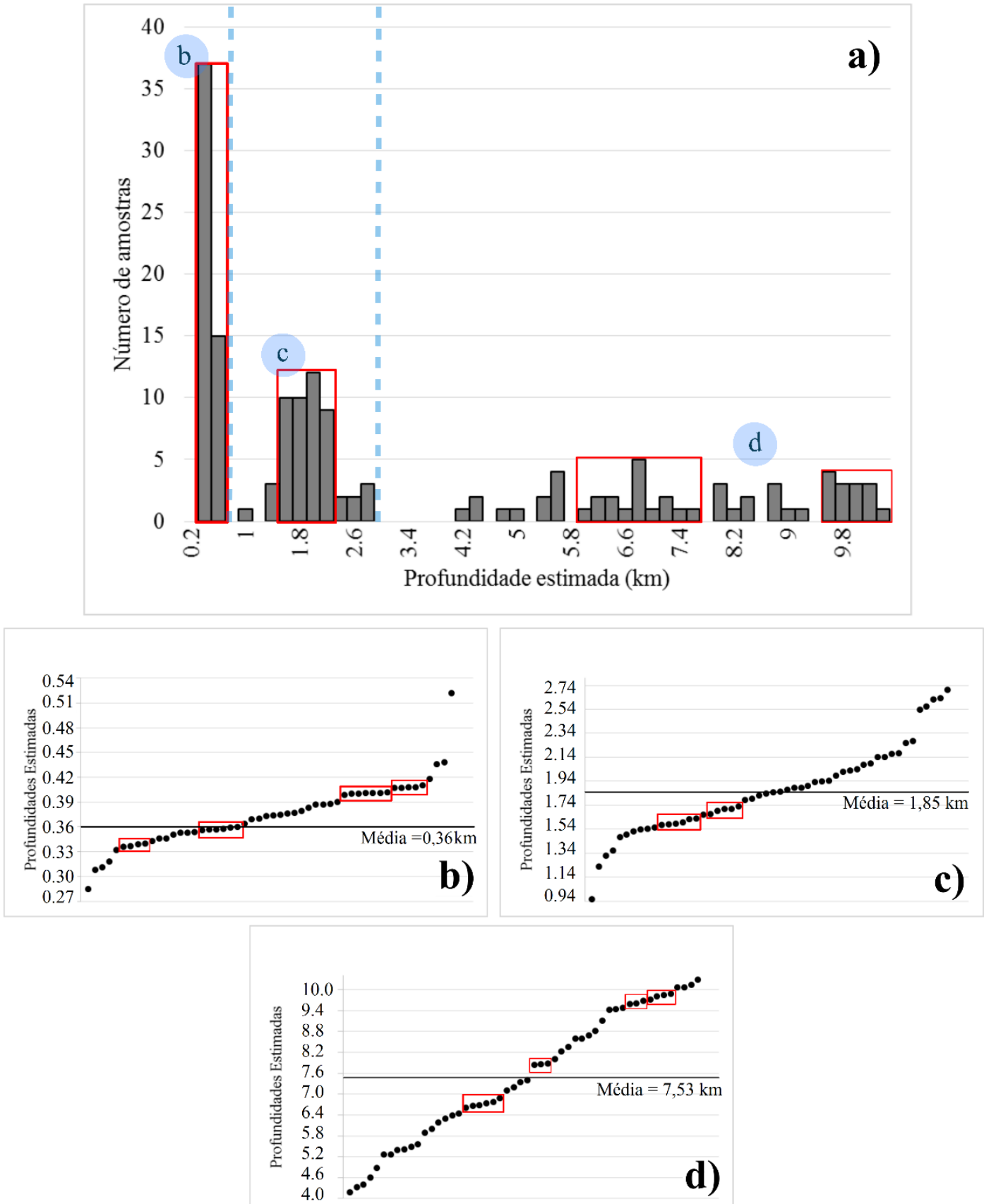

Figura 5.6. (a) Histograma de densidades em que os retângulos vermelhos indicam as populações principais. As linhas pontilhadas indicam os limites dos intervalos de dados de cada profundidade respectiva aos gráficos de (b) a (d), correspondentes à média ponderada de cada população. Os retângulos apontam patamares na distribuição dos dados, indicando maior importância para esses intervalos de valores.

Os valores encontrados para as profundidades rasa e intermediária foram bem ajustados, visto que o coeficiente de variação dessas populações foi inferior a 0,2 nos dois casos (respectivamente 0,1 e 0,19). Esse coeficiente é dado pela razão entre o desvio padrão e a média. Quanto maior o valor do coeficiente de variação, maior é a dispersão dos valores do conjunto e quanto menor o valor do coeficiente de variação, mais homogêneo é o conjunto. Assim, valores 
inferiores a 0,2 indicam uma amostra homogênea enquanto que, para valores maiores que 0,2 trata-se de amostra heterogênea. A população de fontes mais profunda apresenta coeficiente de variação igual a 0,24 .

Com isso, é evidente que o nível mais profundo apresenta valores de profundidades bastante variáveis, podendo estar associados a fontes distintas. Devido a isto, não é possível considerar apenas uma única profundidade em 7,53 $\mathrm{km}$ (Figura 5.7), visto que essa profundidade representaria uma média grosseira entre diferentes padrões geológicos, não possuindo sentido geológico interpretável. Dado que essa família de valores das fontes mais profundas foi retirada da reta com maior inclinação no espectro de cada sub-área, duas hipóteses são formuladas a partir desses resultados: i) presença de apenas uma fonte magnética associada à maior profundidade no sinal do espectro para uma sub-área individualizada e de uma outra fonte magnética distinta associada à maior profundidade para outra sub-área de forma que, ao analisar conjuntamente tanto o histograma quanto o gráfico de profundidades, é possível observar essa dispersão dos valores, que pode estar variando devido a presença de fontes profundas isoladas em diferentes sub-áreas; ou ii) presença de mais de uma fonte profunda no sinal do espectro de uma sub-área individualizada onde, na marcação das retas, estas foram interpretadas apenas como uma inclinação, pois a região do espectro com a maior inclinação é a parte mais minuciosa na marcação das retas e pode ocorrer que duas profundidades sejam interpretadas como apenas uma, gerando um valor de profundidade intermediário entre estas duas.

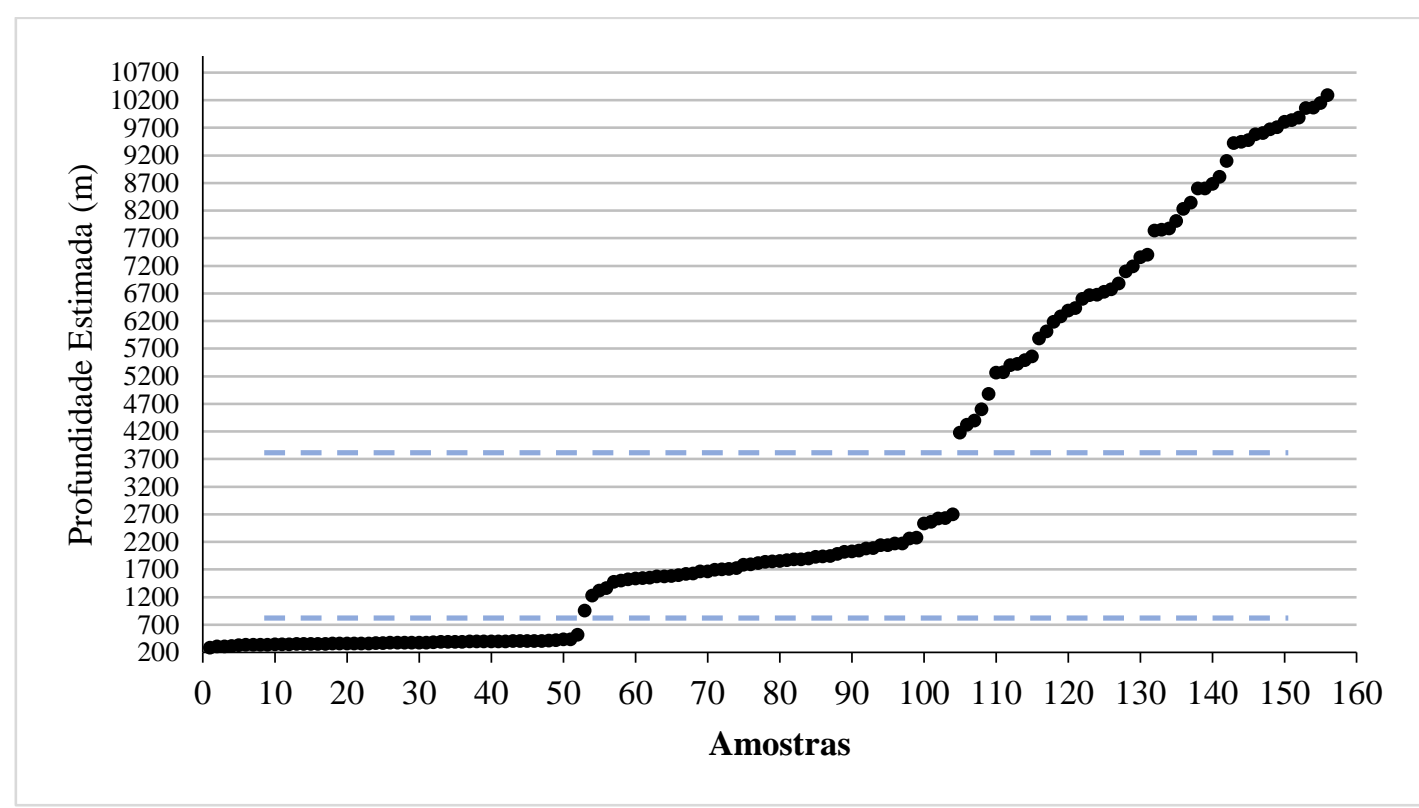

Figura 5.7. Níveis de profundidade detectados utilizando o Matched Filter. Note que o nível mais profundo possui valores bastante dispersos variando entre $4200 \mathrm{~m}$ e $10300 \mathrm{~m}$. 
A fim de resolver a ambiguidade em relação às fontes mais profundas foi realizada média aritmética simples para o segmento de reta mais profundo, desta vez tomada para cada sub-área e seus respectivos desvios padrão, de forma a analisar um valor único correspondente a cada bloco (Tabela 5.4). Para isto foi necessário assumir a hipótese que a reta no espectro de cada subárea está associada apenas a um padrão geológico. Os resultados são apresentados na Figura 5.8.

Tabela 5.4. Associação entre as profundidades de cada bloco, em cada tentativa, e suas médias.

\begin{tabular}{ccccccc}
\hline Sub-área & $\mathbf{1}^{\mathbf{a}}$ & $\mathbf{2}^{\mathbf{a}}$ & $\mathbf{3}^{\mathbf{a}}$ & $\mathbf{4}^{\mathbf{a}}$ & Média $(\mathbf{m})$ & Desvio Padrão \\
\hline $\mathbf{1}$ & 8347 & 5884 & 6288 & 9582 & 7525.25 & 1510.79 \\
$\mathbf{2}$ & 8601 & 7193 & 7839 & 6670 & 7575.75 & 722.38 \\
$\mathbf{3}$ & 5266 & 4180 & 5495 & 6601 & 5385.50 & 859.79 \\
$\mathbf{4}$ & 7405 & 7098 & 6388 & 8013 & 7226.00 & 585.24 \\
$\mathbf{5}$ & 9837 & 9808 & 10057 & 9602 & 9826.00 & 161.23 \\
$\mathbf{6}$ & 8816 & 10293 & 10147 & 9882 & 9784.50 & 578.25 \\
$\mathbf{7}$ & 5273 & 6877 & 6729 & 6776 & 6413.75 & 660.78 \\
$\mathbf{8}$ & 9447 & 10068 & 9714 & 9425 & 9663.50 & 259.77 \\
$\mathbf{9}$ & 9102 & 8600 & 8681 & 9477 & 8965.00 & 351.71 \\
$\mathbf{1 0}$ & 4399 & 4323 & 5401 & 4882 & 4751.25 & 432.07 \\
$\mathbf{1 1}$ & 5559 & 5424 & 6187 & 4602 & 5443.00 & 564.50 \\
$\mathbf{1 2}$ & 8231 & 6677 & 9672 & 6011 & 7647.75 & 1419.42 \\
$\mathbf{1 3}$ & 7353 & 7854 & 6436 & 7877 & 7380.00 & 583.85 \\
\hline
\end{tabular}

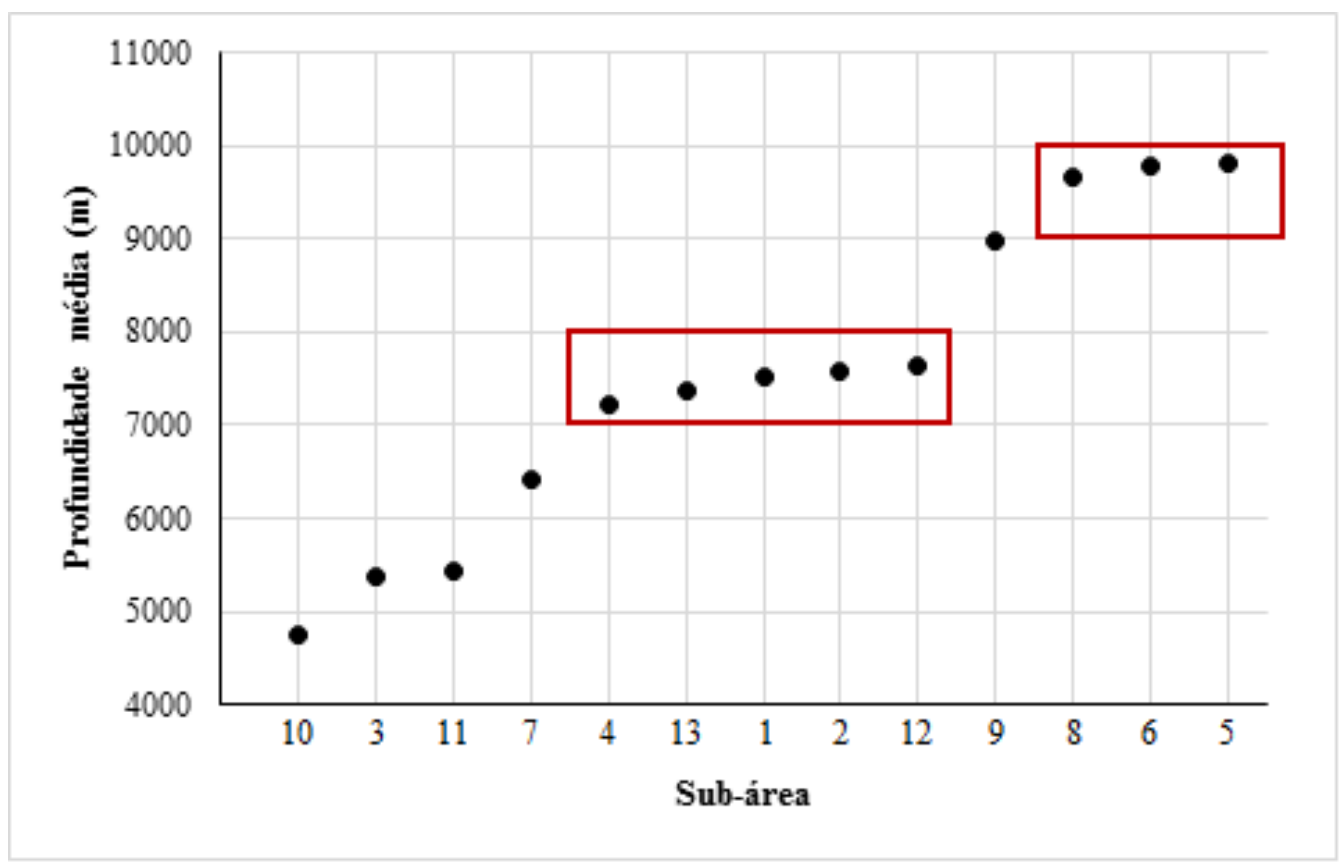

Figura 5.8. Profundidades médias associadas aos níveis mais profundos para cada sub-área. 
Feita a média aritmética para os valores de cada bloco, plotada em um gráfico de profundidades, é perceptível a presença de dois patamares de profundidades bem definidos, entre 7 e $8 \mathrm{~km}$ e outro entre 9 e $10 \mathrm{~km}$. Com isso, ficam estabelecidas quatro profundidades bem definidas para a região que engloba o Grupo Araí em: (i) $0,36 \mathrm{~km}$; (ii) $1,85 \mathrm{~km}$; (iii) 7,4 km e (iv) 9,7 km.

\subsection{LINEAMENTOS}

Unidades de rochas magnéticas, seus limites e descontinuidades, assim como a direção preferencial dos trends geológicos podem ser observados e delimitados a partir do traçado de lineamentos magnéticos nos mapas do campo magnético e seus produtos. Os minerais magnéticos são concentrados principalmente ao longo ou alinhados com algumas estruturas e/ou feições sedimentares, tais como falhas ou limites geológicos. Para o Grupo Araí, o traçado dos lineamentos é crucial para a identificação das principais estruturas magnéticas da região e sua correlação com o arcabouço estrutural do rifte. Na elaboração de mapa de interpretação estrutural com base nos lineamentos magnéticos foram escolhidos os produtos que mais revelassem as estruturas em diferentes níveis crustais.

A partir dos resultados obtidos com o traçado dos lineamentos, observou-se que a direção preferencial das estruturas magnéticas da área de estudo é de N40E, relacionada à maior concentração de feições a noroeste do mapa - pertencentes aos altos do embasamento que expõe parte do complexo Rio dos Mangues, e o coloca ao lado das rochas do Arco Magmático de Goiás, por influência do Lineamento Transbrasiliano. Devido a isto, a análise dos lineamentos se processou em duas etapas: uma regional envolvendo toda a área de estudo, com evidência das respostas magnéticas ao Transbrasiliano, e uma local envolvendo apenas a Zona Externa na qual o Grupo Araí está inserido.

Os produtos utilizados para o traçado dos lineamentos e interpretação do arcabouço estrutural compreendem a derivada vertical de primeira ordem (DZ), a derivada Tilt (TDR), além do ângulo Tilt horizontal (TDX) - Figura 5.9, gerados a partir do mapa do campo magnético anômalo. $\mathrm{O}$ traçado dos lineamentos correspondentes a esses produtos encontra-se nas figuras $5.10,5.11$ e 5.12 .

Os lineamentos também foram analisados para diferentes profundidades de fontes magnéticas anômalas a partir das bandas de profundidade obtidas no Matched Filter englobando toda a região de estudo (Figura 5.4), aplicando a seus mapas a derivada vertical de primeira ordem (DZ) e a derivada Tilt do Gradiente Horizontal Total (TAHG), a fim de observar 
seu comportamento e continuidade em diferentes níveis de profundidade. O TAHG foi aplicado somente aos níveis mais profundos devido a densidade de lineamentos para os níveis mais rasos ser alta, com um grau de detalhe exacerbado para os interesses deste estudo. A escolha da aplicação do TAHG aos níveis mais profundos se deu pelo fato de esse produto realçar feições lineares profundas sem prejudicar a resolução de amplitude das mesmas, além de proporcionar detalhes mais amplos sobre fontes sobrepostas. Com isso, feições que muitas vezes não aparecem em outros produtos são evidenciadas pelo TAHG. As figuras 5.13, 5.14 e 5.15 mostram os resultados desses produtos aplicados ao Matched Filter. 

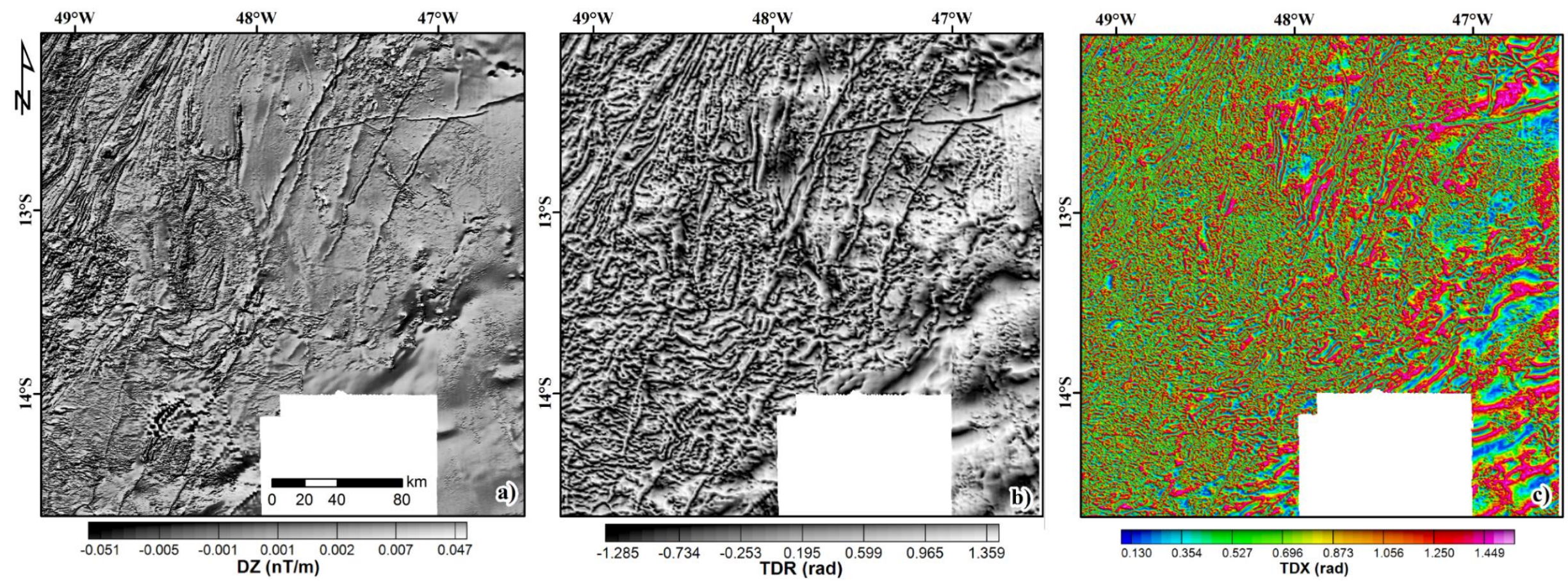

Figura 5.9. Mapas utilizados para o traçado dos lineamentos da área de estudo: (a) Derivada Vertical, (b) Derivada Tilt e (c) Ângulo Tilt Horizontal. 


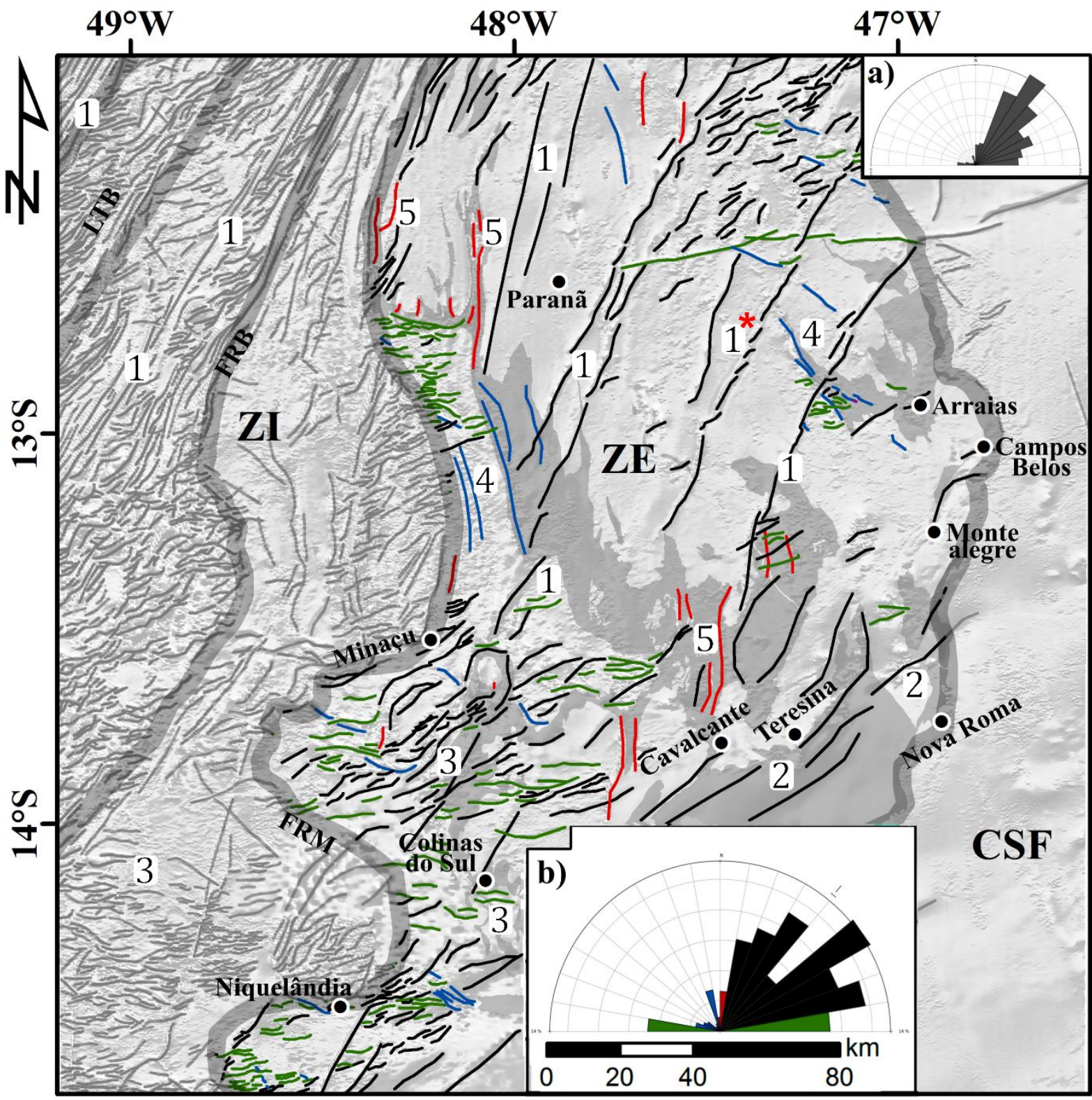

Grupo Araí $\longrightarrow$ N S N W N E Limites Tectônicos

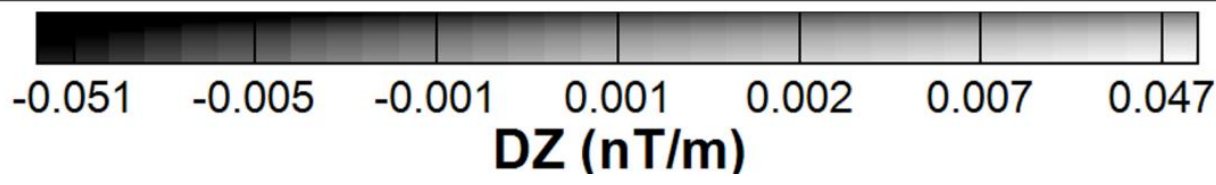

Figura 5.10. Estruturas magnéticas interpretadas a partir do mapa da Primeira Derivada Vertical (DZ) do campo magnético anômalo e diagrama de rosetas correspondente a: (a) lineamentos totais extraídos da área de estudo e (b) lineamentos extraídos da parte da Zona Externa da Faixa Brasília que abrange a presente área. Os lineamentos em cinza são aqueles que se localizam fora da ZE e sua direção preferencial se encontra somada aos lineamentos da ZE na roseta indicada em (a), que representa os lineamentos totais. Os lineamentos assinalados em (1) a (5) encontram-se comentados no texto subsequente. ZI: Zona Interna; ZE: Zona Externa; CSF: Cráton São Francisco. 

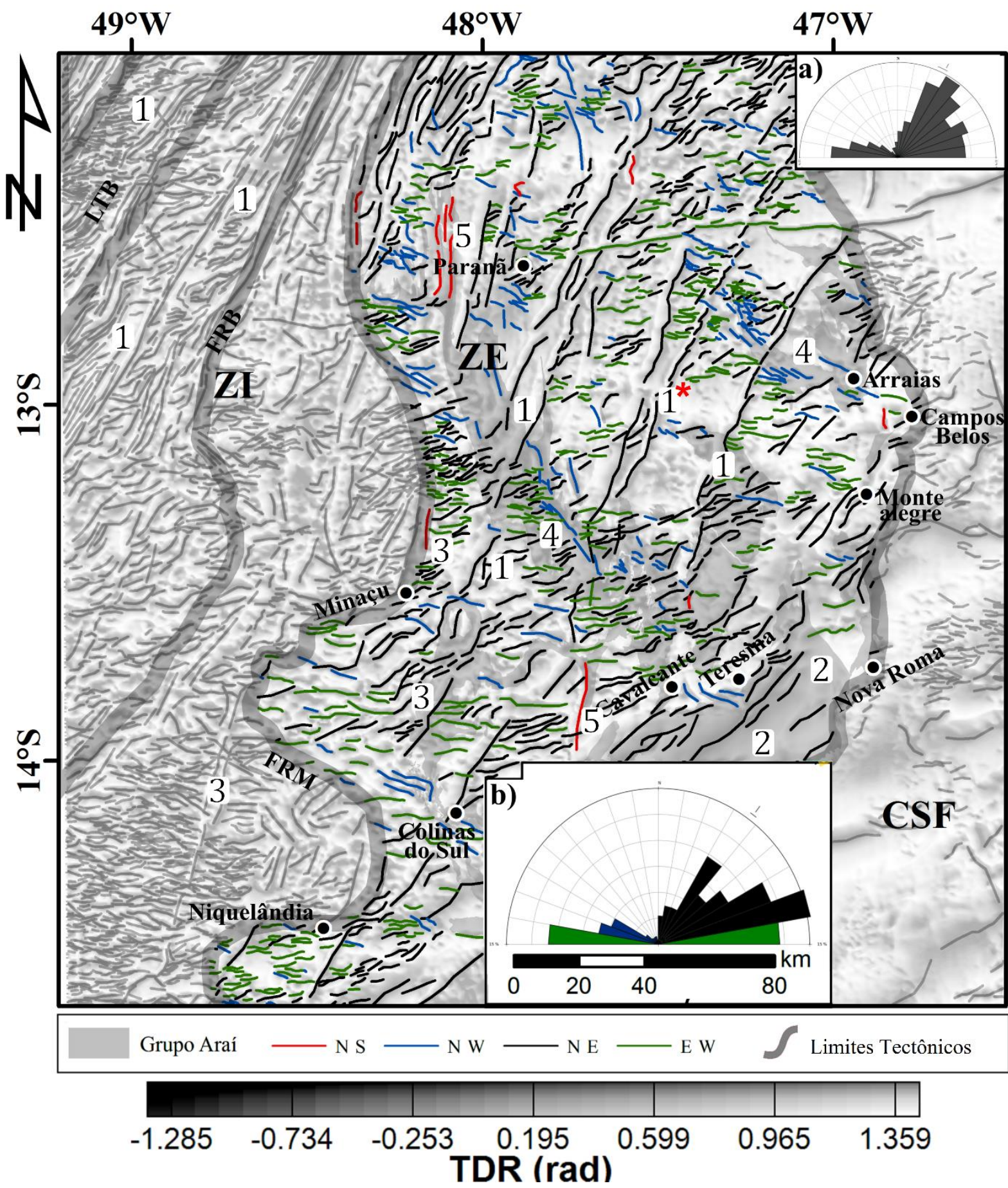

Figura 5.11. Estruturas magnéticas interpretadas a partir do mapa da Derivada Tilt (TDR) do campo magnético anômalo e diagrama de rosetas correspondente a: (a) lineamentos totais extraídos da área de estudo e (b) lineamentos extraídos da parte da Zona Externa da Faixa Brasília que abrange a presente área. Os lineamentos em cinza são aqueles que se localizam fora da ZE e sua direção preferencial se encontra somada aos lineamentos da ZE na roseta indicada em (a), que representa os lineamentos totais. Os lineamentos assinalados em (1) a (5) encontram-se comentados no texto subsequente. ZI: Zona Interna; ZE: Zona Externa; CSF: Cráton São Francisco. 

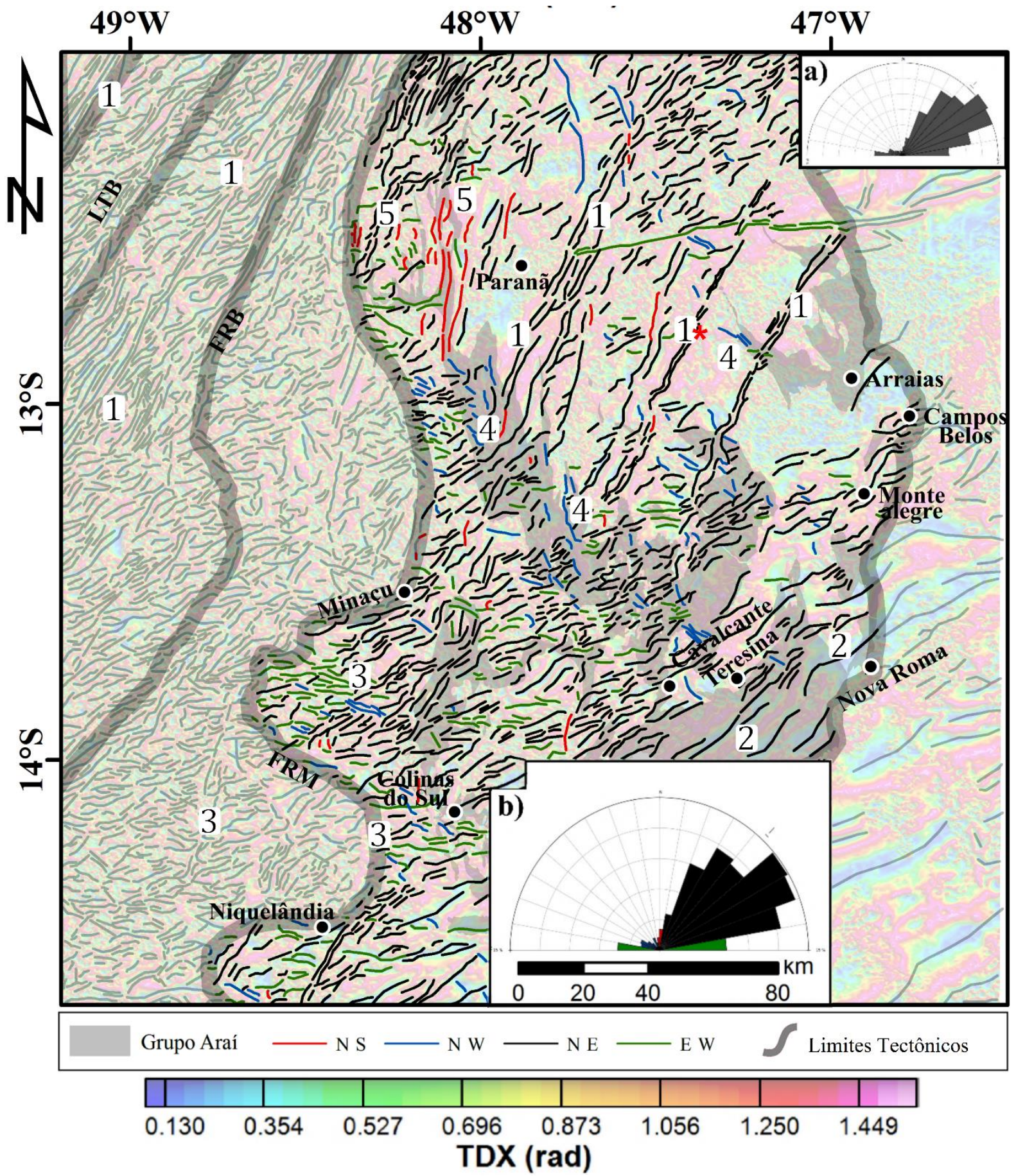

Figura 5.12. Estruturas magnéticas interpretadas a partir do mapa do Ângulo Tilt Horizontal (TDX) do campo magnético anômalo e diagrama de rosetas correspondente a: (a) lineamentos totais extraídos da área de estudo e (b) lineamentos extraídos da parte da Zona Externa da Faixa Brasília que abrange a presente área. Os lineamentos em cinza são aqueles que se localizam fora da ZE e sua direção preferencial se encontra somada aos lineamentos da ZE na roseta indicada em (a), que representa os lineamentos totais. Os lineamentos assinalados em (1) a (5) encontram-se comentados no texto subsequente. ZI: Zona Interna; ZE: Zona Externa; CSF: Cráton São Francisco. 


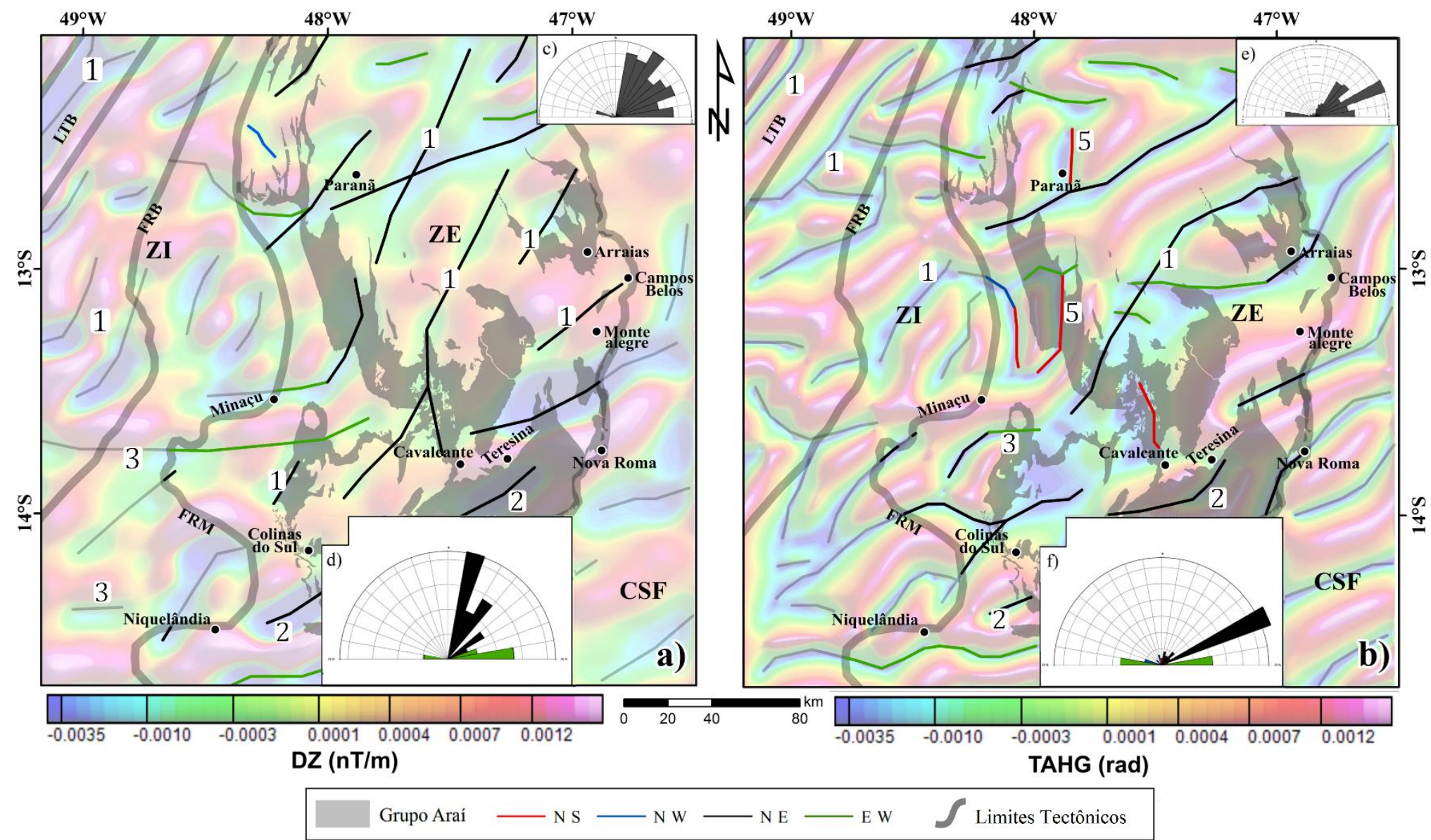

Figura 5.13. Principais estruturas magnéticas interpretadas a partir dos mapas (a) da Derivada Vertical (DZ) e (b) Derivada Tilt do Gradiente Horizontal Total (TAHG) do campo magnético anômalo, ambos correspondentes a profundidade de 21,8 km, e diagrama de rosetas correspondente a: (c) e (e) lineamentos totais extraídos da área de estudo; (d) e (f) lineamentos extraídos da parte da Zona Externa da Faixa Brasília que abrange a presente área. Os lineamentos em cinza são aqueles que se localizam fora da ZE e sua direção preferencial se encontra somada aos lineamentos da ZE na roseta indicada em (c) e (e), que representam os lineamentos totais. Os lineamentos assinalados em (1) a (5) encontram-se comentados no texto subsequente. ZI: Zona Interna; ZE: Zona Externa; CSF: Cráton São Francisco. 


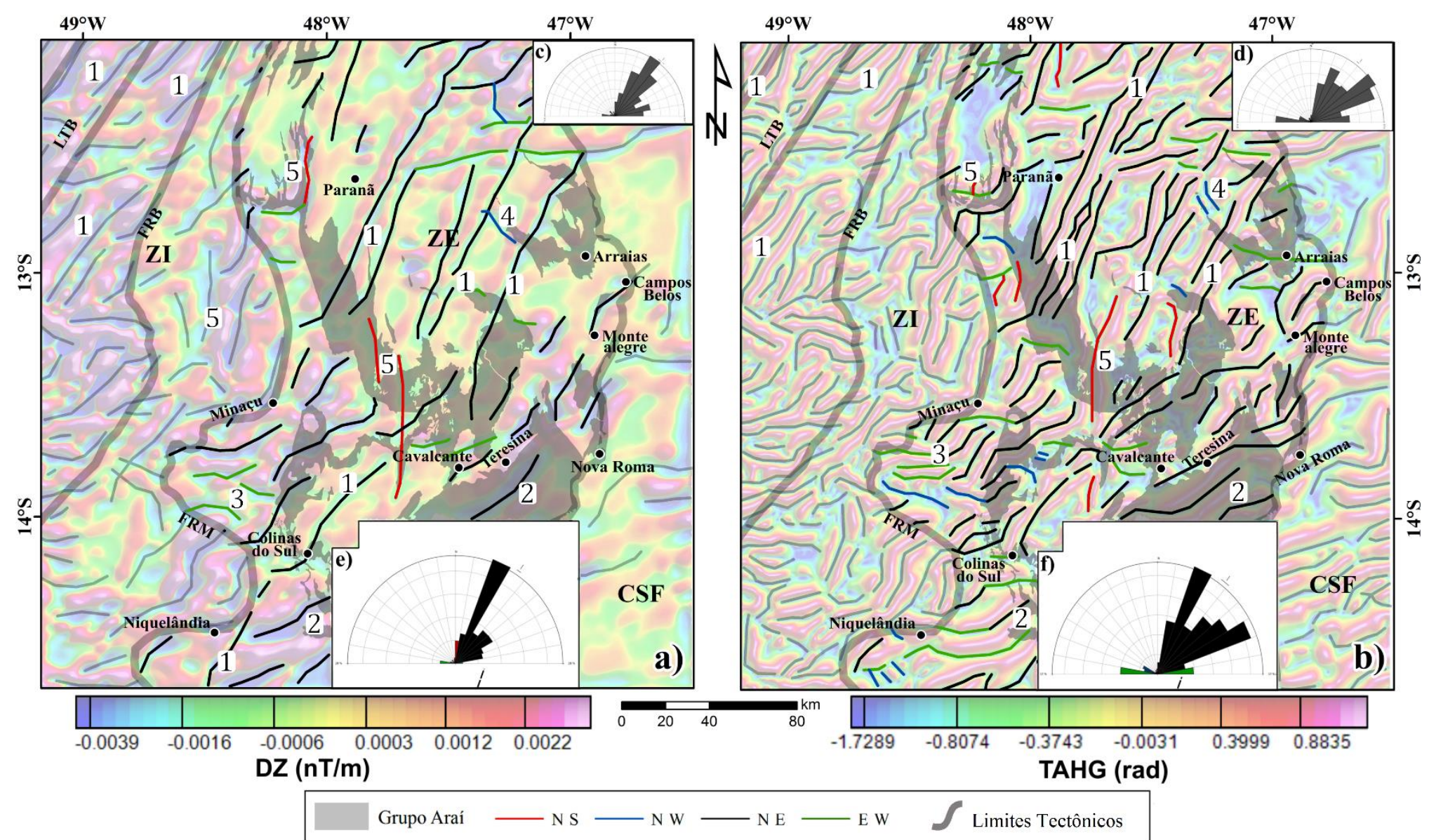

Figura 5.14. Estruturas magnéticas interpretadas a partir dos mapas (a) da Derivada Vertical (DZ) e (b) Derivada Tilt do Gradiente Horizontal Total (TAHG) do campo magnético anômalo, ambos correspondentes a profundidade de 6,6 km, e diagrama de rosetas correspondente a: (c) e (e) lineamentos totais extraídos da área de estudo; (d) e (f) lineamentos extraídos da parte da Zona Externa da Faixa Brasília que abrange a presente área. Os lineamentos em cinza são aqueles que se localizam fora da ZE e sua direção preferencial se encontra somada aos lineamentos da ZE na roseta indicada em (c) e (e), que representam os lineamentos totais. Os lineamentos assinalados em (1) a (5) encontramse comentados no texto subsequente. ZI: Zona Interna; ZE: Zona Externa; CSF: Cráton São Francisco. 


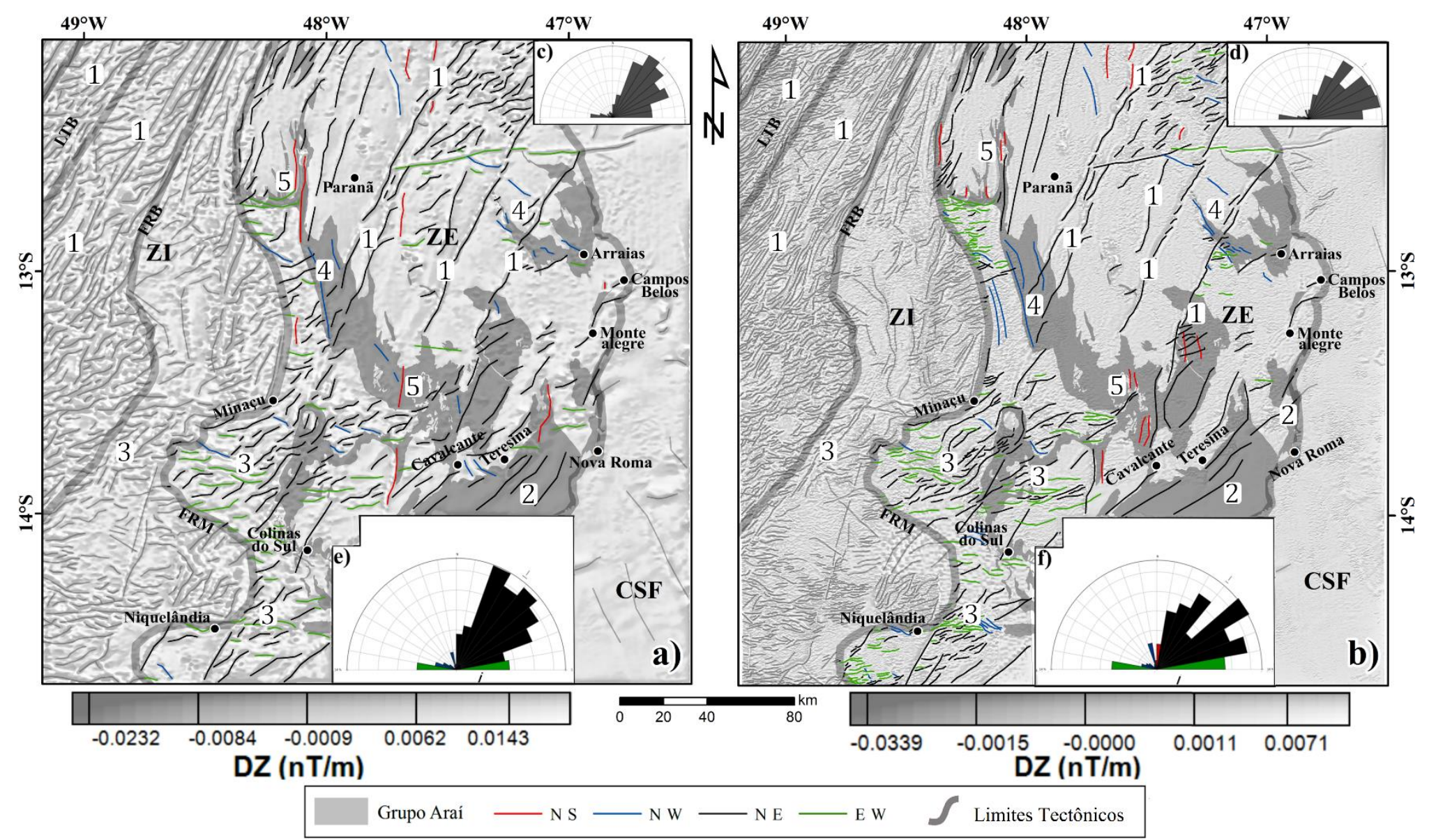

Figura 5.15. Estruturas magnéticas interpretadas a partir dos mapas (a) e (b) da Derivada Vertical (DZ) do campo magnético anômalo, correspondentes às profundidades de 1,6 km e $0,5 \mathrm{~km}$ respectivamente, e diagrama de rosetas correspondente a: (c) e (e) lineamentos totais extraídos da área de estudo; (d) e (f) lineamentos extraídos da parte da Zona Externa da Faixa Brasília que abrange a presente área. Os lineamentos em cinza são aqueles que se localizam fora da ZE e sua direção preferencial se encontra somada aos lineamentos da ZE na roseta indicada em (c) e (e), que representam os lineamentos totais. Os lineamentos assinalados em (1) a (5) encontram-se comentados no texto subsequente. ZI: Zona Interna; ZE: Zona Externa; CSF: Cráton São Francisco. 
Dentre os principais resultados verificados com o traçado dos lineamentos e anomalias magnéticas destacam-se:

(i) O sinal magnético tem um padrão diferente em relação à densidade de lineamentos observados na porção que abrange o Terreno Almas-Cavalcante, que apresenta comportamentos distintos referentes às diferentes compartimentações do embasamento. $\mathrm{Na}$ parte norte do Araí, o embasamento apresenta uma quantidade quase inexistente de lineamentos de $3^{\mathrm{a}}$ ordem (caracterizados por estruturas rasas de pequena extensão), o que não ocorre nas outras porções, que apresentam maior densidade de lineamentos, porém também distintas (padrão este observável principalmente no mapa do Ângulo Tilt Horizontal - Figura 5.12). Essa característica no sinal magnético deve estabelecer um comportamento composicional/reológico diferente entre os blocos do embasamento expostos na região.

(ii) Sobre o Cráton São Francisco o relevo magnético e o padrão dos lineamentos também é diferente em relação à zona de influência do Transbrasiliano, o qual possui assinatura magnética na direção N60-90E). A Zona Interna apresenta relevo magnético com maior frequência e lineamentos observáveis em todas as profundidades. A Zona Externa apresenta anomalias de maior comprimento de onda (Figura 4.7) e quantidade menor de lineamentos marcando estruturas rasas (figuras 5.10, 5.11 e 5.12). Essas anomalias provavelmente resultam de estruturas profundas como o embasamento e/ou relevo na superfície Curie.

(iii) Ainda em relação ao padrão das anomalias da ZE, é observável um dipolo linear de grande extensão que vai desde as proximidades da cidade de Niquelândia, em direção NE, até Campos Belos. Essa anomalia pode estar associada ao sinal magnético relacionado às principais falhas do rifte. A assinatura magnética contrastante dessa porção em relação à litologia adjacente pode ocorrer pela variação na susceptibilidade magnética e remanência devido a alterações de tamanho do grão durante a recristalização, por exemplo, em zonas miloníticas (Isles \& Rankin, 2013).

Sobre as direções preferenciais dos lineamentos:

(iv) Estruturação NE: principal trend estrutural da área, caracterizada por lineamentos de grande continuidade, podendo chegar a uma extensão de até $200 \mathrm{~km}$. É evidenciada nas Zonas Interna e Externa em seu embasamento rochoso e, em menor quantidade, na cobertura sedimentar. Essas megaestruturas possuem direção preferencial N25E, N30E e 
N40E (marcadas por número 1 nas figuras 5.10 a 5.15). Na Zona Interna possuem relação direta com o Lineamento Transbrasiliano e suas reativações (N30-40E). Na Zona Externa são associadas, em sua maioria, a fases de deformação do Brasiliano, cortando toda esta zona (direção N25-30E), responsáveis pelo controle regional de heterogeneidades crustais, como a compartimentação entre o embasamento e as unidades metassedimentares, associados à falhamentos e/ou zonas de cisalhamento bem marcadas. Parte desses lineamentos não se encontram mapeados em superfície, porém um desses lineamentos magnéticos indicado em $1^{*}$ (figuras $5.10,5.11$ e 5.12) a nordeste é relacionado, em mapeamento geológico, a uma falha/zona de cisalhamento transcorrente dextral. São estruturas profundas, observadas em todas as camadas do Matched Filter até a profundidade de $21,8 \mathrm{~km}$, além de lineamentos $\mathrm{NE}$ secundários de curta extensão relacionados a estruturas rasas. Além dessas importantes estruturas, outras de grande relevância para a região são evidenciadas na Zona Externa, na Formação Arraias. Possuem direção preferencial N50-70E (marcadas por número 2 nas figuras 5.10 a 5.15) e têm relação com os sistemas São Jorge-Alto Paraíso-Cormari e Cavalcante-Teresina (sistemas de falhas transcorrentes dextrais, conforme descrito por Fonseca et al., 1995 e Fonseca, 1996).

(v) Estruturação ENE: caracterizada por um grande número de lineamentos de extensão curta a intermediária em relação aos anteriores, com maior concentração na região dos grupos Serra da Mesa e Paranoá e comprimento variando entre 5 a 20 quilômetros, de direção preferencial N60-90E (marcados por número 3 nas figuras 5.10 a 5.15). Nas adjacências do Granito Serra da Mesa (pertencente à suíte de granitos da Subprovíncia Tocantins, localizado logo abaixo do complexo máfico-ultramáfico de Canabrava - Figura 2.3) essas estruturas podem estar correlacionadas à cinemática do Sistema Rio Maranhão e sua interação com o Granito Serra da Mesa, interação esta detalhada por Fonseca (1996). Essa direção se expressa na forma de lineamentos de segunda e terceira ordem, referentes a eventos finais da descompressão das tensões orogênicas. Essa cinemática, observada próxima à cidade de Minaçu, é compatível com uma colisão frontal de encurtamento na direção EW e estruturas transcorrentes tardias acomodando a deformação. São ressaltados principalmente na Derivada Tilt e no Ângulo Tilt Horizontal, mostrando-se evidentes no diagrama de rosetas desses produtos. Nas diferentes camadas do Matched Filter preservase essa tendência direcional, observada principalmente no TAHG. Na DZ mais profunda 
(21,8 km) é possível observar, ainda, lineamento profundo que coincide com a direção de encurtamento máxima, orientada oeste-leste (Fonseca, 1996).

(vi) Estruturação NW: menos expressiva na região, seus lineamentos possuem extensão curta a intermediária de até $40 \mathrm{~km}$, e se encontram espalhados ao longo de toda a área de estudo, inclusive nas coberturas sedimentares. São, por vezes, perpendiculares aos lineamentos NE e possuem direção preferencial N30-80W (marcados por número 4 nas figuras 5.10 a 5.15). Parte desses lineamentos evidenciam o contato do Araí com o Paranoá e parte está diretamente relacionada ao Sistema Arraias-Campos Belos (reverso, oblíquo - Fonseca, 1996). São estruturas com representatividade rasa.

(vii) Estruturação NS: Esse lineamentos possuem direção preferencial NS-N15E (marcados por número 5 nas figuras 5.10 a 5.15). São pouco significativos e se encontram dispostos principalmente no contato entre o braço do Araí com a falha Rio Maranhão, podendo se extender para norte. Fonseca (1996) descreve lineamentos morfoestruturais no embasamento próximos à cidade Paranã com forte estruturação norte-sul reconhecidos como foliações que truncam estruturas mais antigas, com indicação de movimentação frontal. Essa tendência é observada desde Paranã até o Grupo Serra da Mesa no contato com a Rio Maranhão.

\subsection{DECONVOLUÇÃO DE EULER}

Para reforçar a interpretação geológica das estruturas que controlaram a formação do rifte e sua posterior deformação, foi utilizado o resultado fornecido pela Deconvolução de Euler para dados do campo magnético anômalo e da Anomalia Bouguer, verificando sua distribuição e continuidade. Nesse procedimento empregou-se uma janela quadrada de $10 \mathrm{~km}$ de lado para ambos os dados, com índice estrutural 1 para os dados de gravimetria e índices 0,1 e 2 para os dados magnéticos. Os resultados para a deconvolução dos dados gravimétricos e magnéticos encontram-se, respectivamente, nas figuras 5.16 e 5.17 . 


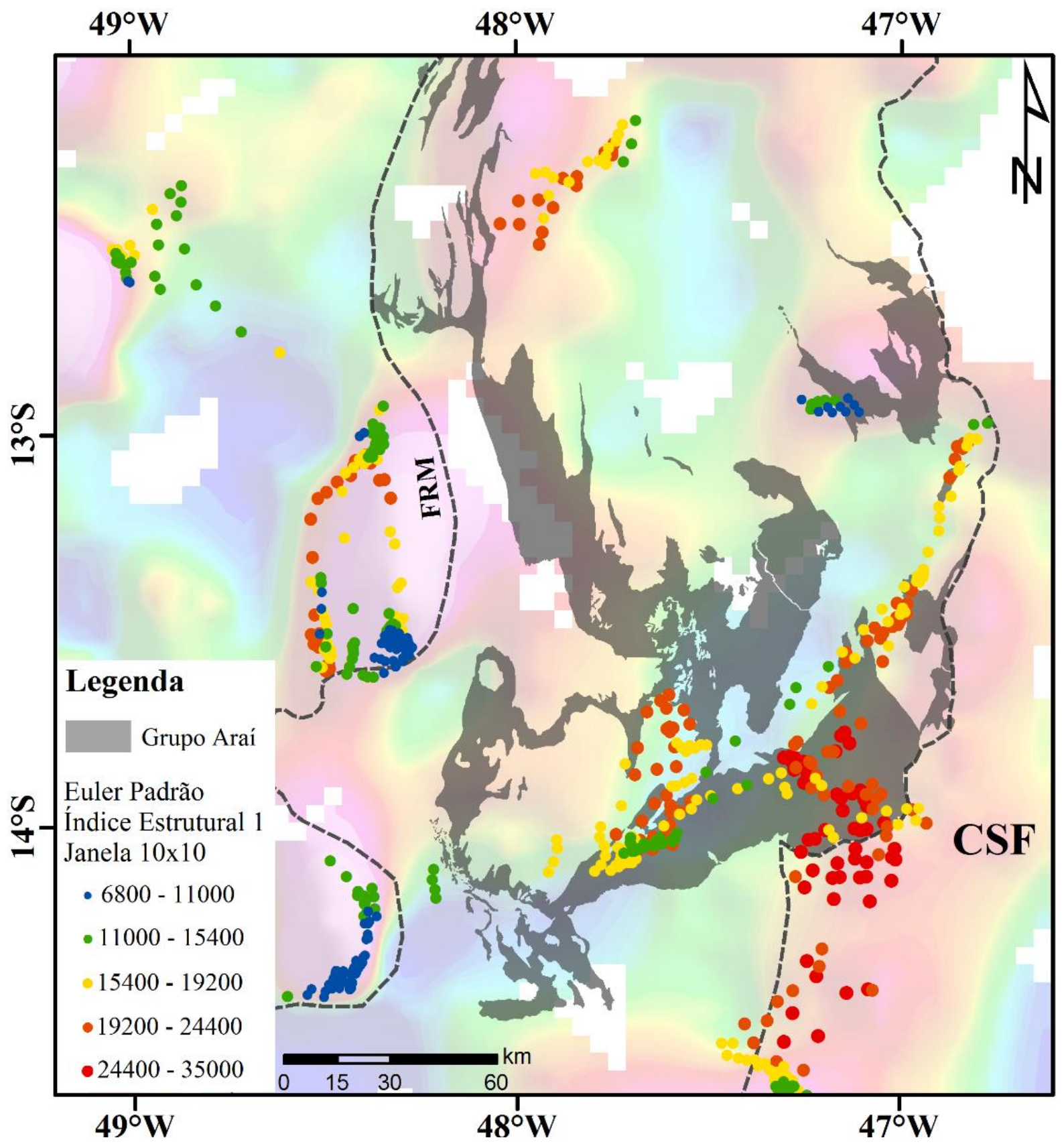

Figura 5.16. Soluções de Euler utilizando o método Padrão para o mapa da Anomalia Bouguer com remoção de tendência regional de ordem 2 (ao fundo), sobrepondo o respectivo sinal. FRM: Falha Rio Maranhão; CSF: Cráton São Francisco. 

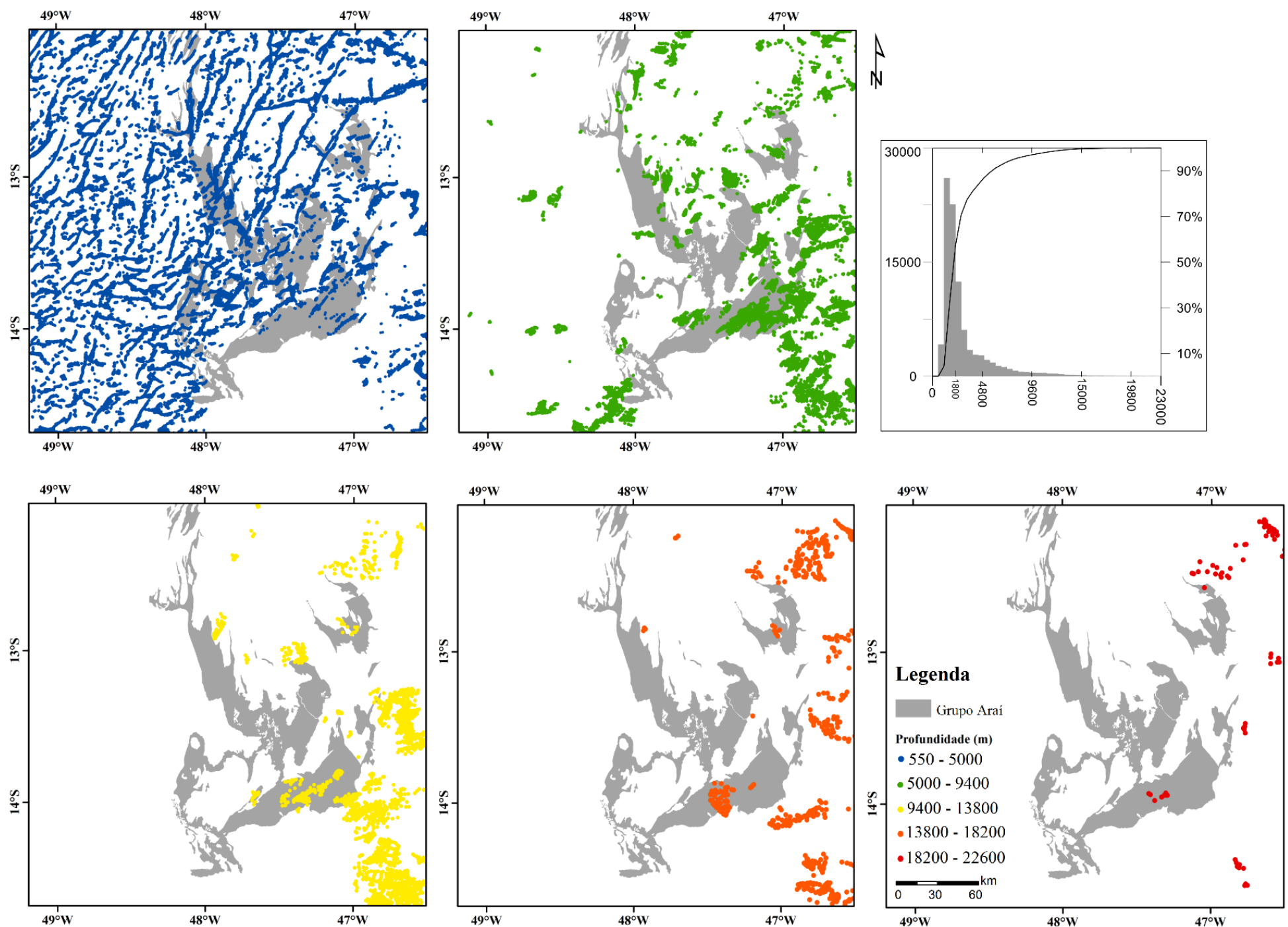

Figura 5.17. Soluções de Euler individualizadas em intervalos de profundidades utilizando o método da Deconvolução Padrão com índice estrutural 2 e janela $10 x 10$ km para o mapa do campo magnético anômalo e histograma de densidades das soluções. 
O resultado da Deconvolução de Euler associado aos dados gravimétricos indica soluções com profundidade de até $35 \mathrm{~km}$, por ser um dado com forte componente regional. Em articulação com a Falha Rio Maranhão (FRM), as soluções marcam a geometria dos complexos máficos-ultramáficos de Cana Brava e Niquelândia em contato com as sequências metavulcanossedimentares de Palmeirópolis e Indaianópolis, estas apresentando características mais profundas em relação aos complexos máficos-ultramáficos. As soluções também discriminam a falha de empurrão que sobrepõe rochas do Grupo Paranoá às do Grupo Bambuí, pertencente ao Sistema Paranã, demostrando que essa falha possui características profundas que são detectadas nas soluções à profundidade limite de $35 \mathrm{~km}$, articulando com o Cráton São Francisco. Esse limite, de acordo com Soares et al. (2006) corresponderia a um afinamento da crosta, retornando a profundidades maiores a partir do distanciamento da falha.

A feição mais importante detectada pelas soluções de Euler compreende uma megaestrutura de direção NE-SW com topo entre 11 e 24 km (Figura 5.16) que parece estar relacionada à direção de abertura do rifte, também descrita por Marques (2010). Essa estrutura é verificada tanto no sinal gravimétrico como no sinal magnético, sendo detectada entre as longitudes $46,9^{\circ} \mathrm{W}$ e $48,4^{\circ} \mathrm{W}$, com extensão aproximada de $170 \mathrm{~km}$. É representada em superfície por falhas compressionais e transcorrentes dextrais que correspondem a reativações do Brasiliano, em que a maioria destas tem relação com antigas falhas extensionais do próprio rifte, mudando seu regime com a inversão do brasiliano e gerando transcorrências tardias pelo alívio de tensões e segundo zonas de fraqueza herdadas do estágio rifte. As estruturas transcorrentes fazem referência aos sistemas São Jorge-Alto Paraíso-Cormari e CavalcanteTeresina, articulando com o sistema transpressivo frontal Teresina-Nova Roma. Esses sistemas configuram a fase F1 de deformação do Brasiliano, descritas por Fonseca et al. (1995), onde sistemas de falhas frontais e transcorrentes foram geradas a partir de zonas de fraqueza préexistentes, embora as transcorrências, associadas principalmente aos sistemas São Jorge-Alto Paraíso-Cormari e Cavalcante-Teresina, tenham sido construídas tardiamente, sendo integradas a uma fase essencialmente transcorrente, consideradas como as últimas manifestações estruturais ocorridas durante a inversão brasiliana.

O resultado da Deconvolução de Euler aplicada aos dados magnéticos indica que as soluções estão concentradas, em sua maioria, em profundidades relativamente rasas, entre 1,2 $\mathrm{km}$ e $3 \mathrm{~km}$. Isto ocorre devido ao mapa do campo magnético anômalo apresentar grande parte das feições magnéticas associadas a anomalias de alta frequência, consequentemente relacionadas a fontes mais rasas. Além disso, há exposição do embasamento rochoso em grande 
parte da área estudada, o que pode mascarar as respostas mais profundas associadas a este padrão litológico, realçando apenas as fontes mais rasas, visto que as profundidades das soluções representam não a base, mas o topo de fontes magnéticas.

É possível observar que as soluções da Deconvolução de Euler do campo magnético anômalo possuem boa correlação com o traçado dos lineamentos magnéticos, principalmente no que diz respeito aos resultados mais rasos do Matched Filter. Isso demonstra que são estruturas com topo em profundidades rasas, algumas delas discriminadas em superfície. Porém, os lineamentos de grande extensão possuem características profundas, como visto nas maiores profundidades do Matched Filter, com detecção em até 21,8 km de profundidade, podendo retornar profundidades maiores. As soluções de Euler com topo entre 5 e $18 \mathrm{~km}$ (principalmente o intervalo entre 9,4 e 13,8 km) mostram de forma clara os limites do Cráton São Francisco e a profundidade que o mesmo atinge nessa porção. Os limites mais profundos detectados pertencem aos limites do cráton e à porção da Formação Arraias onde podem estar nucleadas importantes estruturas relacionadas ao rifte.

As soluções de Euler para os dados gravimétricos e magnéticos possui boa correlação no que diz respeito aos sistemas transcorrentes, observados desde Niquelândia até Campos Belos na porção que estaria relacionada ao rifte. A associação entre os diferentes índices estruturais dá forma à geometria de subsuperfície que essas zonas de cisalhamento assumem na região (sistemas São Jorge-Alto Paraíso-Cormari, Cavalcante-Teresina e Teresina-Nova Roma). Essas caraterísticas são observadas na Figura 5.18.

Além disso, a partir da observação da integração das soluções de Euler para diferentes índices estruturais, é possível identificar segmentos de reta contínuos em todas as soluções que caracterizariam o sinal magnético preservado referente às principais falhas do rifte (Figura 5.18). Esse segmento linear já foi observado anteriormente em diferentes produtos magnéticos e gravimétricos e é confirmado a partir de observações em mapeamento geológico nas folhas Cavalcante - SD.23-V-C-V, Monte Alegre de Goiás - SD.23-V-C-III e Nova Roma - SD.23V-C-VI (Alvarenga et al., 2007b) ao longo do qual são encontrados espessos conglomerados de leques aluviais relacionados à fase rifte. 


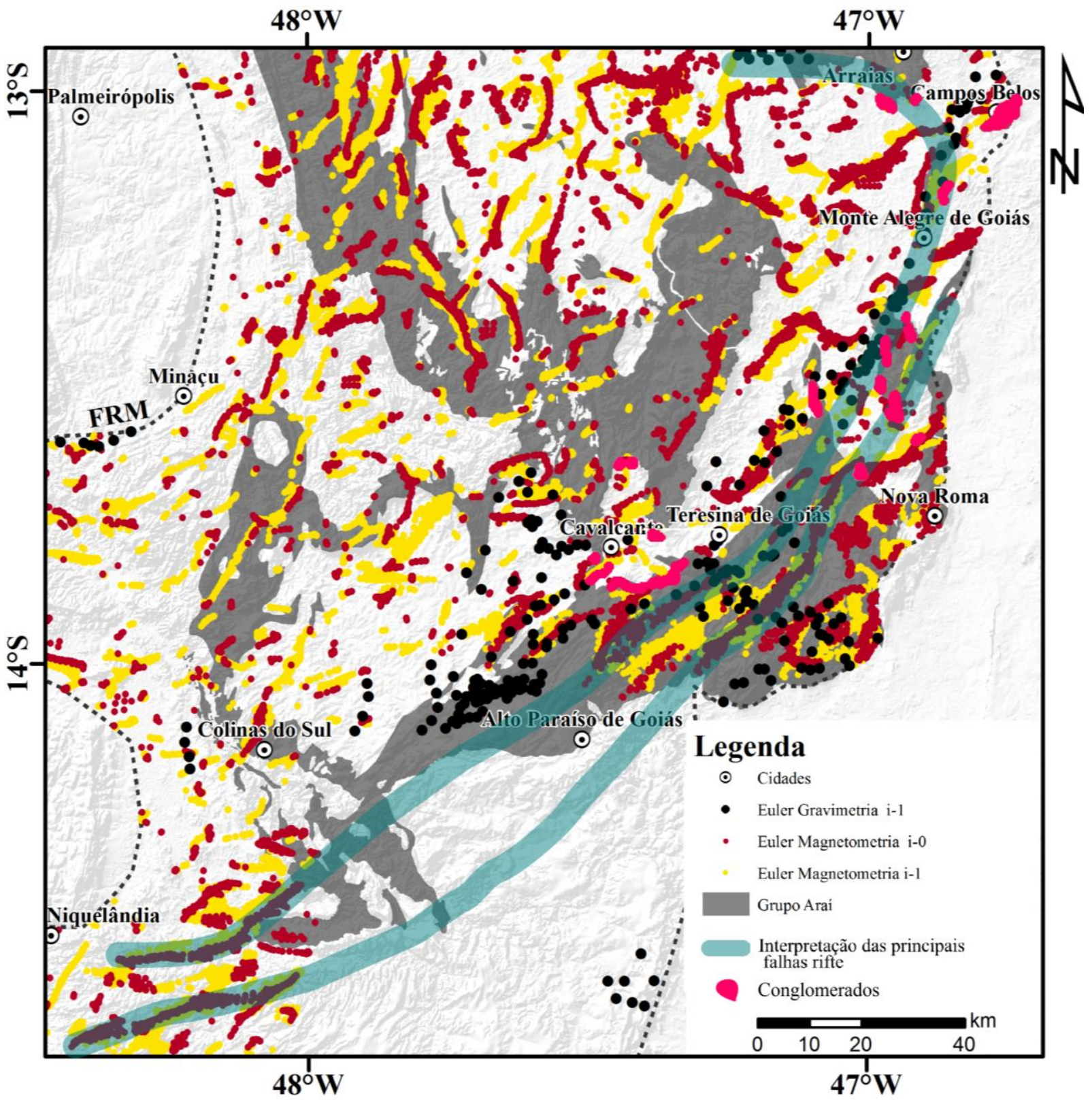

Figura 5.18. Integração das soluções de Euler para os dados magnéticos e gravimétricos com janela quadrada fixa de 10x10 km utilizando diferentes índices estruturais na região do Grupo Araí. 


\subsection{INTEGRAÇÃO DOS RESULTADOS}

\subsubsection{Profundidades de fontes}

Os resultados, sintetizados na Figura 5.19, para valores de profundidades de fontes magnéticas e gravimétricas compreenderam a análise do espectro de potência magnético e gravimétrico abrangendo toda a região de estudo, análise do Matched Filter de dados magnéticos aplicado a sub-áreas nas adjacências do Grupo Araí e análise das soluções obtidas na Deconvolução de Euler aplicada a dados magnéticos (índices estruturais 0, 1 e 2) e gravimétricos (índice estrutural 1). Esses resultados também foram comparados a dados geológicos e geofísicos consolidados na literatura obtendo, dessa forma, uma correlação às interfaces geológicas na região desse estudo.

Os resultados encontrados no espectro de potência para toda a área de estudo indicam os seguintes valores: (i) para a magnetometria, profundidades de fontes magnéticas em 0,$5 ; 1,6$; 6,6 e $21,8 \mathrm{~km}$; (ii) para a gravimetria, profundidades de fontes em 1,8; 6; 12,5 e $37 \mathrm{~km}$. As profundidades encontradas são de abrangência regional e as interfaces possuem características espectrais de toda a região de estudo, onde cada valor não possui ligação restrita com o Grupo Araí, mas abrangem um conjunto de fontes com diferentes comprimentos de onda envolvendo tanto parte da Zona Interna, Zona Externa e Zona cratônica.

Os resultados encontrados a partir da análise do Matched Filter aplicados a sub-áreas (Figura 5.5) nas adjacências do Grupo Araí indicam os seguintes valores: 0,36; 1,85; 7,4 e 9,7 $\mathrm{km}$. Esse resultados são mais localizados e envolvem profundidades referentes, principalmente, ao Grupo Araí.

Foram adicionados a estes resultados as profundidades detectadas na Deconvolução de Euler de dados magnéticos e gravimétricos correspondentes ao início do intervalo de soluções e ao final, representando o topo e a base de fontes com assinaturas magnéticas distintas, podendo acrescentar informações à integração das profundidades. Para o resultado da Deconvolução magnética de índice estrutural zero foi considerado apenas a base visto que o topo das soluções se iniciava na superfície zero. 


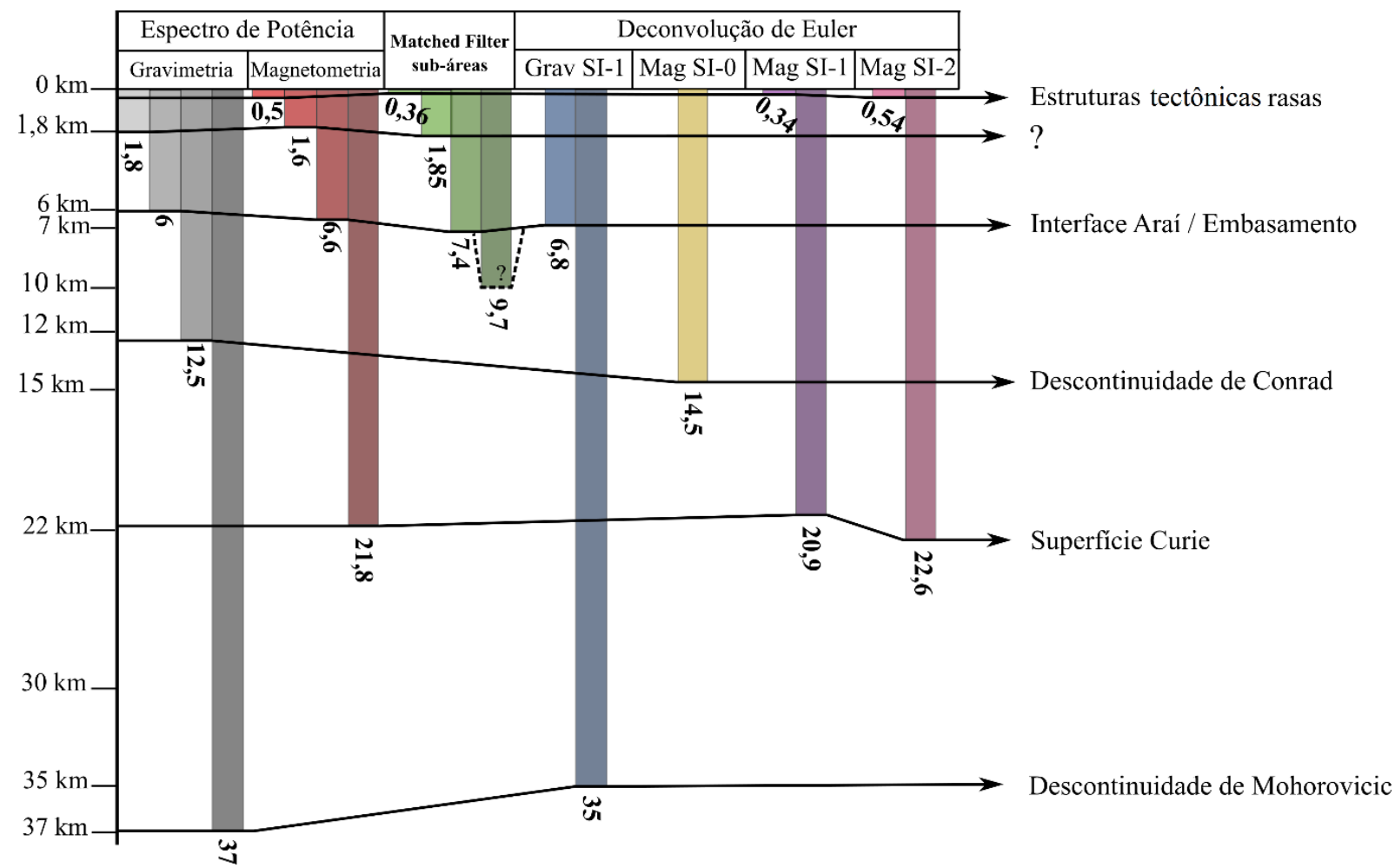

Figura 5.19. Síntese dos principais resultados de profundidades obtidas destacando as metodologias utilizadas.

As profundidades referentes aos intervalos 0,34;0,36; 0,5 e 0,54 km são caracterizadas como estruturas rasas, provavelmente fraturas de pequena extensão que caracterizam a geometria do arcabouço em lineamentos magnéticos de terceira ordem.

As profundidades entre 6 e 7,4 km indicam a variação de profundidade apresentada pela interface entre a camada sedimentar e o embasamento e foram confirmadas a partir da modelagem gravimétrica 2D para a região modelada, apresentada posteriormente na Figura 5.23 .

O valor de 9,7 km encontrado no Matched Filter aplicado às sub-áreas parece não se ajustar a profundidade de nenhuma interface previamente caracterizada neste trabalho, mas pode fazer referência a intrusões graníticas pontuais na região do rifte referentes à granitogênese das subprovíncias Paranã e Tocantins (indicadas na Figura 2.3).

A profundidade de 12,5 - 14,5 km é interpretada como a Descontinuidade de Conrad, o limite entre a crosta superior e inferior, detectável principalmente em termos de mudança de velocidades sísmicas, mas também em padrões de densidade. Esse resultado é semelhante à 
modelagem crustal, com base em dados de sísmica de refração, realizada por Soares et al. (2006), com valores variando entre aproximadamente 10 e $15 \mathrm{~km}$.

A profundidade de 21,8 - 22,6 km detectada na magnetometria é associada à Superfície Curie média da área, que pode variar alguns quilômetros para mais ou para menos, dependendo das condições de temperatura à qual as rochas estão submetidas. Blum \& Pires (1996) estimam a profundidade média da superfície Curie na região central de Goiás em 30,8km e Blum (1999) encontra um valor de profundidade de 19,3 km na região de Niquelândia, podendo chegar a $21,3 \mathrm{~km}$ na porção a leste da mesma.

A profundidade de 35 a $37 \mathrm{~km}$ indica o limite crosta/manto, correspondente à Descontinuidade de Mohorovicic, o que está de acordo com os estudos de sísmica de refração profunda realizados nos limites da bacia, com espessuras crustais variando entre 36 e $43 \mathrm{~km}$ (Berrocal et al., 2004; Soares et al., 2006; Ventura et al., 2011). A partir desse resultado, com base nos estudos desses autores, é possível inferir que essa seja a profundidade média da Moho na região de estudo, principalmente nas porções entre Porangatu e Minaçu, que possui um degrau mais raso que as profundidades vizinhas onde, no Arco Magmático, são apresentadas profundidades de 36 - 38 km e no Maciço de Goiás de 38 km (Soares et al., 2006). Além disso, a partir de resultados de espessura crustal com base em dados sísmicos na estação PEXB (distante $30 \mathrm{~km}$ da cidade de Peixe - TO) Assumpção et al. (2013) encontra valor de 37,8 km para a profundidade dessa interface.

\subsubsection{Sistema de lineamentos na região do rifte Araí}

As informações adquiridas a partir da interpretação das estruturas magnéticas, juntamente com as estruturas geológicas discriminadas em mapeamento foram integradas, fornecendo um mapa geofísico-geológico (Figura 5.20). As assinaturas lineares interpretadas estão associadas a expressivas zonas de fratura e/ou cisalhamento marcantes para o arcabouço da região. Essas assinaturas se prolongam em profundidade, de acordo com as observações fornecidas pelos mapas gerados com o Matched Filter, e apresentam extensão e continuidade regional, associadas aos limites físicos que condicionaram o desenvolvimento e arquitetura atual do rifte (Figura 5.18) e suas zonas adjacentes. Parte dos lineamentos se apresentam perfeitamente preservados nas rochas expostas do embasamento e nas coberturas sedimentares, de acordo com dados da literatura. Aqueles que não estão diretamente associados a traços em superfície indicam o comportamento estrutural em maiores profundidades. 


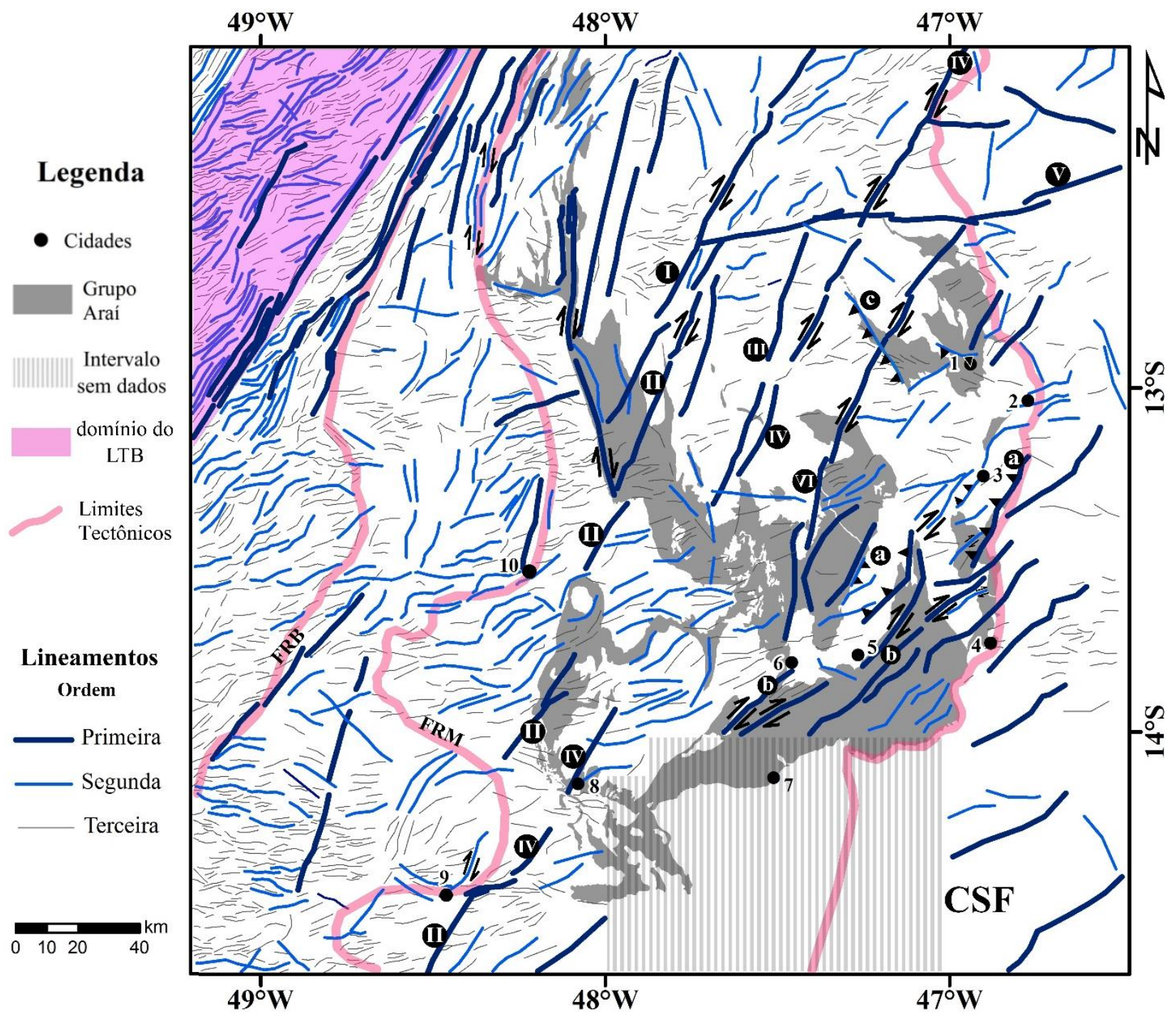

Figura 5.20. Arranjo estrutural interpretado, com as regiões de influência dos Sistemas: (a) Teresina-Nova Roma, (b) Cavalcante-Teresina e (c) Arraias-Campos Belos. Os indicadores cinemáticos foram alocados apenas na Zona Externa da FDB, nos limites mais importantes relacionados ao Araí, de acordo com a geologia conhecida. Cidades: 1 - Arraias, 2 - Campos Belos, 3 - Monte Alegre, 4 - Nova Roma, 5 - Teresina, 6 - Cavalcante, 7 - Alto Paraíso, 8 - Colinas do Sul, 9 - Niquelândia, 10 - Minaçu.

A combinação entre os elementos interpretados revela um complicado arranjo estrutural (Figura 5.20), onde estruturas profundas são evidenciadas pela presença de estruturas mais sutis nas porções superficiais, pois o movimento ao longo de uma falha profunda assentada dentro de uma bacia sedimentar é susceptível de desenvolver uma extensa zona de falhas, dobras e veios nos sedimentos sobrejacentes. Esses "corredores estruturais" possuem uma expressão ampla, mas sutil e formam famílias de estruturas com um espaçamento quase regular, relacionadas de forma complexa com a espessura da crosta, contraste reológico, taxas de deformação, gradientes térmicos, etc (Isles \& Rankin, 2013). As falhas-mestre de primeira 
ordem, representadas pelos lineamentos de grandes comprimentos de onda, geralmente controlam o desenvolvimento de estruturas de menor escala (segunda e terceira ordem). As manifestações dos lineamentos magnéticos de primeira ordem desde Colinas do Sul até Nova Roma (Figura 5.20), passando pelos principais sistemas de cisalhamento descritos na literatura, indicam o comportamento dessas falhas em subsuperfície nas profundidades onde a falha se torna mais coesa e sua geometria não representa sua manifestação direta em superfície, apesar de as estruturas mapeadas (descritas como falhas de transcorrência dextral e/ou compressional) estarem subordinadas a estas grandes feições. Esses lineamentos magnéticos são relacionados a reativações das principais estruturas desenvolvidas na abertura rifte, mudando seu regime estrutural durante a inversão da bacia no ciclo Brasiliano, também ocorrendo a geração de novas falhas a partir de antigas zonas de fraqueza.

Os lineamentos magnéticos expressivos que cortam a Zona Externa na porção setentrional da FDB, numerados em II, IV e VI na Figura 5.19 possuem assinatura profunda, detectados em todas as camadas do Matched Filter até a profundidade de 21,8 km, esta identificada como a Superfície Curie média, ou seja, essas falhas podem alcançar profundidades ainda maiores. Os lineamentos I e III são secundários a estes. Eles não são visualizados nesta profundidade, mas são todos identificados na profundidade de $6,6 \mathrm{~km}$, mostrando que esta deve ser sua extensão mínima, sendo mais rasos que $21,8 \mathrm{~km}$. Estes lineamentos possuem direção paralela ao Lineamento Transbrasiliano e são relacionados a estruturas formadas no ciclo Brasiliano, configurando expressivas falhas transcorrentes dextrais que cortam toda a Zona Externa na porção setentrional, sendo que nem todas são mapeadas em superfície. O lineamento numerado em V é identificado na camada mais profunda, porém com direção N60E parecendo infletir, à medida que se aproxima da superfície, para direção essencialmente EW. Também configura estrutura do Brasiliano.

Os lineamentos indicados como "a" e "b" são estruturas magnéticas também detectadas em todas as profundidades do Matched Filter, convergindo, nas porções mais profundas, para uma megaestrutura de direção aproximadamente N60-70E (Figura 5.13). Como observado nos lineamentos traçados na profundidade de $6,6 \mathrm{~km}$, essa estrutura inicia-se com direção N60-70E e inflete para N30E, de oeste para leste, desde as proximidades de Niquelândia até a altura de Campos Belos. Possui assinatura visível principalmente nos mapas do campo magnético anômalo em forma de expressivo dipolo, no Sinal Analítico 3D e Gradiente Horizontal Total como anomalias de grande comprimento de onda e na Deconvolução de Euler dos dados 
gravimétricos e magnéticos a profundidades de até $24 \mathrm{~km}$. Isso demonstra o caráter profundo do rifte.

Na cobertura sedimentar da ZE, precisamente no Grupo Araí, as estruturas também são, em grande maioria, de direção N60-70E, podendo variar até N40-80E, identificadas com estruturas de terceira ordem, bem visualizadas no TDX. São fracamente visualizadas também estruturas com direção variando NW (Figura 5.12), podendo estar relacionadas à fase rifte e pós-rifte.

Em geral, o arranjo magnético da área estudada possui uma forte assinatura NE tanto nas Zonas Interna, Externa e, mais fracamente na Zona Cratônica. São estruturas magnéticas, em grande parte, relacionadas à deformação do Brasiliano. As estruturas NS detectadas entre as cidades de Paranã e Jaú do Tocantins (visualizadas no TDR) também são brasilianas e sua geometria (falhas inversas) reflete a resposta ao empurrão da FRM por sobre os grupos Paranoá e Araí nessa porção. A fraca detecção de estruturas com direção NS e NW pode ser explicada pela falta de contraste da magnetização com as rochas adjacentes, porém na derivada Tilt é possível verificar lineamentos NW na região do Sistema Arraias-Campos Belos que seriam tardios aos lineamentos N30-40E relacionados ao sistema Teresina-Nova Roma.

Hasui \& Haralyi (1985) em análise magnética na Província Tocantins detectaram estruturas magnéticas NS, NW e WNW onde as relações de truncamento indicariam que essas orientações são mais antigas que as estruturas NE a ENE. Essas estruturas mais antigas são visualizadas na área de estudo principalmente na Zona Interna, pois na porção da Zona Externa os lineamentos magnéticos NS e NW são condicionados principalmente pelo cavalgamento entre embasamento e cobertura sedimentar. É difícil estabelecer idade definida para tais descontinuidades, por carência de informações geológicas. Segundo esses autores, um processo de cisalhamento dúctil de alto ângulo gerando lineamentos diácronos com direções NW a WNW e NE a ENE estaria associado a essas estruturas, ocorrendo possivelmente no Paleoproterozoico e sendo explicado como reação interna da massa continental então existente a rotações do conjunto.

Ainda sobre os lineamentos magnéticos, a partir da observação de seu traçado e com base nas diferentes características do embasamento exposto na região é possível inferir que o mesmo possui aspectos distintos seja em sua composição seja na reologia, que condicionaram a atual geometria da bacia Araí. Esse mesmo aspecto já foi observado por Haralyi \& Hasui $(1982,1985)$ de forma mais amplas, no que diz respeito a grandes blocos crustais com diferentes características que dividiriam a Província Tocantins, separados por descontinuidades 
gravimétricas. Uma dessas descontinuidades observada por esses autores, denominada Descontinuidade do Paranã, de direção NW e rejeito sinistral, que separou diferentes blocos crustais no Arqueano-Paleoproterozoico (Figura 5.21) não aparece com clareza no mapa da anomalia Bouguer apresentada neste trabalho podendo ser devido à tecnologia de aquisição, ao espaçamento das amostras e diferente célula de interpolação, não englobando os comprimentos de onda das anomalias referidas pelos mesmos. No entanto, no traçado dos lineamentos magnéticos é visível a mudança de comportamento no limite dessa descontinuidade, separando terrenos de natureza distinta que, segundo Marques (2010), representariam os terrenos AlmasDianópolis e Jaú-Cavalcante.

Assim como a Descontinuidade do Paranã separaria diferentes terrenos, na porção da ZE referente ao Grupo Araí é verificada a existência de outros blocos crustais menores que também possuem natureza diferenciada entre si e que envolveram o Grupo Araí durante os eventos de deformação posteriores à formação do rifte, condicionando a atual geometria da bacia (Figura 5.22). Cada bloco possui característica intrínseca no que diz respeito à intensidade e comportamento dos lineamentos magnéticos, sendo verificado que os blocos mais rígidos possuem menor quantidade de lineamentos de segunda e terceira ordem e àqueles menos rígidos vale o inverso. Os blocos numerados em 3 possuem características muito semelhantes, sendo o bloco menor envolvido pelo Grupo Araí no momento da deformação, assim como o bloco 4, proporcionando a atual geometria. Não foi possível relacionar o bloco 5 a outro bloco ou separálo dos outros por falta de levantamento magnético nesta região. 


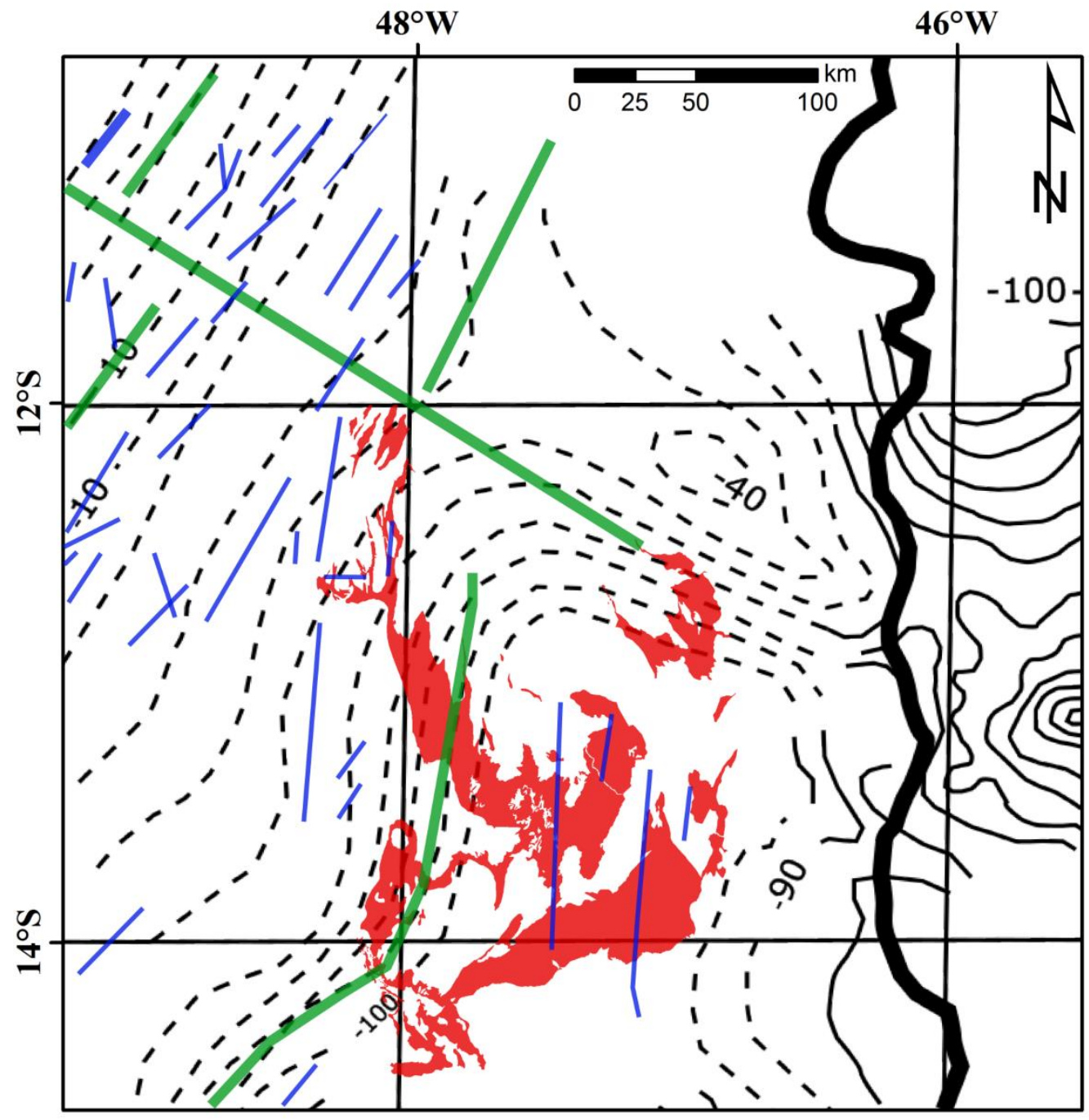

\section{Legenda}

Limite Província Tocantins

Isolinhas da anomalia Bouguer

Isolinhas por inferência a partir de estações gravimétricas isoladas
Lineamentos magnéticos

Descontinuidades e falhas (gravimetria)

Grupo Araí

Figura 5.21. Interpretação gravimétrica e magnética na região do Grupo Araí segundo Haralyi \& Hasui (1982, 1985). 


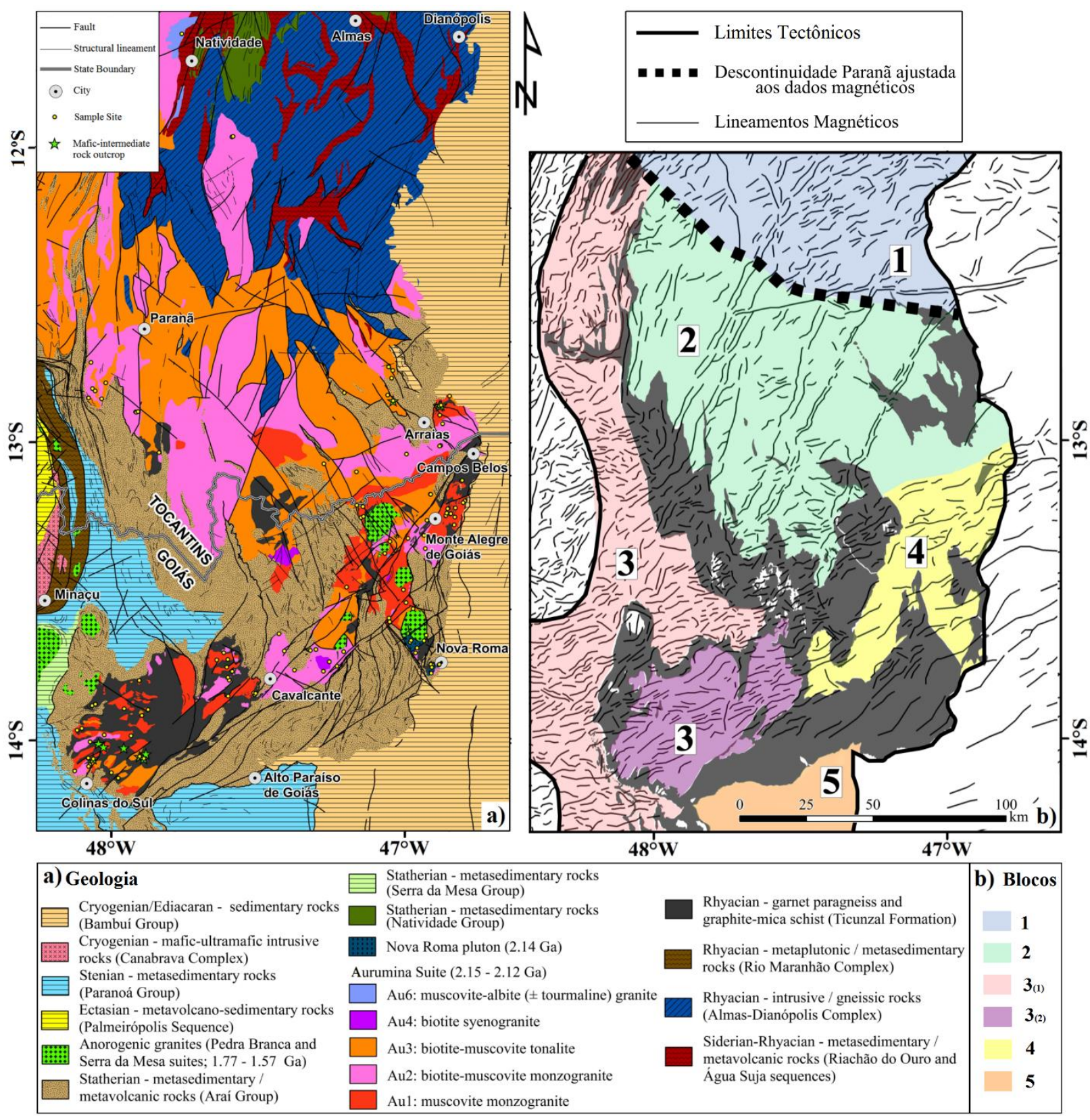

Figura 5.22. (a) Mapa geológico a partir da integração das cartas SC.23, SD.22, SD.23, SC.22-Z-D, SD.22-X-D, SD.23-V-A, SC.23-Y-C, SD.23-V-C-III, SD.23-V-C-V e SD.23-V-C-VII (adaptado de Cuadros \& Botelho, 2015), o qual é possível identificar as unidades do embasamento e semelhanças à (b) interpretação dos blocos crustais na região do Grupo Araí com base no traçado dos lineamentos magnéticos e na proposta de Haralyi \& Hasui (1985). A descontinuidade do Paranã ajustada aos lineamentos deste trabalho é representada no mapa pela linha tracejada. Os lineamentos magnéticos correspondem aos traçados do TDX (Figura 5.12). 


\subsubsection{Modelagem gravimétrica 2D}

Para a confecção de modelo 2D na porção da bacia referente ao perfil gravimétrico foram utilizados valores de densidade determinados segundo amostras coletadas em campo (Tabela 2.1). Os outros valores de densidade foram estimados com base naqueles contidos em Telford et al. (1990). O valor para o manto foi estipulado em $3,25 \mathrm{~g} / \mathrm{cm}^{3}$, assumindo composição essencialmente peridotítica. O valor para a crosta inferior foi estipulado em $3 \mathrm{~g} / \mathrm{cm}^{3}$ e para as rochas do embasamento na crosta superior foi atribuído valor de $2,85 \mathrm{~g} / \mathrm{cm}^{3}$. Esses valores são compatíveis com alguns dos valores apresentados por Ventura et al. (2011), visto que alguns pontos entre as duas aquisições gravimétricas são bastante próximos.

As profundidades relacionadas a interfaces geofísicas foram incorporadas ao modelo com base na integração de profundidades de fontes dos diferentes métodos empregados. Mesmo não havendo grande contraste na Anomalia Bouguer no perfil escolhido, (visto que o baixo gravimétrico desta região é relacionado a assinatura litosférica, segundo Soares et al., 2005 um bloco litosférico suportado pelo mesmo bloco do Cráton São Francisco, com características distintas do bloco a oeste, separados pela falha Rio Maranhão) foi realizada a modelagem nesta direção devido a acreditar-se cruzar a principal porção do rifte, deformada por eventos posteriores.

A primeira interface incorporada ao modelo corresponde à Descontinuidade de Mohorovicic, variando entre $35-37$ km. O ajuste à curva da anomalia Bouguer demostrou que mais a norte o limite entre crosta e manto fica mais profundo, chegando a $42 \mathrm{~km}$. O valor de espessura crustal encontrado por função do receptor (Soares et al., 2006 - Figura 4.4) parece corroborar com essa tendência onde na região de Cavalcante foi encontrado valor de $40 \mathrm{~km}$.

Em seguida, foi adicionada interface correspondente à Descontinuidade de Conrad, variando entre 12,5 - 14,5 km. Ajustada, essa interface passa a variar entre 11 e 15,6 km.

A interface correspondente à profundidade da cobertura sedimentar foi incorporando segundo os valores de $6-7,4 \mathrm{~km}$ que, ajustada ao modelo chega no valor máximo de $8 \mathrm{~km}$. Essa profundidade corresponde à porção interpretada em que as rochas do Grupo Araí estariam encobertas pelas do Paranoá. Não se sabe ao certo da existência de rochas do Grupo Araí abaixo do Grupo Paranoá por falta de dados geológicos que comprovem tal circunstância, porém é certo que a cobertura sedimentar nessa região é mais espessa devido ao baixo gravimétrico observado, que pode estar sendo condicionado pela espessura do pacote sedimentar. 
Esses resultados de profundidade da bacia são semelhantes àqueles atribuídos por Green et al. (1989) em estudo de sísmica de reflexão no sistema de rifte proterozoico denominado Mid Continent Rift (MCR) - regiões de Ontario, Minnesota, Winsconsin e Michigan (USA) - o qual os autores encontraram valor de 5-8 km para a espessura do pacote sedimentar. Esse rifte possui algumas semelhanças evolutivas em relação ao Rifte Araí: ambos sofreram extensão, um período de sedimentação e subsidência termal, extrapolando os limites originais do rifte e, após o final da subsidência, um regime compressional (inversão da bacia) com mudança no regime de falhas previamente estabelecidas no rifte e geração de novas falhas. Sua geometria também é semelhante, não configurando em planta um sistema linear, mas curvilíneo.

Na parte do perfil que abrange desde Alto Paraíso até Cavalcante a cobertura sedimentar é menos espessa, cerca de $2,3 \mathrm{~km}$ e a norte da cidade de Cavalcante apresenta espessura média de $2,1 \mathrm{~km}$. Portanto a porção menos espessa da bacia deve representar a interface encontrada na análise de profundidades correspondente ao intervalo 1,6 - 1,85 km (Figura 5.19). Ao modelo também foram incorporadas rochas basálticas correspondentes ao vulcanismo de idade 1,7 Ga (Pimentel et al., 1991), ajustada à curva da anomalia Bouguer, representado o extravasamento vulcânico relacionado ao estágio sin-rifte da bacia. Por último foram adicionados ao modelo a Formação Ticunzal (a partir de observações de superfície) e o Grupo Paranoá.

Os dados estruturais foram adicionados ao modelo com base nas estruturas de superfície contidas nos mapas geológicos na escala 1:1.000.000 por Lacerda Filho et al. (2004) e Souza et al. (2004) - cartas SD22 e SD23 - e no mapa geológico na escala 1:100:000 da Folha Cavalcante - SD.23-V-C-V. A profundidade das falhas foi verificada a partir da análise do Matched Filter e Deconvolução de Euler dos dados magnéticos para os diferentes índices estruturais. Todas essas falhas observadas são do Brasiliano, que reativaram estruturas rifte, mascarando as falhas originais do rifte. Na região onde é ausente o recobrimento aeromagnético não se conseguiu verificar a presença ou ausência de estruturas e, por essa razão, não foi possível estabelecer o comportamento das estruturas em profundidade, porém a disposição das camadas ajusta-se muito bem à anomalia observada. $\mathrm{O}$ resultado da modelagem é apresentado na Figura 5.23. 


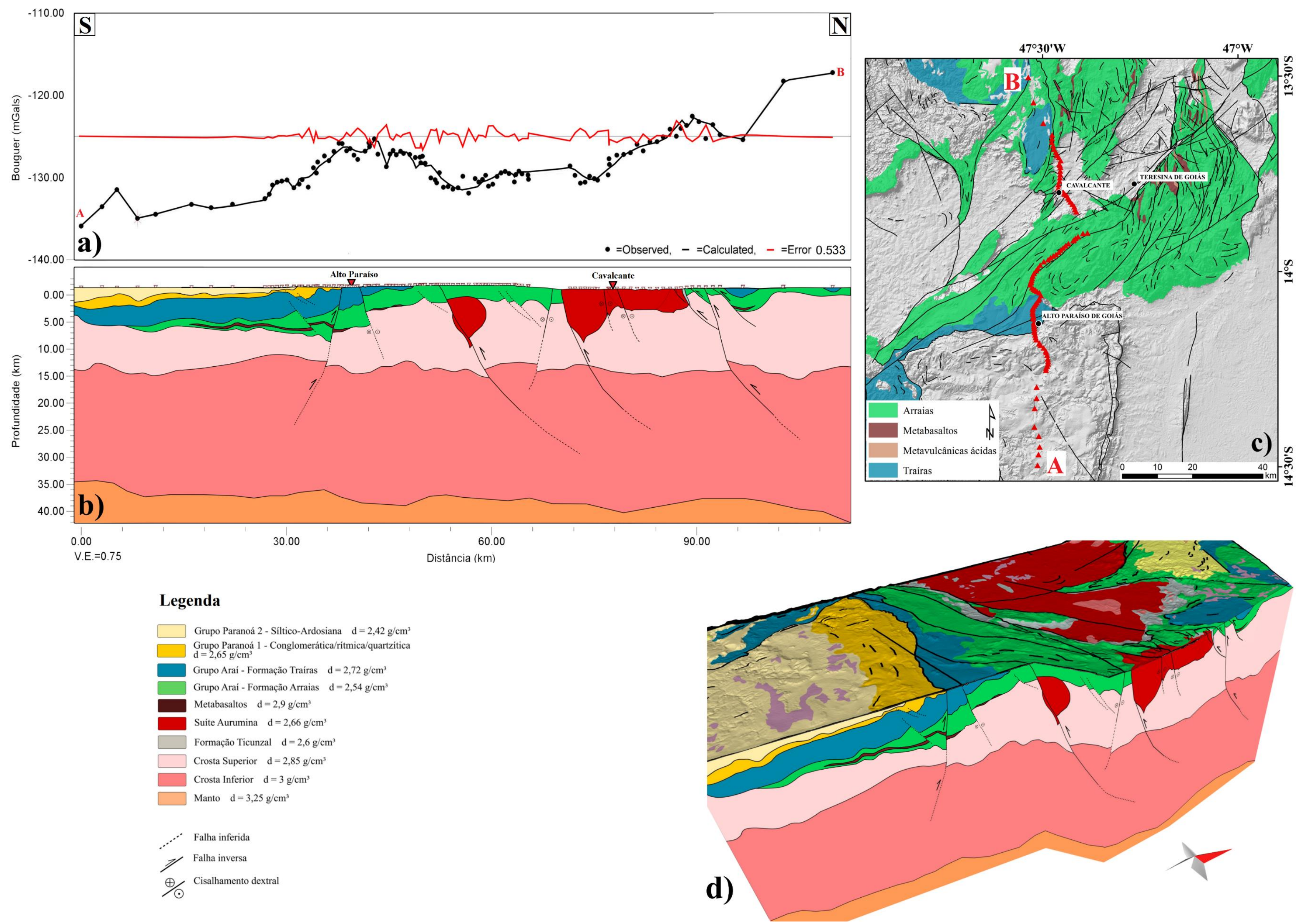

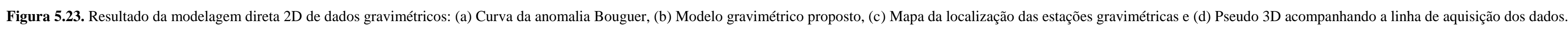




\section{Capítulo 6 \\ CONCLUSÕES}

Diante dos resultados apresentados nos capítulos precedentes, enumera-se, a seguir, uma série de conclusões:

(i) Em relação à profundidade da bacia

As técnicas de profundidade dos dados geofísicos demonstraram que há uma interface variando entre 6 e 8 km associada majoritariamente, mas não restrita, à profundidade da interface entre cobertura sedimentar e embasamento na porção do Grupo Paranoá. Em outras porções o pacote sedimentar é mais raso, apresentando espessura média de 2,2 km, representada pelas rochas do Grupo Araí, onde o evento Brasiliano teria soerguido essa unidade. Esses resultados foram encontrados a partir do espectro radial de potência para toda a área e aplicado a sub-áreas, além de soluções de Euler com topo em 6,8 km, que corresponderiam ao topo do embasamento, também verificados na modelagem gravimétrica. $O$ resultado de $7,4 \mathrm{~km}$ encontrado nas sub-áreas valida essa hipótese, pois a análise limita os comprimentos de onda de fontes relacionadas somente à porção amostrada pelas sub-áreas, eliminando outras fontes que não são de interesse nessa porção.

(ii) Em relação aos sistemas de falhas principais

$\mathrm{O}$ arcabouço tectônico de toda a região estudada possui direção preferencial N40E, compreendendo principalmente feições relacionada à Orogenia Brasiliana. Essa tendência se dá principalmente pela proximidade com o Lineamento Transbrasiliano, que controla feições de direções variando em N25-40E.

O Grupo Araí possui assinaturas magnéticas preferenciais nas direções N50-80E divididas entre estruturas formadas essencialmente no Brasiliano e estruturas relacionadas a reativações brasilianas de falhas extensionais do rifte e alívio de tensões que possuem relação direta a estas. Essas estruturas compreendem os sistemas São Jorge-Alto Paraíso-Cormari, Cavalcante-Teresina e Teresina-Nova Roma. As transcorrências sinistrais do Sistema ArraiasCampos Belos, pouco evidenciadas nos dados geofísicos, são relacionadas a uma fase tardia de deformação em relação às estruturas NS e NE apresentadas pelos outros sistemas, os quais evidenciam falhas diretamente relacionadas ao rifte Araí, que convergem para uma falha 
principal detectada até a profundidade de 21,8 km pela análise do Matched Filter e 22,6 km na Deconvolução de Euler magnética de índice estrutural 2, podendo ser mais profunda.

As falhas que possuem relação direta com o sistema rifte foram delimitadas a partir da integração das soluções de Euler de diferentes índices estruturais apresentada na Figura 5.18, nas quais foram verificadas em toda sua extensão indícios de conglomerados de leques aluviais relacionados à fase rifte.

Toda a porção setentrional da Zona Externa, a qual o Grupo Araí está inserido, é dominada por grandes zonas de cisalhamentos transcorrentes dextrais que chegam a $200 \mathrm{~km}$ de extensão e direção N25-30E, propagando-se desde a superfície até grandes profundidades, sendo os principais lineamentos detectados no Matched Filter na profundidade de 21,8 km, aos quais é atribuído o controle regional de heterogeneidades crustais, de idade brasiliana. Subordinadamente encontram-se feições NS na altura da cidade de Paranã e em mais algumas porções da cobertura sedimentar relacionadas a estruturas geradas no brasiliano, configurando o cavalgamento entre o embasamento e o pacote sedimentar.

(iii) Em relação ao retrabalhamento tectônico de suas unidades e a sua atual compartimentação

A compartimentação atual da bacia-rifte Araí foi influenciada pela deformação do Brasiliano, onde o Grupo Araí foi envolvido numa tectônica do tipo thick-skinned em que seus braços provavelmente representam os limites de blocos crustais com características distintas, similar ao que ocorreu no MCR (Merino et al., 2013), onde há evidências de microblocos que contornam esse sistema rifte. Essas evidências são comprovadas em escala regional pelos trabalhos de Haralyi \& Hasui (1982, 1985 e 1986) e pela presente dissertação, através da comparação da assinatura magnética de blocos composicionalmente e reologicamente distintos que envolveram o Grupo Araí e condicionaram a atual geometria da bacia (Figura 5.22). A configuração tectônica das falhas diretamente relacionada ao estágio rifte foi perfeitamente verificada nos resultados da Deconvolução de Euler gravimétrica e magnética e comprovada a partir de evidências geológicas, como descrito anteriormente.

Observando os resultados geofísicos encontrados neste trabalho é válida a sugestão de que o Rifte Araí estaria associado a um processo extensional incompleto, não desenvolvendo margem passiva, mas compreendendo um rifte intracontinental isolado similar ao MCR. A assinatura gravimétrica da bacia-rifte Araí corresponde a um baixo gravimétrico condicionado por seu preenchimento sedimentar, combinado a baixo gravimétrico de grande comprimento de onda proveniente de características litosféricas. A assinatura magnética compreende anomalias 
de grande comprimento de onda, que inclusive marcam perfeitamente a porção relacionada ao rifte, caracterizada por dipolo linear de grande extensão. 


\section{REFERENCIAS BIBLIOGRÁFICAS}

Almeida, F.F.M. 1968. Evolução tectônica do centro-oeste brasileiro no proterozóico superior. Anais... Acad. Bras. Ciências, n. 40, p 285-295.

Almeida, F.F.M. 1977. Províncias estruturais brasileiras. In: Simpósio de Geologia do Nordeste, 8, 1977. Campina Grande, Atas Campina Grande: SGB, p. 363-391.

Almeida, F.F.M., \& Hasui, Y. 1984. O Pré-Cambriano do Brasil. São Paulo, Edgar Blücher, $378 \mathrm{p}$.

Almeida, F.F.M., Hasui, Y., Brito Neves, B.B. 1976. The Upper Precambrian of South America. Bol. IG 7 :45-80, Inst. Geoc. Univ. S. Paulo.

Almeida, F.F.M.; Hasui, Y.; Brito Neves, B.B.; Fuck, R.A. 1981. Brazilian structural provinces: an introduction. Earth Science Review, 17, p. 1-29.

Almeida, T. 2009. Contribuição das imagens R99sar e de dados geofísicos para o mapeamento geológico do Rifte Araí, nordeste de Goiás. Tese de Doutorado. Universidade de Brasília, Brasília. 208p.

Alvarenga, C.J.S., Botelho, N.F., Dardenne, M.A., Campos, J.E.G., Martins, F.A.L., Menezes, P.R., Moura, M.A. 2000. Magmatic and stratigraphic evolution of a Paleo/Mesoproterozoic syn-rift to post-rift basin: example of the Araí Basin, Brazil. In: Intern Geol Congress 2000, Rio de Janeiro, Abstracts - CDROM.

Alvarenga, C. J.; Botelho, N. F.; Dardenne, M. A.; Campos, J. E.; Meneses, P.; Moura, M. A.; Martins, F.A.L. 2002. Eventos rifte e pós rifte do final do Paleoproterozóico no embasamento da Faixa Brasília. In: XLI Congresso Brasileiro de Geologia, João Pessoa. Anais. João Pessoa: SBG - Núcleo Nordeste, 2002. p. 289-290.

Alvarenga, C.J.S.; Botelho, N.F.; Dardenne, M.A.; Lima, O.T.B. de; Almeida, T. 2007a. Mapa Geológico da Folha SD.23-V-C-VI - Nova Roma. (Cartas, mapas ou similares/Mapa).

Alvarenga, C.J.S.; Dardenne, M.A.; Botelho, N.F.; Machado, M.A.; Lima, O.N.B.; Almeida, T. 2007b. Relatório Final das Folhas Monte Alegre, Cavalcante e Nova Roma. Programa Geologia do Brasil (PGB/LGB), Convênio UNB/FINATEC/CPRM. Brasília.

Andrade, G. F. E Danni, J. C. M. 1978. As mineralizações de estanho, berílio, e cobre do granito da Serra Branca, Cavalcante-GO. CONGR. BRAS. GEOLOGIA, 30, Recife. Anais..., Recife, v.6, 1978, p. 2579-2593.

Araujo, S.M. 1986. Petrologia e mineralizações sulfetadas da Sequência Vulcano-Sedimentar de Palmeirópolis-Goiás. Dissertação de Mestrado - Universidade de Brasília, Brasília. $196 \mathrm{p}$.

Araujo, S.M. \& Nilson, A.A. 1987. Caracterização petroquímica e petrotectônica dos anfibolitos da Sequência Vulcano-Sedimentar de Palmeirópolis- Goiás. In: CONG. BRAS. GEOQ., 1, Porto Alegre, 1987, Anais....Porto Alegre,SBGq\SBG, v.1, p.335-348.

Araújo, V. A. \& Alves A. C. 1979. Projeto Canabrava-Porto Real, Relatório Final. CPRM, Goiânia, 191p. 
Araújo Filho, J.O. 1992. The Pirineus Mega Inflection in Central Brazil: an example of polydeformed Brasiliano fold-thrust belt. 13 Geowissenschaftliches Lateinamerika Kolloquium, Münter, p.18-19.

Araújo Filho, J.O. 1980. Geology of the Pirineus mega-inflection, Goiás, central Brazil. In: GEOWISS. LATEINAMERIKA KOLL., 7, Heidelberg, 1980, Kurzfassugen..., Heidelberg. p 9-11.

Araújo Filho, J.O., Dantas, E.L., Moura, M.A., Bühn, B., Matteini, M. 2007. Trabalho Final de Graduação, projeto Jaú-Peixe. Mapeamento Geológico 1:50.000 das Folhas Jaú e São Salvador, Universidade de Brasília, Brasília.

Assumpção, M., Bianchi, M.B., Jordi J., Dias, F.L., França, G.S.L., Nascimento, R., Stéphane, D., Pavão, C.G., Albuquerque, D.F. 2013. Crustal thickness map of Brazil: Data compilation and main features. Journal of South American Earth Sciences, 43, 7485.

Babinski, M., Pedreira, A.J., Brito Neves, B.B., Van Schmus, W.R. 1999. Contribuição à geocronologia da Chapada Diamantina. Simpósio Nacional de Estudos Tectônicos, 7. SBG, Lençóis, pp. 118-120 (Anais, Section 2).

Baranov, V. 1957. A new method for interpretation of aeromagnetic maps: Pseudo-gravimetric anomalies. Geophysics, 22, 359383.

Baranov V. \& Naudy H. 1964. Numerical Calculation of the Formula of Reduction of the Magnetic Pole: Geophysics, 29: 67-79.

Barbosa, O., Baptista, M.B., Braun, O.P., Dyer, R.G., Cotta, J.C. 1969. Geologia e inventário dos recursos minerais do Projeto Brasília. Relatório Prospec/DNPM, 225p, Rio de Janeiro.

Berrocal, J., Marangoni, Y., Côgo, S. N., Fuck, R.A., Soares, J.E.P., Dantas, E., Perosi, F., Fernandes C. 2004. Deep seismic refraction and gravity crustal model and tectonic deformation in Tocantins Province, Central Brazil. Tectonophysics, 388, 187-199.

Blakely, R.J. 1995. Potential Theory in Gravity and Magnetic Applications: Cambridge University Press, London. 441p.

Blakely, R. J. \& Simpson, R. W. 1986. Approximating edges of source bodies from magnetic or gravity anomalies. Geophysics 51, 1494-1498.

Blum, M.L.B. 1999. Processamento e interpretação de dados de geofísica aérea no Brasil Central e sua aplicação à geologia regional e à prospecção mineral. Tese (Doutorado em Geociências), Instituto de Geociências, Universidade de Brasília, Brasília, 229 p.

Blum, M.L.B. \& Pires, A.C.B. 1996. Superfície Curie da região central de Goiás, Rev. Bras. de Geociências, 26(3), 197-208.

Botelho, N.F. 1992. Lês ensembles granitique subalcalins a peralumineux mineralisés em $\mathrm{Sn}$ et In de la Sous-province Paraná, État de Goiás, Brésil (paragenèses hydrothermales associées: micas lithinifères, helvite, cassitérite, minéraux d'indium). Doctorate Thesis, Univ. Pierre et Marie Curie (Paris VI), 343 p.

Botelho, N.F.; Alvarenga, C.J.S.; Dardenne, M.A.; Almeida, T. 2007. Mapa Geológico da Folha SD.23-V-C-V - Cavalcante. (Cartas, mapas ou similares/Mapa). Brasília. 
Botelho, N.F., Alvarenga, C.J.S., Dardenne, M.A., Lima, O.N.B., Machado, M.A. 2006b. Relatório Final da Folha SD.23-V-C-V Cavalcante, Estado de Goiás, escala 1:100.000. Programa Geologia do Brasil (PGB/LGB) - Carta Geológica. UnB/CPRM. Brasília.

Botelho, N.F., Alvarenga, C.J.S., Silva, L.H.D.R., Menezes, P.R., Souza, C.S., Matos, J.M.S., Kitajima, L.F.W. 1995. Projeto Paranã (Área III - Rio das Pedras) Relatório Preliminar. UnB, Brasília. 130 p.

Botelho, N.F., Dantas, E. L., Fuck, R.A., Laux, J.H., Junges, S.L. 2006a. The Paleoproterozoic peraluminous Aurumina granite suite, Goiás and Tocantins, Brazil: geological, whole rock geochemistry and $\mathrm{U}-\mathrm{Pb}$ and $\mathrm{Sm}-\mathrm{Nd}$ isotopic constraints. In: The Paleoproterozoic record of the São Francisco craton, Ouro Preto, p. 92.

Botelho, N. F. \& Pimentel, M.M. 1993. Geocronologia Rb-Sr das Fases Intrusivas do Maciço Granítico da Pedra Branca, Província Estanífera de Goiás. In: Congresso Brasileiro De Geoquímica, 4, 1993, Brasília. Resumos... Brasília:SBG, 1993. p.253-254.

Braun, O.P.G. 1980. Uma discussão sobre alguns aspectos geotectônicos e estratigráficos das sequências Pré-Cambrianas do centro-leste de góias. In: Simpósio de Geologia do CentroOeste, Goiânia. Anais Goiânia: SBG, 1981. P9-29.

Brito Neves, B.B., Fuck, R.A., Pimentel, M.M. 2014. The Brasiliano collage in South America: a review. Brazilian Journal of Geology, 44(3): 493-518.

Brito Neves, B.B.; Sá, J. M.; Nilson, A. A.; Botelho, N. F. 1996. A tafrogênese estateriana nos blocos paleoproterozóicos da América do Sul e processos subseqüentes. Geonomos, 3: $1-21$.

Brod, J.A. 1988. Geologia das rochas vulcano-sedimentares da região de Indaianópolis, GO e lineamentos adjacentes, Dissertação de Mestrado, Universidade de Brasília, Brasília. $267 \mathrm{p}$.

Brod J. A. et al. (22 autores) 1991. Tectono-estratigrafia da Faixa Brasília na região do Alto Paranaíba. Simpósio de Geologia do Centro-Oeste 3, Cuiabá 1991. Anais... Cuiabá, 1991. SBG, pp. 155-168.

Clark, D.A. \& Emerson, D.W. 1991. Notes on rock magnetization characteristics in applied geophysical studies. Exploration Geophysics 22, 547-555.

Cooper, G.R.J. \& Cowan, D.R. 2004. Filtering using variable order vertical derivatives: Computers \& Geosciences, 30, 455-459.

Cooper G.R.J. \& Cowan D.R. 2005. Differential reduction to the pole. Computers and Geosciences, 31, 8, 989-999.

Cooper, G.R.J. \& Cowan, D.R. 2006. Enhancing potential field data using filters based on the local phase. Computers \& Geosciences, 32(10), 1585-1591.

Cordani, U.G. \& Hasui, Y. 1975. Comentários sobre as idades geocronológicas disponíveis para a Folha de Goiânia. In: Carta Geológica do Brasil ao Milionésimo; Folha Goiás (SD.22). Brasília: Departamento Nacional de Produção Mineral. Pp. 85-95.

Cordani, R. \& Shukowsky, W. 2009. Magnetização remanescente: um parâmetro crucial para a interpretação e modelamento de anomalias magnéticas em território brasileiro. Revista Brasileira de Geofísica, v. 27(4), 659-667. 
Cordani U.G., Pimentel M.M., Araújo C.E.G, Basei M.A.S, Fuck R.A., Girardi V.A.V. 2013. Was there an Ediacaran Clymene Ocean in central Brazil? American Journal of Sciences, 313:517-539.

Cordell, L. \& Grauch, V.J.S. 1985. Mapping basement magnetization zones from aeromagnetic data in the San Juan basin,New Mexico. In: W. J. Hinze, ed., The utility of regional gravity and magnetic anomaly maps: SEG, 181-197.

Correia, C. T. \& Girardi, V. A. 1998. Geoquímica e Petrologia das Rochas Máficas e Ultramáficas do Complexo Estratiforme de Cana Brava, e das suas encaixantes. Bol. IG - USP, Série Cientifica 29:1-37.

Correia, C. T.; Girardi, V. A. V.; Tassinari, C. C. G. \& Jost, H. 1997. Rb-Sr and Sm-Nd Geocronology of the Cana Brava Layered Mafic-Ultramafic Intrusion, Brazil, and Considerations regarding its Tectonic Evolution, Rev. Bras. Geoc. 27(2):163-168.

Costa, L.A.M. \& Angeiras, A.G. 1971. Geosynclinal evolution of the Epi-Baykalian Plataforma of Central Brazil. Geol. Rundschau, 60(3): 1024-1050.

Costa, L.A.M., Angeiras, A.G., Valença, J.G., Stevenazzi, V. 1970. Novos conceitos sobre o Grupo Bambuí e sua divisão em tectonogrupos. Rio de Janeiro, Bol. Geol. Inst. Geociências. 5: 3-34.

Cowan, D.R. \& Cowan, S. 1993. Separation filtering applied to aeromagnetic data. Exploration Geophysics, 24, 429-436.

Cruz, E.L.C.C. \& Kuyumjian, R.M. 1996. Chemical characterization of metabasalts and granitoids from the Almas-Dianópolis granite-greenstone terrane, Central Brazil. In: SBG/Núcleo Brasília. Symposium on Archaean Terranes of South American Platform, Extended abstracts, 53-54.

Cruz, E.L.C.C. \& Kuyumjiam, R.M. 1998. The geology and tectonic evolution of the Tocantins granite-greenstone terrane: Almas-Dianópolis region, Tocantins State, Central Brasil. Rev. Bras. Geoc., 28(2):173-182.

Cuadros, F. A. \& Botelho, N. F. 2015. Geotermometria de xistos grafitosos da Formação Ticunzal usando espectroscopia Raman. In: XIV Simpósio de Geologia do Centro Oeste, 2015, Brasília. Anais... SBG.

D’el-Rey Silva L.J.H, Oliveira I.L., Pohren, C.B., Tamizaki, M.L.N., Carneiro, R.C., Fernandes G.L.F., Aragão, P.E. 2011. Coeval perpendicular shortenings in the Brasilia belt: collision of irregular plate margins leading to oroclinal bending in the neoproterozoic of Central Brazil. Journal South Am. Earth Sciences 32: 1-13.

D'el-Rey Silva, L.J.H., Vasconcelos, M.A.R., Silva, D.V.G. 2008. Timing and role of the Maranhão River Thrust in the evolution of the Neoproterozoic Brasília Belt and Tocantins Province, central Brazil. Gondwana Research. 13 (3), 352-374.

Danderfer A., de Waele B., Pedreira A.J., Nalini H.A. 2009. New geochronological constraints on the geological evolution of Espinhaço basin within the São Francisco Craton-Brazil. Precambrian Research, 170: 116-128.

Danni, J. C. M., Fuck, R. A. 1981. Unidades tectonoestratigráficas do embasamento das faixas dobradas da margem ocidental do Cráton do São Francisco. II Simpósio Sobre o Cráton do São Francisco e suas Faixas Marginais, 130-139. Salvador: SBG. 
Danni, J.C.M., Fuck, R.A., Leonardos Jr., O.H. 1982. Archean and lower Proterozoic Units in Central Brazil. Geol. Rundsch. 71, 291-317.

Danni, J.C.M., Kuyumjian, R.M. 1984. A origem dos anfibolitos basais da sequência vulcanosedimentar de Juscelândia; Goiás. In: CONG.BRAS.GEOL., 33, Rio de Janeiro, 1984. Anais... Rio de Janeiro, SBG, p. 4.126- 4.136.

Danni, J.C.M. \& Leonardos, O.H. 1980. Granulite metamorphism and deformation in ancient composite layered intrusions: The Niquelândia Complex, Brazil. In: XXVI International Geologique Congres. 1, Paris, Abstracts...Paris, 35.

Dardenne, M. A. 1974. Geologia da região de Vazante, Minas Gerais, Brasil. In: SGB, XXVIII. Congresso Brasileiro de Geologia, Porto Alegre, Resumos, p.182- 185.

Dardenne, M.A. 1978a. Zonação Tectônica na borda ocidental do Cráton do São Francisco. $30^{\circ}$ Congresso Brasileiro de Geologia, Recife, SBG, 1:299-308.

Dardenne, M.A. 1978b. Síntese sobre a estratigrafia do Grupo Bambuí no Brasil Central. In: Congresso Brasileiro de Geologia, 30, Anais do..., Recife, v.2, p.597-610.

Dardenne, M.A. 1979. Les mineralisations de plomb, zinc, fluor du Protérozoïque Supérieur dans le Brésil Central. Thèse de Doctorat d'Etat, Université de Paris 6, 251 p.

Dardenne, M.A. 1981. Os grupos Paranoá e Bambuí na faixa dobrada Brasília. Anais $1^{\circ}$ Simpósio sobre o Cráton do São Franciscoe suas faixas marginais. Salvador, 1979, SGMCOM/NBA-SE, p. 140-157.

Dardenne, M.A., 2000. The Brasília Fold Belt. In Cordani U.G., Milani E.J., Thomaz Filho A., Campos D.A. (Eds.), Tectonic Evolution of South América, Brazil 2000, 31th Intern. Geological Congress, Rio de Janeiro, p.231-263.

Dardenne, M.A.; Alvarenga, C.J.S.; Botelho, N.F.; Lima, O.T.B.; Almeida, T. 2007. Mapa Geológico da Folha SD.23-V-C-III - Monte Alegre de Goiás. (Cartas, mapas ou similares/Mapa). Brasília.

Dardenne, M.A.; Alvarenga, C.J.S.; Martins, F.A.L.; Campos, J.E.G. 1998. Geologia do Parque Nacional da Chapada dos Veadeiros, GO. Plano de Manejo do Parque Nacional da Chapada dos Veadeiros - PNCV. Convênio UnB-IBAMA. Brasília. 38p.

Dardenne, M. A., Campos J.E.G., Alvarenga C.J.S., Martins F.A.L., Botelho, N.F. 1999. A sequência sedimentar do Grupo Araí na região da Chapada dos Veadeiros, Goiás. In: Simpósio de Geologia do Centro Oeste, 7, e Simpósio de Geologia de Minas Gerais, 10, Brasília., Atas, p. 100.

Dardenne, M.A., Faria, A., Andrade, G.F. 1973. Ocorrências de estromatólitos colunares na região de São Gabriel, Goiás. Cong. Bras. Geol., 27, SBG, Aracaju, Bol. Esp. n 1, p. 139-141.

Dardenne, M. A., Moura, M. A., Dantas, E. L., Pimentel, M. M., Rocha, G. A., Mendonça, F. C. 2003. O granito Serra Dourada (Goiás): um biotita granito intrusivo no Grupo Serra da Mesa. In: VIII Simpósio do Centro-Oeste, 2003, Cuiabá. Anais, 2003. p. 83-84.

Davis, J. C. 1986. Statistics and data analysis in geology. $2^{\text {nd }}$ Ed. Wiley, New York, 646 p.

Delgado, I.M., Souza, J.D., Silva, L.C., Silveira Filho, N.C., Santos, R.A., Pedreira, A.J., Guimarães, J.T., Angelim, L.A.A., Vasconcelos, A.M., Gomes, I.P., Lacerda Filho, J.V., Valente, C.R., Perrota, M.M., Heineck, C.A. 2003. Geotectônica do Escudo 
Atlântico. In: Bizzi, L.A, Schobbenhaus, C., Vidotti, R.M., Gonçalves, J.H. (eds). Geologia, Tectônica e Recursos Minerais do Brasil. CPRM, 227-334.

Dyer, R.C. 1970. Grupo Araí. Um Grupo de metamorfitos do Centro-Leste de Goiás, Revista da Escola de Minas de Ouro Preto, v. 28.

Eggers, D.E \& Thompson, D.T. 1984. An evaluation of the marine magnetic gradiometer. Geophysics, 49: 771-778.

Faria, A. 1995. Estratigrafia e Sistemas Deposicionais do Grupo Paranoá nas Áreas de Cristalina, Distrito Federal e São João D’Aliança - Alto Paraíso de Goiás. Dissertação de Mestrado - Universidade de Brasília, Brasília. 199p.

Fedi, M.; Florio, G.; Rapolla, A. 1994. A method to estimate the total magnetization direction from a distortion analysis of magnetic-anomalies. Geophys. Prospect. 42(3): 261-274

Feininger T., Dantas J. J. \& Girardi V.A.V. 1991. Gravity interpretation and possible regional significance of the Niquelândia layered basic-ultrabasic complex, Goiás, Brazil. J. South Am. Earth Sci., 4(4):343-350.

Fernandes, P. E. C. A., Montes, M. L., Braz, E.R.C., Montes, A.S.L., Silva, L.L., Oliveira, F.L.L., Sigas, J.R.O., Castro, H.E.F. 1982. Formação Ticunzal. In: Projeto RADAMBRASIL, Folha SD-23, Brasília, MME, p. 61-63.

Ferreira F. D. F., Souza J., Bongiolo A. DE B. E S., Castro L. G. 2013. Enhancement of the total horizontal gradient of magnetic anomalies using the tilt angle. Geophysics, 78: 3341.

Ferreira Filho, C.F., Araujo, S.M., Cruz, H.P. 1999. Estruturas vulcânicas preservadas em granulitos da sequiência vulcano sedimentar Juscelândia, GO. Rev. Bras. Geociências. 29 (4): 461-468.

Ferreira Filho C. F., Nilson A. A., Naldrett A. J. 1992. The Niquelândia Mafic-Ultramafic Complex, Goias, Brazil: a contribution to the ophiolite X stratiform controversy based on new geological and structural data. Precambrian Research. 59:125-143.

Fonseca, M. A. 1996. Estilos estruturais e arcabouço tectônico do segmento setentrional da Faixa Brasília. Tese de Doutorado - Universidade de Brasília,Brasília. 172p.

Fonseca, M.A. \& Dardenne, M.A. 1994. Compartimentação Estrutural de parte da Zona Externa da Faixa Brasília ao norte da Inflexão dos Pirineus. Anais $4^{\circ}$ Simp. Geol. CentroOeste. SBG Núcleo Brasília e Centro Oeste, Brasília. Resumos Expandidos, p. 181-186.

Fonseca, M.A., Dardenne, M.A., Uhlein, A.1995. Faixa Brasília setor setentrional: estilos estruturais e arcabouço tectônico. Revista Brasileira de Geociências, 25 (4): p. 267-278.

Fuck, R.A. 1990. Dobramentos Neoproterozóicos da margem ocidental do Cráton do São Francisco. 33 Cong. Bras. Geol., Natal, SBG, Bol. Resumo, p. 288-289.

Fuck, R.A. 1994. A Faixa Brasília, e a compartimentação tectônica na província Tocantins. IV Simpósio de Geologia do Centro-Oeste. SBG, Brasília, 184-187.

Fuck,R.A.,Danni,J.C.M.,Winge,M.,Andrade,G.F.,Barreira,C.F.,Leonardos,O.H.,Kuyum jian,R.M. 1981. Geologia da Região de Goianésia. In: SIMP. GEOL. CENTRO-OESTE, 1, Goiânia, 1981.Atas...Goiânia, SBG. pp 447-467.

Fuck, R. A., Dantas, E. L., Pimentel, M. M., Botelho, N.F., Junges, S. L., Hollanda, M. H. B. M., Moraes R., Armstrong, R. 2002. Crosta continental paleoproterozóica no 
embasamento da porção norte da Faixa Brasília: novos dados $\mathrm{Sm}-\mathrm{Nd}$ e U-Pb. In: Cong. Bras. Geol., 41, João Pessoa, 2002. Anais... João Pessoa, SBG, p. 308.

Fuck, R.A.; Jardim De Sá, E.F.; Pimentel, M.M.; Dardenne, M.A.; Pedrosa-Soares, A.C. 1993. As faixas de dobramentos marginais do Cráton São Francisco: Síntese dos conhecimentos. In: J.M.L. Domingues; Misi, A. (eds). O Cráton do São Francisco, SBG/SGM/CNPq, p.161-185.

Fuck, R. A. \& Marini, O. J. 1979. Projeto São Félix: Geologia da Folha Córrego São Bento. Brasília:FUB/Eletronorte. 49 p. (Convênio FUB/ELETRONORTE). Relatório Inédito.

Fuck, R.A., Marini, O.J. 1981. O Grupo Araxá e Unidades Homotaxiais. In: Simp. Sobre O Cráton Do São Francisco E Suas Faixas Marginais, 1, Salvador, 1981. Anais... Salvador, SBG/CPM, p.118-130.

Fuck, R.A.; Pimentel, M.M. \& D'el Rey Silva, L.J.H. 1994. Compartimentação tectônica da porção oriental da Província Tocantins. In: Congr. Bras. Geol., 38, Balneário Camboriú. Anais... Florianópolis, SBG, 1994, p. 215-216.

Geosoft. 2010. Montaj Gephysics v7.1 Tutorial and User Guide. Acesso em 12 de março de $2016 \mathrm{em}$ : http://www.geosoft.com/support/downloads/technical-documentation.

Girardi, V.A.V.; Kawashita, K.; Basei, M.A.S.; Cordani, U.G. 1978. Algumas considerações sobre a evolução geológica da região de Cana Brava, a partir de dados geocronológicos. In: Cong. Bras. Geol.; 30.Recife, 1978. Anais...Recife, SBG. v.1, p.337347.

Giustina, M.E.S.D.; Barbosa, M.F.N. 2005. Trabalho final de graduação, área VII, Projeto Nova Roma - Porto Real. Universidade de Brasília, 127p, Brasília, 2005.

Grant, F.S. \& Dodds, J. 1972. MAGMAP FFT Processing System Development Notes, Paterson Grant and Watson Ltd, Toronto, Canada.

Green, A.G., Cannon, W.G., Milkereit, B., Hutchinson, D.R., Davidson, A., Behrendt, J.C., Spencer, C., Lee, M.W., Morel-à-l'Huissier, P., and Agena, W.F. 1989. A "GLIMPCE" of the deep crust beneath the Great Lakes, Crust, in Mereu, R.F., Mueller, S., and Fountain, D.M., eds., Properties and Processes of Earth's Lower Crust: American Geophysical Union, Geophysical Monograph Series 51, p. 65-80.

Guimarães E.M. 1997. Estudos de proveniência e diagênese com ênfase na caracterização dos filossilicatos dos Grupos Paranoá e Bambuí, na região de Bezerra-Cabeceiras (GO). Tese de Doutorado - Universidade de Brasília, Brasília, 270p.

Haralyi, N.L.E. \& Hasui, Y. 1982. The gravimetric information and the Arquean proterozoic structural framework of Eastern Brazil. Revista Brasileira de Geociências, São Paulo, 12: 160-166.

Haralyi, N.L.E. \& Hasui, Y. 1985. Interpretation of gravity and magnetic data, central and eastern Brazil. In: HINZE WJ (Ed.). The utility of regional gravity and anomaly maps. Tulsa, Oklahoma, Society of Exploration Geophysicists, p. 124-131.

Hardwick, C.D. 1984. Important design considerations for inboard airborne magnetic gradiometers: Geophysics, 49: 2004-2018.

Hasui, Y. \& Almeida, F.F.M. 1970. Geocronologia do Centro Oeste Brasileiro. Bol. Soc. Bras. Geol., 19(1): 7-26. 
Hasui, Y., Costa, J.B.S., Gorayeb, P.S. de S., Lemos, R.L., Gama Jr., T.,Bemerguy, R.L. 1984. Geologia do Pré-Cambriano da região de Paraíso do Norte de Goiás. In: Congr. Bras. Geol., 33, Rio de Janeiro, 1984. Anais... Rio de Janeiro, SBG, v.5, p. 2220-2233.

Hasui, Y. \& Haralyi, N.L.E. 1985. A megaestruturação de Goiás. In: Simpósio de Geologia do Centro-Oeste, 2. Goiânia, Ata... Goiânia, SBG. p. 120-140.

Hinze, J.W., Vonfrese, R., R., B., Saad, A., H. 2013. Gravity and Magnetic Exploration Principles, Practice and Applications. Cambridge University Press, New York. 512p.

Isles D.J., Rankin L.R. 2013. Geological Interpretation of Aeromagnetic Data. ASEG. e-book.

Johnson, A., Cheeseman, S., Ferris, J. 1999. Improved compilation of Antartic Peninsula magnetic data by new interactive grid suturing and blending methods. Annali de Geofisica, 42(2): 249-259.

Jost H., Chemale Jr. F., Fuck R.A., Dussin I.A. 2013. Uvá complex, the oldest orthogneisses of the Archean-Paleoproterozoic terrane of central Brazil. Journal of South American Earth Sciences, 47:201-212.

Kearey, P., Brooks, M., Hill, I. 2009. Geofísica de exploração. São Paulo: Oficina de textos, $438 \mathrm{p}$.

Kitajima, L. F. W. 2002. Mineralogia e petrologia do Complexo Alcalino de Peixe -Tocantins. Tese de Doutorado - Universidade de Brasília, Brasília.

Klein, E.L., \& Moura, C.A.V. 2008. São Luís craton and Gurupi belt (Brazil): possible links with the West-African craton and surrounding Pan-African belts. In: Pankhurst, R.J., Trouw, R.A.J., Brito Neves, B.B., de Wit, M.J. (Eds.), West Gondwana: Pre-Cenozoic Correlations Across the South Atlantic Region. Geological Society, London, Special Publications 294, p. 137-151.

Lacerda Filho J. V., Rezende A., Silva, A. 1999. Programa de Levantamentos Geológicos Básicos do Brasil - Geologia e Recursos Minerais do Estado de Goiás e Distrito Federal. Goiânia: CPRM, METAGO S.A., UnB, $2^{\circ}$ edição. 184 p.

Lacerda Filho, J.V., Valente, C.R., Bahia, R.B.C., Lopes, R.C., Romanini, S.J. Oliveira, I.W.B., Oliveira, C.C., Sachs, L.L.B., Silva, V.A., Batista. I.H., 2004. Folha SD.22 Goiás. In: Schobbenhaus, C., Gonçalves, J.H., Santos, J.O.S., Abram, M.B., Leão Neto, R., Matos, G.M.M., Vidotti, R.M., Ramos, M.A.B., Jesus, J.D.A. de. (eds.). Carta Geológica do Brasil ao Milionésimo, Sistemas de Informações Geográficas-SIG. Programa Geologia do Brasil, CPRM, Brasília. CD-ROM.

Langel, R.A. \& Hinze, W.J. 1998. The Magnetic Field of the Earth's Lithosphere-the Satellite Perspective, University Press, Cambridge.

Leão Neto, R. \& Olivatti, O. 1983. Projeto Palmeirópolis - Etapa preliminar. Convênio DNPM-CPRM.Goiânia, 29p. (inédito).

Li, X. 2006. Understanding 3D analytic signal amplitude: Geophysics 71, 13-16.

Luiz, J. G., Silva, L. M. C. 1995. Geofísica de prospecção. Editora Cejup Ltda. Belém-PA. $311 \mathrm{p}$.

Macambira, M. J. B.; Villas, R. N. 1984. A geologia da extremidade meridional da Serra Dourada, Goiás: variedades litológicas, metamorfismo e mineralizações associadas. In: 
Cong. Bras. Geol., 33, 1984, Rio de Janeiro. Anais ... Rio de Janeiro: SBG, 1984, 123124.

Mantovani, M.S.M., \& Brito Neves, B.B. 2005. Geophysical boundaries of Paranapanema Proterozoic block: its importance for the Rodinia to Gondwana evolutionary theories. Gondwana Research, 8, 18-22.

Marangoni Y.R., Assumpção M., Fernandes E.P. 1995. Gravimetria no norte de Goiás, Brasil. Rev. Bras. Geofis. 13: 205-219.

Marini, O. J. \& Botelho, N. F. 1986. A província de granitos estaníferos de Goiás. Revista Brasileira de Geociências 16: 119-131.

Marini, O. J.; Fuck, R.A.; Danni, J.C.M.; Dardenne, M.A. 1981. Evolução Geotectônica da Faixa Brasília e do seu embasamento. I Simpósio do Cráton do São Francisco. SBG, Salvador. 100-115.

Marini, O.J.; Fuck, R.A.; Danni, J.C.; Dardenne, M.A.; Loguercio, S.O.; Ramalho, R. 1984a. As faixas de dobramento Brasília, Uruaçu e Paraguai-Araguaia e o Maciço Mediano de Goiás. In: SCHOBBENHAUS, C.; DIÓGENES, A.C.; DERGE, G.R.; ASMOS, M.G. (Coord.) 1984. Geologia do Brasil. Brasília. DNPM. p. 251-303.

Marini, O.J., Fuck, R.A., Dardenne, M.A., Danni, J.C.M. 1984b. Província Tocantins: setore Central e Sudeste. In: ALMEIDA, F.F.M., HASUI, Y. (Coord.). O Pré-Cambriano do Brasil. São Paulo. Edgar Blücher. p. 205-264.

Marini, O.J., Fuck, R.A., Dardenne, M.A., Faria, A. 1978a. Dobramentos da borda Oeste do Cráton São Francisco. Publ. Esp. 3: 155-193, Salvador.

Marini, O.J.; Fuck, R.A., Figueiredo, A.N. 1976. Projeto São Félix: Relatório Final. Convênio FUB/ELETRONORTE, Brasília. 125p.

Marini, O.J., Liberal, C.S., Reis, L.T., Trindade, C.A.H., Souza, S.L. 1978b. Nova unidade litoestratigráfica do Pré-Cambriano no Estado de Goiás. Bol. Esp. 1: 126-127, 30 Congr. Bras. Geol. Recife.

Marques, G.C. 2010. Geologia dos grupos Araí e Serra da Mesa e seu embasamento no sul do Tocantins. Dissertação de Mestrado - Universidade de Brasília, Brasília. 116p.

Martins, F.A.L., 1999. Análise faciológica e estratigráfica do Paleo-Mesoproterozóico: Sequiência Araí no Parque Nacional da Chapada dos Veadeiros, Goiás. Dissertação de Mestrado - Universidade de Brasília, Brasília. 137p.

Martins-Neto, M.A.; Alkmim, F.F. 2001. Estratigrafia e evolução tectônica das bacias neoproterozóicas do paleocontinente São Francisco e suas margens: Registro da quebra de Rodínia e colagem de Gondwana. In: Pinto, C.P., Martins-Neto, M.A. (ed.) Bacia do São Francisco: Geologia e Recursos Naturais, SBG/Núcleo MG, 31-54.

Massucato, A.J. 2003. Caracterização estrutural do Embasamento do Grupo Araí na zona externa da Faixa Brasília (GO). Tese de Doutorado - UNESP, Rio Claro. 167 p.

Merino, M., Keller, G.R., Stein, S., and Stein, C. 2013. Variations in Mid-Continent Rift magma volumes consistent with microplate evolution: Geophysical Research Letters, v. 40, p. 1513-1516.

Miller, H. G. \& Singh, V. 1994. Potential field tilt- a new concept for location of potential field sources. J. Appl. Geophys. 32, 213-217. 
Minty, B. R. S. 1991. Simple micro-levelling for aeromagnetic data. Exploration Geophysics, 22: 591-592.

Moraes, R. 1997. Condições e evolução do metamorfismo no Complexo Barro Alto e litogeoquímica do vulcanismo bimodal da seqüência Juscelândia, Goianésia, Goiás. Tese Ph.D - Universidade de Brasília, Brasília.

Moreira, M. L. O., Moreton, L. C., Araújo, V. A., Lacerda Filho, J. V., Costa, H. F. 2008. Geologia do Estado de Goiás e Distrito Federal. Brasília: MME; CPRM-SIC; FUNMINERAL/GO.

Nabighian, M.N. 1972. The analytic signal of two-dimensional magnetic bodies with polygonal cross-section; Its properties and use for automated anomaly interpretation. Geophysics 37 (3), 507-517.

Nabighian, M.N., Ander, M.E., Grauch, V.J.S. et al. 2005. Historical development of the magnetic method in exploration. Geophysics, 70:33ND-61ND.

Nilson, A.A., Botelho, N.F., Ferreira Filho, C.F. 1994. Rifteamento crustal MesoProterozóico no centro-norte de Goiás. In XXXVIII Congresso Brasileiro de Geologia, Camboriú, Anais SBG, 1, Simpósios, 258-259.

Oliveira, M.A. 1967. Contribuição à geologia da parte sul da Bacia do São Francisco e áreas adjacentes. DEPIN/CENPES/PETROBRAS. Coletâneas de Rel. de Exploração, 1: 71105.

Olsen, N., T. J. Sabaka, and L. R. 2007. Gaya-Pique, Study of an Improved Comprehensive Magnetic Field Inversion Analysis for Swarm, Final Report, Tech. Rep. ESA CONTRACT No 11570/05/NL/AR, Danish National Space Center (DNSC).

Petri S., Coimbra A.M., Amaral G., Ojeda H.O., Fúlfaro W.J., Ponçano W.L. 1986a. Código brasileiro de nomenclatura estratigráfica. Revista Brasileira de Geociências, 16(4):372-376.

Petri S., Coimbra A.M., Amaral G., Ponçano W.L. 1986b. Guia brasileiro de nomenclatura estratigráfica. Revista Brasileira de Geociências, 16(4):376-415.

Phillips, J. D. 2001. Designing matched band-pass and azimuthal filters for the separation of potential-field anomalies by source region and source type, 15 th Geophysical Conference and Exhibition, Australian Society of Exploration Geophysicists, extended abstract.

Phillips, J. D. 2007. Geosoft eXecutables (GX's) developed by U.S. Geological Survey, version 2.0, with notes on GX development from Fortran code: U.S. Geological Survey Open-File Report 2007, 1355p.

Pimentel, M.M. 1991. Late Crustal Evolution of the Tocantins Province in Cetral Brasil: an isotopic and geochemical study. PhD Thesis, University of Oxford. $250 \mathrm{p}$.

Pimentel, M.M. 2016. The tectonic evolution of the Neoproterozoic Brasília Belt, central Brazil: a geochronological and isotopic approach. Brazilian Journal of Geology, 46: 6782.

Pimentel, M. M. \& Botelho, N. F. 2001. Sr and Nd isotopic characteristics of 1,77-1,58 Ga rift-related granites and volcanics of the Goiás tin province, Central Brazil. Anais da Academia Brasileira de Ciências, 73: 263 - 276. 
Pimentel M.M., Dardenne M.A., Fuck R.A., Viana M.G., Junges S.L., Fischel D.P., Seer H.J., Dantas E.L. 2001. Nd isotopes and the provenance of detrital sediments of the Neoproterozoic Brasilia Belt, Central Brazil. Journal of South American EarthSciences, 14:571-585.

Pimentel, M.M., Ferreira Filho, C.F., Armstrong, R.A. 2004a. SHRIMP U-Pb and Sm-Nd ages of the Niquelândia layered complex: Meso- $(1,25 \mathrm{Ga})$ and Neoproterozoic age (0,79Ga) extensional events in central Brasil. Precambrian Research, 132: 133-153.

Pimentel, M.M. \& Fuck, R.A. 1991. Origin of orthogneiss and metavolnic rock units in western Goiás: Neoproterozoic crustal accretion. Geochim. Brasil. n.5, p.133- 152.

Pimentel, M.M. \& Fuck, R.A. 1992. Neoproterozoic crustal accretion in Central Brasil. Geology, 20: 375-379.

Pimentel, M. M.; Fuck, R. A., Botelho, N. F. 1999. Granites and the geodynamic history of the neoproterozoic Brasília belt, Central Brazil: a review. Lithos, 46: 463-483.

Pimentel, M. M.; Fuck, R. A.; Jost. H.; Ferreira Filho, C. F.; Araujo, S. M. 2000. The basement of the Brasília Fold Belt and the Goiás Magmatic Arc. in: Tectonic Evolution of South America. CORDANI, U. G.; MILANI, E. J.; THOMAZ FILHO, A. J.; CAMPOS, D. A. eds. Cong. Inter. Geol, Rio de Janeiro, pp 195-229.

Pimentel, M.M., Fuck, R.A., Silva, J.L.H. 1996. Dados Rb-Sr e Sm-Nd da região de JussaraGoiás-Mossâmedes (GO), e o limite entre terrenos antigos do Maciço de Goiás e o Arco Magmático de Goiás. Revista Brasiliera de Geociências 26, 61-70.

Pimentel, M.M.; Heaman, L.; Fuck, R.A. 1992. Idade do meta-riolito da seqüência Maratá, Grupo Araxá, Goiás: estudo gcocronológico pelos métodos $\mathrm{U}-\mathrm{Pb} \mathrm{cm}$ zircão, $\mathrm{Sm}-\mathrm{Nd}$ c $\mathrm{Rb}$ Sr. An. Acad. Brás. Ciências, 64:19-28.

Pimentel M.M., Heaman, L., Fuck, R.A., Marini, O.J. 1991. U-Pb Zircon Geochronology of Precambrian tin-bearing continental - type acid in central Brazil. Precambrian Research, 52: 321-335.

Pimentel M.M., Rodrigues J.B., Dellagiustina M.E.S., Junges S.L., Matteini M., Armstrong R. 2011. The tectonic evolution of the Neoproterozoic Brasília Belt, central Brazil, based on SHRIMP and LA-ICPMS UePb sedimentary provenance data: A review. Journal of South American Earth-Sciences, 31: 345-357.

Pimentel M.M., Yost H., Fuck R.A. 2004b. O embasamento da Faixa Brasília e o Arco Magmático de Goiás. In: V. Mantesso-Neto, A. Bartorelli, C.D.R. Carneiro, B.B. Brito Neves (eds). Geologia do Continente Sul-Americano: evolução da obra de Fernando Flávio Marques de Almeida. Ed. Beca, São Paulo, p.355-368.

Reeves, C. 2005. Aeromagnetic Surveys: Principles, Practice and Interpretation. Geosoft. 68p.

Reid, A.B., Allsop, J.M., Granser, H., Millett, A.J., Somerton, I.W. 1990. Magnetic interpretation in three dimensions using Euler deconvolution: Geophysics 55, 80-91.

Reid, A. B.,Ebbing, J., Webb, S.J. 2014 . Avoidable Euler errors - The use and abuse of Euler deconvolution applied to potential fields: Geophysical Prospecting, 1-7.

Reynolds, J. M. 1997. An Introduction to Applied and Environmental Geophysics. John Wiley \& Sons, Chichester. 796p. 
Ribeiro Filho, E. \& Teixeira N.A. 1981. Seqüência vulcano-sedimentar da borda oeste dos complexos de Niquelândia e Cana Brava. Boletim Informativo. Núcleo Centro-Oeste, 10:157-177.

Rocha, G.A. 2003. Petrologia e gênese da mineralização de alexandrita na borda sul do maciço granítico de Serra Dourada. Dissertação de Mestrado - Universidade de Brasília, Brasília. $109 \mathrm{p}$.

Roest, W. R., Verhoef, J., Pilkington, M. 1992. Magnetic interpretation using the 3D analytic signal. Geophysics 57 (1), 116-125, doi: 10.1190/1.1443174.

Rossi, P.; Andrade, G.F.; Cocherie, A. 1992. The 1,58 G.A. type granite of Serra da Mesa (GO): an example of "NYF" fertile granite pegmatite. In: CONGRESSO BRASILEIRO DE GEOLOGIA, 37, 1992, São Paulo. Res. Exp.... São Paulo: SBG, v.1, p.389-390.

Santos R.V., Alvarenga C.J.S., Dardenne M.A., Sial A.N., Ferreira V.P. 2000. Carbon and oxygen isotope profiles across MesoNeoproterozoic limestones from Central Brazil: Bambuí and Paranoá groups. Precambrian Research, 104: 107-122.

Schobbenhaus, C. 1993. O Proterozóico Médio no Brasil com ênfase à Região Centro-Oeste. Tese de Doutorado - Freiburg in Breisgau, Alemanha. 166p.

Schobbenhaus, C.; Hoppe, A.; Baumann, A.; Lork, A. 1994. Idade U/Pb do vulcanismo Rio dos Remédios, Chapada Diamantina, Bahia. In: Congresso Brasileiro de Geologia, 38., Balneário Camboriú, SC, 1994. Boletim de Resumos Expandidos... Balneário Camboriú, SBG, v.2, p. 397-399.

Schobbenhaus, F. C., Ribeiro, C. L., Oliva, L. A., Takanohashi, J. T., Lindenmayer, Z. G., Vasconcelos, J. B., Orlandi, V. 1975. Carta Geológica do Brasil ao Milionésimo. Folha Goiás (SD.22). Brasília: Departamento Nacional de Produção Mineral.

Shiraiwa S., Ussami, N. 2002. Gravity survey on the Pantanal Wetland: data acquisition and processing. Rev. Bras. Geof., 19:315-323.

Simpson R.W., Jachens, R.C., Blakely, R.J. 1986. A new isosta-tic residual gravity map of the Conterminous United States witha discussion on the significance of isostatic residual anomalies,J. Geophys. Res. 91 (B-8), 8348-8372.

Skeels, D.C. 1947. Ambiguity in gravity interpretation. Geophysics, 12: 43-56.

Soares J.E.P., Fuck R.A., Berrocal J. 2005. Geophysical signature of the lithosphere at the western border of São Francisco plate. In: SBG, Simpósio sobre o Cráton do São Francisco, 3, Salvador, Anais, 1:48-51.

Soares, J.E.P., Berrocal, J., Fuck, R.A., Mooney, W., Ventura, D.B.R. 2006. Seismic characteristics of central Brazil crust and upper mantle: a deep seismic refraction study. Journal of Geophysical Research, 111:B12302.

Souza, J. D., Kosin, M., Heineck, C.A., Lacerda Filho, J.V., Teixeira, L.R., Valente, C.R., Guimarães, J.T., Bento, R.V., Borges, V.P., Santos, R.A., Leite, C.A., Neves, J.P., Oliveira, I.W.B., Carvalho, L.M., Pereira, L.H.M., Paes, V.J.C. 2004. Folha SD.23, Brasília. In: Schobbenhaus, C. et al. (Eds.). Carta Geológica do Brasil ao Milionésimo, Sistemas de Informações Geográficas-SIG. Programa Geologia do Brasil, CPRM, Brasília. CD-ROM. 
Souza, J.O. \& Leão Neto, R. 1998. Programa Levantamentos Geológicos Básicos do Brasil. Projeto Borda Oeste dos Maciços Básico-Ultrabásicos de Niquelândia e Barro Alto. Estado de Goiás, 1:100.000, Brasília: CPRM, 56p.

Spector A. \& Grant F.S. 1970. Statistical models for interpreting magnetic data. Geophysics, 35, 2, 293-302.

Strieder, A.J. 1990. Análise estrutural da região de Abadiânia-GO. Rev. Bras. Geoc., 20: 239257.

Tanizaki, M.L.N. 2013. Geologia do Grupo Araí: exemplo de rifte continental no Brasil Central. Dissertação de Mestrado - Universidade de Brasília, Brasília. 137 p.

Tarling, D.H. \& Hrouda, F. 1993. The Magnetic Anisotropy of Rocks. Chapman and Hall, London.

Tassinari, C.C.G.; Siga Jr., O.; Teixeira, W. 1981. Panorama geocronológico do centro-oeste brasileiro: soluções, problemáticas e sugestões. Atas $2^{\circ}$ Simpósio de Geologia do CentroOeste, Goiânia, p. 93-116.

Telford, W.M; Geldart, L.P., Sheriff, R.E. 1990. Applied Geophysics. 2nd ed. Cambridge University Press, New York. 859p.

Thompson, D.T. 1982. EULDPH - a new technique for making computer-assisted depth estimates from magnetic data. Geophys. Prosp. 45, 207-246.

Uhlein, A., Caxito, F. A., Egydio-Silva, M., Barbosa, J. S. F. 2012. Faixa de dobramentos Rio Preto e Riacho do Pontal. In: J. S. F. Barbosa (Coord.) Geologia a Bahia Pesquisa e Atualização, v. 2, 87-130. Salvador: Convênio CBPM-UFBA.

Unrug R. 1997. Rodinia to Gondwana, the geodynamic map of Gondwana supercontinent assembly. GSA Today, 7(1): 1-6.

Urquhart, T. 1988. Decorrugation of enhanced magnetic field maps. 58th Annual International Meeting, Society of Exploration Geophysicists, Expanded Abstracts; 371- 372.

Valente, C. R. 1992. Utilização de Produtos de Sensores Remótos com Enfase na Tectônica e Prospecção Mineral. Dissertação de Mestrado, INPE -Instituto Nacional de Pesquisas Espaciais, São José dos Campos. 189 p.

Valeriano, C.M.; Dardenne, M.A.; Fonseca, M.A.; Simões, L.S.A.; Seer, H.J. 2004. A evolução tectônica da Faixa Brasília. In: Mantesso-Neto, V.; Bartorelli, A.; Carneiro, C.D.R.; Brito Neves, B.B. (eds.) Geologia do Continente Sul-Americano: Evolução da obra de Fernando Flávio Marques de Almeida. São Paulo, Beca, p. 575-592.

Vasconcelos, E.P., Lima Neto, F. F. \& Roos, S. 1990. Unidades de correlação da Formação Açu, Bacia Potiguar. In: SBG/Núcleo Nordeste, Congresso Brasileiro de Geologia, 36, Natal, Anais, 1:227-240.

Ventura, D.B.R., Soares, J.E.P., Fuck, R.A., Caridade, L.C.C. 2011. Caracterização sísmica e gravimétrica da litosfera sob a linha de refração sísmica profunda de Porangatu, Província Tocantins, Brasil Central. Revista Brasileira de. Geociências, 41, 130-140.

Verduzco, B., Fairhead, J. D., Green, C. M., MacKenzie, C. 2004. New insights into magnetic derivatives for structural mapping. The Leading Edge 23, 116-119.

Vidotti R.M., Ebinger C.J., Fairhead J.D. 1998. Gravity signature of the western Paraná Basin, Brazil. Earth and Planetary Science Letters, 139:117-132. 


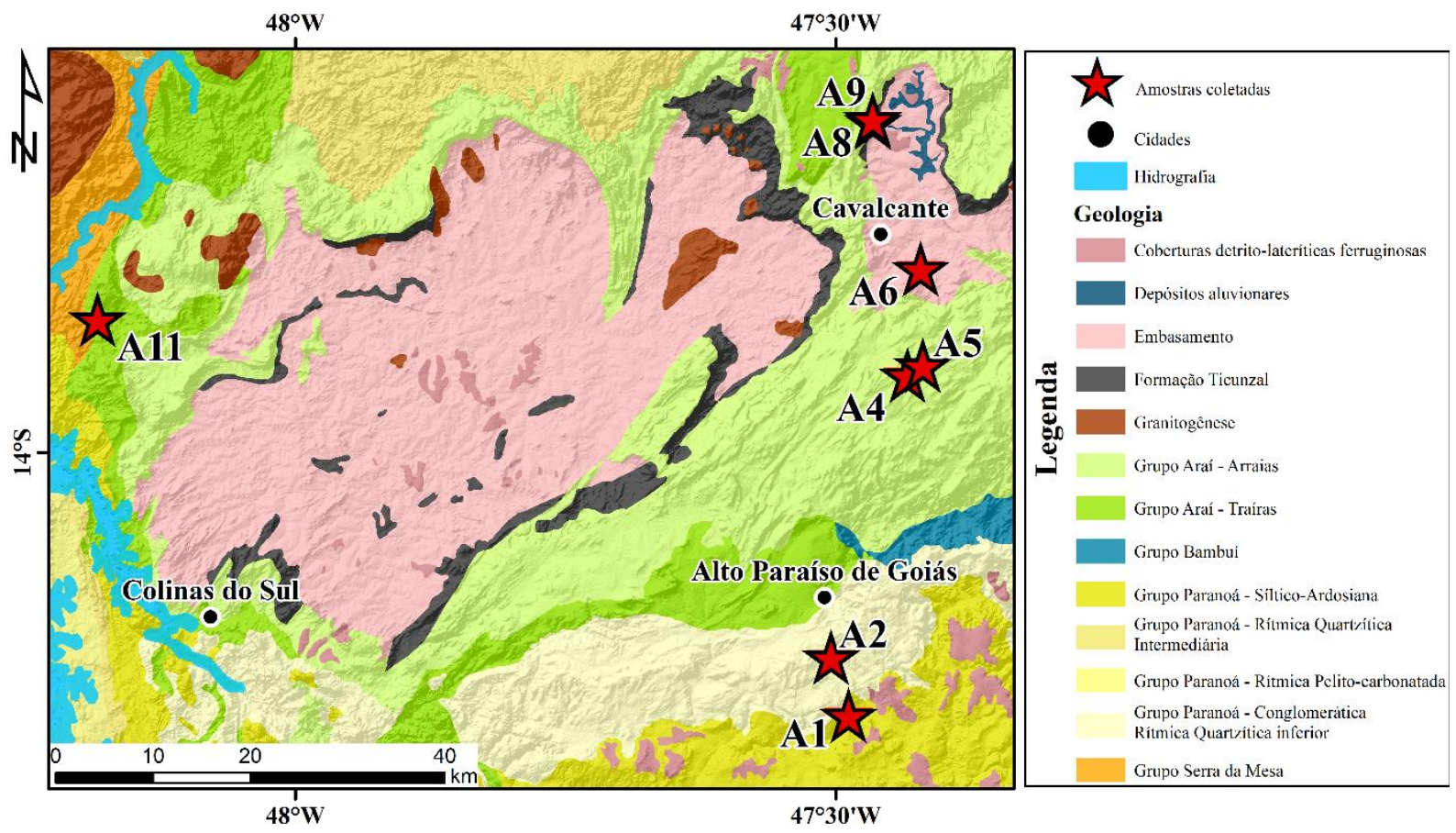

Figura A1. Mapa das amostras de rocha coletadas em campo. 